Florida International University FIU Digital Commons

3-5-2009

\title{
Quantitative Diatom-Based Reconstruction of Paleoenvironmental Conditions in Florida Bay and Biscayne Bay, U.S.A.
}

Anna Honorata Wachnicka

Florida International University, wachnick@fiu.edu

DOI: $10.25148 /$ etd.FI10022556

Follow this and additional works at: https://digitalcommons.fiu.edu/etd

\section{Recommended Citation}

Wachnicka, Anna Honorata, "Quantitative Diatom-Based Reconstruction of Paleoenvironmental Conditions in Florida Bay and Biscayne Bay, U.S.A." (2009). FIU Electronic Theses and Dissertations. 221.

https://digitalcommons.fiu.edu/etd/221 


\section{FLORIDA INTERNATIONAL UNIVERSITY}

Miami, Florida

\section{QUANTITATIVE DIATOM-BASED RECONSTRUCTION OF \\ PALEOENVIRONMENTAL CONDITIONS IN FLORIDA BAY AND BISCAYNE BAY, U.S.A.}

A dissertation submitted in partial fulfillment of the

requirements for the degree of

DOCTOR OF PHILOSOPHY

in

\section{GEOSCIENCES}

by

Anna Honorata Wachnicka

2009 
To: Dean Kenneth Furton

College of Arts and Sciences

This dissertation, written by Anna Honorata Wachnicka, and entitled Quantitative Diatom-Based Reconstruction of Paleoenvironmental Conditions in Florida Bay and Biscayne Bay, U.S.A., having been approved in respect to style and intellectual content, is referred to you for judgment.

We have read this dissertation and recommend that it be approved.

$\begin{array}{r}\hline \text { Evelyn E. Gaiser } \\ \hline \text { Bradford Clement } \\ \hline \text { William T. Anderson } \\ \hline \text { Laurel S. Collins, Major Professor N. Boyer }\end{array}$

Date of Defense: March 5, 2009

The dissertation of Anna Honorata Wachnicka is approved.

$\begin{array}{r}\begin{array}{r}\text { Dean Kenneth Furton } \\ \text { College of Arts and Sciences }\end{array} \\ \hline \begin{array}{r}\text { Dean George Walker } \\ \text { University Graduate School }\end{array}\end{array}$

Florida International University, 2009 


\section{DEDICATION}

I would like to dedicate this work to my husband Dariusz Kosiorek for his patience, support and most of all love, my grandmother Helena Stańczyk for raising me and supporting me throughout my life, and all my past and present teachers who introduced me to the fascinating world of science 


\section{ACKNOWLEDGMENTS}

I would like to thank my committee members, Dr. Laurel S. Collins, Dr. Evelyn E. Gaiser, Dr. Joseph N. Boyer, Dr. William T. Anderson, and Bradford Clement. I need to give special thanks to Dr. Gaiser for her continuous financial support during all the years in the program, critical guidance on data analysis and mentoring me to be a good scientist. Also, special thanks go to my major professor Dr. Collins for initial financial support, continuous research advice, and keeping me on track during my research and school. Additionally, I would like to thank Dr. Boyer, Dr. Anderson and Dr. Clement for for his valuable comments on my research, Dr. Lynn Wingard of USGS for providing me with Biscayne Bay sediment cores and helping me interpret the results of paleoenvironmental reconstructions in Florida Bay, and Dr. Frank Marshal for his valuable comments on my dissertation results. Finally, I would like to thank my coworkers from Periphyton Lab, husband Dariusz Kosiorek and friend Olga Soulova for helping me with sample collection. Furthermore, I need to thank Diana Johns and Heather Singler of Freshwater Biogeochemistry Lab, Seagrass Lab, and SERC lab for their help with nutrient analysis. Financial support for this study was provided through National Science Foundation through Division of Earth Science Geology and Paleontology Program (EAR-071298814) to Collins et al. for collecting and sampling cores from Florida Bay, the Faculty Research Seed Funds program of the Southeast Environmental Research Center's Endowment to Wachnicka for sample collection in Florida Bay, Biscayne National Park (\#5284-AP00-371) to Gaiser for sample collection in Biscayne Bay, and USGS (\#03ERAG0049) to Gaiser for Biscayne Bay core analyses. 


\begin{abstract}
OF THE DISSERTATION
QUANTITATIVE DIATOM-BASED RECONSTRUCTION OF

PALEOENVIRONMENTAL CONDITIONS IN FLORIDA BAY AND BISCAYNE
\end{abstract}

BAY, U.S.A.

by

Anna Honorata Wachnicka

Florida International University, 2009

Miami, Florida

Professor Laurel S. Collins, Major Professor

The spatial and temporal distribution of modern diatom assemblages in surface sediments, on the most dominant macrophytes, and in the water column at 96 locations in Florida Bay, Biscayne Bay and adjacent regions were examined in order to develop paleoenvironmental prediction models for this region. Analyses of these distributions revealed distinct temporal and spatial differences in assemblages among the locations. The differences among diatom assemblages living on subaquatic vegetation and sediments, and in the water column were significant. Because concentrations of salts, total phosphorus (WTP), total nitrogen (WTN) and total organic carbon (WTOC) are partly controlled by water management in this region, diatom-based models were produced to assess these variables. Discriminant function analyses showed that diatoms can also be successfully used to reconstruct changes in the abundance of diatom assemblages typical for different habitats and life habits.

To interpret paleoenvironmental changes, changes in salinity, WTN, WTP and WTOC were inferred from diatoms preserved in sediment cores collected along 
environmental gradients in Florida Bay (4 cores) and from nearshore and offshore locations in Biscayne Bay (3 cores). The reconstructions showed that water quality conditions in these estuaries have been fluctuating for thousands of years due to natural processes and sea-level changes, but almost synchronized shifts in diatom assemblages occurred in the mid-1960's at all coring locations (except Ninemile Bank and Bob Allen Bank in Florida Bay). These alterations correspond to the major construction of numerous water management structures on the mainland. Additionally, all the coring sites (except Card Sound Bank, Biscayne Bay and Trout Cove, Florida Bay) showed decreasing salinity and fluctuations in nutrient levels in the last two decades that correspond to increased rainfall in the 1990's and increased freshwater discharge to the bays, a result of increased freshwater deliveries to the Everglades by South Florida Water Management District in the 1980's and 1990's. Reconstructions of the abundance of diatom assemblages typical for different habitats and life habits revealed multiple sources of diatoms to the coring locations and that epiphytic assemblages in both bays increased in abundance since the early 1990's. 


\section{TABLE OF CONTENTS}

CHAPTER

PAGE

1. INTRODUCTION 1

REFERENCES $\quad 8$

2. DEVELOPING DIATOM-BASED INFERENCES OF ENVIRONMENTAL CHANGE IN FLORIDA BAY, U.S.A.

Abstract $\quad 13$

2.1. Introduction 14

2.2. Study Area 17

2.3. Methods 18

2.3.1. Sample Collection, Preparation and Laboratory Analysis 18

2.3.2. Data Analysis 20

2.4. Results 24

2.4.1. Diatom Species Composition 24

2.4.2. Environmental Conditions $\quad 27$

2.4.3. Environmental Preferences and Transfer Functions 28

2.4.4. Prediction of Community Types 30

2.5. Discussion 31

2.6. Conclusions 38

Acknowledgments $\quad 39$

REFERENCES

3. DIATOM-BASED EVIDENCE OF LONG-TERM WATER QUALITY

FLUCTUATION ALONG A COASTAL GRADIENT IN FLORIDA BAY, FLORIDA

Abstract $\quad 59$

3.1. Introduction $\quad 61$

3.2. Study Area 65

3.3. Methods 67

3.3.1. Core Collection $\quad 67$

$\begin{array}{ll}\text { 3.3.2. Radiometric Dating } & 67\end{array}$

$\begin{array}{ll}\text { 3.3.3. Laboratory Methods } & 68\end{array}$

3.3.4. Data Analysis $\quad 69$

3.4. Results $\quad 71$

3.4.1. Lithostratigraphy and Chronology 71

3.4.2. Diatom Stratigraphy $\quad 72$

3.4.3. Compositional Species Turnover 81

3.4.4. Reconstructions 82

3.5. Discussion $\quad 84$

3.6. Conclusions $\quad 95$

Acknowledgments 96

REFERENCES 115 
4. DEVELOPMENT OF DIATOM-BASED PREDICTION MODELS FOR ASSESSMENT OF PAST WATER QUALITY IN BISCAYNE BAY, U.S.A. 121

Abstract

4.1. Introduction

4.2. Study Area

4.3. Material and Methods

4.3.1. Sampling and Laboratory Methods

4.3.2. Statistical Methods

4.4. Results

4.4.1. Diatom Species Composition

4.4.2. Spatial and Temporal Patterns

4.4.3. Water Quality Conditions

4.4.4. Environmental Preferences

136

4.4.5. Transfer Functions and Prediction of Community Types

REFERENCES

5. DIATOM-BASED EVIDENCE OF 660 YEARS OF WATER QUALITY FLUCTUATIONS IN BISCAYNE BAY, FLORIDA

Abstract

5.1. Introduction

5.2. Study Area

5.3.1. Core Collection 177

$\begin{array}{ll}\text { 5.3.2. Chronology } & 178\end{array}$

$\begin{array}{ll}\text { 5.3.3. Laboratory Methods } & 178\end{array}$

$\begin{array}{ll}\text { 5.3.4. Data Analyses } & 178\end{array}$

$\begin{array}{ll}\text { 5.4. Results } & 180\end{array}$

5.4.1. Lithostratigraphy and Chronology 180

5.4.2. Diatom Stratigraphy, Beta Diversity and Water Quality Conditions

6. GENERAL CONCLUSIONS 212

$\begin{array}{ll}\text { REFERENCES } & 215\end{array}$

$\begin{array}{ll}\text { APPENDICES } & 216\end{array}$

$\begin{array}{ll}\text { VITA } & 217\end{array}$ 


\section{LIST OF TABLES}

TABLE

PAGE

2.1 Spearman rank correlation coefficients (quantitative variables) matrix and Kruskall-Wallis values (categorical variables) of the mean values of water total nitrogen (WTN), water total phosphorus (WTP), water total organic carbon (WTOC), depth (D), oxygen (O2), turbidity (TURB.), salinity (SAL.), temperature (TEMP.), $\mathrm{pH}$, sediment total nitrogen (STN), sediment total phosphorus (STP), and sediment total carbon (STC) among seasons. Values with asterisk indicate significant correlation at $\alpha<0.05$

2.2 Diatom species identified by indicator species analysis as significantly associated with different clusters distinguished by cluster analysis based on their relative abundance and frequency of occurrence in these clusters. Taxa optima (Opt.) and tolerances (Tol.) for salinity (Sal.), water total nitrogen (WTN), water total phosphorus (WTP) and water total organic carbon (WTOC) calculated by weighted averaging regression are also provided

2.3 Diatom taxa identified by indicator species analysis as significantly associated with planktonic, epiphytic and epipelic habitats based on their relative abundance and frequency of occurrence in these groups

2.4 Pearson correlation coefficients for correlations between residual values of salinity (Sal.), water total nitrogen (WTN), water total phosphorus (WTP) and water total organic carbon (WTOC) derived for the final transfer function models and mean annual values of other measured chemical and physical water variables. Values with asterisk indicate significant correlation at $\alpha<0.05$

3.1 Radiocarbon dates determined from shells for Trout Cove, Russell Bank, Bob Allen Bank and Ninemile Bank cores. Ages obtained by L. Collins from Beta Analytic Laboratory, Miami, FL

3.2 Mean salinity, water total nitrogen (WTN), water total phosphorus (WTP) and water total organic carbon (WTOC) in different time periods as determined from diatom assemblages. Zones were determined using stratigraphically constrained cluster analysis using CONISS.

4.1 Indicator species of clusters identified by ISA and optima (Opt.) and tolerances (Tol.) for salinity (Sal.) and water total nitrogen (WTN), water total phosphorus (WTP), and water total organic carbon (WTOC) as 
calculated by weighted averaging regression. All indicator values are significant at $\alpha<0.05$

4.2 Spearman rank correlation coefficients for quantitative variables and Kruskall-Wallis values for categorical variables for environmental variables of interest measured in dry and wet seasons. Asterisk next to values indicate significant correlation at $\alpha<0.05$. Asymp. Sig. $=$ Asymptotic significance, Chi-Square $=$ Chi-square statistical test. Symbols indicate: Sal.=salinity, Turb=turbidity, $\mathrm{O} 2=$ oxygen, Temp. $=$ temperature, $\mathrm{STP}=$ sediment total phosphorus, $\mathrm{STN}=$ sediment total nitrogen, $\mathrm{STC}=$ sediment total carbon, $\mathrm{WTN}=$ water total nitrogen, $\mathrm{WTP}=$ water total phosphorus, WTOC $=$ water total organic carbon

4.3 Indicator species of planktonic, epiphytic and epipelic habitats identified by Indicator Species Analysis (ISA). All indicator values are significant at $\alpha<0.05$

5.1 Updated salinity (Sal.), water total nitrogen (WTN), water total phosphorus (WTP) and water total organic carbon (WTOC) optima (Opt.) and tolerance (Tol.) of taxa used in the development of the inference models

5.2 Mean values of salinity (Sal.), water total nitrogen (WTN), water total phosphorus (WTP) and water total organic carbon (WTOC) for different biozones present in the studied cores during specific time periods 


\section{LIST OF FIGURES}

FIGURE

PAGE

1.1 Map showing study area with locations of the modern sampling sites and sediment cores

2.1 Map showing location of the sampling sites in Florida Bay and adjacent coastal wetlands (a) grouped together by the cluster analysis (b) based on diatom compositional similarity. Symbols indicate: Long Term Ecological Research sites in Taylor Slough (TS), Southeast Environmental Research Center water quality monitoring sites in Florida Bay (WQ), and additional sites chosen in Florida Bay (FB) and coastal lakes in southwestern Florida (LK)

2.2 NMDS ordination of sites based on Bray-Curtis similarity in diatom composition. Sites are coded by location and circles represent clusters. Arrows show the direction and magnitude of correlation of environmental variables with species compositional differences. Cluster 1 represents freshwater Everglades sites, cluster 2 coastal mangrove sites, and cluster 3 Florida Bay sites

2.3 Non-metric multidimentional scaling ordination of sites based on BrayCurtis similarity in diatom composition. Sites are coded by life habitat type

2.4 Plots of observed vs. predicted salinity (a), WTN (ppm) (b), WTP (ppm) (c), and WTOC (ppm) using WA-PLS regression with jack-knife cross validation on the combined wet and dry season dataset

2.5 Diatom-based WA-PLS predictions of salinity (a), WTN (b), WTP (c), and WTOC (d) based on the 37-site dry season training set for 38-site wet season test set compared to the measured values of these variables

2.6 Diatom-based predictions of geographical location $(a, b)$ and life-habitat type (c-j) based on discriminant function analysis using the combined dry and wet season data (a,c,e,g,i) and dry season data only to predict the locations and life-habitat type from the wet season data $(b, d, f, h, j)$

3.1 Map of Florida Bay, Florida, showing sediment core locations

3.2 Description of the Trout Cove (a), Russell Bank (b), Bob Allen (c), and Ninemile Bank (d) cores. Depths are in centimeters 
3.3 ${ }^{210} \mathrm{~Pb}$ models for the Trout Cove (a), Russell Bank (b), Bob Allen (c), and Ninemile Bank (d) cores (Charles Holmes, USGS)

3.4 Organic carbon (OC) and inorganic carbon (IC) content in the Trout Cove (a), Russell Bank (b), Bob Allen (c), and Ninemile Bank (d) cores

3.5 Stratigraphy of the most common diatom taxa in the Trout Cove sediment core. Zones are based on constrained cluster analysis by the method of incremental sum of squares (CONISS). Solid line represents boundary between major clusters and dashed lines represent the boundary between major sub-zones. Gray shading represents levels in the sediment core with very low diatom count

3.6 Diatom-inferred salinity, water total nitrogen (WTN), water total phosphorus (WTP), water total organic carbon (WTOC), species richness, species diversity determined by the Shannon-Wiener diversity index, abundance of diatom groups typical for different type of habitats and dominant life habits in the Trout Cove core. Abbreviations:

$\mathrm{FM}=$ freshwater marshes, $\mathrm{M}=$ mangroves, $\mathrm{NS}=$ nearshore, $\mathrm{OB}=$ open-bay, $\mathrm{EL}=$ sediment, $\mathrm{EP}=$ epiphyton, $\mathrm{P}=$ plankton

3.7 Stratigraphy of the most common diatom taxa in the Russell Bank sediment core. Zones, lines and shadings as in Fig. 3.5

3.8 Diatom-inferred salinity, water total nitrogen (WTN), water total phosphorus (WTP), water total organic carbon (WTOC), species richness, species diversity determined by the Shannon-Wiener diversity index, abundance of diatom groups typical for different type of ecosystems and dominant assemblage types in the Russell Bank core. Abbreviations as in Fig. 3.6

3.9 Stratigraphy of the most common diatom taxa in the Bob Allen sediment core. Zones, lines and shadings as in Fig. 3.5

3.10 Diatom inferred salinity, water total nitrogen (WTN), water total phosphorus (WTP), water total organic carbon (WTOC), species richness, species diversity determined by the Shannon-Wiener diversity index, abundance of diatom groups typical for different type of ecosystems and dominant assemblage types in the Bob Allen core. Abbreviations as in Fig. 3.6

3.11 Stratigraphy of the most common diatom taxa in the Ninemile Bank sediment core. Zones, lines and shadings as in Fig. 3.5 
3.12 Diatom inferred salinity, water total nitrogen (WTN), water total phosphorus (WTP), water total organic carbon (WTOC), species richness, species diversity determined by the Shannon-Wiener diversity index, abundance of diatom groups typical for different type of ecosystems and dominant assemblage types in the Ninemile Bank core. abbreviations as in Fig. 3.6

3.13 3.13 Changes in $\beta$-diversity (species turnover rate) over time in Trout Cove (a), Russell Bank (b), Bob Allen (c), and Ninemile Bank (d) cores

3.14 Major constructions plans and hurricane events that affected Everglades and adjacent estuaries landscape and hydrology

3.15 Changes of water flow from major South Florida Water Management District structures into the Everglades and fluctuations of rainfall at two stations in South Florida (http://www.sfwmd.gov/). Highlighted areas indicate co-occurance of increased rainfall and water flow from the canals.

4.1 Map of Biscayne Bay showing locations of the sampled sites

4.2 Dendrograms showing groups of sites clustered based on diatom assemblage similarities in the dry season (a) and in the wet season (b). Open circles represent open-bay sites and black diamonds represent nearshore sites

4.3 NMDS ordination site scores for dry (a) and wet (b) seasons coded by geographical location and separated into clusters (solid lines) and subclusters (broken line) based on the cluster analysis of Fig. 4.2. Vectors correspond to the direction of maximum correlation of environmental variables having significant correlation with NMDS site scores. Symbols of the variables represented by the vectors have been defined in the text

4.4 NMDS ordination site scores for dry (a) and wet (b) seasons coded by life habit types in two dimensional space

4.5 Relationships between observed vs. diatom-inferred salinity (a), WTN (b), WTP (c) and WTOC (d) WA-PLS and WA regression and calibration models

4.6 Diatom-based WAPLS predictions of salinity (a), WTN (b), WTP (c), and WTOC (d) based on 96-site training set for 37-site Florida Bay independent test-set (Chapter 2) with site specific root mean square error of prediction indicated by error bars compared to the measured values of these variables 
4.7 Diatom-based predictions of habitat $(\mathrm{a}-\mathrm{c})$ and life-habit type in Cluster 1 $(\mathrm{d}-\mathrm{f})$ and Cluster $2(\mathrm{~g}-\mathrm{i})$ based on discriminant function analysis using dry- and wet-season data sets

5.1 Map of Biscayne Bay, Florida showing Sites where sediment cores were collected

5.2 Changes in $\beta$-diversity over time at No Name Bank (a), Featherbed Bank (b), and Card Sound Bank (c)

5.3 Stratigraphy of the most common diatom taxa in the No Name Bank sediment core. Zones are based on constrained cluster analysis by the method of incremental sum of squares (CONISS). The solid line represents the boundary between major clusters and dashed lines represent the boundaries between major sub-zones

5.4 Diatom-inferred salinity, water total nitrogen (WTN), water total phosphorus (WTP), water total organic carbon (WTOC), species richness, Shannon-Wiener (Shannon's H) diversity and abundance of assemblages typical for nearshore (1) and open-bay (2) diatom assemblages in the No Name Bank core

5.5 Stratigraphy of the most common diatom taxa in the Featherbed Bank sediment core. Zones and lines as in Figure 5.3. Gray shading represents levels with very low diatom abundance

5.6 Diatom-inferred salinity, water quality and diversity typical for nearshore (1) and open-bay (2) diatom assemblages in the Featherbed Bank core. Abbreviations and shading as in Figures 5.4.

5.7 Stratigraphy of the most common diatom taxa in the Card Sound Bank sediment core. Zones, lines and shading as in previous figures

5.8 Diatom-inferred salinity, water quality and diversity of assemblages typical for nearshore (1) and open-bay (2) diatom assemblages in the Card Sound Bank core. Abbreviations and shading as in previous figures

5.9 Changes of water flow from major South Florida Water Management District structures into Biscayne Bay and fluctuations of rainfall at Miami International Airport (MIA) weather station (http://www.sfwmd.gov/). Highlighted areas indicate co-occurance of increased rainfall and water flow from the canals. 


\section{CHAPTER 1. INTRODUCTION}

Estuarine and coastal environments are among the most productive and valuable aquatic ecosystems on Earth. They serve as feeding and nursery grounds for aquatic animals, and are home to a countless number of aquatic plants (Costanza et al. 1997). As a result of growing human population in nearshore areas, especially in the last few centuries, these ecosystems have significantly been impacted by human activities (Howarth et al. 1991; Carnahan et al. 2008). Urbanization, agriculture, industrialization and tourism represent major sources of stress in coastal areas, which are responsible for depletion of seagrass beds and wetland habitats, degradation of water quality, and increased rates of non-native species invasions (Lotze et al. 2006; Taffs et al. 2008). Additionally, these areas are vulnerable to recent sea level rise caused by humanaccelerated global warming. This phenomenon is already responsible for inundation of coastal wetlands (e.g., mangroves, salt marshes) and other low lying areas around the world (e.g., Maldive Islands), intensive flooding, increased salinity in lagoons and estuaries, salt water intrusions into rivers and ground water aquifers that endanger freshwater supplies, and beach erosion (Vellinga and Leatherman 1989; Michener et al. 1997; Scavia et al. 2002). Detecting the effects that anthropogenic activities have on natural environments is a very important issue in environmental science and resource management, but it requires detailed studies in order to distinguish the natural changes from those caused by humans (Hewitt et al. 2001).

Florida Bay and Biscayne Bay (Fig. 1.1) are subtropical estuaries in south Florida which have been significantly affected by anthropogenic and climate-driven changes. 
The intensive urbanization of the South Florida coastal areas that took place in the early and mid 1900's included construction of flood-protection structures, highways and railroads, and resulted in expansion of agricultural areas that altered surface and groundwater hydrologic systems, which affected the quantity and quality of water flowing into the adjacent estuaries (McIvor et al. 1994; Forqurean and Robblee 1999; Meeder and Boyer 2001). All of these alterations have also been blamed in both bays for chronic hypersalinity (Cronin et al. 2002), changes in water mass circulation (Meeder and Boyer 2001), increased water turbidity and algal blooms (Brand 1994; Philips and Badylak 1996), seagrass and sponge die-offs (Robblee et al. 1991; Butler et al. 1995), and decline in fishery and shrimp harvests (Tilmant 1989; Nance 1994). The anthropogenic modifications of the South Florida environment are superimposed on long-term, climatedriven changes such as sea-level rise, which has already been held responsible for reduction of pine forest in the Florida Keys (Ross et al. 1994).

Understanding and predicting the effects that these two factors may have on the fragile ecosystems of Florida Bay and Biscayne Bay depend heavily upon identifying which part of the variability is attributable to natural sources, and which to human-caused disturbances. This can be achieved by examining the environmental conditions present in this region prior to and after 19th century urban development. Because continuous monitoring programs in this region do not predate the 1980's, the history of freshwater delivery and nutrient loading into Florida Bay and Biscayne Bay is unknown, which prevents realistic target-setting in restoration design. In lieu of long-term historical records, paleoecological data can provide an assessment of past environmental conditions and their drivers in these South Florida estuaries. 
Diatoms are well known as excellent and reliable bio-indicators (Battarbbee 1986), and have been used in ecological and paleoenvironmental studies from the early 1900's (Juggins 1992). The majority of the diatom-based paleoenvironmental studies have been conducted in freshwater areas, but in the last few decades they have also been successfully carried out in estuaries and coastal regions to study eutrophication (Cooper 1993), water circulation (Witak et al. 2005), water temperature (De Seve 1999), salinity (Juggins, 1992), and sea level changes (Hamilton and Shennan 2005). Most of these investigations have been done in higher latitudes and only a few have been carried out in subtropical and tropical coastal regions (Fluin et al. 2007; Taffs et al. 2008) and estuaries (e.g., Zong et al. 2006; Sounders et al. 2007).

Ecological, paleoenvironmental and taxonomic studies involving diatoms are very scarce in estuaries and coastal wetlands of South Florida. The only taxonomic work in this area involved surveys of Amphora and Seminavis (Wachnicka and Gaiser 2007), examination of taxa occupying sediments in coastal mangroves near Biscayne Bay (Gaiser et al. 2005), and coral reef sands and Thalassia testudinum leaves in Florida Bay (Montgomery 1978; Frankovich et al. 2006). Pioneering ecological studies involving diatoms in Florida Bay and Biscayne Bay focused mostly on their distribution and diversity (DeFelice and Lynts 1978; Montgomery 1978; Reyes-Vasquez 1970; Brandt 1988). In recent years, modern diatom assemblages have been used in biomonitoring to track rates of saltwater encroachment on the coastal mangrove areas adjacent to Biscayne Bay (Ross et al. 2001), and to create salinity models that can be used in the study of sealevel change there (Gaiser et al. 2005). The relationship between epipelic communities and salinity was studied in eastern Florida Bay to hindcast salinity fluctuations (Huvane 
2002), and ecological preferences (salinity and phosphorus) of diatoms growing on Thalassia testudinum were described from several sites located throughout the bay (Frankovich et al. 2006). Additionally, the response of planktonic diatoms to increased nutrient supplies related to freshwater runoff from Shark River Slough was investigated in southwest Florida shelf (Jurado et al. 2007). Although the aforementioned studies provided some information about the relationships between diatoms and salinity and nutrients, especially in Florida Bay and the coastal mangroves adjacent to Biscayne Bay, no comprehensive studies exist that investigate the distribution of diatoms across a full suite of parameters, representing ranges expected to have occurred in the past in these estuaries, in order to produce reliable paleoenvironmental estimates.

Most paleoenvironmental studies conducted in these regions have employed foraminifera, ostracodes, mollusks, stable isotopes of oxygen and carbon, or chemical biomarkers (Swart et al. 1996; Brewster-Wingard and Ishman 1999; Cronin et al. 2001; Xu et al. 2006, 2007; Gaiser et al. 2006), but diatoms have been involved in just a few (Pyle et al. 1998; Huvane and Cooper 2001). None of them used the approach of a quantitative transfer function, where first the relationships between species and environmental variables of interest are quantified (in a statistical regression), and then the modeled species-environment relationships are used to infer environmental values from fossil diatom records (calibration) (Birks 1995). Instead, the first interpretation of diatom assemblages preserved in a 70-cm-long, chronologically uncalibrated sediment core collected near Pass Key in Florida Bay was based on information regarding diatom ecological preferences obtained from the literature (Pyle et al. 1998). More careful interpretation of fossil communities was given for two chronologically calibrated 
sediment cores extracted from Russell Bank and near Pass Key in Florida Bay (Fig. 1) (Huvane and Cooper 2001). Both of the above-mentioned studies concluded that salinity fluctuated during the last 200 years, and that there was a clear trend towards higher salinity in the last few decades. To my knowledge, no paleoenvironmental studies of diatoms have been conducted in Biscayne Bay. In response to these needs, I conducted a comprehensive study of modern diatom assemblages at 38 sites in Florida Bay, the adjacent coastal mangroves and the freshwater Everglades marshes, and at 58 sites in Biscayne Bay. Additionally, I analyzed fossil diatom communities preserved in 4 sediment cores collected in Florida Bay and 3 in Biscayne Bay.

This dissertation includes six chapters that were written to stand alone. Chapter 1 is a general introduction to the study area and research. The main objectives of Chapter 2 are 1) to determine spatial and temporal differences in diatom assemblages among sites in Florida Bay, the adjacent coastal mangroves and freshwater marshes; 2) to determine the physico-chemical controls on the diatom community structure existing in this area at the present time; 3) to produce quantitative prediction models for salinity, WTN, WTP, and WTOC; and 4) to test the possibility of inferring habitat types and life habits from fossil diatom records using the contemporary diatom assemblages. The key goals of Chapter 3 are: 1) to reconstruct salinity, WTN, WTP and WTOC from fossil diatom records preserved in four Florida Bay sediment cores using the prediction models developed in Chapter 2; and 2) to reconstruct the availability and quality of common substrata (i.e., plankton, underwater vegetation, bare sediments) and habitat types (freshwater marshes, coastal mangroves, estuary) in the past using information about the distribution of modern diatom assemblages in the bay. The main objectives of Chapter 4 are: 1) to 
determine the spatial and temporal differences in diatom assemblages among 58 sites in Biscayne Bay; 2) to determine the physico-chemical factors responsible for structuring these communities; 3) to develop inference models for salinity, WTN, WTP and WTOC based on the modern diatom training set and present day environmental data; and 3) to test the possibility of predicting habitat types (freshwater marshes, coastal mangroves, estuary) and availability of common substrata (e.g., underwater vegetation, bare sediment, plankton) from fossil diatom records using the modern diatom assemblages. The goals of Chapter 5 are: 1) to reconstruct salinity, WTN, WTP and WTOC from fossil diatom records preserved in three sediment cores collected in Biscayne Bay using prediction models developed in Chapters 4 and 2; and 2) to determine changes in habitat types and common substrata from fossil diatoms using information about the distribution of contemporary diatom assemblages in the bay. Chapter 6 is general summary of major findings of this study. These steps will provide valuable information about water quality and environmental conditions present in Florida Bay and Biscayne Bay in the past, before and after human introduced changes on mainland altered these conditions in the bays, which will allow federal and state agencies responsible for Comprehensive Everglades Restoration Program (www.evergladesplan.org) that aims to increase freshwater flow into the Everglades and ultimately Florida Bay, and decrease the amount of freshwater flow into Biscayne Bay by restoring the historic overland flow through coastal wetlands, to develop strategies that will allow them to accomplish their goals of restoring these unique ecosystems to their natural states. Additionally, this study will also suggest how communities may respond to rising sea level and to the hydrologic changes expected if restorative policies continue to be delayed. 


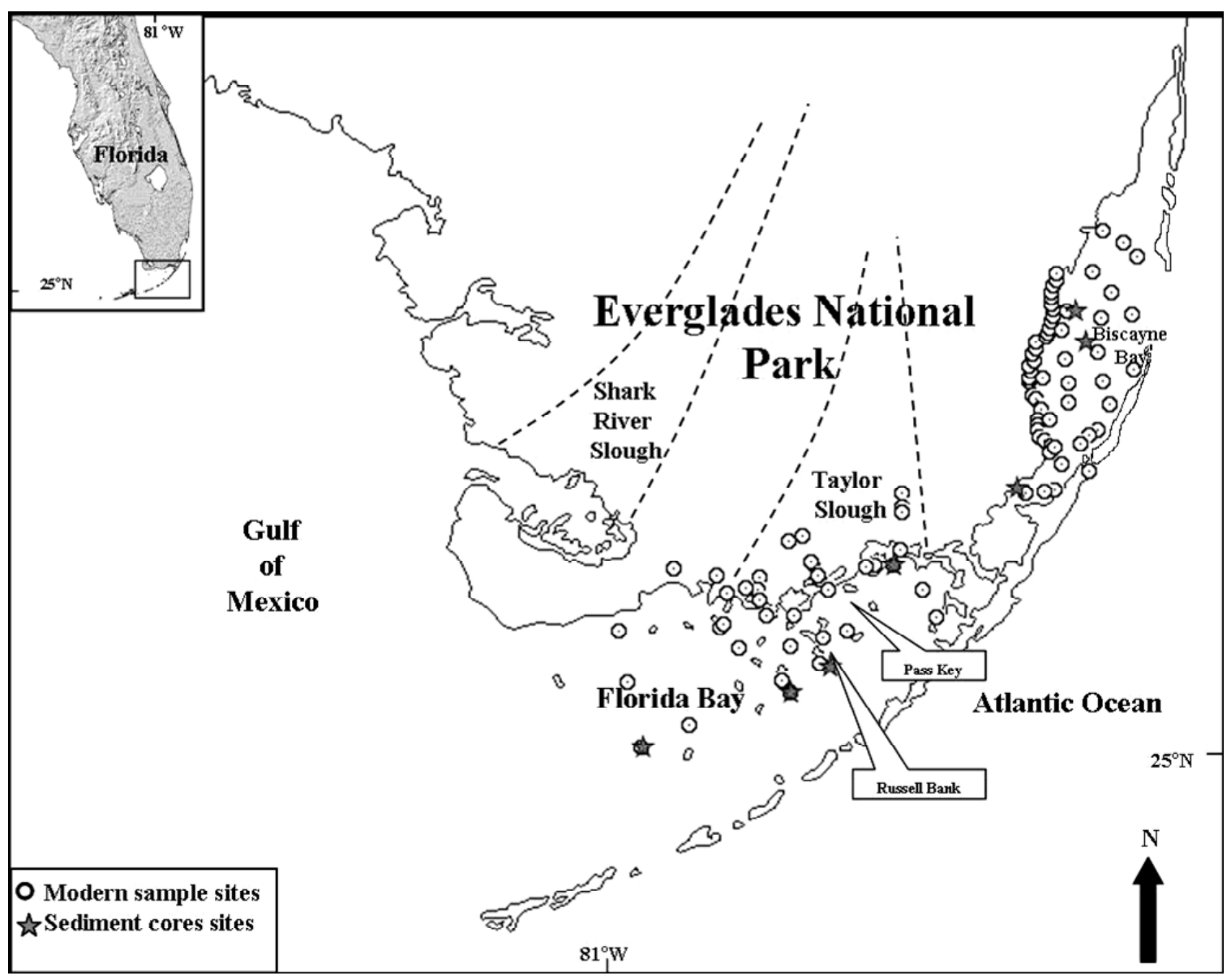

Fig. 1.1 Map showing study area with locations of the modern sampling sites and sediment cores. 


\section{REFERENCES}

Battarbee, R.W. 1986. Diatom analysis. In: B.E. Berglund (Editor), Handbook of Holocene Palaeoecology and Palaeohydrology. The Blackburn Press, Caldwell, New Jersey, USA, pp. 527-570.

Birks, H.J.B. 1995. Quantitative paleoenvironmetal reconstructions. In: D. Maddy, J.S. Brew (Editors), Statistical Modelling of Quaternary Science Data, Technical Guide No. 5. Quaternary Research Association, Cambridge, pp. 161-236.

Brand, L.E. 1988. Assessment of plankton resources and their environmental interaction in Biscayne Bay, Florida. Dade Environmental Resource Management Technical Report 88-1. pp. 79.

Brand, L.E. 1994. Physiological ecology of marine coccolithophores. In: Coccolithophores. A. Winter, W. Siesser (Editors), Cambridge University Press, pp. 3949.

Brewster-Wingard, G.L., and S.E. Ishman. 1999. Historical trends in salinity and substrate in central and northern Florida Bay: A Paleoecological Reconstruction using modern analogue data. Estuaries 22:369-383.

Butler, M.J.I., J.H. Hunt, W.F. Herrnkind, T. Matthews, D. Childress, R. Bertelsen, W. Sharp, J.M. Field, and H. Marshall. 1995. Cascading disturbances in Florida Bay, USA: cyanobacteria blooms, sponge mortality, and implications for juvenile spiny lobster Panulirus argus. Marine Ecology Progress Series 129:119-125.

Carnahan, E. A., A. M. Hoare, P. Hallock, B. H. Lidz, and C.D. Reich (2008).

Distribution of Heavy Metals and Foraminiferal Assemblages in Sediments of Biscayne Bay, Florida, USA. Journal of Coastal Research 24:159-169.

Cooper, S.R., and G.S. Brush. 1993. A 2500 year history of anoxia and eutrophication in Chasapeake Bay. Estuaries 16:617-626.

Costanza, R., R. d'Arge, R. de Groot, S. Farber, M. Grasso, B. Hannon, K. Limburg, S. Naeem, R. V. O’Neill, J. Paruelo, R. G. Raskin, P. Sutton, and M. van de Belt. 1997. The Value of the World's Ecosystem Services and Natural Capital. Nature 387:253-260.

Cronin, T.M., Holmes, C.W., Brewster-Wingard, G.L., Ishman, S.E., Dowsett, H.J., Keyser, D., and N. Waibel. 2001. Historical trends in epiphytal ostracodes from Florida Bay: Implication for seagrss and macro-benthic algal variability, In: B.R. Wardlaw (Editor), Paleoecological Studies of South Florida: Bulletins of American Paleontology 361:159-198. 
DeFelice, D. R., and G.W. Lynts. 1978. Benthic marine diatom associations: upper Florida Bay (Florida) and associated sounds. Journal of Phycology 14:25-33.

De Seve, M. A. 1999. Transfer function between surface sediment diatom assemblages and sea-surface temperature and salinity of the Labrador Sea. Marine Micropaleontology, 36:249-269.

Fluin, J., P. Gell, D. Haynes, J. Tibby, and G. Hancock. 2007. Paleolimnological evidence for the independent evolution of neighbouring terminal lakes, the Murrey Darling Basin, Australia. Hydrobiologia 591:117-134.

Fourqurean, J.W., and M. Robblee. 1999. Florida Bay: A history of recent ecological changes. Estuaries 22:345-357.

Frankovich, T.A., E. Gaiser, A. Wachnicka, and J.C. Zieman. 2006. Spatial and temporal distributions of epiphytic diatoms: relationships to salinity and nutrients in a subtropical ecosystem. Hydrobiologia 569:259-271.

Gaiser, E.E., A. Wachnicka, P. Ruiz, F.A. Tobias, and M.S. Ross. 2005. Diatom indicators of ecosystem change in coastal wetlands. In: S. Bortone (Editor), Estuarine Indicators. CRC Press, Boca Raton, FL, pp. 127-144.

Gaiser, E.E., J.H. Richards, J.C. Trexler, R.D. Jones, and D.L. Childers. 2006. Periphyton responses to eutrophication in the Florida Everglades: Cross-system patterns of structural and compositional change. Limnology and Oceanography 51:617-630.

Gaiser, E.E., A. Zafiris, P.L. Ruiz, F.A.C. Tobias, and M.S. Ross. 2006. Tracking rates of ecotone migration due to salt-water encroachment using fossil mollusks in coastal South Florida. Hydrobiologia 569:237-257.

Hamilton, S.L., and I. Shennan. 2005. Late Holocene relative sea-level changes and the earthquake deformation cycle around upper Cook Inlet, Alaska. Quaternary Science Reviews 24:1479-1498.

Hewitt, C.D., A.J. Broccoli, J.F.B. Mitchell, and R.J. Stouffer. 2001. A coupled model of the last glacial maximum: Was part of the North Atlantic relatively warm? Geophysical Research Letters 28:1571- 1574.

Howarth, R.W., J.R. Fruci, and D. Sherman. 1991. Inputs of sediment and carbon to an estuarine ecosystem: influence of land use. Ecological Applications 1:27-39.

Huvane, J.K., and S.R. Cooper. 2001. Diatoms as indicators of environmental change in sediment cores from Northeastern Florida Bay. Bulletins of American Paleontology 361:145-158. 
Huvane, J.K. 2002. Modern diatom distributions in Florida Bay: A preliminary analysis. In: J.W. Porter, K.G. Porter (Editors), The Everglades, Florida Bay, and coral reefs of the Florida Keys: an ecosystem sourcebook. CRC Press, Boca Raton, FL, pp. 479-493.

Juggins, S. 1992. Diatoms in the Thames Estuary, England: ecology, paleoecology, and salinity transfer function. J. Cramer, Berlin-Stuttgard, pp. 216.

Jurado, J., G.L. Hitchcock, and P.B. Ortner. 2007. Seasonal variability in nutrient and phytoplankton distributions on the southwest Florida inner shelf. Bulletin of Marine Science 80:21-43.

Lotze, H.K., H.S. Lenihan, B.J. Bourque, R.H. Bradbury, R.G. Cooke, M.C. Kay, S.M. Kidwell, M.X. Kirby, C.H. Peterson, and J.B.C. Jackson. 2006. Depletion, degradation, and recovery potential of estuaries and coastal seas. Science Magazine 312:1806-1809.

McIvor, C.C., J.A. Ley, and R.D. Bjork. 1994. Changes in freshwater inflow from the Everglades to Florida Bay including effects on biota and biotic processes: a review. In: S.M. Davis, J.C. Ogden (Editors), Everglades: The ecosystem and its restoration. St. Lucie Press, Delray Beach, FL, pp. 117-143.

Meeder, J. and J. N. Boyer. 2001. Total ammonia concentrations in soil, sediments, surface water, and groundwater along the western shoreline of Biscayne Bay with the focus on Black Point and a reference mangrove site. Final Report to the National Park Service under NPS/FIU Cooperative Agreement No. CA5280-8-9038.

Nance, J.M. 1994. A biological review of the Tortugas pink shrimp fishery through December 1993. Galveston Laboratory, Southeast Fisheries Science Center, National Marine Fisheries Service, Galveston, Texas.

Philips, E.J., and S. Badylak. 1996. Spatial variability in phytoplankton standing crop and composition in a shallow inner-shelf lagoon, Florida Bay, Florida. Bulletin of Marine Science 58:203-216.

Pyle, L., S.R. Cooper, and J.K. Huvane. 1998. Diatom paleoecology Pass Key core 37, Everglades National Park, Florida Bay. Open-File Report 98-522, pp 38.

Reyes-Vasquez G. 1970. Studies on the diatom flora living on Thalassia testudinum König in Biscayne Bay, Florida. Bulletin of Marine Science 20:105-134.

Robblee, M.B., T.B. Barber, P.R. Carlson, M.J. Durako, J.W. Fourqurean, L.M. Muehlstein, D. Porter, L.A. Yabro, J.C. Zieman, and R.T. Zieman. 1991. Mass mortalityof the tropical seagrass Thalassia testudinum in Florida Bay (USA). Marine Ecology Progress Series 71: 297-299. 
Ross, M.L., J.J. O’Brien, and L.D.S. Sternberg. 1994. Sea-level rise and the reduction in pine forests in the Florida Keys. Ecological Applications 4:144-156.

Ross, M.S., E.E. Gaiser, J.F. Meeder, and M.T. Lewin. 2001. Multi-taxon analysis of the "white zone", a common ecotonal feature of South Florida coastal wetlands. In: J. Porter, K. Porter (Editors), The Everglades, Florida Bay, and coral reefs of the Florida Keys. CRC Press, Boca Raton, FL, USA. pp. 205-238.

Michener W.K., E.R. Blood, K. L. Bildstein, M.M. Brinson, and L.R. Gardner. 1997. Climate change, hurricanes and tropical storms, and rising sea level in coastal wetlands. Ecological Applications 7:770-801.

Montgomery, R.T. 1978. Environmental and ecological studies of the diatom communities associated with the coral reefs of the Florida Keys. Ph.D. Dissertation, Florida State University, Tallahassee, FL, USA.

Saunders, K.M., A. Mcminn, D. Roberts, D.A. Hodgson, and H. Heijnis. 2007. Recent human-induced salinity changes in Ramsar-listed Orielton Lagoon, south-east Tasmania, Australia: a new approach for coastal lagoon conservation and management. Aquatic Conservation: Marine and Freshwater Ecosystems 17:51-70.

Scavia, D., J.C. Field, D.F. Boesch, R.W. Buddemeier, V. Burkette, D.R. Cayan, M. Fogarty, M.A. Harwell, R.W. Howarth, C. Mason, D.J. Reed, T.C. Royer, A.H. Sallenger, and J.G. Titus. 2002. Climate change impacts on U.S. coastal and marine ecosystems. Estuaries 25:149-164.

Swart, P.K., G. Healy, R.E. Dodge, P. Kramer, J.H. Hudson, R.B. Halley, and M.B. Robblee. 1996. The stable oxygen and carbon isotopic record from a coral growing in Florida Bay: A 160 year record of climatic and anthropogenic influence, Palaeogeography, Palaeoclimatology, Palaeoecology 123:219-237.

Taffs, K.H., L.J. Farago, H. Heijnis, and G. Jacobsen. 2008. A diatom-based Holocene record of human impact from a coastal environment: Tuckean Swamp, eastern Australia. Journal of Paleolimnology 39:71-82.

Tilmant, J.T. 1989. A history and an overview of recent trends in the fisheries of Florida Bay. Bulletin of Marine Science 44:3-22.

Vellinga P., and S.P. Leatherman. 1989. Sea level rise, consequences and policies. Climatic Change 15:175-189.

Wachnicka, A., and E.E. Gaiser. 2007. Morphological characterization of Amphora and Seminavis (Bacillariophyceae) from South Florida, U.S.A. Diatom Research 22:387-455. 
Witak, M., A. Wachnicka, A. Kuijpers, M.A. Prins, S.R. Troelstra, and A. Witkowski. 2005. Holocene North Atlantic surface circulation and climate variability: evidence from diatom records. The Holocene 15:85-96.

Zong, Y., J.M. Lloyd, M.J. Leng, W.W.-S. Yim, and G. Huang. 2006. Reconstruction of Holocene monsoon history from the Pearl River estuary, southern China, using diatoms and carbon isotope ratios. The Holocene 16:251-263.

Xu, Y., R. Jaffe, A. Wachnicka, and E.E. Gaiser. 2006. Occurrence of C25 highly branched isoprenoids in Florida Bay: Paleoenvironmental indicators of diatom-derived organic matter inputs. Organic Geochemistry 37:847-859. 


\section{CHAPTER 2: DEVELOPING DIATOM-BASED INFERENCES OF \\ ENVIRONMENTAL CHANGE IN FLORIDA BAY, U.S.A.}

Abstract

The spatial and temporal distribution of diatom assemblages in surface sediments, on the most dominant macrophytes, and in the water column at 38 locations in the freshwater Everglades, coastal mangroves, and Florida Bay was examined in order to develop paleoenvironmental prediction models for the region. Assemblages were grouped into three spatial clusters representing regionality in salinity and nutrient availability. Seasonal differences in diatom assemblages were distinguishable in clusters of coastal mangrove and Florida Bay sites, but not in the Everglades. Epiphytic assemblages differed from planktonic and epipelic, but more significant overlap between the latter two indicated low benthic habitat affinity or a high degree of mixing in the shallow waters of Florida Bay. The relationship between each taxon and salinity, water total phosphorus (WTP), water total nitrogen (WTN), and water total organic carbon (WTOC) was determined and incorporated into multi-taxon prediction models using weighted averaging partial least squares regression (WA-PLS). Salinity was the most influential variable to diatom assemblages, resulting in a highly resolved prediction model $\left(r^{2}=0.97\right.$, RMSEP $\left.=2.64\right)$ that can be used to calibrate sediment assemblages and infer ecological consequences of changes resulting from changes in climate and water management in the Everglades drainage. Independent models predicting WTN, WTP and WTOC were also strong $\left(\mathrm{r}^{2}=0.75, \mathrm{RMSEP}=0.16 \mathrm{ppm}\right.$; $\mathrm{r}^{2}=0.75, \mathrm{RMSEP}=0.01 \mathrm{ppm}$; 
$\mathrm{r}^{2}=0.79$, RMSEP $=2.70 \mathrm{ppm}$. respectively), providing accurate predictions of changes in nutrient availability across the salinity gradient. A discriminant function analysis (DF) showed that diatom assemblages can also be used to reconstruct the availability of common benthic substrata, a novel and useful addition to the numerical water quality predictions.

\subsection{Introduction}

Estuaries and shallow coastal embayments around the world have been heavily impacted by human activities in the last few centuries (Lotze et al. 2006) and are among the ecosystems most threatened by urbanization and sea-level rise (Nicholls et al. 1999). The degree to which modern anthropogenic changes are altering coastal ecosystems can be scaled to that imposed by natural variability through long-term, spatially explicit monitoring and paleoecological investigations. Because monitoring programs in many parts of the world are only recently established, paleoenvironmental proxies such as diatoms provide a critical tool to determine the direction and rates of changes in environmental drivers and ecological responses. These microscopic algae are well known as sensitive and useful paleoecological indicators due to their widespread occurrence, high species diversity and quick response to environmental changes (Battarbee 1986).

More than half of the original Everglades and associated coastal ecosystems in South Florida have been lost to expanding urban and agricultural areas in the last century (Lodge 2005). All of these changes significantly altered the quantity and quality of water 
flowing into the Everglades marshes and adjacent estuaries (McIvor et al. 1994), thus causing changes in the biota (Fourqurean and Robblee 1999). Understanding and predicting the effects of anthropogenic and climate-driven alterations on the environmental conditions in Florida Bay depend heavily upon understanding of the paleoconditions present in this region prior to and after 19th century urban development. In order to use diatoms in these studies it is necessary to first establish the relationship between these algae and the most important environmental variables influencing their assemblages in the South Florida region. Although several ecological and paleoecological studies have been conducted in Florida Bay and adjacent areas using diatoms, there is still very little known about the autecology and taxonomy of the unique assemblages inhabiting this coastline. In addition, there has been no comprehensive study that examines diatoms across the full gradient of nutrient and salinity conditions, precluding accurate identification of paleoenvironmental predictions from this powerful proxy group.

In previous investigations, nutrients have been shown to regulate diatom community compositions within the freshwater Everglades (Cooper et al. 1999; Gaiser et al. 2006), as well as at particular sites in Florida Bay (Frankovich et al. 2006) and on the southwest Florida shelf (Jurado et al. 2007). However, temporal and spatial variability in salinity appears to override nutrient effects when examined across a broad gradient (Frankovich et al. 2006). Huvane (2002) found that diatom communities living at less saline sites are distinct from and less diverse than communities occupying more saline sites. Similarly, Ross et al. (2001) and Gaiser et al. (2005) found steep gradients in diatom assemblage composition in a compacted salinity gradient in the coastal wetlands 
of neighboring Biscayne Bay. A high degree of habitat affiliation for coastal and estuarine diatoms was suggested in the work of DeFelice and Lynts (1978) and Montgomery (1978), where epiphytic diatoms occurring on Thalassia testudinum were distinguished from those occupying a carbonate mud substratum or coral sand habitats. These studies suggest that highly resolved inferences of salinity, water quality and habitat structure are possible across the broad spectrum of ecological conditions representing current and past conditions in the region.

The main objectives of this study are: 1) to ascertain whether spatial variability in the coastal Everglades habitat mosaic is greater than intra-annual variability in diatom assemblage composition in order to justify predictions of coastal habitat zone (i.e., freshwater marsh, mangrove ecotone, estuary); 2) to determine the physico-chemical controls on species composition in order to produce quantitative prediction models for salinity, water total nitrogen (WTN), water total phosphorus (WTP), and water total organic carbon (WTOC). These variables can then be reconstructed from fossil diatom records preserved in Florida Bay sediments to help understand how an increased freshwater flow into the Everglades and ultimately Florida Bay, which is a goal of the Comprehensive Everglades Restoration Program, may impact the distribution of organisms and their productivity in this estuary; 3) to determine whether the availability and quality of common substrata (i.e., plankton, underwater vegetation, bare sediments) can be predicted from assemblage composition, in order to add a biological proxy to future paleoecological interpretations. 


\subsection{Study Area}

A total of 38 sites were selected in Florida Bay and the adjacent coastal wetlands of South Florida, USA (Fig. 2.1a) to encompass the gradients of salinity, nutrient availability and habitat structure characterizing the region. In order to characterize temporal variability, I sampled in two distinct seasons that regulate circulation and water chemistry in this subtropical environment (Boyer et al. 1997). Sampling in September and October 2006 characterized the "wet season" when freshwater input to the system is greatest, and collections in March and April 2007 characterized the following "dry season".

The study area includes freshwater and marine areas. Taylor Slough is one of the largest sources of freshwater for Florida Bay (McIvor et al. 1994). During wet seasons water from Taylor River flows into the bay, while during dry seasons high evaporation in the Everglades marshes combined with reduced rainfall result in higher salinity (up to 50) throughout the mangrove zone (McIvor et al. 1994; Davis et al. 2001). The northern and central portions of Taylor Slough have a short to intermediate hydroperiods while the southernmost portion is usually inundated for the entire year (Davis et al. 2001). Lakes and embayments located in the southwest portion of Everglades National Park (ENP) are oriented along freshwater flow paths from the interior to Florida Bay. The bathymetry of this area is shaped by storms, tides, freshwater flow, and sea level change (Browder and Ogden 1999). In the wet season the lakes are highly stained by humic substances from flooding of the surrounding mangroves, whereas in the dry season some of the lakes clear completely, while others experience intensive algal blooms that result in yellow 
coloration of the water (A. Wachnicka, pers. obs.). Florida Bay is a shallow ( 1 m mean depth) estuary that is divided into a series of small "basins" separated from each other by carbonate mud banks and small islands (McIvor et al. 1994). There are three major sources of freshwater for the bay: precipitation, freshwater flow from the mainland, and indirect flow from Shark River Slough (Swart and Price 2002). The eastern portion of the bay is phosphorus-limited (Boyer et al. 1997) and experiences the greatest annual salinity variations (McIvor et al. 1994), while the central part has a long history of hypersaline conditions that reach 70 (Finucane and Dragovich 1959) due to limited freshwater supply, high turbidity levels (Burd and Jackson 2002), and inorganic N:P ratio close to the Redfield ratio (Brand 2002). The western part of Florida Bay is strongly influenced by tidal exchange of water with the Gulf of Mexico (Burd and Jackson 2002), has salinity close to 35 and near-Redfield N:P ratio (Boyer 1997). The southern part is influenced by water coming from the Atlantic Ocean and the Gulf Stream, and has salinity values between 35 and 40 (Fourqurean et al. 1993).

\subsection{Methods}

\subsubsection{Sample Collection, Preparation and Laboratory Analysis}

Three types of samples were collected during each sampling event: sediment, epiphyton and plankton. A 3-cm-in-diameter syringe was used to collect $1 \mathrm{~cm}$ of surface sediments representing approximately one year of sedimentation (Holmes et al. 2001). Epiphytes were obtained by cutting off at least 10 leaves of the dominant plant species 
from the bottom while plankton was collected by pumping water from mid-depth in the water column onto a $20 \mu \mathrm{m}$ mesh. Salinity, oxygen, $\mathrm{pH}$, turbidity, and temperature were recorded during each sampling event using multiparameter sonde YSI 6600 EDS (Appendix 2.2). Water depth was measured using a hand-held sonar depth sounder. Sediment samples were homogenized to break down large particles, epiphytes were removed from the plant blades using a razor blade, and plankton accumulated on the meshes was removed by spraying with deionized water. A $10 \mathrm{ml}$ volume of slurry obtained from each of the sample types was collected for diatom analysis. The remaining sample was dried and ground for sediment total phosphorus (STP), sediment total nitrogen (STN) and sediment total carbon (STC) analysis. WTP and STP were analyzed with a UV-2101PC Scanning Spectrophotometer using a dry ashing, acid hydrolysis technique (Solorzano and Sharp 1980). WTN was measured with an ANTEK 7000N Nitrogen Analyzer using $\mathrm{O}_{2}$ as carrier gas to promote a complete recovery of nitrogen in the water samples (Frankovich and Jones 1998). STN and STC were analyzed in a Perkin Elmer Series II CHNS/O (2400) Analyzer by using high temperature catalytic combustion (Nelson and Sommers 1996). WTOC was measured with a Shimadzu TOC5000 following methods described in USEPA (1983). Samples were cleaned for diatom analysis using oxididation method described by Battarbee (1986). Approximately $1 \mathrm{ml}$ of slurry was placed on No.1 coverslips, air dried and then mounted onto glass slides using Naphrax ${ }^{\circledR}$. At least 500 diatom valves were counted on each slide on random transects. Identification and enumeration of diatoms was made using a Nikon E400 light microscope at $788 \mathrm{x}$ magnification $($ N.A. $=1.4)$. The identification of species was based on local and standard diatom taxonomic literature. 


\subsubsection{Data Analysis}

The abundance of each taxon was expressed as relative abundance. Only taxa occurring in more than $5 \%$ of the samples and having a mean relative abundance of over $0.5 \%$ were included in the analysis, since the occurrence of rare species could be due to chance and increase noise in the data set. Relative abundance was arcsine squareroot transformed to improve normality by down-weighting the importance of highly abundant species, and by ensuring that the rarer species will also contribute to the results (McCune and Grace 2002). Environmental data with skewness $>1$ were squareroot transformed, checked for outliers and relativized by adjustment to standard deviates ("z-scored") in order to more closely approximate a normal distribution and equalize variable distribution to a common scale (Clark and Warwick 2001; McCune and Grace 2002). Analysis of variance (ANOVA), a statistical technique which allows testing the differences between two or more sample means, followed by a post-hoc Tukey test, which determines which means are significantly different from one another, were used to determine the differences in water parameters of interest between the sampling locations (Quinn and Keough 2002). Spearman rank correlation analysis and the Kruskal-Wallis test were used to test for independence among environmental variables (Quinn and Keough 2002). The BIO-ENV procedure was used to determine the combination of environmental variables that provides the best correlation between biotic and abiotic matrices (Clark and Warwick 2001).

Non-metric multidimensional scaling (NMDS) (Kruskal and Wish 1978) with the Sørensen similarity index (Bray and Curtis 1957) was used to illustrate spatial and 
temporal patterns in distribution of modern diatom species among sampling sites, to depict the separation between different life habits of diatoms, to identify the environmental variables that influence taxa the most, and to determine how robustly the environmental variables of interest can be reconstructed on statistical grounds (Battarbee et al. 2001). This is a multivariate ordination technique that searches for the best position of objects on axes ( $k$-dimensions) that minimizes stress (goodness of fit between dissimilarity and distance) of the $k$-dimensional configuration (McCune and Grace 2002). Joint plots were constructed to graphically summarize the relationship between environmental variables and diatom community patterns. The angle and length of the "vectors" on the joint plots indicate the strength and direction of the maximum correlation of each environmental variable with site similarity. Hierarchical clustering with the Sørensen distance measure and flexible beta $(\beta=-0.25)$ linage method was used to define groups of sites with distinct diatom community structure (McCune and Grace 2002). These groups were later superimposed on the ordination diagrams. The statistical significance of spatial and temporal differences in diatom community structure was tested using analysis of similarities (ANOSIM) (Clarke and Gorley 2001). This is a nonparametric permutation procedure applied to the rank similarity matrix classification of samples that tests null hypothesis that there is no difference in community composition between sites (Clark and Gorley 2001). Samples were grouped according to the results of the cluster analysis, habitats, life habits and seasons. The Global R reported in this analysis ranged from 0 to 1 and increased with increasing dissimilarity among samples (Clark and Warwick 2001). The Mantel test was used to test the relationship between 
diatom assemblages and environmental parameters of the same dimensions by evaluating results from repeated randomization (McCune and Grace 2002).

To determine which individual species contribute most to the separation of the groups defined in cluster analysis, I used the species contribution to similarity method (SIMPER) which measures the percentage each species contributes to average dissimilarity between two groups (an average of all possible pairs of dissimilarity coefficient taking one sample from each group) (Clark 1993). Indicator species analysis (ISA) was used to identify diatom indicator taxa, based on the concentration of species abundances in a particular group and on the faithfulness of occurrence in that group (Dufrene and Legendre 1997).

The weighted averaging (WA) regression (Ter Braak and Barendregt 1986) was used to calculate optima and tolerances for indicator species for salinity, WTN, WTP, and WTOC. The main assumption of this method is that, at a site with a specific value of the environmental variable, taxa that have optima nearest to that value will be most abundant (Birks 1995). The taxon's optimum for environmental variable is the average of all values for that environmental variable present at the sampling sites in the training set in which a taxon occurred, weighted by it's relative abundance; while taxon's tolerance is a weighted standard variation of the environmental variable (Birks 1995). I used the length of the gradient, expressed in standard variation units (SD), calculated by detrended canonical correspondence analysis (DCCA), a multivariate direct gradient analysis technique that relate community composition to known variation in the environment (Ter Braak 1986), to determine the method (linear if gradient length is $\leq 2 \mathrm{SD}$ or unimodal if gradient length $>2 \mathrm{SD}$ ) that should be used for development of the diatom-based 
prediction models for salinity, WTN, WTP, and WTOC (Birks, 1998). The gradient length is the range of the sample scores divided by the average within-species standard deviation along the axis and is a measure of how unimodal the species responses are along an ordination axis (Ter Braak and Šmilauer 2002). The weighted averaging partial least squares (WA-PLS) regression procedure (Ter Braak and Juggins 1993) with leaveone-out cross validation (Dixon 1993) was used to develop statistical prediction models for use in reconstructions of past environmental conditions in Florida Bay. This method combines the features of WA and partial least squares (PLS) and uses residual correlation structure in the data to improve the fit between biological data and environmental data in the training set (Birks 1995). The randomization t-test was used to determine if the chosen model is not overfitted by discriminating "hidden" overfitting from real systematic model improvements (Juggins, pers.com.). The predictive abilities of transfer functions were assessed by examining the relationship between the observed and inferred values of the variables of interest in the training set, and evaluation of root mean square error of prediction (RMSEP) and maximum and average bias in the models that contained the smallest useful partial least square (PLS) components (Birks et al. 1990). The observed values of the variables were plotted against the residuals in order to look for unusual trends that could explain the bias of the prediction models. I also plotted the residuals between the observed and inferred salinity, WTN, WTP, and WTOC against each of the other measured environmental factors, and looked for relationships that could provide any additional information about the bias. The $\mathrm{r}^{2}$, which measures the strength of the relationship between observed and estimated values of the environmental variables, was used to compare models for different environmental variables (Birks 1998). In order 
to assess the performance of diatom-based transfer functions in an independent way, I used the intra-set cross-validation procedure. The full training set was divided into two data sets (dry and wet season). A 37-site dry season calibration set was used to develop transfer functions, and an independent 38 -site wet season test set was used to test the prediction precision of the developed transfer functions. Discriminant function (DF) analysis (Quinn and Keough 2002) was used to determine the probability of assessing a diatom community of unknown life habit or habitat to the correct life habit or habitat. This is a classification eigenanalysis technique, which generates a linear combination of variables that maximizes the probability of correctly assigning observations to their predetermined groups or classifies new observations into one of the groups (Quinn and Keough 2002). The dry season dataset was used as a calibration set and wet season dataset as a test set to test the precision of the predictions.

All of the above mentioned analyses were performed using PC-ORD Version 5.0 (McCune and Mefford 1999), Primer Version 5.2.9. (Clark and Warwick 2001), C2 Version 1.4.2. (Juggins 2005), and SPSS Version 13.0 (Levesque 2007), the location of the sites was mapped using spatial modeling and analysis in ArcView GIS 3.2a.

\subsection{Results}

\subsubsection{Diatom Species Composition}

A total of 592 diatom species were identified in both sampling seasons from 38 sites in the Everglades, coastal mangroves, and Florida Bay (Appendix 2.1). After 
removing rare taxa, only 215 species remained. These species represented more than 95\% of the assemblage. The most common genera were Amphora (70 taxa) and Mastogloia (63 taxa). There were 12 taxa that occurred in more than $50 \%$ of the samples: Cocconeis placentula var. euglypta (73.8\%), Hyalosynedra laevigata $(71.8 \%)$, Brachysira aponina (68.8\%), Mastogloia crucicula (68.3\%), Mastogloia pusilla (66.3\%), Amphora tenerrima (64.9\%), Cyclotella choctawhatcheeana (64.9\%), Mastogloia ovalis (57.9\%), Mastogloia erythraea (56.4\%), Cyclotella distinguenda (55.4\%), Seminavis robusta (52\%), and Cyclotella litoralis (50.5\%). Differences in diatom communities were captured in a 2-dimensional NMDS with low stress (stress $=$ 6.67) (Fig. 2.2). These two axes represented $74.5 \%$ and $17.5 \%$ respectively (cumulative 92.1\%) of variance in the ordination space. A Mantel test revealed that there was a statistically significant $(\mathrm{r}=0.45, \mathrm{p}=0.04)$ relationship between diatom species composition and environmental conditions. The BIO-ENV procedure revealed that the variable that best grouped the sites in a manner consistent with the diatom assemblage patterns was salinity $\left(\rho_{\mathrm{w}}=0.716\right)$ represented by the longest vector in the NMDS ordination (Fig. 2.2). Three major groups of sites were distinguished by cluster analysis based on diatom assemblage similarity (Figs 1b, 2.2). These contained diatom assemblages that were $73 \%$ dissimilar from each other: cluster 1 comprised all freshwater Everglades sites, cluster 2 all coastal mangrove sites, and cluster 3 all Florida Bay sites. The differences between these clusters were highly significant $(\mathrm{R}=0.845, \mathrm{p}=0.001)$. The freshwater Everglades contained completely different diatom assemblages from Florida Bay $(\mathrm{R}=1, \mathrm{p}=0.001)$ while mangrove sites included some taxa typical for both of the regions $(\mathrm{R}=0.953, \mathrm{p}=0.001$ and $\mathrm{R}=0.736, \mathrm{p}=0.001$ respectively $)$. 
Additionally, there were significant differences in diatom assemblages among sites located in different habitats within the clusters $(\mathrm{R}=0.665, \mathrm{p}=0.001)$, with the exception of sites located in the freshwater Everglades, which were indistinguishable from each other ( $>0.05$ ). In cluster 2, lake sites located in southwest ENP contained significantly different diatom assemblages from those in the southern part of Taylor Slough $(\mathrm{R}=$ $0.661, p=0.001)$. Significant differences were also observed between west and central and east part of Florida Bay representing cluster $3(R=0.642, p=0.001)$, but the differences were smaller between nearshore and open-bay sites in the same cluster $(\mathrm{R}=$ $0.195, \mathrm{p}=0.011)$. The average contribution of the diatom taxa to the total average dissimilarity between clusters 3 and 1 was 97.78 . Much of this difference was controlled by the presence of two species, Encyonema evergladianum and Mastogloia smithii which together contributed $12.9 \%$ of the difference, while H. laevigata, C. placentula var. euglypta, Fragilaria synegrotesca, and Brachysira aponina were also important. The average contribution of the species to the total dissimilarity between groups 3 and 2 was 72.62 , and the best discriminators between these groups, in order of decreasing importance, were: C. choctawhatcheeana, H. laevigata, C. placentula var. euglypta, B. aponina, C. litoralis, Mastogloia braunii, M. pusilla, and C. distinguenda. The contribution of taxa to the average dissimilarity between groups 1 and 2 was 93.25 , and E. evergladianum, M. smithii, and C. choctawhatcheeana contributed the most to this difference. All the best discriminators from cluster 1 were also identified by ISA as very good indicators of this cluster (Table 2.2). The same was true for coastal mangroves (cluster 2), and Florida Bay sites (cluster 3), which contained additional species with high 
indicator values (Table 2.2). Cluster 3 had the highest numbers of indicator species, followed by cluster 2 and cluster 1 .

Seasonal differences in diatom assemblages were not detected in the full dataset $(\mathrm{R}=0.05, \mathrm{p}=0.02)$, but there was a significant season-site interaction. Seasonal differences were detected in clusters 2 and $3(R=0.432, p=0.001$ and $R=0.437$, $\mathrm{p}=0.001$ respectively) but not in cluster $1(\mathrm{R}=0.04, \mathrm{p}=0.335)$. The overall differences within diatom assemblages living in the water column, and attached to the bottom or to the macrophytes were small but statistically significant (Global $\mathrm{R}=0.213, \mathrm{p}=0.001$ ) (Fig. 2.3). The differences increased when season $($ Global $\mathrm{R}=0.221, \mathrm{p}=0.001)$ and habitat (Global $\mathrm{R}=0.386, \mathrm{p}=0.001)$ factors were taken into account. Seasonal differences in species composition were significant only for plankton (Global $\mathrm{R}=0.561$, $p=0.001)$ in cluster 2 , while the same differences were significant for all life habits in cluster 3, with strongest observed for epiphyton (Global $\mathrm{R}=0.321, \mathrm{p}=0.001)$ and smaller for sediment and plankton (Global $\mathrm{R}=0.124, \mathrm{p}=0.003$ and $\mathrm{R}=0.227, \mathrm{p}=0.001$ respectively). ISA identified several species which are considered good indicators of each life habits, with planktonic communities containing the highest number of indicators (9 taxa) followed by epiphyton (4 taxa) and sediment (4 taxa; Table 2.3).

\subsubsection{Environmental Conditions}

Sites differed spatially and seasonally in salinity, WTN, WTP, and WTOC levels. ANOVA revealed that the seasonal differences were significant among clusters for all measured water parameters except for WTN, turbidity, and temperature. Among the 
environmental variables that are of greatest interest in this study, salinity showed the greatest difference among clusters and was strongly correlated with many other water chemistry variables, locations and seasons but not with life habitats (Table 2.1). Significant differences in WTP and WTOC were observed among freshwater Everglades, coastal mangroves, and Florida Bay sites (mangrove sites had, on average, higher WTP and WTOC levels compared to freshwater Everglades and open Florida Bay sites in both seasons), but no differences in WTN were observed among clusters. WTN, WTP and WTOC were strongly correlated with each other and with several other variables (Table 2.1). These variables also showed significant correlations with locations and seasons but not with habitats (Table 2.1).

\subsubsection{Environmental Preferences and Transfer Functions}

Optima and tolerances for salinity, WTN, WTP, and WTOC were determined for the 215 diatom taxa included in this study. From these, only a few had narrow tolerances around optima for salinity ( 4 species could tolerate salinity less than \pm 2 ). WA regression showed that species inhabiting all sampling locations could tolerate wide changes in salinity but only taxa occupying mangrove ecosystem could tolerate significant changes in nutrient levels (Table 2.2).

The amount of diatom compositional change (gradient length) along the salinity gradient (as assessed by DCCA Axis 1) was 2.75 SD units, reassuring us that the unimodal-based regression method would be the most appropriate in prediction model development for this variable. Additionally, even though the gradient length for WTN, 
WTP and WTOC was less than 2SD units (1.431 SD, $1.48 \mathrm{SD}$, and 1.632 SD

respectively), suggesting a linear relationship between diatoms and these variables (ter Braak et al. 1995), I used WA-PLS method instead of linear response models to develop diatom-WTN, WTP, and WTOC transfer functions. This was done because WA-PLS outperformed the PLS (Partial Least Squares) regression method that I also tested. The WA-PLS technique revealed that the most parsimonious models for reconstruction of salinity, WTN, WTP, and WTOC from sedimentary diatom records would be the 2component models. The relationship between observed and predicted values of salinity, WTN, WTP and WTOC were very strong (Fig. 2.4a-d). However, the models still seemed to slightly overestimate the values of these variables at the low gradients end and slightly underestimate the values at the high gradients end, which was exposed in residual values. Significant correlations were found between residual values for the final salinity WTN, WTP and WTOC models, and observed values for several other water parameter variables (Table 2.4).

The intra-set cross-validation transfer functions for the 37-site dry season training set and the 38 -site wet season test set were based on a similar number of diatom taxa as the combined season data set. As a result of significant seasonal differences in salinity, WTN, WTP, and WTOC, training and test sets included different ranges of these variables. Performance statistics of the 37-site dry season training set salinity, WTN, WTP, and WTOC transfer functions were slightly different than for the combined season training set transfer functions (Figs 2.4a-d and 5a-d). Overall, all the models had higher prediction errors, and most of them (except for the salinity model) displayed slightly stronger relationships between observed and predicted values than the models based on 
combined dry and wet season data (Figs 2.4a-d, 5a-d). Additionally, the intra-set crossvalidation showed that the salinity, WTN, WTP and WTOC transfer functions based on the 37-site training set provided a good estimation of measured values of these variables in the 38-site test set for the sites where the annual variability of the above mentioned water quality variables was the lowest (Fig 2.5a-d).

\subsubsection{Prediction of Community Types}

The DF analysis determined that among community types specific to each of the clusters, $31 \%$ of the cases could be correctly identified as either nearshore, freshwater, mangrove or open-bay habitats as assessed by the cross-validation (CV) method, and about $51 \%$ as assessed by intra-set cross-validation (ICV) method. The freshwater Everglades location (cluster 1) showed the highest predictability, followed by the mangroves (cluster 2), open bay (cluster 3 in part), and nearshore (cluster 3 in part) locations, as assessed by the CV and ICV methods (Fig. 2.6a,b). Moreover, according to these methods, $77 \%(\mathrm{CV})$ and $63 \%$ (ICV) of the sites that had been classified by cluster analysis as nearshore sites hosted diatom assemblages typical either of open bay, mangrove or freshwater areas. Similarly, cluster 2 (coastal mangroves) hosted about 64\% (CV) and 44\% (ICV) of assemblages typical of either nearshore, freshwater or open bay sites. Finally, $77 \%(\mathrm{CV})$ and $46 \%$ (ICV) of total errors in prediction in the open bay group were due to the presence of either cluster 1,2, or nearshore diatom assemblages. The total error of prediction of zero (CV) and 30\% (ICV) occurred only in cluster 2. Regarding life habit, 81.3\% (CV) and 70\% (ICV) could be correctly identified as either 
sediment or epiphyton (Fig. 2.6c,d) within the freshwater Everglades group. Within the coastal mangrove group $42.6 \%(\mathrm{CV})$ and $47.2 \%$ (ICV) could be correctly identified as either sediment, epiphyton or plankton (Fig. 2.6e,f). The diatoms with different life mode within the nearshore areas could be identified correctly in $27.8 \%(\mathrm{CV})$ and $58.3 \%$ (ICV) of cases (Fig. 2.6g,h). In open bay areas that was possible in $41 \%$ (CV) and $46.2 \%$ (ICV) (Fig. 2.6i,j).

\subsection{Discussion}

The diatom communities in Florida Bay, the coastal mangroves, and the freshwater Everglades recorded during this investigation were generally similar to assemblages described by others in the region (Montgomery 1978; DeFelice and Lynts 1978; Gaiser et al. 2005; Frankovich et al. 2006; Tobias and Gaiser 2006; Wachnicka and Gaiser 2007; Slate and Stevenson 2007) from similar locations. In general, Florida Bay diatom assemblages were dominated by Amphora and Mastogloia species, which have been commonly reported in earlier studies in this area (DeFelice and Lynts 1978; Montgomery 1978; Frankovich et al. 2006). Sites in eastern and central Florida Bay were dominated by Amphicocconeis disculoides, B. aponina, H. laevigata, and Nitzschia liebetruthii, previously described in this region as species able to flourish under P-limited conditions and often associated with seagrass-dominated sites (Frankovich et al. 2006). Diatom assemblages of coastal mangroves contained species often found at marine (e.g., C. distinguenda, M. pusilla, C. choctawhatcheana, C. litoralis) and brackish water (e.g., T. granulata, M. braunii, N. pseudocrassirostris) sites (Huvane 2002; Gaiser et al. 2005; 
Frankovich et al. 2006), which reflects the transitional character of this area between these two ecosystems. Additionally, a high abundance of small Cyclotella species (e.g., C. choctawhatcheana, C. meneghiniana, C. atomus) at nutrient-rich, turbid sites in the mangrove lakes and nearshore Florida Bay sites agrees with earlier findings of Cooper (1995b), Andrén et al. (2000), and Weckstrőm and Juggins (2005) who reported them from highly disturbed, nutrient-rich waters of Chesapeake Bay and the Baltic Sea. Some of the coastal mangrove lakes contained taxa which were seldom or never found at any other sampling locations (e.g., Gyrosigma sp. LK4, Navicula sp. 01LK2, Pravifusus hyalinus). This may be a consequence of the relative geographic isolation of this region from other similar environments, which was also suggested by Davis and Williams (1950), who studied the plankton distribution in the mangrove areas of southwestern Florida. I found freshwater sites to be dominated by E. evergladianum and M. smithii species which are common in short-hydroperiod marshes in unenriched periphyton mats throughout the freshwater Everglades (Gaiser et al. 2006; Gottlieb et al. 2006). The diatom flora at my study sites was to some extent also similar to the flora described from other subtropical and Caribbean carbonate coasts (e.g., Foged 1984; Hein et al. 2008). A remarkable number of taxa (96 out of 433) were not found after an exhaustive search of literature and reference collections, implying that they might be new to science and that further taxonomic explorations in this region are warranted.

A high degree of spatial variability in the water chemistry controlled, to a large extent, the distribution of diatom species in the sampled region. The most influential variable was salinity, commonly recognized by many as an important factor controlling the distribution of organisms in estuarine environments (Snoeijs 1994; Underwood 1998; 
Frankovich et al. 2006; Tibby et al. 2007). Additionally, nutrient availability, which has been found to structure algal communities in this region (Armitage et al. 2006), influenced species composition, especially in the coastal mangrove zone. A spatial difference in salinity was responsible for completely different diatom assemblages at freshwater Everglades and Florida Bay sites ( 0 at the northern Taylor Slough sites in both seasons and between 16 and 47 at the Florida Bay sites). Moreover, the distance between these two regions prevents mixing of their diatom communities. The mangrove ecotone, which separates the freshwater Everglades from Florida Bay, acts as a buffer zone to intercept freshwater and marine taxa during constant movement of water through this zone from both directions. This causes some overlap in species within these two regions, but different water quality and physical settings at these sites are responsible for the difference. The significant differences in diatom communities among sites located in different areas within the freshwater, mangrove, nearshore and open-bay habitats are caused by the same factors. In the coastal mangrove zone (cluster 2), the lakes located in southwest ENP had, on average, higher nutrients, WTOC, $\mathrm{pH}$, and salinity levels than the sites in the southern part of Taylor Slough. The nearshore sites (part of cluster 3) are significantly influenced by waters coming from the mainland, and thus experience significant inter- and intra-annual fluctuations in salinity and nutrients. In contrast, the open bay sites are influenced mostly by precipitation and water coming from the Gulf of Mexico and Atlantic Ocean, which stabilizes water quality variability in this region (Swart and Price 2002). The differences between diatom assemblages in west and central and east parts of Florida Bay are most likely due to the higher, on average, water salinity and phosphorus levels in western part of the bay, which was also observed by Frankovich 
et al. (2006). The differences in phosphorus levels were even more pronounced in sediment samples.

The relatively small number of indicator taxa identified by ISA for different habitats is most likely due to the dynamic hydrology of South Florida. Assemblages are easily transported by flow from the freshwater region of the Everglades towards the mangroves, and are easily redeposited in the nearshore areas of northern Florida Bay by tides and storms. Sherrod (1999) reported that offshore taxa are redeposited in the marshes during high tides, and De Jonge (1985) found that loosely attached diatoms living on mudflats and in channels may be scoured off the substratum by tidal currents and transported into adjacent environments. Additionally, the vertical mixing of sediments, especially in the shallow-water central and northern parts of Florida Bay (Prager and Halley, 1999), also contributes to the small number of indicator species identified for sediment, epiphyton, and plankton, but mostly for the first two habits. Many taxa that were found in the water column and were identified by ISA as good indicators of planktonic communities (e.g., Amphora cf. leavis, Navicula sp. 05BB, Climaconeis colemaniae, Hyalosynedra laevigata), are rather tychoplanktonic in nature (represent pseudo-plankton). This hypothesis is based on the original description of the habitats from which they were described, which was usually sediment or epiphyton (Prasad et al. 2000; Reid and Williams 2002).

The enormity of the spatial gradient in water chemistry covered by this study probably damped any strong seasonal effects that might have been present in the overall dataset. However, within habitats exhibiting a great degree of intra-annual variability (as in mangrove and nearshore Florida Bay sites), I did find diatom assemblages responding 
in concert to these changes. For example, in coastal mangroves, C. litoralis,

Thalassiosira sp. 01 and M. pusilla were the most abundant species in the dry season, while in the wet season they were replaced by C. choctawhatcheana, Navicula pseudocrassirostris and Cyclotella atomus. In Florida Bay, C. placentula var. euglypta, H. laevigata and B. aponina were the most abundant species in the dry season, but in the wet season C. placentula var. euglypta and B. aponina were more abundant and were joined by abundant $C$. choctawhatcheana and $C$. distinguenda in the coastal mangroves. However, in some highly variable sites (e.g., southern Taylor Slough sites), diatom assemblages did not differ significantly among seasons, indicating some degree of adaptation to the highly variable environment.

The salinity optima and tolerances of diatoms living in different locations along this gradient differ slightly from the values reported earlier by Frankovich et al. (2006) and Huvane (2002) from a more limited number of sites in Florida Bay (optima were higher in former and lower in the latter than ours). Gaiser et al. (2005) report lower optima for taxa living at the high-salinity end and higher optima for taxa at intermediate to low salinity for the neighboring mangrove zone along Biscayne Bay. The optima and tolerances for indicator taxa of northern Taylor Slough are very similar or higher than those reported by Gaiser et al. (2005) for the same taxa in mangroves adjacent to Biscayne Bay. The WTP optima and tolerances for species indicative of Florida Bay are close to those reported by Frankovich et al. (2006). The differences in optima and tolerance values are most likely due to the fact that I investigated a greater number of sites along broader salinity and nutrient gradients during the two sampling events, and therefore I provided a more comprehensive interpretation of taxon preferences. My 
discovery of wide tolerances for salinity and nutrients for taxa living in northern Taylor Slough, mangrove and nearshore sites are similar to those reported by Admiral (1984) for most of the epipelic diatoms in Ems-Dollard Estuary and Tibby et al. (2007) for diatoms in coastal wetlands in southeast Australia. Both authors reported that the extreme variability experienced by these estuaries and wetlands selects for taxa with broad tolerances. The presence of well documented freshwater diatoms (e.g., $E$. evergladianum, M. smithii) in regions of higher salinity (coastal mangroves and nearshore Florida Bay) does not necessarily mean the in situ growth of these taxa at the time of collection. The situation can often indicate transport and redeposition of valves from the adjacent areas, or presence of dead cells of taxa that flourished in highly fluctuating salinity regions when the conditions were favorable (e.g., during the wet season salinity can drop to 0 in the southern part of Taylor Slough).

The prediction models obtained from the WA-PLS regression are strong, but some of them (e.g., WTN model) slightly overestimate values at the low end and underestimate values at the high end of the represented gradients. This condition is most likely due to the "edge effect" (truncation at the gradient edges) and inverse deshrinking (inverse linear regression), that are known to introduce such a bias between measured and inferred values (Birks 1998). The inference models for salinity allow this variable to be predicted from diatom assemblages with very small prediction error (smaller than $12 \%$ of the average salinity recorded at the sampling sites in both seasons). The prediction error was almost twice that large for WTN and WTOC and four times larger for WTP. The predictive power of my salinity model is a bit stronger than those reported in earlier investigations in this and other regions of the world $\left(r^{2}=0.97\right.$ vs. $r^{2}=0.91$ in Fritz et al. 
1991; $\mathrm{r}^{2}=0.91$ in Gaiser et al. 2005) and similar for WTN, WTP and WTOC (for WTN, $r^{2}=0.75$ vs. $r^{2}=0.84$ in Clark et al. 2003 and $r^{2}=0.73$ in Weckstrőm et al. 2004; for WTP $\mathrm{r}^{2}=0.75$ vs. $\mathrm{r}^{2}=0.68$ in Ramstack et al. 2003 and $\mathrm{r}^{2}=0.57$ in Weckstrőm et al. 2004; for WTOC $\mathrm{r}^{2}=0.79$ vs. $\mathrm{r}^{2}=0.94$ in Rosen et al. 2000). The differences in model strengths may be due to the gradient length studied, the number of samples collected to develop the transfer function, the methods used to analyze the data, and how diatoms perceive and react to changing environments. The errors in estimations in my prediction models are most likely due to species responses to gradients in other measured water quality variables. For example, errors in estimating salinity may be in part caused by variation in nutrient levels (WTN, WTP) and degree of light limitation (correlation with WTOC and turbidity) across the salinity gradient, causing different responses of diatoms to this driving variable. WTN estimation error may result from variation in turbidity, WTP estimation error from variation in WTN and WTOC, and WTOC error from changes of depth and STC. These results agree with earlier findings that highlighted the influences of salinity, nutrient and light limitation on diatoms (Frankovich et al. 2006; Jurado 2007).

The question of whether diatom-based transfer functions for salinity, WTN, WTP, and WTOC can be used as a reliable tool in reconstructions of past values of these variables, and whether only one season of measured water quality and diatom data can be used in development of such transfer functions, was addressed by the intra-set crossvalidation procedure. This procedure showed that the salinity, WTN, WTP, and WTOC transfer functions based on the 37-site dry season training set estimated (with some discrepancies) the measured values of these variables obtained during my sampling event 
in an independent 38-site wet season test set. Due to the high intra-annual variability of these variables in the nearshore and mangrove areas, the perfect relationship between diatoms and salinity and nutrient levels can most likely never be obtained if only one season of measured data is included in predictions (and the predictive powers for sites with highly variable hydrology will be low). However, if more frequent sampling can not be done, the diatom models should be used with prior knowledge of the natural conditions present at the study sites during the year. The DF analysis proved that the diatom records can also be successfully used in tracking shifts in community types and different types of habitats.

In general, my diatom-based models provide a very powerful and reliable tool for quantitative salinity reconstruction from fossil assemblages and good inferences about past WTN, WTP and WTOC. As in the above-mentioned cases, the diatom-based predictions were not perfect but they will undeniably provide a unique method to studying past vegetation and ecosystem changes in Florida Bay caused by anthropogenic activities and climatic change experienced in this region.

\subsection{Conclusions}

My study shows that not only can I quantify change in single environmental variables from diatom communities in Florida Bay, but I can also quantify the impact of multiple environmental factors on the inferences. I showed that one season of sampling is insufficient to develop reliable salinity, WTN, WTP, and WTOC transfer functions. 
Diatoms provide a functional estimate of past environmental conditions in Florida Bay at sufficient resolution to detect the onset and magnitude of change.

Future research can apply the transfer functions developed in this study to fossil records for reconstruction of past salinity, WTN, WTP and WTOC conditions in Florida Bay in order to determine the magnitude of human- and climate-induced changes on natural conditions in the bay. The following changes in sediment cores should be detectable by this approach: (1) The type of ecosystems (freshwater marshes, coastal mangroves, estuary) present in the past can be determined by using DF analysis; (2) The same method can also determine the type of life habit (planktonic, epiphytic or epipelic) dominant to help assess vegetation cover; and (3) WA-PLS prediction models can be used for quantitative reconstructions of past salinity, WTN, WTP, and WTOC conditions. Although my study shows that diatom assemblages provide a reliable tool to quantify past salinity, WTN, WTP, and WTOC changes, they should be used together with other paleoenvironmental proxies.

\section{Acknowledgments}

Financial support was provided through the Faculty Research Seed Funds program of the Southeast Environmental Research Center's Endowment, National Science Foundation (EAR-071298814), and National Science Foundation through the Florida Coastal Everglades Long Term Ecological Research Program (DEB-9910514). Many thanks are due to Greg Losada, Damon Rondeau, Carlos Tudela, Christine Taylor, Dariusz Kosiorek, Olga Saoulova and Jay Munyon for their valuable field assistance. 
Table 2.1 Spearman rank correlation coefficients (quantitative variables) matrix and Kruskall-Wallis values (categorical variables) of the mean values of water total nitrogen (WTN), water total phosphorus (WTP), water total organic carbon (WTOC), depth (D), oxygen (O2), turbidity (TURB.), salinity (SAL.), temperature (TEMP.), pH, sediment total nitrogen (STN), sediment total phosphorus (STP), and sediment total carbon (STC) among seasons. Values with asterisk indicate significant correlation at $\alpha<0.05$.

\begin{tabular}{|c|c|c|c|c|c|c|c|c|c|c|c|c|}
\hline $\begin{array}{l}\text { Environmental } \\
\text { Variable }\end{array}$ & $\begin{array}{l}\text { WTN } \\
(\mathrm{ppm})\end{array}$ & $\begin{array}{l}\text { WTP } \\
(\mathrm{ppm})\end{array}$ & $\begin{array}{l}\text { WTOC } \\
(\mathrm{ppm})\end{array}$ & $\mathrm{D}(\mathrm{m})$ & $\begin{array}{c}\mathrm{O} 2 \\
\left(\mathrm{mg} \mathrm{l}^{-1}\right)\end{array}$ & $\begin{array}{l}\text { TURB. } \\
\text { (NTU) }\end{array}$ & SAL. & TEMP. $\left({ }^{\circ} \mathrm{C}\right)$ & $\mathrm{pH}$ & STN (ppm) & $\begin{array}{c}\text { STP } \\
(\mathrm{ppm})\end{array}$ & STC (ppm) \\
\hline WTN (ppm) & 1 & $0.789^{*}$ & $0.542 *$ & $0.461 *$ & -0.045 & $0.513^{*}$ & 0.303 & -0.264 & 0.234 & -0.195 & 0.028 & $-0.400 *$ \\
\hline WTP(ppm) & $0.789 *$ & 1 & $0.351 *$ & 0.267 & 0.087 & $0.478 *$ & 0.262 & 0.055 & $0.324 *$ & -0.218 & 0.229 & -0.387 \\
\hline WTOC (ppm) & $0.542 *$ & $0.351 *$ & 1 & 0.15 & 0.158 & 0.12 & -0.212 & 0.134 & -0.083 & 0.153 & -0.12 & 0.17 \\
\hline SAL. & 0.303 & 0.262 & -0.212 & $0.456^{*}$ & 0.175 & $0.375^{*}$ & 1 & -0.154 & $0.675^{*}$ & $-0.610^{*}$ & 0.123 & $-0.775^{*}$ \\
\hline Clusters & 5.129 & 8.882 & 6.406 & 18.045 & 5.729 & 17.154 & 46.731 & 0.971 & 25.764 & 29.289 & 22.448 & 40.322 \\
\hline & 0.1630 & $0.031 *$ & 0.093 & $0.000 *$ & 0.126 & $0.001 *$ & $0.000 *$ & 0.808 & $0.000 *$ & $0.000 *$ & $0.000 *$ & $0.000 *$ \\
\hline Seasons & 0.248 & 27.966 & 3.132 & 1.973 & 2.595 & 1.068 & 13.367 & 52.084 & 18.111 & 8.219 & 2.733 & 3.700 \\
\hline Habitats & 2.421 & 1.203 & 0.364 & 5.067 & 1.345 & 2.118 & 4.706 & 0.107 & 5.303 & 4.162 & 0.001 & 5.704 \\
\hline & 0.298 & 0.548 & 0.834 & 0.079 & 0.510 & 0.347 & 0.095 & 0.948 & 0.071 & 0.125 & 1.000 & 0.058 \\
\hline
\end{tabular}


Table 2.2 Diatom species identified by indicator species analysis as significantly associated with different clusters distinguished by cluster analysis based on their relative abundance and frequency of occurrence in these clusters. Taxa optima (Opt.) and tolerances (Tol.) for salinity (Sal.), water total nitrogen (WTN), water total phosphorus (WTP) and water total organic carbon (WTOC) calculated by weighted averaging regression are also provided.

\begin{tabular}{|c|c|c|c|c|c|c|c|c|c|}
\hline Taxon name & $\begin{array}{l}\text { Obs. } \\
\text { Ind. } \\
\text { Value }\end{array}$ & $\begin{array}{l}\text { Sal. } \\
\text { (ppt) } \\
\text { Opt. }\end{array}$ & $\begin{array}{c}\text { Sal. } \\
\text { (ppt) } \\
\text { Tol. }\end{array}$ & $\begin{array}{l}\text { WTN } \\
\text { (ppm) } \\
\text { Opt. }\end{array}$ & $\begin{array}{c}\text { WTN } \\
\text { (ppm) } \\
\text { Tol }\end{array}$ & $\begin{array}{l}\text { WTP } \\
\text { (ppm) } \\
\text { Opt. }\end{array}$ & $\begin{array}{l}\text { WTP } \\
\text { (ppm) } \\
\text { Tol. }\end{array}$ & $\begin{array}{l}\text { WTOC } \\
\text { (ppm) } \\
\text { Opt. }\end{array}$ & $\begin{array}{l}\text { WTOC } \\
\text { (ppm) } \\
\text { Tol. }\end{array}$ \\
\hline \multicolumn{10}{|l|}{$\begin{array}{c}\text { Cluster 1 } \\
\text { (Freshwater Everglades) }\end{array}$} \\
\hline $\begin{array}{l}\text { Encyonema } \\
\text { evergladianum }\end{array}$ & 97.2 & 2.59 & 8.27 & 0.46 & 0.25 & 0.01 & 0.01 & 12.24 & 4.66 \\
\hline Mastogloia smithii & 97.0 & 2.83 & 7.55 & 0.48 & 0.26 & 0.01 & 0.02 & 11.84 & 4.97 \\
\hline Brachysira neoexilis & 82.6 & 3.19 & 6.69 & 0.45 & 0.23 & 0.01 & 0.01 & 13.00 & 4.94 \\
\hline Nitzschia palea var. & 82.0 & 3.16 & 5.62 & 0.45 & 0.19 & 0.01 & 0.00 & 10.58 & 2.68 \\
\hline Fragilaria synegrotesca & 77.2 & 5.01 & 7.28 & 0.46 & 0.25 & 0.01 & 0.01 & 11.74 & 4.14 \\
\hline Nitzschia serpentiraphe & 75.0 & 1.62 & 7.74 & 0.45 & 0.26 & 0.01 & 0.00 & 12.32 & 3.86 \\
\hline \multicolumn{10}{|l|}{$\begin{array}{c}\text { Cluster } 2 \\
\text { (Coastal Mangroves) }\end{array}$} \\
\hline $\begin{array}{l}\text { Navicula } \\
\text { pseudocrassirostis }\end{array}$ & 62.9 & 19.30 & 7.03 & 0.94 & 0.47 & 0.05 & 0.05 & 18.49 & 10.29 \\
\hline Mastogloia braunii & 46.8 & 18.42 & 6.95 & 0.98 & 0.41 & 0.05 & 0.05 & 19.51 & 10.47 \\
\hline Achnanthes submarina & 44.9 & 16.73 & 6.09 & 0.80 & 0.44 & 0.04 & 0.05 & 16.30 & 10.08 \\
\hline \multicolumn{10}{|l|}{ Cluster 3} \\
\hline \multicolumn{10}{|l|}{ (Open Florida Bay) } \\
\hline Hyalosynedra laevigata & 61.3 & 31.70 & 7.63 & 0.73 & 0.25 & 0.02 & 0.02 & 11.00 & 4.61 \\
\hline Rhopalodia pacifica & 57.2 & 32.76 & 7.12 & 0.70 & 0.27 & 0.02 & 0.02 & 10.54 & 4.99 \\
\hline $\begin{array}{l}\text { Grammatophora } \\
\text { oceanica }\end{array}$ & 47.3 & 33.38 & 6.00 & 0.68 & 0.29 & 0.02 & 0.02 & 10.48 & 5.70 \\
\hline Mastogloia crucicula & 45.3 & 30.38 & 7.22 & 0.73 & 0.26 & 0.02 & 0.02 & 11.01 & 5.15 \\
\hline Synedra sp. 01FB & 45.2 & 31.68 & 6.97 & 0.76 & 0.16 & 0.02 & 0.01 & 11.77 & 2.41 \\
\hline $\begin{array}{l}\text { Mastogloia lacrimata } \\
\text { (Nearshore Florida Bay) }\end{array}$ & 45.1 & 34.87 & 3.26 & 0.71 & 0.21 & 0.02 & 0.01 & 10.27 & 3.24 \\
\hline Mastogloia halophila & 52.2 & 27.36 & 7.58 & 0.79 & 0.30 & 0.03 & 0.03 & 12.41 & 6.87 \\
\hline Mastogloia cyclops & 49.2 & 30.07 & 6.48 & 0.70 & 0.22 & 0.02 & 0.01 & 10.34 & 3.78 \\
\hline Cyclotella distinguenda & 46.9 & 27.48 & 7.27 & 0.75 & 0.24 & 0.02 & 0.02 & 11.73 & 5.23 \\
\hline Climaconeis colemaniae & 46.3 & 28.49 & 6.00 & 0.74 & 0.19 & 0.02 & 0.01 & 10.83 & 3.62 \\
\hline Brachysira aponina & 45.1 & 25.90 & 9.65 & 0.73 & 0.25 & 0.02 & 0.02 & 11.66 & 5.02 \\
\hline Mastogloia gibbosa & 40.2 & 27.32 & 7.90 & 0.69 & 0.20 & 0.02 & 0.01 & 9.97 & 2.54 \\
\hline
\end{tabular}


Table 2.3 Diatom taxa identified by indicator species analysis as significantly associated with planktonic, epiphytic and epipelic habitats based on their relative abundance and frequency of occurrence in these groups.

\begin{tabular}{|c|c|c|c|c|}
\hline \multirow[b]{2}{*}{ Taxon Name } & \multicolumn{3}{|c|}{$\begin{array}{c}\% \text { of samples in given group where taxon } \\
\text { is present }\end{array}$} & \multirow{2}{*}{$\begin{array}{c}\text { Observed } \\
\text { Indicator } \\
\text { Value }\end{array}$} \\
\hline & Sediment & Epiphyton & Plankton & \\
\hline \multicolumn{5}{|l|}{ Plankton } \\
\hline \multicolumn{5}{|l|}{ Dry season } \\
\hline Entomoneis cf. gigantea & 3 & 6 & 61 & 57.5 \\
\hline Cyclotella choctawhatcheeana & 72 & 61 & 86 & 52.1 \\
\hline Amphora cf. leavis & 14 & 0 & 57 & 50.8 \\
\hline Cyclotella litoralis & 64 & 31 & 75 & 49.4 \\
\hline Navicula sp. 05BB & 8 & 0 & 54 & 47.2 \\
\hline Climaconeis colemaniae & 36 & 42 & 79 & 46.7 \\
\hline Pleurosigma cf. salinarum & 17 & 11 & 57 & 43.5 \\
\hline Thalassiophysa hyalina var. insecta & 3 & 8 & 46 & 41.5 \\
\hline Hyalosynedra laevigata var. angustata & 11 & 17 & 57 & 41.4 \\
\hline \multicolumn{5}{|l|}{ Wet season } \\
\hline Cyclotella choctawhatcheeana & 53 & 39 & 89 & 65.6 \\
\hline Thalassiophysa hyalina var. insecta & 0 & 17 & 61 & 54.6 \\
\hline \multicolumn{5}{|l|}{ Epiphytes } \\
\hline \multicolumn{5}{|l|}{ Dry season } \\
\hline Cocconeis placentula & 75 & 89 & 71 & 56.8 \\
\hline Brachysira aponina & 44 & 83 & 71 & 53.2 \\
\hline Navicula durrenbergiana & 11 & 81 & 71 & 51.1 \\
\hline Amphora sp. 05FB & 14 & 67 & 29 & 49.3 \\
\hline \multicolumn{5}{|l|}{ Wet season } \\
\hline Cocconeis placentula & 68 & 83 & 50 & 54.5 \\
\hline Mastogloia pusilla & 55 & 78 & 54 & 45.1 \\
\hline Brachysira aponina & 58 & 89 & 68 & 44.8 \\
\hline \multicolumn{5}{|l|}{ Sediment } \\
\hline \multicolumn{5}{|l|}{ Wet season } \\
\hline Diploneis suborbicularis & 58 & 3 & 4 & 53.8 \\
\hline Amphora cymbifera var. heritierarum & 53 & 11 & 7 & 44.1 \\
\hline Rhopalodia acuminata & 58 & 14 & 14 & 42.4 \\
\hline Cyclotella distinguenda & 76 & 31 & 43 & 40.4 \\
\hline
\end{tabular}


Table 2.4 Pearson correlation coefficients for correlations between residual values of salinity (Sal.), water total nitrogen (WTN), water total phosphorus (WTP) and water total organic carbon (WTOC) derived for the final transfer function models and mean annual values of other measured chemical and physical water variables. Values with asterisk indicate significant correlation at $\alpha<0.05$.

\begin{tabular}{|l|c|c|c|c|c|c|c|c|c|c|c|c|}
\hline Residuals & $\begin{array}{c}\text { WTN } \\
(\mathrm{ppm})\end{array}$ & $\begin{array}{c}\text { WTP } \\
(\mathrm{ppm})\end{array}$ & $\begin{array}{c}\text { WTOC } \\
(\mathrm{ppm})\end{array}$ & $\mathrm{D}(\mathrm{m})$ & $\begin{array}{c}\mathrm{O} 2 \\
\left(\mathrm{mg} \mathrm{l}^{-1}\right)\end{array}$ & $\begin{array}{c}\text { TURB. } \\
(\mathrm{NTU})\end{array}$ & Sal. & $\begin{array}{c}\text { TEMP. } \\
\left({ }^{\circ} \mathrm{C}\right)\end{array}$ & $\begin{array}{c}\mathrm{pH} \\
\begin{array}{c}\text { STN } \\
(\mathrm{ppm})\end{array}\end{array}$ & $\begin{array}{c}\text { STP } \\
(\mathrm{ppm})\end{array}$ & $\begin{array}{c}\text { STC } \\
(\mathrm{ppm})\end{array}$ \\
\hline Sal. & $-0.374^{*}$ & $-0.339^{*}$ & $-0.387^{*}$ & 0.099 & 0.141 & $-0.378^{*}$ & -0.199 & 0.116 & 0.103 & -0.138 & -0.102 & 0.013 \\
\hline WTN (ppm) & $-0.486^{*}$ & -0.265 & -0.168 & 0.127 & 0.208 & $-0.327 *$ & -0.187 & 0.226 & 0.050 & -0.057 & 0.075 & 0.107 \\
\hline WTP (ppm) & $-0.577^{*}$ & $-0.578^{*}$ & $-0.407^{*}$ & 0.102 & 0.059 & -0.309 & -0.224 & 0.090 & -0.052 & 0.118 & 0.002 & 0.170 \\
\hline WTOC (ppm) & -0.080 & -0.134 & $-0.399^{*}$ & $0.321^{*}$ & -0.090 & 0.022 & 0.228 & -0.218 & 0.197 & -0.087 & 0.218 & $-0.341^{*}$ \\
\hline
\end{tabular}


Fig. 2.1 Map showing location of the sampling sites in Florida Bay and adjacent coastal wetlands (a) grouped together by the cluster analysis (b) based on diatom compositional similarity. Symbols indicate: Long Term Ecological Research sites in Taylor Slough (TS), Southeast Environmental Research Center water quality monitoring sites in Florida Bay (WQ), and additional sites chosen in Florida Bay (FB) and coastal lakes in southwestern Florida (LK).

a)

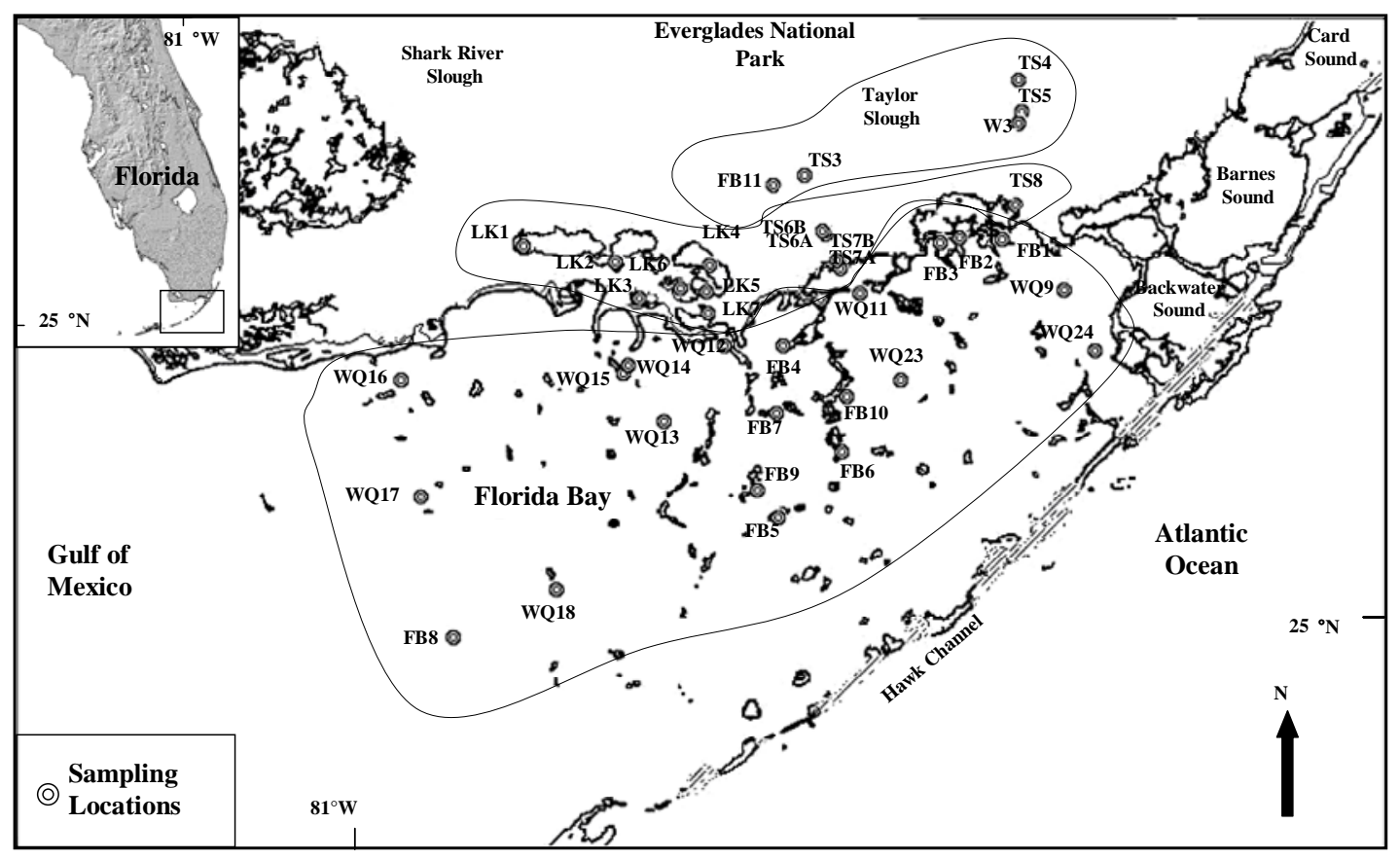




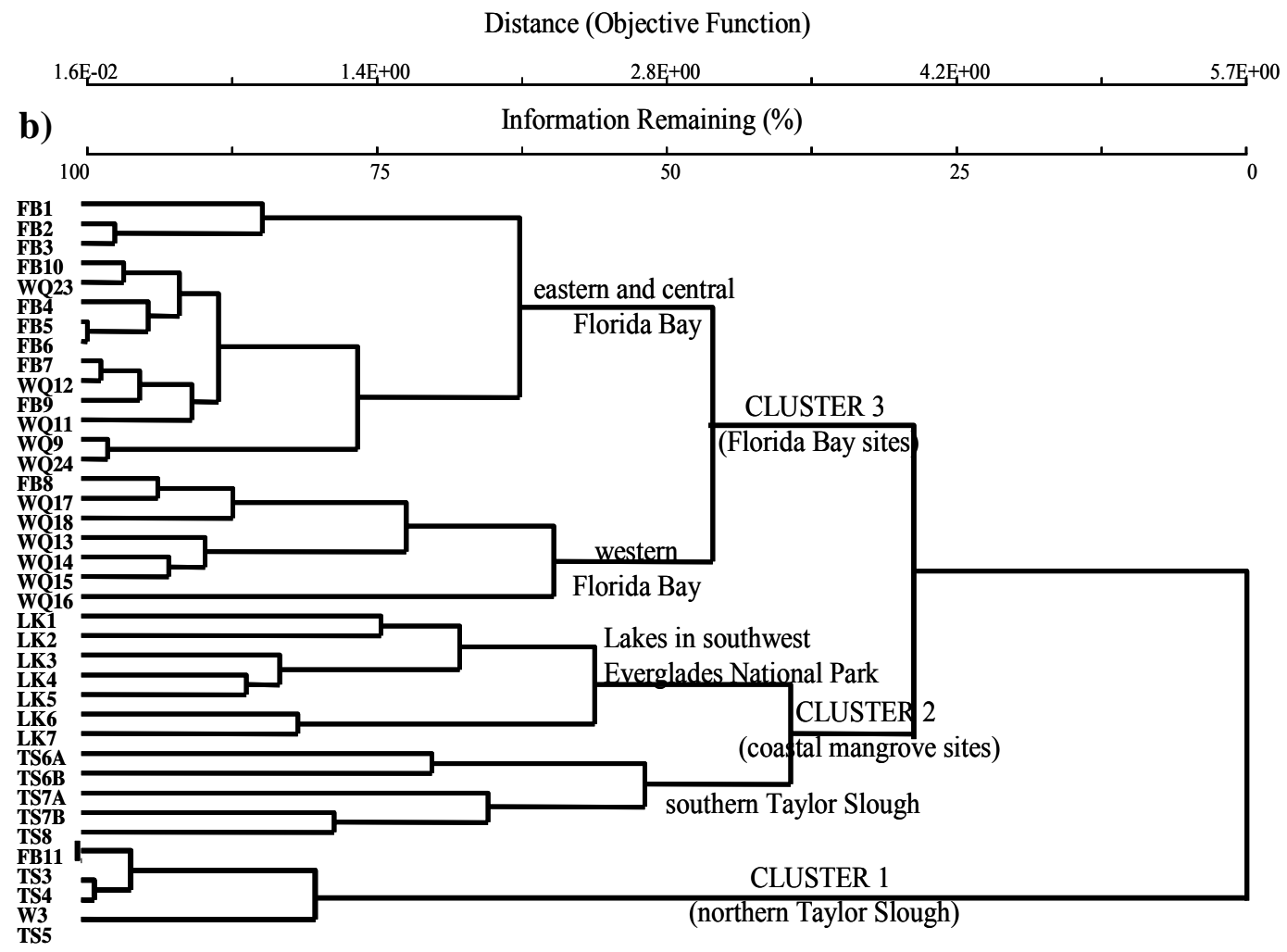


Fig. 2.2 NMDS ordination of sites based on Bray-Curtis similarity in diatom composition. Sites are coded by location and circles represent clusters. Arrows show the direction and magnitude of correlation of environmental variables with species compositional differences. Cluster 1 represents freshwater Everglades sites, cluster 2 coastal mangrove sites, and cluster 3 Florida Bay sites.

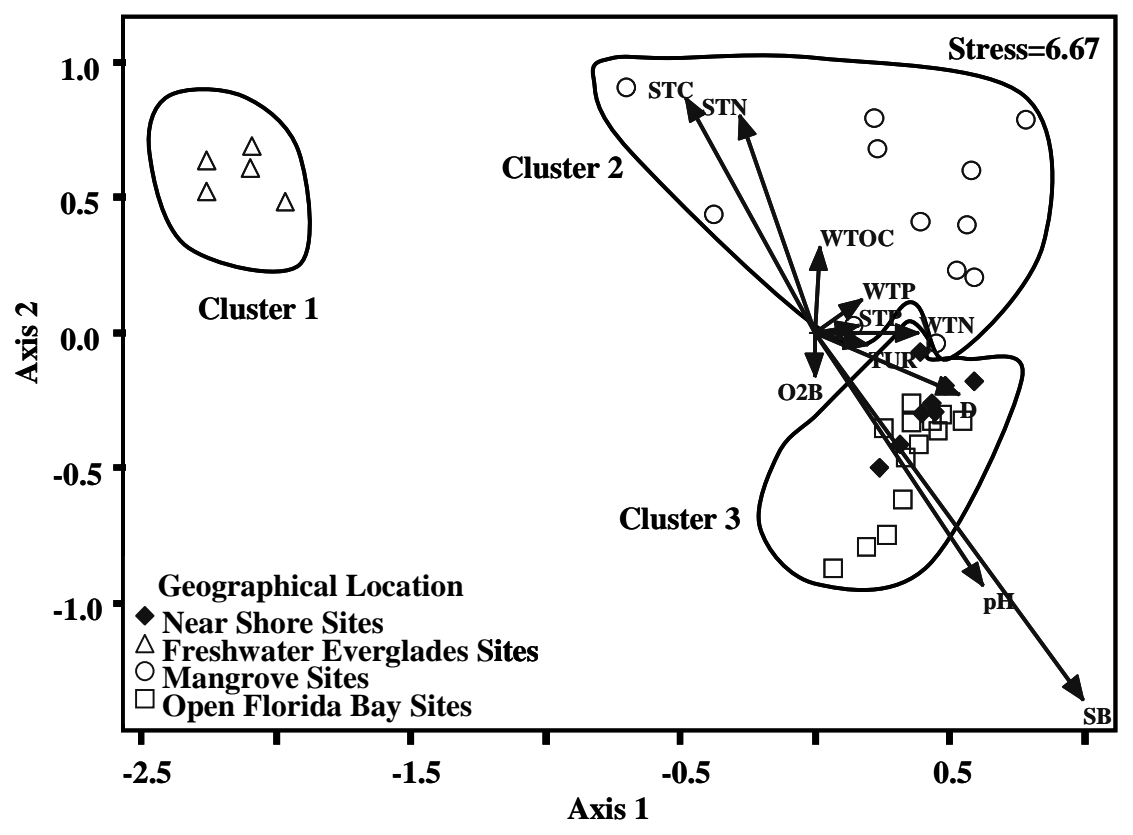


Fig. 2.3 Non-metric multidimentional scaling ordination of sites based on BrayCurtis similarity in diatom composition. Sites are coded by life habitat type.

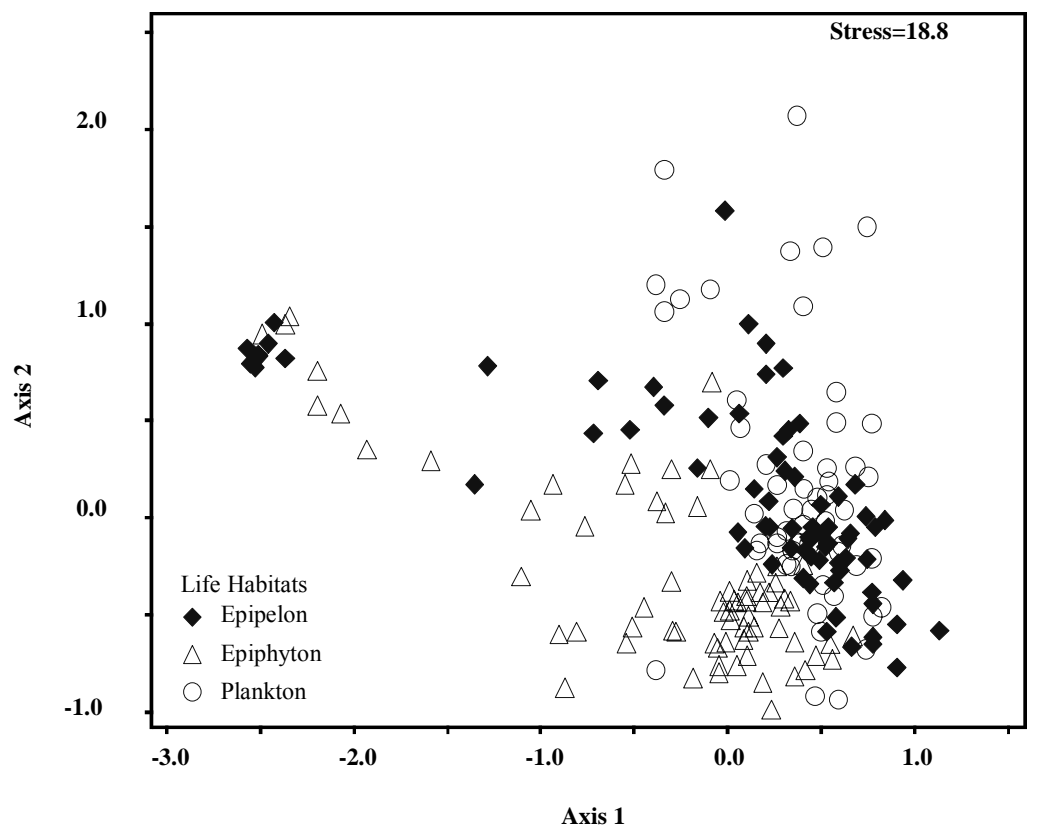


Fig. 2.4 Plots of observed vs. predicted salinity (a), WTN (ppm) (b), WTP (ppm) (c), and WTOC (ppm) using WA-PLS regression with jack-knife cross validation on the combined wet and dry season dataset.
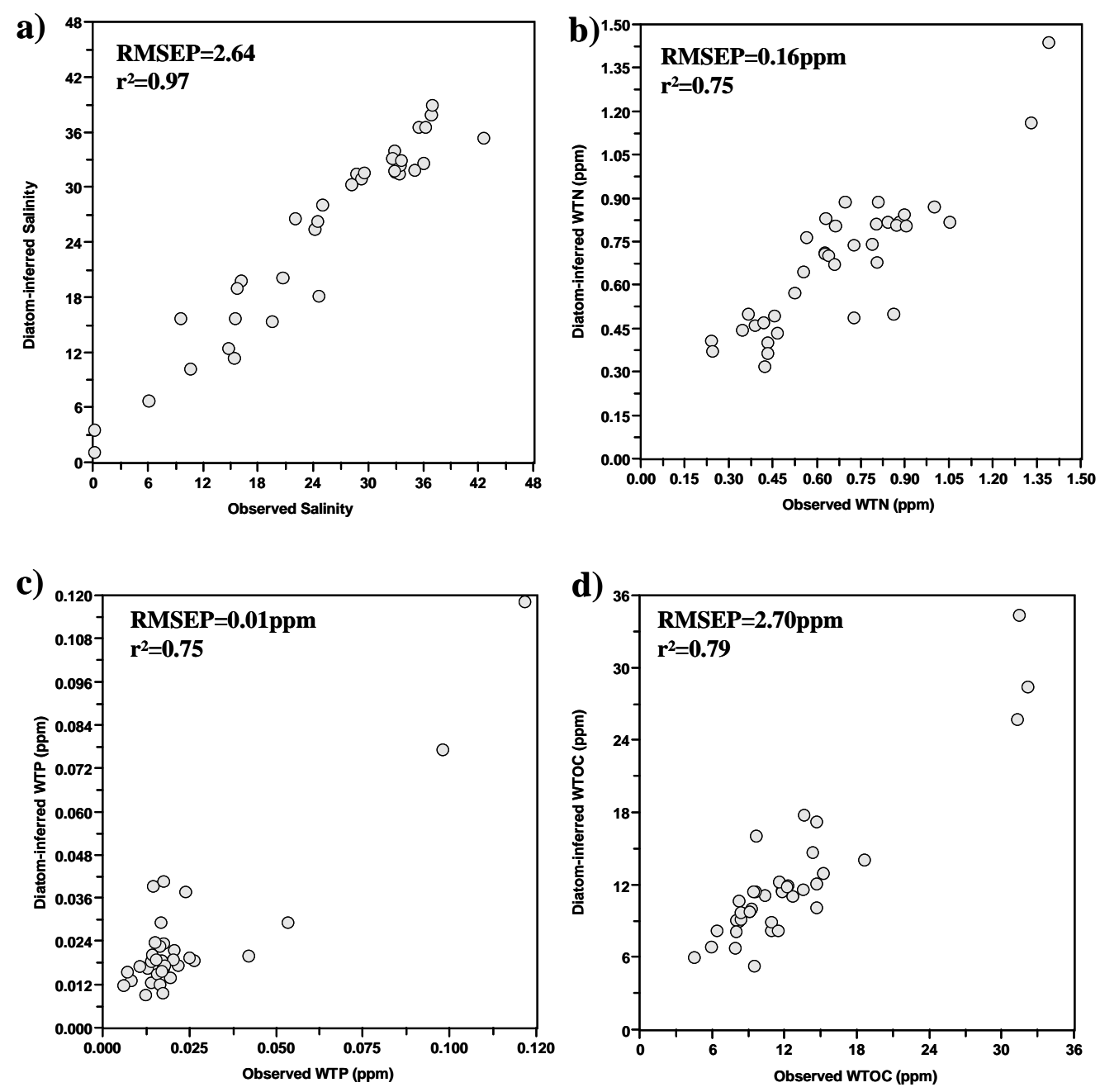
Fig. 2.5 Diatom-based WA-PLS predictions of salinity (a), WTN (b), WTP (c), and WTOC (d) based on the 37-site dry season training set for 38-site wet season test set compared to the measured values of these variables.
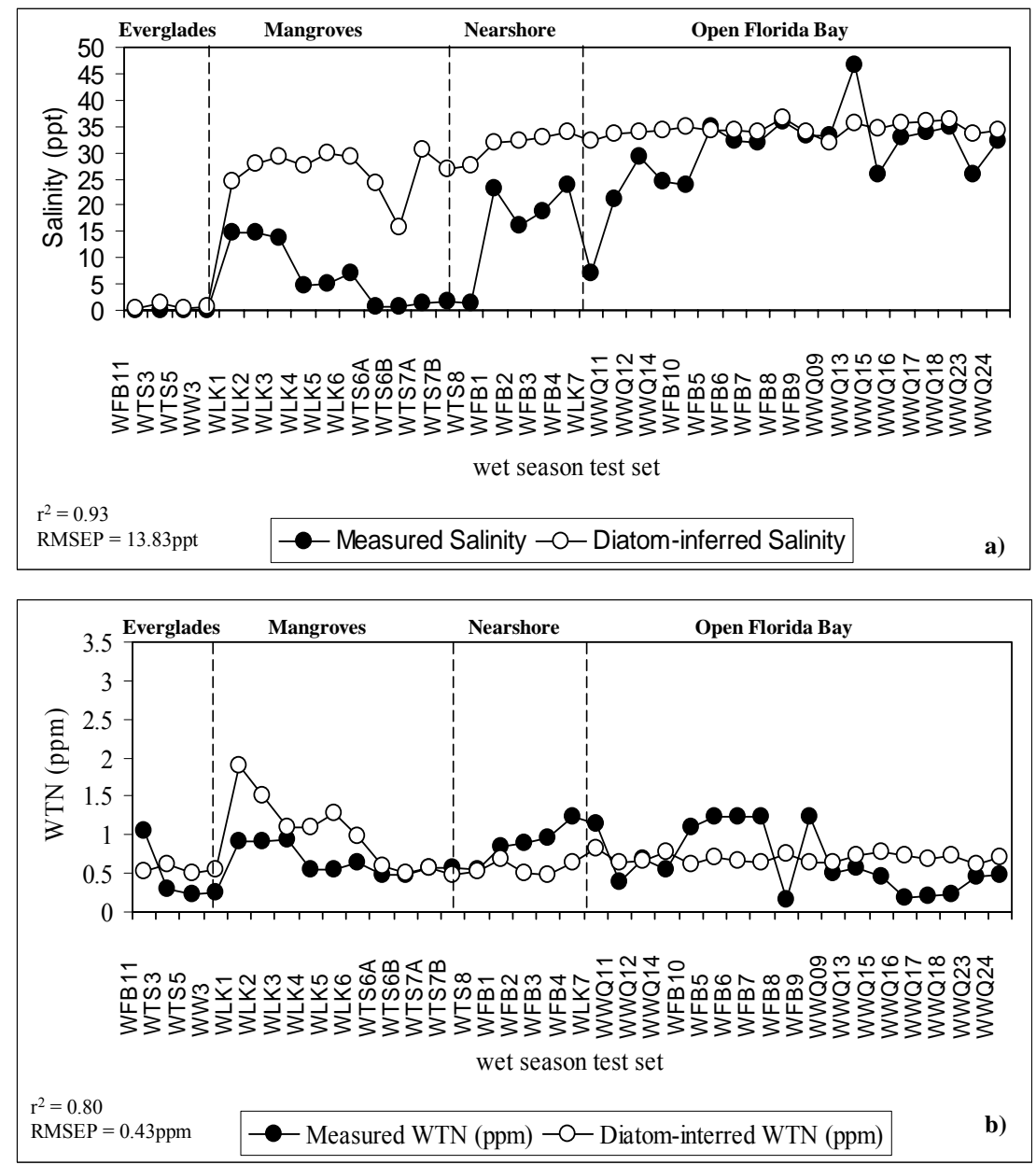


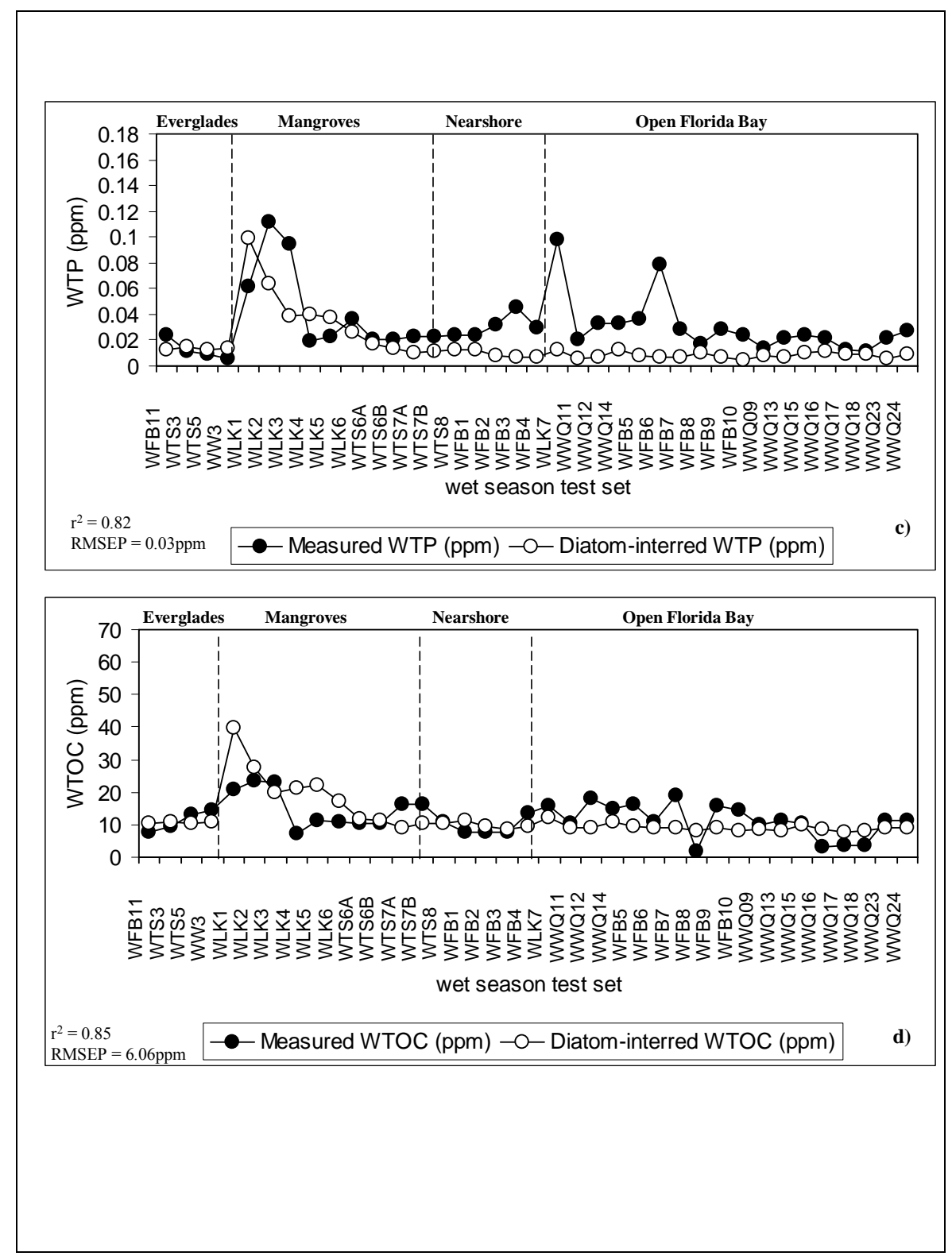


Fig. 2.6 Diatom-based predictions of geographical location $(a, b)$ and life-habitat type (c-j) based on discriminant function analysis using the combined dry and wet season data $(\mathrm{a}, \mathrm{c}, \mathrm{e}, \mathrm{g}, \mathrm{i})$ and dry season data only to predict the locations and life-habitat type from the wet season data $(b, d, f, h, j)$.
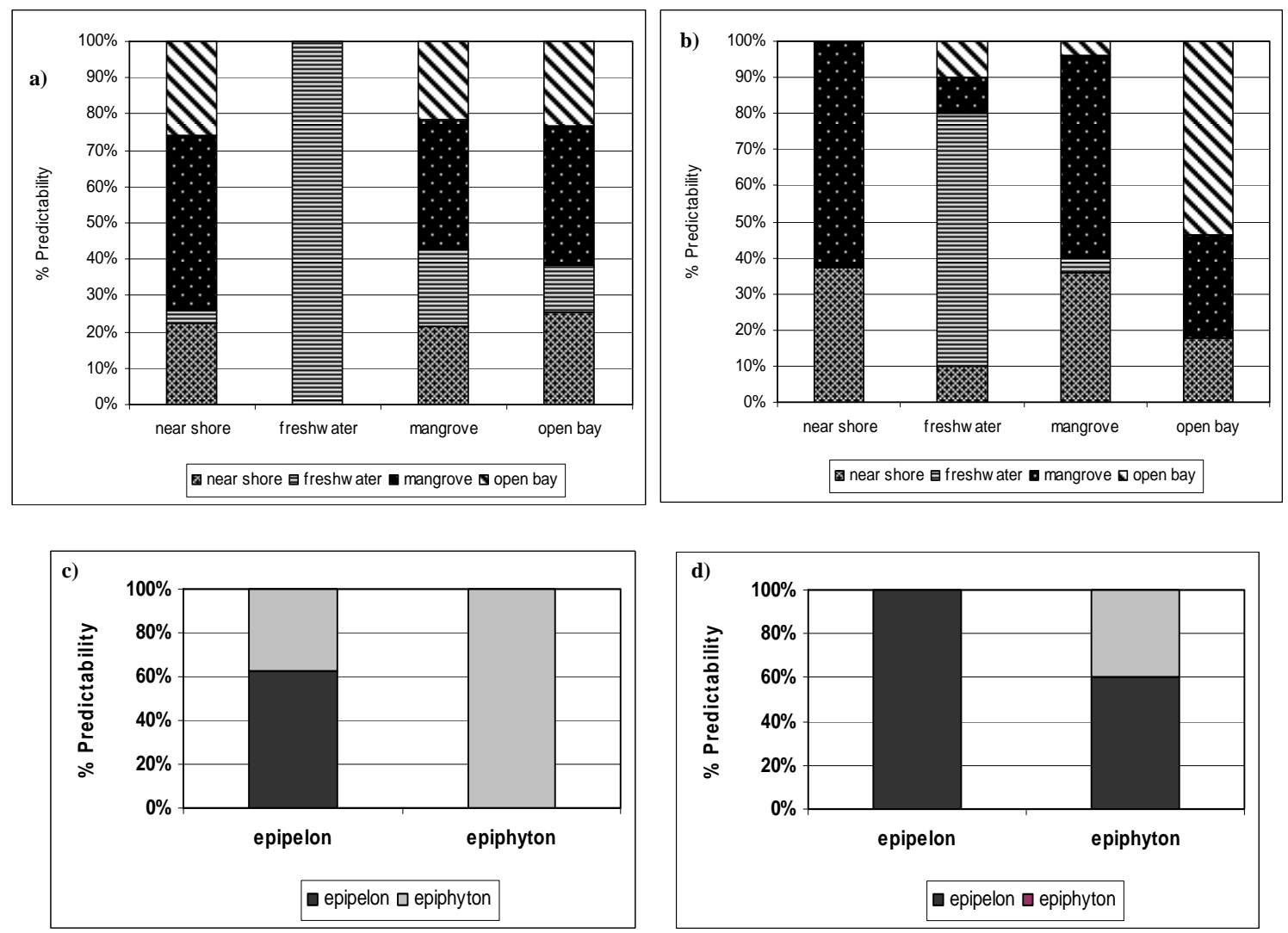

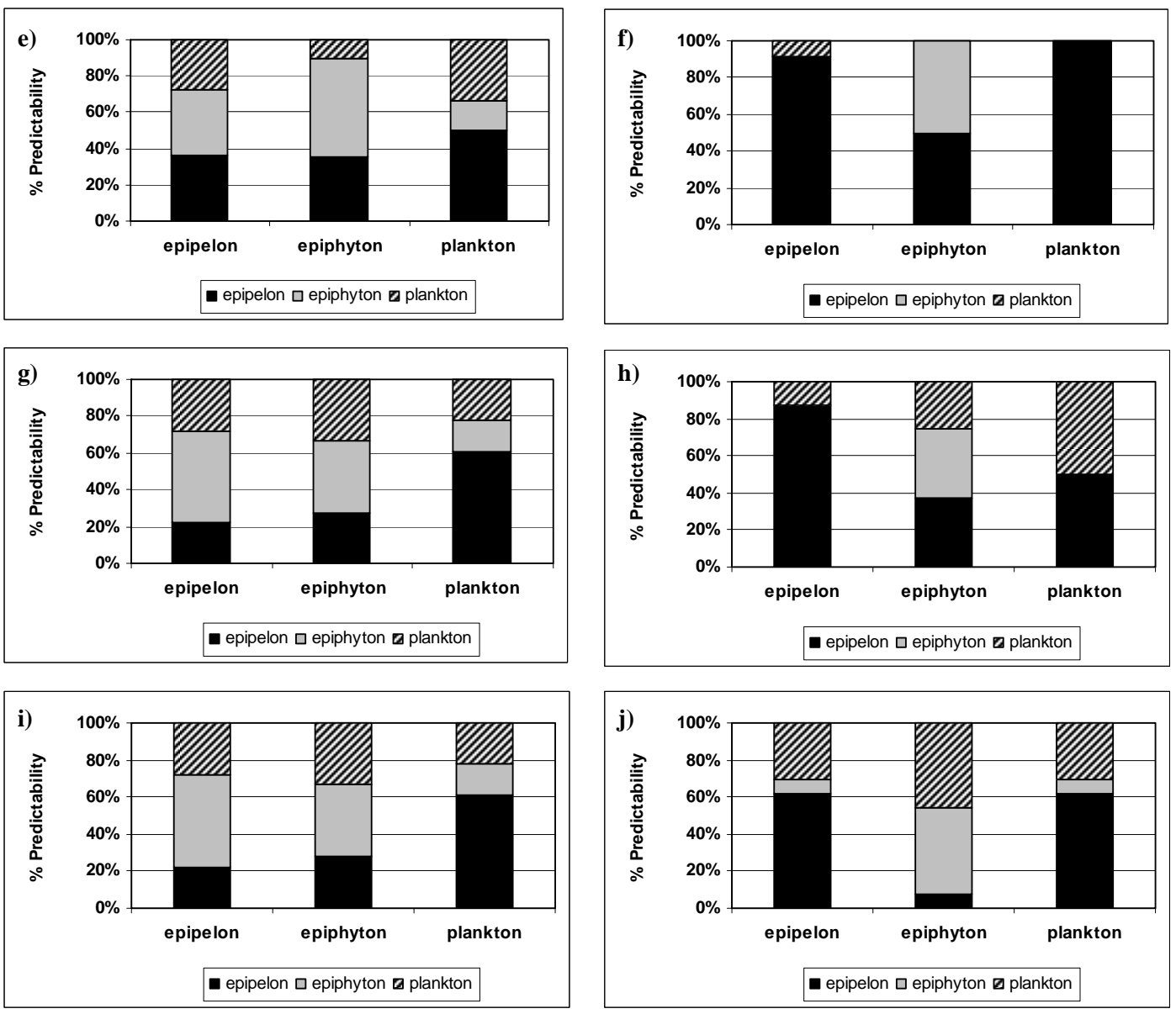


\section{REFERENCES}

Admiral,W. 1984. The ecology of estuarine sediment-inhabiting diatoms. Progress in Phycological Research 3:269-322.

Andrén E., Andren T., and H. Kunzendorf. 2000. Holocene history of the Baltic Sea as a background for assessing records of human impact in the sediments of the Gotland Basin. Holocene 10:687-702.

Armitage, A.R., Frankovich, and T.A., Fourqurean, J.W., 2006. Variable responses within epiphytic and benthic microalgal communitiestonutrient enrichment. Hydrobiologia 569:423-435.

Battarbee, R.W. 1986. Diatom analysis. In: B.E. Berglund (Editor), Handbook of Holocene Palaeoecology and Palaeohydrology. The Blackburn Press, Caldwell, New Jersey, USA, pp. 527-570.

Battarbee, R.W., Jones, V.J., Flower, R.J., Cameron, N.G., and G. Benoit. 2001. Diatoms. In: J.P. Smol, H.J.B. Birks, and W.M. Last (Editors), Tracking environmental change using lake sediments. Volume 3: Terrestrial, algal, and siliceous indicators. Kluwer Academic Publishers, Dordrecht, Netherlands, pp. 155-202.

Birks, H.J.B., Line, J.M., Juggins, S., Stevenson, A.C., and C.J.F. Ter Braak. 1990. Diatoms and pH reconstruction. Phil. Trans. R. Soc. Lond. B. 327:263-278.

Birks, H.J.B. 1995. Quantitative paleoenvironmetal reconstructions. In: D.Maddy, J.S. Brew (Editors), Statistical Modelling of Quaternary Science Data, Technical Guide No. 5. Quaternary Research Association, Cambridge, pp. 161-236.

Birks, H.J.B. 1998. Numerical tools in paleolimnology - progress, potentialities, and problems. Journal of Paleolimnology 20:307-332.

Boyer, J.N., Fourqurean, J.W., and R.D. Jones. 1997. Spatial characterization of water quality in Florida Bay and Whitewater Bay by multivariate analyses: zones of similar influence. Estuaries 20:743-758.

Brand, L.E. 2002. The transport of terrestrial nutrients to South Florida coastal waters. In: J.W. Porter, K.G. Porter (Editors), The Everglades, Florida Bay, and Coral Reefs of the Florida Keys: An Ecosystem Sourcebook. CRC Press, pp. 361-409.

Bray, J.R., and J.T. Curtis. 1957. An ordination for the upland forest of Southern Wisconsin. Ecological Monographs 27:325-349.

Browder, J., and J.C. Ogden. 1999. The natural South Florida system II: pre-drainage ecology. Urban Ecosystems 3:125-158. 
Burd, A.B., and G.A. Jackson. 2002. An analysis of water column distributions in Florida Bay. Estuaries 25:570-585.

Clark, A.L., Juggins, S., and D.J. Conley. 2003. A 150-year reconstruction of the history of coastal eutrophication in Roskilde Fjord, Denmark. Marine Pollution Bulletin 46:1614-1617.

Clarke K.R. 1993. Non-parametnc multivariate analyses of changes in community structure. Australian Journal of Ecology 18:117-143.

Clarke, K.R., and R.M. Warwick. 2001. Change in marine communities: an approach to statistical analysis and interpretation. Primer-E Ltd. Plymouth.

Clarke K R., and R.N. Gorley. 2001. Primer v5: user manual/tutorial. - Primer-E Ltd. Plymouth.

Cooper, S.R. 1995b. An abundant, small brackish water Cyclotella species in Chesapeake Bay, U.S.A., In: J.P. Kociolek, M.J., Sullivan (Editors), A Century of Diatom Research in North America: A Tribute to the Distinguished Careers of Charles W. Reimer \& Ruth Patrick. Belog Scientific Books, pp. 127-134.

Cooper, S. R., Huvane, J., Vaithiyanathan, P., and C.J. Richardson. 1999. Calibration of diatoms along a nutrient gradient in Florida Everglades Water Conservation Area-2A, USA. Journal of Paleolimnology 22:413-437.

Davis, R., and H. Williams. 1950. Brackish water plankton of mangrove areas in Southern Florida. Ecology 31:519-531.

Davis, S.E., Childers, D.L., Day, J.W., Rudnick, D.T., and F.H. Sklar. 2001. Carbon, nitrogen and phosphorus dynamics in a non-tidal dwarf mangrove wetland of the Southern Everglades, FL, USA. Estuaries 42:609-622.

DeFelice, D.R., and G.W. Lynts. 1978. Benthic marine diatom associations: upper Florida Bay (Florida) and associated sounds. Journal of Phycology 14:25-33.

De Jonge, V.N. 1985. The occurrence of epipsammic diatom populations: a result of interaction between physical sorting of sediment and certain properties of diatom species. Estuarine, Coastal and Shelf Science 21:607-622.

Dixon, P.M. 1993. The bootstrap and the jackknife: describing precision in ecological studies. In: S.M. Scheiner, J. Gurevitch (Editors), Design and analysis of ecological experiments. New York Chapman and Hall, pp. 290-318.

Dufrêne, M., and P. Legendre. 1997. Species assemblages and indicator species: the need for a flexible asymmetrical approach. Ecological Monographs 67:345-366. 
Finucane, J.H., and A. Dragovich. 1959. Counts of red tide organisms, Gymnodinium breve, and associated oceanographic data from Florida west coast, 1954-57. U.S. Fish and Wildlife Service Special Scientific Report-Fisheries 289, pp. 1-220.

Foged, N. 1984. Freshwater and littoral diatoms from Cuba. Bibliotheca Diatomologica 5:1-243.

Fourqurean, J.W., Jones, R.D., and J.C. Zieman. 1993. Processes influencing water column nutrient characteristics and phosphorus limitation of phytoplancton biomass in Florida Bay, FL, USA: inferences from spatial distributions. Estuarine, Coastal and Shelf Science 36:295-314.

Fourqurean, J.W., and M. Robblee. 1999. Florida Bay: A history of recent ecological changes. Estuaries 22:345-357.

Frankovich, T.A., and R.D. Jones. 1998. A rapid, precise, and sensitive method for the determination of total nitrogen in natural waters. Marine Chemistry 60:227-234.

Frankovich, T.A., Gaiser, E., Wachnicka, A., and J.C. Zieman. 2006. Spatial and temporal distributions of epiphytic diatoms: relationships to salinity and nutrients in a subtropical ecosystem. Hydrobiologia 569:259-271.

Fritz, S.C., Juggins, S., Battarbee, R.W., and D.R. Engstrom. 1991. Reconstruction of past changes in salinity and climate using a diatom-based transfer function. Nature 352:706-708.

Gaiser, E.E., Wachnicka, A., Ruiz, P., Tobias, F.A., and M.S. Ross. 2005. Diatom indicators of ecosystem change in coastal wetlands. In: S. Bortone (Editor), Estuarine Indicators. CRC Press, Boca Raton, FL, pp. 127-144.

Gaiser, E.E., Richards, J. H., Trexler, J.C., Jones, R.D., and D.L. Childers. 2006. Periphyton responses to eutrophication in the Florida Everglades: Cross-system patterns of structural and compositional change. Limnology and Oceanography 51:617-630.

Gottlieb, A.D., Richards, J.H., E.E. Gaiser. 2006. Comparative study of periphyton community structure in long and short hydroperiod Everglades marshes. Hydrobiologia 569:195-207.

Hein, M.K., Winsborough, B.M., and M.J. Sullivan. 2008. Bacillariophyta (Diatoms) of the Bahamas. Iconographia Diatomologica 19:1-300.

Holmes, C.W., Robbins, J., Halley, R.B., Bothner, M., Ten Brink, M., and M. Marot. 2001. Sediment dynamics of Florida Bay mud banks on a decadal time scale. Bulletins of American Paleontology 361:31-40. 
Huvane, J.K. 2002. Modern diatom distributions in Florida Bay: A preliminary analysis. In: J.W. Porter, K.G. Porter (Editors), The Everglades, Florida Bay, and Coral Reefs of the Florida Keys: An Ecosystem Sourcebook. CRC Press, Boca Raton, FL, pp. 479-493.

Juggins, S., 2005. The C2 Software for Ecological and Palaeoecological Data Analysis and Visualisation. University of Newcastle, Newcastle-upon-Tyne, United Kingdom.

Jurado, J., Hitchcock, G.L., and P.B. Ortner. 2007. Seasonal variability in nutrient and phytoplankton distributions on the southwest Florida inner shelf. Bulletin of Marine Science 80:21-43.

Kruskal, J.B.,and M. Wish. 1978. Multidimensional scaling. In J.L. Sullivan, R.G. Niemi (Editors), Quantitative Applications in Social Sciences Series 11, Beverly Hills, CA: Sage University Series, 92 pp.

Levesque, R. 2007. SPSS Programming and Data Management: A Guide for SPSS and SAS Users, Fourth Edition, SPSS Inc., Chicago Ill.

Lodge T.E. 2005. The Everglades handbook - understanding the ecosystem. Boca Raton, FL: CRC Press, 336 pp.

Lotze, H.K.., Lenihan, H.S., Bourque, B.J., Bradbury, R.H., Cooke, R.G., Kay, M.C., Kidwell, S.M., Kirby, M.X., Peterson, C.H., and J.B.C. Jackson. 2006. Depletion, Degradation, and Recovery Potential of Estuaries and Coastal Seas. Science Magazine 312:1806-1809.

McCune, B., and J.B. Grace. 2002. Analysis of Ecological Communities. MJM Software Design, Gleneden Beach, Oregon.

McCune, B., and M.J. Mefford. 1999. PC-ORD. Multivariate Analysis of Ecological Data, Version 4. MJM Software Design, Gleneden Beach, Oregon, USA.

McIvor, C.C., Ley, J.A., and R.D. Bjork. 1994. Changes in freshwater inflow from the Everglades to Florida Bay including effects on biota and biotic processes: a review. In: S.M. Davis, J.C. Ogden (Editors), Everglades: The ecosystem and its restoration. St. Lucie Press, Delray Beach, FL, pp. 117-143.

Montgomery, R.T. 1978. Environmental and ecological studies of the diatom communities associated with the coral reefs of the Florida Keys. Ph.D. Dissertation, Florida State University, Tallahassee, FL, USA.

Nelson, D.W., and L.E. Sommers. 1996. Total carbon, organic carbon, and organic matter. In: A.L. Page (Editor), Methods of Soil Analysis, Part 2, Agronomy. 9. Am. Soc. of Agron., Inc. Madison, Wisconsin, USA, pp. 961-1010. 
Nicholls R J, Hoozemans, M.J., and M. Marchand. 1999. Increasing flood risk and wetland losses due to global sea-level rise: regional and global analyses. Global Environmental Change 9:69-87.

Quinn, G.P., and M.J. Keough. 2002. Experimental design and data analysis for biologists. Cambridge, UK Cambridge University Press, Relyea, RA.

Prager, E.J., and R.B. Halley. 1999. The influence of seagrass on shell layers and Florida Bay mudbanks. Journal of Coastal Research 15:1151-1162.

Prasad, A.K.S. Riddle, K.A., and J.A. Nienow. 2000. Marine diatom genus Climaconeis (Berkeleyaceae, Bacillariophyta): two new species, Climaconeis koenigii and $C$. colemaniae, from Florida Bay, USA. Phycologia 39, 199-211.

Ramstack, J.M., Fritz, S.C., Engstrom, D.R., and S.A. Heiskary. 2003. The application of a diatom-based transfer function to evaluate regional water-quality trends in Minnesota since 1970. Journal of Paleolimnology 29:79-94.

Reid, G., and D.M. Williams. 2002. The marine diatom genus Climaconeis (Berkeleyaceae, Bacillariophyta): two new species from Abu Dhabi, United Arab Emirates. Diatom Research 17:309-318.

Ross, M.S., Gaiser, E.E, Meeder, J. F., and M.T. Lewin. 2001. Multi-taxon analysis of the "white zone", a common ecotonal feature of South Florida coastal wetlands. In: J. Porter, K. Porter (Editors), The Everglades, Florida Bay, and Coral Reefs of the Florida Keys. CRC Press, Boca Raton, FL, USA. pp. 205-238.

Rosen P., Hall R., Korsman T., and I. Renberg. 2000. Diatom transfer functions for quantifying past air temperature, $\mathrm{pH}$ and total organic carbon concentrations from lakes in northern Sweden. Journal of Paleolimnology 24:109-123.

Sherrod, B.L. 1999. Gradient analysis of diatom assemblages in a Puget Sound salt marsh: can such assemblages be used for quantitative paleoecological reconstructions? Palaeogeography, Palaeoclimatology, Palaeoecology 149:213-226.

Slate, J.E., and R.J. Stevenson. 2007. The diatom flora of phosphorus-enriched and unenriched sites in an Everglades marsh. Diatom Research, 22:355-386.

Snoeijs, P., 1994. Distribution of epiphytic diatom species composition, diversity and biomass on different macroalgal hosts along seasonal and salinity gradients in the Baltic Sea. Diatom Research 9:189-211.

Solorzano, L. and J.H. Sharp. 1980. Determination of total dissolved nitrogen in natural waters. Limnology and Oceanography 25:751-754. 
Swart, P.K. and M. Price. 2002. Origin of salinity variation in Florida Bay. Limnology and Oceanography 47:1234-1241.

Ter Braak, C.J.E., 1986. Canonical correspondence analysis: a new eigenwector technique for multivariate direct gradient analysis. Ecology 67:1167-1179.

Ter Braak, C.J.E, Juggins, S., Birks, H.J.B., and H. Van der Voet. 1993. Weighted averaging partial least squares regression (WA-PLS): definition and comparison with other methods for speciesenvironment calibration. In: G.R Patil, C.R. Rao (Editors), Multivariate Environmental Statistics. North-Holland, Amsterdam, Nederlands, pp. 525560.

Ter Braak, C.J.F., and P. Šmilauer, 2002. CANOCO Reference manual and CanoDraw for Windows user's guide: Software for Canonical Community Ordination (version 4.5), Microcomputer Power, Ithaca, NY, USA.

Tibby, J., Gell, P.A., Fluin, J., and I.R.K. Sluiter. 2007. Diatom-salinity relationships in wetlands: assessing the influence of salinity variability on the development of inference models. Hydrobiologa 591:207-218.

Tobias, F. A., and E.E. Gaiser. 2006. Taxonomy and distribution of taxa in the genus Gomphonema from the Florida Everglades, U.S.A. Diatom Research 21, 379-405.

U.S. EPA (1983). EPA Method 150.1, pH, in Methods for Chemical Analysis of Water and Wastes, EPA/600/4-79/020.

Underwood, G.J., Phillips, C., and J.K. Saunders. 1998. Distribution of estuarine benthic diatom species along salinity and nutrient gradients. European Journal of Phycology 33:173-183.

Wachnicka, A., and E.E. Gaiser. 2007. Morphological characterization of Amphora and Seminavis (Bacillariophyceae) from South Florida, U.S.A. Diatom Research 22:387-455.

Weckström, K., Juggins, S., and A. Korhola. 2004. Quantifying background nutrient concentrations in coastal waters: A case study from an urban embayment of the Baltic Sea. Ambio 33:324-327.

Weckström, K., and S. Juggins. 2005. Coastal diatom-environment relationships from the Gulf of Finland, Baltic Sea. Journal of Phycology 42:21-35. 


\section{CHAPTER 3. DIATOM-BASED EVIDENCE OF LONG-TERM WATER QUALITY \\ FLUCTUATION ALONG A COASTAL GRADIENT IN FLORIDA BAY, FLORIDA}

Abstract

Although water quality conditions in Florida Bay have been fluctuating for thousands of years due to the natural processes and sea-level changes caused by the changing climate, the ecological conditions in the bay started to deteriorate at an increasing rate in the last few decades as a result of accelerating urban development in South Florida. Fluctuations in water quality conditions greatly affected Thalassia testudinum seagrass population abundance in Florida Bay, which was demonstrated by numerous studies. Changes in salinity, water total nitrogen (WTN), water total phosphorus (WTP) and water total organic carbon (WTOC) were inferred from diatoms preserved in four sediment cores collected from a coastal gradient in Florida Bay. The position of the cores along the estuarine gradient helped to determine which fluctuations in water quality conditions were related to natural processes, and which to humanassociated processes. The main goals of this research were to reconstruct the historical changes in water quality conditions (salinity, WTN, WTP, WTOC) and diatom assemblage types (sediment, epiphyton, plankton), and to look for possible relationships between them.

Using stratigraphically constrained cluster analysis (CONISS), assemblages in each core were grouped into stratigraphically distinct clusters. Changes in species turnover ( $\beta$-diversity ) were recorded in the late 1800's in the Bob Allen Bank and the 
Russell Bank cores, followed by changes in the early 1900's in the Trout Cove and the Ninemile Bank cores. A second period of change in $\beta$-diversity occurred at Bob Allen Bank, Russell Bank and Trout Cove in the mid-1950's and Ninemile Bank in the mid1980's. Inference models indicate that salinity in the last 100 years at the Trout Cove location was higher in the early 1900's than in the late 1900's, decreased between 19001920, and then started increasing to the modern record (last few decades). At Ninemile Bank, salinity varied little untill the 1980 's, then it began to decrease, while at Russell Bank it increased untill the mid-1960's, then slightly decreased in the 1970's before increasing again after the early 1980's. Salinity at Bob Allen Bank has slowly decreased since the beginning of the $20^{\text {th }}$ century. The reconstructions indicate that the central and western parts of the bay experienced fluctuations earlier in the record (before $\sim 1880$ at Russell Bank, between $\sim 1740-\sim 1900$ and before approximately $17^{\text {th }}$ century at Bob Allen Bnak, and before $\sim 1840$ at Ninemile Bank). Nutrient and TOC conditions were variable throughout the core records, although peaks were observed in the 1980's and 1990's that might be related to seagrass die-offs and algal blooms that happened at that time.

Reconstructions based on the relative abundance of diatom assemblages typical of different ecosystem types revealed that physical processes such as erosion, deposition, sediment transport and water circulation significantly influenced species composition. Reconstructions based on the relative abundance of the dominant assemblage type (plankton, epiphyton, sediment) were inconclusive due to the dynamic hydrology of Florida Bay that induces significant assemblage mixing. 


\subsection{Introduction}

Estuaries and coastal regions are among the most productive ecosystems on Earth and have the highest biotic diversity (Bianchi 2007). These ecosystems have been under tremendous pressure due to the world's human population growth in cvoastal zones. About $61 \%$ of the total world's population and more than half of the United States population live in coastal zones (Alongi 1998). In addition to natural processes, such as tides and storms, affecting environmental conditions in estuaries, these ecosystems are also stressed by multiple human factors and sea-level rise which is caused by global warming that is part of the natural climate cycle but has been accelerated by human activities in recent time. Among human factors, the most problematic and widely studied are nutrient enrichment, which often causes harmful algal blooms and water anoxia, and industrial pollution (Howarth 2002). Dredging and filling of salt marshes eliminates fish and shellfish nursery grounds, while diversion of water in areas directly adjacent to estuaries results in changes in the quantity of freshwater, organic matter, inorganic material and sediments entering these systems (Hobbie 2000). The historical records of multiple proxy data from different estuarine systems around the world have shown that environmental conditions have greatly deteriorated over the last 150 to 300 years (Lotze et al. 2006).

The Florida Bay estuary (Fig. 3.1) has also been affected by the above-mentioned factors due to the rapid development of South Florida. At the beginning of the $20^{\text {th }}$ century, the South Florida landscape was still intact, but now this region qualifies as a human-altered ecosystem (Douglas 1988; Harwell 1998). Large parts of the landscape 
have been converted to agriculture, urban areas and flood protection systems, which has led to the elimination of vast areas of freshwater and coastal wetlands, degradation of water quality, and alteration of the quantity of water entering the Everglades marshes and adjacent estuaries (Lodge 2005). The aforementioned changes on South Florida mainland are blamed for the declining conditions of Florida Bay habitats (Forqurean and Robblee 1999).

In order to understand the underlying ecological mechanisms that drive long-term ecosystem changes and determine the scale of these changes in the Florida Bay estuary, it is necessary to obtain information about the conditions that existed there prior to and after the $20^{\text {th }}$ century urban development. In lieu of long-term water quality data, proxy data, such as diatoms, foraminifera, ostracodes, mollusks, stable isotopes, and organic biomarkers, have proved to be reliable tools in reconstructing of the paleoecological conditions of Florida Bay (Swart et al. 1996; Brewster-Wingard and Ishman 1999; Cronin et al. 2001; Xu et al. 2006, 2007; Gaiser et al. 2006). Multi-proxy studies have shown that natural processes such as regional rainfall, which is influenced by the El Niňo Southern Oscillation (ENSO), influence salinity conditions in Florida Bay more than anthropogenically-caused changes of the environment of the South Florida region (Swart et al. 1999; Cronin et al. 2001, 2002; Nelsen et al. 2002). However, anthropogenic changes do influence the diversity and abundance of ostracodes in Oyster Bay as well as the magnitude of salinity variation in the central part of Florida Bay (near Bob Allen and Russell banks; Brewster-Wingard and Ishman 1999; Alvarez Zakaria et al. 2001; Dwyer and Cronin 2001; Nelsen et al. 2002). Additionally, it has been shown that the freshwater influence in the northeastern part of the bay (at the mouth of Taylor Creek and Mud 
Creek) has decreased in the last 100 years (Willard et al. 1997; Holmes et al. 1999). The changes in salinity coincided with decreased diversity and increased abundance of salinity-tolerant species of mollusks in the eastern and central parts of the bay (BrewsterWingard et al. 2001). Several geochemical investigations (e.g., sediment nutrient, stable isotopes) demonstrated that increased nutrient levels in eastern Florida Bay over the past two decades and central Florida Bay in the early 1980's might be related to seagrass dieoffs and algal blooms (Orem et al. 1999; Swart et al. 1999).

Although paleoecological studies in estuaries using diatoms have been rare compared to freshwater lake investigations (Kuylenstierna, 1990), they have proven to be an important proxy for reconstruction of past salinity conditions (Juggins 1992; Sounders et al. 2007), eutrophication (Cooper 1993, 1995; Weckström and Juggins 2005; Branderberger et al. 2008), sea-level rise (Horton et al. 2007) and the history of monsoons (Zong et al. 2006). Diatom-based paleoecological studies are very rare in South Florida due to the paucity of taxonomic work in this region and the scarcity of autecological data available for the marine taxa. The only studies of fossil diatom records conducted in Florida Bay were those by Pyle et al. (1998), who analyzed diatom assemblages preserved in the sediment core collected near Pass Key, and Huvane and Cooper (2001) who studied two chronologically-calibrated sediment cores extracted from Russell Bank and near Pass Key. These descriptive analyses of fossil diatom assemblages, based on limited autecological information available in the literature, were used to describe past salinity and productivity levels at those locations. Both studies concluded that salinity fluctuated at these sites in the last 200 years and that there was a clear trend towards higher salinity over approximately the last 40 years. 
The main objectives of this study were as follows: 1) To reconstruct past salinity, water total phosphorus (WTP), water total nitrogen (WTN) and water total organic carbon (WTOC) from fossil diatom records preserved in four sediment cores collected along an environmental gradient, by applying quantitative prediction models developed with modern diatom records of Florida Bay and adjacent coastal regions (Chapter 2). Ninemile Bank, located in southwest part of Florida Bay, has the most stable salinity and nutrient conditions due to its location near the Gulf of Mexico and I suspect that it experienced very small variation in salinity and nutrients in the past, which I hypothesize, resulted in continuous seagrass dominance in this area during the time represented by the core. Furthermore I hypothesize that sites positioned in central part of Florida Bay near Russell Key and Bob Allen Keys, which in recent time are subject to great inter- and intra-annual changes in salinity and nutrients, experienced similar changes in the past. These changes may have caused fluctuations in seagrass abundance and the occurrence of algal blooms. Additionally, I hypothesize that salinity and nutrient levels in Trout Cove, positioned close to the coast in northeastern Florida Bay, were greatly influenced by human activities since the beginning of the $20^{\text {th }}$ century, and seagrass cover was influenced by these changes as well. 2) To reconstruct the availability and quality of common substrata (plankton, sediment, epiphyton). I hypothesize that the dominance of epiphytic diatoms will indicate dense seagrass cover, while the dominance of planktonic forms will indicate increased nutrient levels and algal blooms. 3) To reconstruct the diatom community types (freshwater, mangrove, nearshore and open-bay). I hypothesize that the dominance of one of these types of communities may help to determine the source of diatoms and physical processes influencing the study sites. 


\subsection{Study Area}

Florida Bay is a relatively large $\left(\sim 2200 \mathrm{~km}^{2}\right)$, shallow embayment $(\sim 1 \mathrm{~m}$ mean depth) in the southern part of Florida that is composed of a series of small basins separated from each other by carbonate mud banks and small mangrove islands (Tilmant 1989; McIvor et al. 1994; Fig. 3.1). The sediments of Florida Bay consist mostly of biogenic mud produced by calcareous algae, bivalve and gastropod mollusks, and foraminifera that accumulated during the last ca. 4500 years (Bosence 1989; Lodge 2005). During this period, sea level rise resulted in gradual flooding of the bay that flooded the southwestern portion around 4500 years ago and the eastern part ca. 1500 years ago (Enos and Perkins 1979). The calcareous mud deposits lie on top of brackish and freshwater peat deposits that are between 2500 to 5500 years old (Davies and Cohen 1989). All these sedimentary deposits accumulated on top of the Pleistocene Miami Oolite bedrock in the Holocene during low sea-level stages (about $4 \mathrm{~m}$ lower than today ca. 4500 years ago) (Davies 1980; Wanless et al. 1994).

The four sediment cores used for this study were retrieved from Trout Cove $\left(25^{\circ} 12.632^{\prime} \mathrm{N}, 80^{\circ} 31.955^{\prime} \mathrm{W}\right)$ in northeastern Florida Bay, near Russell Key $\left(25^{\circ} 03.870^{\prime}\right.$ $\left.\mathrm{N}, 80^{\circ} 37.503^{\prime} \mathrm{W}\right)$ and Bob Allen Keys $\left(25^{\circ} 01.731^{\prime} \mathrm{N}, 80^{\circ} 40.795^{\prime} \mathrm{W}\right)$ in the central part of the bay, and from Ninemile Bank $\left(24^{\circ} 57.186^{\prime} \mathrm{N}, 80^{\circ} 53.545^{\prime} \mathrm{W}\right)$ in the southwestern part of the bay in June and August 2002 (Fig. 3.1). The sites were selected to represent a gradient in the hypothesized stability of salinity, water quality, and seagrass communities over the length of the cores. The northeastern part of the bay experiences the largest inter- and intra-annual variability in water quality due to the seasonality of rainfall in this 
subtropical region (e.g., salinity can range between $0 \mathrm{ppt}$ and $>50 \mathrm{ppt}$ ). Variations are much smaller in the central and southwestern parts of the bay (e.g., salinity in the central bay can range between $25 \mathrm{ppt}$ and $50 \mathrm{ppt}$ and in the southwestern part between $28 \mathrm{ppt}$ and 40 ppt; http://serc.fiu.edu/wqmnetwork/SFWMD-CD/Pages/FB.htm).

The coring site in Trout Cove, positioned near a small unnamed mangrove island south of Trout Creek, was $0.43 \mathrm{~m}$ deep at the time of collection, had calcareous sediments mixed with broken shells, and was sparsely vegetated by Halodule wrightii and Thalassia testudinum seagrasses. The Russell Bank site was $0.48 \mathrm{~m}$ deep and was positioned between Russell Key and Manatee Key. This site was densely vegetated by Thalassia testudinum and red alga Acanthophora sp., and had calcareous sediments mixed with broken shells at the surface. The Bob Allen core was collected at a 0.64-m-deep site between two mangrove keys that contain small lagoons and lakes, was sparsely vegetated by Thalassia testudinum, and at the surface had calcareous muddy sediments mixed with a very small amount of broken shells. The Ninemile Bank core was retrieved from a 0.65-m-deep site covered with soft calcareous mud that was densely vegetated by Thalassia testudinum and Syringodium filiforme seagrasses, and green algae Penicillus sp., Halimeda sp. and Caulerpa sp. 
3.3 Methods

\subsubsection{Core Collection}

Sediment cores were collected following procedures described by Sansone et al. (1994) using the U. S. Geological Surveys pontoon barge. All cores were sectioned into 2-cm intervals. The samples were placed in a cooler filled with ice and transported to the laboratory for further analysis. Additionally, all cores were X-rayed to determine the presence of lamination and to evaluate the extent of sediment disruption (e.g., bioturbation), and examined visually for the type of deposits.

\subsubsection{Radiometric Dating}

Age models for each core were developed by Charles Holmes (USGS) using ${ }^{210} \mathrm{~Pb}$ for sediments less than $\sim 125$ years old (Figs 3a-d). The radiocarbon method was used for sediments older than $\sim 125$ years (Table 3.1).

The ${ }^{210} \mathrm{~Pb}$ activity was measured by alpha spectrometry according to the methods described by Flynn (1968) using the secular equilibrium model (Robbins et al. 2000; Holmes et al. 2001). In this model the flux of atmospheric ${ }^{210} \mathrm{~Pb}$ and sediment accumulation rate are assumed to be constant and any variability in ${ }^{210} \mathrm{~Pb}$ concentration (except for decay-related variations) is averaged by sedimentological processes (Robbins et al. 2000). The ${ }^{14} \mathrm{C}$ activity was measured using accelerator mass spectrometry (AMS). Radiocarbon $2 \sigma$ age ranges were calibrated to calendar years, and either the marine or 
terrestrial factor was applied to correct for the reservoir effect (Wingard et al. 2007). The

${ }^{14} \mathrm{C}$ dating was performed at Beta Analytic Radiocarbon Dating Laboratory in Miami, Florida, while the ${ }^{210} \mathrm{~Pb}$ dating at the U.S.G.S. Center for Coastal and Watershed Studies in St. Petersburg, Florida.

\subsubsection{Laboratory Methods}

Approximately $1 \mathrm{~g}$ of wet sediment was removed from every $2 \mathrm{~cm}$ interval in the top and bottom $20 \mathrm{~cm}$ sections of each core, and from each $4 \mathrm{~cm}$ interval in between. The subsamples were placed in $500 \mathrm{ml}$ glass beakers and oxidized using the method described by Battarbee (1986). Permanent diatom slides were made by placing approximately $1 \mathrm{ml}$ of slurry on No.1 coverslips, air dried and then mounted onto glass slides using Naphrax ${ }^{\circledR}$. At least 300 diatom valves were counted on each slide on random transects. Identification and enumeration of diatoms were made using a Zeiss light microscope at $1008 \mathrm{x}$ magnification $($ N.A. $=1.4)$. The identification of species was based on the local and standard diatom taxonomic literature.

The percent of organic and inorganic carbon content (OC and IC respectively) were analyzed in the Seagrass Laboratory at Florida International University. The total carbon content (TC) of the dried core material was measured using a Carlo Erba CHN analyzer (Fisons NA 1500). Additionally, an aliquot of each core sections was ashed for $4 \mathrm{~h}$ at $500^{\circ} \mathrm{C}$ to oxidize all of the organic material, the mass lost on ignition was calculated, and the remaining carbon content of the ash was determined to calculate the 
IC content of the sections. The OC content was calculated as the difference between TC and IC (TC = IC + OC; Fig. 3.4).

\subsubsection{Data Analysis}

The abundance of each taxon was expressed as relative to the total and was arcsine squareroot transformed to more closely approximate a normal distribution by down-weighting the importance of highly abundant species, and to ensure that the rarer species will also contribute to the results (McCune and Grace 2002).

Stratigraphically constrained cluster analysis with the method of incremental sum of squares was performed on the diatom data in the sediment cores. This method is a multivariate method for the quantitative definition of biostratigraphic zones where only stratigraphically adjacent clusters are formed (Grimm 1987). The statistical significance

of chronological differences in the diatom community structure was tested using analysis of similarity (ANOSIM), a nonparametric permutation procedure applied to the rank similarity matrix classification of samples (Clarke and Gorley 2001). Samples were grouped by major zones, which corresponded to the major clusters, and sub-zones, which corresponded to the minor clusters, determined by the stratigraphically constrained cluster analysis. The Global $\mathrm{R}$ reported in this analysis ranged from 0 to 1 and increased with increasing dissimilarity among zones and sub-zones (Clark and Warwick 2001).

The two-component Weighted Averaging Partial Least Squares (WA-PLS) prediction models for salinity, water total phosphorus (WTP), water total nitrogen (WTN) and water total organic carbon (WTOC), which were developed based on contemporary 
diatom assemblages and environmental data collected from 38 sites in Florida Bay, the adjacent coastal mangroves and the freshwater Everglades marshes (Chapter 2), were applied to all four sediment cores in order to track the general trends in the inferred salinity, WTN, WTP and WTOC levels.

Many of the well-preserved taxa in the core have been identified in Chapter 2 as indicators of specific ecosystem types (e.g., Everglades marshes, mangrove zone, nearshore and open bay) and dominant assemblage types (e.g., plankton, sediment, epiphyton), and the information about their optima and tolerances for salinity, WTN, WTP and WTOC was provided.

Discriminant Function (DF) analysis, which generates a linear combination of variables that maximizes the probability of correctly assigning observations to their predetermined groups or classifies new observations into one of the groups (Quinn and Keough 2002), was used to determine the dominance of the diatom community type (e.g., nearshore, open-bay, mangrove or freshwater marshes) or life habit (found on aquatic plants, in the water column or sediments) in specific time periods. This method was successfully used in Chapter 2 to predict diatom community types present at 38 sites in the dry season using the wet season data.

Detrended Canonical Correspondence Analysis (DCCA), a multivariate direct gradient analysis technique (Ter Braak, 1986), was used to estimate the amount of compositional turnover of diatom species (beta ( $\beta$ ) -diversity)), expressed in standard deviation (SD) units, among the cores and within each core (every 10 years) during the last 150 years. This method is a constrained form of Detrended Correspondence Analysis (DCA) and the sole constraining factor in this study was the sample depths, which 
correspond to the specific sample ages. The greater the $\beta$-diversity value, the larger the changes in species composition. All the datasets were analyzed with arcsine squareroot transformed diatom data, no down-weighting of rare taxa, detrending by segments, and non linear rescaling.

The Shannon-Wiener index $\mathrm{H}=-\sum_{i}\left[\mathrm{p}_{i} * \log \left(\mathrm{p}_{i}\right)\right]$, where $\mathrm{p}_{i}=$ proportion of the total number of valves belonging to the $i$ th taxa in the assemblage, was used to measure the alpha $(\alpha)$ diversity of diatoms within each sample (Ricklefs 2000).

All the above-mentioned analyses were done in the program $\mathrm{C} 2$ version 1.4.2. (Juggins 2005), Coniss version 2.70 (Grimm 1987), and CANOCO version 4.53 (TerBraak and Šmilauer 2002).

\subsection{Results}

\subsubsection{Lithostratigraphy and Chronology}

The sediment cores extracted from Trout Cove, Russell Bank, Bob Allen Bank and Ninemile Bank were $96 \mathrm{~cm}, 169 \mathrm{~cm}, 193 \mathrm{~cm}$, and $222 \mathrm{~cm}$, long, respectively. Visual inspection of the cores revealed that they were mostly composed of medium to light grey mud deposits. Additionally, the upper portion of the Trout Cove core contained brownish sandy mud and the bottom parts of the Bob Allen Bank and Ninemile Bank cores contained peat deposits. All cores contained pieces of broken shells of mollusks. The biggest concentrations of the shells were found in the bottom sections of the Russell Bank core and bottom halves of the Bob Allen Bank and Ninemile Bank cores. The upper 
sections of all the cores contained pieces of unidentified plant remains (Fig. 3.2). The OC and IC content fluctuated throughout the cores but the biggest changes in concentrations were observed in the upper halves of the Trout Cove and Ninemile Bank cores (Fig. 3.4).

The chronology of the core sediments revealed relatively uniform sedimentation rates. The average sedimentation rate for Trout Cove core was $0.4 \mathrm{~cm}$ per year and the sediments at 62 -cm-level were approximately 110 years old, as determined by the ${ }^{210} \mathrm{~Pb}$ dating method.. The average sedimentation rate at Russell Bank was $1.1 \mathrm{~cm}$ per year and the sediments at $116 \mathrm{~cm}$ were $\sim 100$ old, as determined by the aforementioned method. The average sediment accumulation rate at Bob Allen Bank was $\sim 0.5 \mathrm{~cm}$ per year and the oldest sediments, as determined by ${ }^{14} \mathrm{C}$ dating method, were approximately 4840 years old. The accumulation rate at Ninemile Bank was $\sim 0.6 \mathrm{~cm}$ per year, and the oldest dated deposits (at 194cm) were approximately 3040 years old (Figs 3a-d and Table 3.1). The approximate eeror of estimated ${ }^{210} \mathrm{~Pb}$ ages was \pm 2 years for the last approximately 30 years and \pm 5 years for older sediments (C. Holmes, written communication 2008).

\subsubsection{Diatom Stratigraphy}

\section{Trout Cove}

A total of 105 diatom taxa were identified in the Trout Cove core but only $74.3 \%$ (78 taxa) were present in the modern training set (Chapter 2), which contained 238 taxa after the elimination of rare species. The preservation of diatom valves in the top $44 \mathrm{~cm}$ was excellent but the valve count dropped below 200 between $44 \mathrm{~cm}$ and $58 \mathrm{~cm}$ and no 
diatoms were found between $62 \mathrm{~cm}$ and $92 \mathrm{~cm}$ (Appendix 3.1). The most frequently occurring taxa in the core that were included in reconstructions were Tryblionella granulata (epipelic species often found in the nearshore areas and the adjacent coastal mangrove zone, (Chapter 2), Cyclotella distinguenda (epipelic or possibly tychoplanktonic) species common in nearshore areas, (Chapter 2), Amphicocconeis disculoides (nearshore, probably epiphytic, but also often found in sediment samples, (Chapter 2), Cyclotella litoralis (marine, planktonic; Lange and Syversten 1989; Chapter 2), and Surirella fastuosa (often recorded in nearshore and mangrove sediments; Gaiser et al. 2005; Chapter 2). The most abundant taxa were T. granulata, Campylodiscus ecclesianus (common in nearshore and mangrove sediments; Gaiser et al. 2005; Chapter 2), Amphicocconeis disculoides, Cocconeis placentula var. 01 (nearshore epiphytic taxon (Gaiser et al. 2005; Chapter 2). and Cyclotella litoralis (Fig. 3.5). A major shift in diatom assemblages occurred around 1965 and this date marks the boundary between Z1 and Z2 (Table 3.2), which contain significantly different diatom assemblages $(R=0.641$, $\mathrm{p}=0.001$ ). The pre-1965 assemblages contained several taxa that do occur in older sediments (e.g., Navicula zosteretii, Seminavis eulensteinii, C. placentula sp. 01, Navicula salinarum and Mastogloia erythraea) and were mixed with species that were common throughout the core (e.g., C. distinguenda, T. granulata). The upper zone was further divided into two sub-zones (Z1S1 and Z1S2; Table 3.2), which contained different diatom assemblages $(\mathrm{R}=0.381, \mathrm{p}=0.03)$. The $\mathrm{Z} 1 \mathrm{~S} 2$ was characterized by larger concentrations of taxa that can tolerate slightly higher salinity conditions (up to 38 ppt;e.g., C. distinguenda and N. zosteretii), than can taxa dominating Z1S1 (e.g., A. disculoides, Dickieia ulvacea, A. sp. 05, Seminavis eulensteinii and Navicula salinarum). 
Zone Z2 was divided into three distinct sub-zones (Z2S1, Z2S2, Z2S3; Table 3.2).

Subzone Z2S1 differed from Z2S2 $(\mathrm{R}=0.331, \mathrm{p}=0.03)$ by containing fewer taxa which were absent from the older sediments (e.g., Mastogloia pusilla and Oestrupia powellii) and taxa that increased in abundance (e.g., C. distinguenda). The assemblages in the lowest sub-zone (Z2S3) were dominated by $C$. litoralis and $C$. distinguenda, whereas $T$. granulata occurred in low abundance. However, this zone was affected by significant valve dissolution, so results need to be interpreted with caution.

The species richness (Fig. 3.6) fluctuated between 18 taxa (between 1971 and 1972) and 56 (between 1996 and 1997) taxa in Zone 1 (Z1) and there were four distinct peaks (around 1964-1965, 1978-1979, 1989-1990 and 1996-1997) in this zone. The $\alpha$ diversity fluctuated in a similar way, between 1.7 and 3.2 in $\mathrm{Z} 1$ with four peaks present around the same time that species richness peaks. Species richness and diversity were low between 4 and 18, and between 0.7 and 1.6) ca. 1894 and ca. 1958, respectively (Fig. 3.6, Table 3.2). Reconstructions of the abundance of diatom assemblages typical for different habitats (e.g., freshwater marsh, mangrove, nearshore and open-bay) and life habits (plankton, sediment, epiphyton) revealed that Trout Cove contained mostly mangrove and freshwater marsh diatoms. The abundance of the open-bay and the nearshore diatom assemblages increased around 1911-1912 (Z2S3) and 1992-1993 (Z1S1). The reconstructions also showed that epipelic diatoms dominated the entire core except for several episodes at the beginning of the $20^{\text {th }}$ century (Z2S2, Z2S3) and around 1968 when many planktonic taxa occured (Fig. 3.6). 


\section{$\underline{\text { Russell Bank }}$}

A total of 235 species were found, of which $45.5 \%$ (107 taxa) were present in the modern training set (Chapter 2). Valve preservation was excellent throughout the core except for the bottom $10 \mathrm{~cm}$ (from $158 \mathrm{~cm}$ level) where valve abundance dropped below 150 (Appendix 3.2). The most abundant taxa in the core were T. granulata, Fragilaria synegrotesca, Mastogloia smithii, C. litoralis, Diploneis didyma and Mastogloia sp. 12. The most frequently occurring species in the fossil dataset were C. litoralis, D. didyma, Synedra sp. 01, Amphora corpulenta var. capitata, Diploneis suborbicularis and Mastogloia erythraea ( $>40$ times; Fig. 3.7). The upper portion of the core representing $\mathrm{Z} 1$ had significantly different diatom assemblages than $\mathrm{Z} 2(\mathrm{R}=0.442, \mathrm{p}=0.001$; Table 3.2). The Z1 contained 3 sub-zones (Z1S1, Z1S2, Z1S3) with distinct diatom assemblages. Zone Z1S1 contained different diatom assemblages than Z1S2 and Z1S3 $(\mathrm{R}=0.784, \mathrm{p}=0.001 ; \mathrm{R}=784, \mathrm{p}=0.01$, respectively $)$. In this part of the core marine species such as epipelic C. distinguenda, planktonic C. litoralis, and epiphytic Mastogloia crucicula and Nitzschia frustulum were the most abundant. The differences in species composition were much smaller between Z1S2 and Z1S3 $(\mathrm{R}=0.276, \mathrm{p}=0.04)$. Species that were the most abundant in these sub-zones (their abundance fluctuated depending on the depth) were marine epiphytes Grammatophora oceanica, Grammatophora macilenta and Synedra sp. 01, epipelic forms such as T. granulata and D. didyma, and planktonic $C$. litoralis. The second major bio-zone was divided into three sub-zones. The middle part of the core representing Z2S1 contained diatom assemblages which were dissimilar from communities in $\mathrm{Z} 2 \mathrm{~S} 2(\mathrm{R}=0.259, \mathrm{p}=0.01)$ and $\mathrm{Z} 2 \mathrm{~S} 3(\mathrm{R}=0.977, \mathrm{p}=0.001)$. The most abundant taxa in the bottommost part of the core were $D$. didyma (marine epipelic), $G$. 
oceanica (marine epiphytic), C. litoralis (marine planktonic) and they were mixed with M. smithii and F. synegrotesca, which are taxa commonly reported from periphyton mats in the Everglades (Gottlieb et al. 2006; Gaiser et al. 2006). The latter two species were completely absent from assemblages in the upper part of the core. The middle section of the core (Z2S1 and Z2S2) contained several species of marine epiphytic Mastogloia which were either absent or occurred in low abundance in the bottom and the top portions of the core.

Diatom assemblages at Russell Bank fluctuated between those typical for mangrove and nearshore habitats, but the latter was more common. Additionally, diatoms typical of those found in sediments dominated the core, except for a few episodes in Z2S2 (corresponding to the boundary between the $19^{\text {th }}$ and $20^{\text {th }}$ century) and one in Z2S1 (corresponding to 1941-1942) where planktonic taxa prevailed (Fig. 3.8). Species richness was on average more than 50 between 1995-2000 and 1883-1966 (59 and 53, respectively) and dropped to 36 between 1966-1995. The lowest species richness (27 taxa) was recorded in the second part of the $19^{\text {th }}$ century. The $\alpha$ diversity followed a similar trend and was highest between 1995-2000 and 1883-1966, decreased in the second part of the $19^{\text {th }}$ century, and was the lowest between 1966-1995 (Fig. 3.8).

\section{$\underline{\text { Bob Allen }}$}

A total of 188 diatom taxa were recorded, of which 58\% (109 taxa) were present in the modern training set (Chapter 2). Valve preservation was good between 0 and 132 $\mathrm{cm}$ level and then dropped to less than 50 valves per slide, except for the depths of 148- 
$150 \mathrm{~cm}, 160-166 \mathrm{~cm}, 172-174 \mathrm{~cm}$ and $186-188 \mathrm{~cm}$, where valve abundance was again higher than 300 per slide (Appendix 3.3).

The most abundant taxa in the core were $F$. synegrotesca, $N$. liebetruthii, $M$. smithii, T. granulata and G. oceanica, while the most frequently occurring species were F. synegrotesca, M. smithii, E. evergladianum, G. oceanica, D. didyma, A. corpulenta var. capitata and C. litoralis (> 40 times). The core was divided into two distinct biozones $(\mathrm{Z} 1$ and $\mathrm{Z2})$ based on species composition $(\mathrm{R}=0.362, \mathrm{p}=0.01$; Table 3.2). Assemblages below $132 \mathrm{~cm}$ were dominated by taxa commonly reported in periphyton mats in the freshwater Everglades marshes (e.g., F. synegrotesca, M. smithii and, E. evergladianum; Gottlieb et al. 2006; Gaiser et al. 2006), which were sporadically mixed with marine taxa (C. distinguenda, Paralia sulcata spp. and G. oceanica), but due to the extremely low valve count, caused by valve dissolution the results are difficult to interpret. The Z2S1 sub-zone contained assemblages dominated by the freshwater Everglades species mentioned above mixed with marine taxa that become more abundant in the upper portion of the sub-zone (e.g., P. sulcata spp., G. oceanica and D. didyma). Assemblages in Z1 still contained the freshwater taxa but many marine species that did not occur in Z2 (e.g., Synedra bacilaris, D. suborbicularis, Amphora proteu and, Synedra sp. 01), as well as taxa for which the abundance fluctuated in different sub-zones were present too. For example, Hyalosynedra laevigata, a species often found on seagrass blades in Florida Bay (Frankovich et al. 2006; Chapter 2), was common only in Z1S4; Synedra sp. 01, commonly found in sediment samples at highly vegetated sites throughout the bay (Chapter 2), appeared only in Z1S2 and Z1S1; T. granulata, a taxon occupying sediments in nearshore and mangrove regions (Gaiser et al. 2005; Chapter 2), 
increased in abundance only in the lower portion of Z1S3 and in Z1S2. Additionally, many marine epiphytic species from the genus Mastogloia which were also often found in sediment samples throughout Florida Bay (Chapter 2) were less abundant in Z1S3, but increased in abundance in the two zones in the upper part of the core (Fig. 3.9).

Assemblages in the uppermost part of the Bob Allen core contained taxa typical of nearshore habitats (Fig. 3.10). In Z1S2 and the bottom of Z1, taxa fluctuated between those typical for the nearshore and open-bay areas. Between 1849-1899 (upper part of Z2S3) taxa fluctuated between those typically recorded in the freshwater marshes and the mangroves. Between 1756-1833 (lower part of Z2S3) assemblages contained taxa mostly associated with the nearshore and open-bay habitats. The entire zone Z2 was dominated by assemblages typical of freshwater marshes and mangroves, but due to the high valve dissolution these records have to be interpreted with caution. The uppermost part of the core contained taxa most often recorded in the sediments, except for a few episodes around $1756,1855,1899$, and one in approximately the $16^{\text {th }}$ century when taxa often found in the water column were dominant (Fig. 3.10). Species richness and diversity fluctuated throughout the core, but were highest in the uppermost part (64 and 3.7, respectively; Fig. 3.10). The lowest number of taxa were recorded in the bottom part of the core $(<10$ species), but a few samples from the upper and middle part of the core had low species richness as well (e.g., the depth 40-42cm contained only 15 taxa, and 24$26 \mathrm{~cm}$ contained 19 species). The diversity was lowest in the bottom part of the core (often $<1$ ), but the $32-34 \mathrm{~cm}$ and $40-42 \mathrm{~cm}$ levels also had low diversity $(<1.5$; Fig. 3.10 ). 


\section{$\underline{\text { Ninemile Bank }}$}

A total of 184 taxa were recorded, of which 56.5\% (104 taxa) were present in the modern training set (Chapter 2). Valve preservation was excellent for the depths 0$106 \mathrm{~cm}$ but below this level the valve count often dropped to less than 50, except for 112 $114 \mathrm{~cm}$ and 136-138cm (Appendix 3.4). The most abundant taxa in the core were $F$. synegrotesca, E. evergladianum, M. smithii, Paralia sulcata var. genuine f. coronata, $G$. macilenta, G. oceanica, D. didyma, Paralia sulcata var. genuine f. radiata and Tryblionella coarctata. The most frequently occurring taxa in the core were P. sulcata var. genuina f. coronata, G. macilenta, G. oceanica, $P$. sulcata var. genuine f. radiata and $M$. cribrosa (Fig. 3.11). The major shifts in diatom stratigraphy occurred at $156 \mathrm{~cm}$, and downcore from $108 \mathrm{~cm}$ taxa which were commonly recorded at the marine and brackish water locations were mixed with freshwater species such as E. evergladianum, F. synegrotesca and M. smithii, but due to the poor valve preservation in this part of the core the results must be interpreted with caution. The upper $86 \mathrm{~cm}$ portion of the core represents approximately 150 years of deposition. During this period, the most significant changes in diatom communities occurred ca. $1898(60 \mathrm{~cm})$ implying that the assemblages in the $19^{\text {th }}$ century were significantly different from those present in the 20th century $(\mathrm{R}=0.446, \mathrm{p}=0.001)$. The $20^{\text {th }}$ century assemblages were divided into three distinct sub-zones. The diatoms in Z1S1 differed almost completely from those in Z1S2 $(\mathrm{R}=0.98, \mathrm{p}=0.001)$, and Z1S2 contained substantially different diatom assemblages than $\mathrm{Z} 1 \mathrm{~S} 3(\mathrm{R}=0.72 ; 0.002)$. The $19^{\text {th }}$ century assemblages in zone Z1S4 were dominated by several marine planktonic, epiphytic and epipelic taxa commonly reported from nearshore and open-bay locations throughout the bay (e.g., D. didyma, G. oceanica and 
G. macilenta) and some that were mostly recorded in the western part of the bay (e.g., Paralia spp.). These taxa were mixed with other marine taxa (e.g., Triceratium reticulum and Actinoptychus senarius), which were more abundant in younger assemblages. The assemblages in the oldest $20^{\text {th }}$ century zone (Z1S3) contained additional taxa typically found only on the grassy mudbanks in western Florida Bay (e.g., Toxarium undulatum and $T$. reticulum), which were almost absent in the $19^{\text {th }}$ century at this location. During the period between 1925-1987 (Z1S2) many taxa that were commonly recorded in the older biozones completely disappeared or significantly decreased in abundance, while Cymatosira lorenziana, another marine taxon often associated with sandy or sandy muds in Biscayne Bay (Chapter 4) and often occurring in western Florida Bay (Frankovich et al. 2006; Chapter 2), became abundant. The most recent assemblages in Z1S1 lack several taxa that dominated older assemblages (e.g., D. didyma, C. litoralis and C. ecclesianus) and contain lower abundances of planktonic taxa. In this zone, several epiphytic and epipelic marine species, some of which were often recorded in nearshore and mangrove zones (e.g., Cocconeis scutellum and S. fastuosa), became abundant (Fig. $3.11)$.

The uppermost two zones in the Ninemile Bank core were dominated by nearshore and open-bay diatom assemblages, but this changed in the lower part of the core, where assemblages typically associated with mangroves and nearshore areas prevailed in Z1S3 and Z1S4, and the freshwater assemblages dominated even older sediments, although the latter results are questionable due to the possible high valve dissolution. The assemblages throughout the four uppermost sub-zones in the core fluctuated between those typically recorded in sediments and the water column, except 
for the episode around 1897 when taxa associated with aquatic plants were the most common group. The lower parts of the core contain mostly benthic and epiphytic assemblages, but the results are problematic to interpret because of possible valve dissolution (Fig. 3.12). Species richness fluctuated throughout the core but it exhibited a decreasing trend from the top to the bottom of the core (Fig 3.12). It reached 51 taxa in the uppermost part of zone Z1 and then dropped to $<35$ taxa in Z1S2 and Z1S3, 22 taxa in Z1S4, and reached $<10$ taxa in Z1S5 and Z2. The Shannon-Wiener diversity displayed a similar trend, with highest values in Z1S1 and Z1S3 and lowest ones in Z2 (Fig. 3.12). There are two peaks in species richness and diversity in the lower part of the core. At the $102-104 \mathrm{~cm}$ level, 58 taxa were found and the diversity increased to 3.3 , and at the $112-114 \mathrm{~cm}$ level 42 taxa were found and the diversity increased to 3.4 .

\subsubsection{Compositional Species Turnover}

Compositional change during approximately the last 150 years (except for Trout Cove core where the changes were studied over approximately 100 years) was the highest in Trout Cove core (2.862 SD units), followed by Ninemile Bank (2.033 SD units), Bob Allen Bank (1.807 SD units) and Russell Bank (1.638 SD units) cores. Striking and almost synchronized shifts in biostratigraphic diatom series occurred in all three cores

extracted in central and western part of Florida Bay (Fig. 3.13b-d) either at the end of $19^{\text {th }}$ in Bob Allen Bank and Russell Bank cores (Fig. 3.13b,c) or at the beginning of the $20^{\text {th }}$ century in Ninemile Bank core (Fig. 3.13d). Additionally, species turnover rates increased in the Ninemile Bank core from the early 1980's, in the Bob Allen Bank core 
since the mid-1950's and in the Russell Bank core in the 1960's and again since 1990's. The major $\beta$-diversity changes in the Trout Cove core began after 1958 with peaks in the 1960's and 1980's (Fig. 3.13a).

\subsubsection{Reconstructions}

All taxa which were identified in Chapter 2 as indicators of the freshwater Everglades marsh habitat were considered allochthonous and were excluded from reconstructions because their inclusion could compromise the water quality reconstruction results. The results instead of reflecting the real changes in water quality conditions would most likely reflect the physical processes acting in the studied areas.

The inferred salinity in Trout Cove has increased since the early 1900's. A slight increase also occurred in the period between 1958 and 1968, corresponding to the boundary between Z2S1 and Z1S2, and around 1925, corresponding to Z2S2, while a slight decrease happened between 1971-1976 and around 1993 (Fig. 3.6). At the same

time, WTN, WTP and WTOC appeared higher during the time period represented by Z2S2 and Z1S2 compared to Z2S1 and Z1S1 (Table 3.2). Distinct peaks in nutrients and WTOC levels occurred around 1982, between 1971-1975, and between 1918-1922 (Fig. 3.6).

No significant salinity fluctuation occurred in the Russell Bank core, except for the bottommost sub-zone (Z2S3). In Z2S1 there were four periods with low salinity conditions around 1914-1918, 1938-1942, 1955-1956, and from the beginning of 1962 to late 1981, which also covers the entire sub-zone Z1S3. The values increased again in 
Z1S1 and Z1S2, except for 1986 and the period between 1989-1991 when salinity decreased again (Fig. 3.8, Table 3.2). The WTN, WTP and WTOC levels generally increased from the 1870's and have experiences large fluctuations since the 1980's (Fig. 3.8, Table 3.2). A distinct increase in nutrients and WTOC levels occurred around 1990, between 1996-2000, and (in WTP only) around 1914, 1942, and 1969. Noticeable decreases took place around 1869, 1901, and 1995 (Fig. 3.8).

The reconstructions revealed that salinity at the Bob Allen location fluctuated less after the early 1900's and has decreased since 1971 (Fig. 3.10). The values were highest in Z1S5 and Z1S4 and lowest in Z2, but the result in the latter zone must be interpreted with caution due to poor valve preservation (Table 3.2). Distinct peaks in salinity in the last 150 years occurred around 1855, 1877, 1938, and 1976 (Fig. 3.10). The WTN and WTOC values seem to be on average higher in the two uppermost sub-zones in the core that represent $20^{\text {th }}$ century period, while the WTP values did not change much (Table 3.2). There are several distinct peaks in nutrients and WTOC levels in the mid-1970's (at $4 \mathrm{~cm}$ ), ca. 1811 (at $60 \mathrm{~cm}$ ), ca. 1778 for WTN only, ca. 1767 for WTP and WTOC only (76 cm), and late 1600's (128 cm for WTN and WTOC and $132 \mathrm{~cm}$ for WTP; Fig. 3.10). Inferred values of salinity at Ninemile Bank indicate that there has been a decrease in salinity since the early 1980's and that there were few episodes of lower salinity conditions in the early 1800's (at $104 \mathrm{~cm}$ ), ca. 1870 (at $76 \mathrm{~cm}$ ), and 1973 (at 16 cm) (Fig. 3.12). There are additional fluctuations in salinity in sub-zone Z1S5 and zone $\mathrm{Z} 2$, but the values need to be treated with caution due to the very low valve count, which may possibly be due to dissolution. The average WTN, WTP and WTOC levels were lowest in sub-zones Z1S2 and Z1S5 (Table 3.2). 


\subsection{Discussion}

The diatom assemblages in all studied cores exhibited an extraordinary temporal and spatial array of taxa, implying that variable ecological conditions were present at the coring locations in the past, and that the assemblage changes were driven by multiple mechanisms. Although all diatom taxa found in fossil deposits were present in the original modern dataset, modern analogs at the community level, were not always available in the training set that was used in the transfer function development. The lower number of taxa occurring in all Florida Bay cores compared to the modern diatom dataset is most likely due to dissolution of small and weakly silicified diatom valves. For example, Cyclotella choctawhatcheeana, which frequently occurred in modern samples at Trout Cove and many other nearshore locations, was completely absent from the Trout Cove core. Earlier studies found that this species is very prone to dissolution (Ryves et al. 2001; Flower et al. 2006). Also, species from the genera Rhizosolenia and Chaetoceros, which were recorded in modern Florida Bay samples, were completely absent from the fossil samples. Cooper $(1993,1995)$ also observed an absence of Rhizosolenia, Cerataulina, Chaetoceros, Leptocylindrus and Asterionella in the studies of diatom assemblages from the Chesapeake Bay. Flower (1993) discovered that valve preservation deteriorates relatively quickly in carbonaceous systems with a high $\mathrm{pH}$, while grazing and bioturbation play important roles as well. Freshwater taxa are usually better preserved compared to marine and brackish water species because they generally have thicker walls (Conley et al. 1989). Furthermore, siliceous valves usually dissolve fast in anoxic, organic-rich environments with neutral $\mathrm{pH}$, which often explains the 
absence or very low abundance of diatoms in peat deposits (Bennett et al. 1991). All these findings provide a good explanation of decreasing species richness and diversity (especially of marine taxa) in the Florida Bay cores, and increasing dominance of freshwater taxa in the bottom sections of these cores. Taxa such as M. smithii, E. evergladianum and F. synegrotesca, commonly reported from the freshwater marshes throughout the Everglades (Gaiser et al. 2006; Gottlieb et al. 2006), were often mixed with marine species (e.g., P. sulcata spp., G. oceanica and G. macilenta) in the bottom section of the Florida Bay cores (except for the Trout Cove core). An autecological study of modern diatoms in Florida Bay, the mangroves and the freshwater Everglades marshes revealed that $M$. smithii, E. evergladianum and F. synegrotesca cannot thrive in saline and hypersaline waters and are most likely allochthonous to the bay, especially in recent times (Chapter 2). Paralia sulcata, which was abundant throughout the Ninemile Bank and Bob Allen Bank cores, including bottommost sections, is well known as a good paleo-indicator of euhaline water conditions (salinity between 30-40 ppt) in coastal environments, and it is heavily silicified and preserves well in sedimentary records (Mcquoid and Hobson 1998; Mcquoid and Nordberg 2003; Witak et al. 2005).

Grammatophora oceanica, another commonly occurring taxon, was originally described by Flower et al. (2006) as "prone to dissolution", but in the Florida Bay cores this species was found even in the oldest deposits, which implies that it is probably still more resistant to dissolution than many other marine species recorded in Florida Bay.

The bottommost section of the Bob Allen Bank core contained thin layers of marine and marl deposits that were sandwiched between freshwater peat deposits. These deposits contained diatom assemblages composed of freshwater and marine taxa that 
were mixed with numerous freshwater sponge spicules. According to earlier studies, there are 12 different types of peat deposits underlying more recent marine carbonate sediments in Florida Bay. This provides evidence that when sea level was lower in the past ( $\sim 4 \mathrm{~m}$ lower around 4500 years ago), the bay was an extension of the freshwater Everglades where long-hydroperiod marshes were replaced by short-hydroperiod marshes during drier periods, and eventually they were transgressed by the sea (Davies and Cohen 1989). The presence of freshwater diatoms in the oldest deposits of the Bob Allen Bank core, which are up to 4100 years old, supports the aforementioned findings and implies that valves of freshwater taxa that were found in this part of the core are autochthonous in nature. Similar patterns are present in the Ninemile Bank core, where a thin layer ( ca. 2 cm) of peat of unknown age was also found. Earlier studies by Davies and Cohen (1989) reported the presence of Rhizophora Transitional Peat and Conocarpus Transitional Peat deposits that underlie marine carbonate deposits at this location. According to this study, this zone reflects a transition between freshwater marshes to brackish and, marine swamps and these deposits can contain elements (including diatoms) derived from many different environments. The presence of similar diatom assemblages in sediments at the bottom of the Russell Bank core (dominant marine assemblages mixed with freshwater taxa), which date back only to approximately the early 1800 's, implies that the valves of freshwater taxa in this core are most likely allochthonous in nature, and that salinity was lower at this location before the $20^{\text {th }}$ century compared to the last few decades. In earlier studies of the historic anthropogenic changes in South Florida, Light and Dineen (1994) reported that the amount of freshwater supplied from the Everglades to the bay was historically much larger than it is today. The allochthonous nature of $F$. synegrotesca, $M$. 
smithii and E. evergladianum in more recent sediments can be further supported by the fact that their valves were only sporadically recorded (often 1 to 2 valves per slide) in modern samples from the bay (especially during wet season) at nearshore and brackish water sites, while they dominated assemblages at freshwater sites with hundreds of valves per slide. Furthermore, earlier autecological studies by Gaiser et al. (2005) on diatom assemblages living at freshwater and brackish sites along Biscayne Bay revealed that freshwater marshes and swamp forest floras were dominated by the above-mentioned species, whereas mangrove sites, separated from the freshwater sites by a canal and levee, contained taxa that are tolerant of more saline conditions (e.g., T. granulata).

Estuaries represent highly dynamic and complicated ecosystems that often contain mixed living and dead diatom assemblages (Juggins 1992). Species compositions of those assemblages represent the end product of multiple processes acting in estuaries, and among them are ecological processes (e.g., habitat type, spatial habitat variability along major environmental gradients, temporal variability) and physical processes such as erosion, transport and deposition of allochthonous valves (Juggins 1992). Based on the above-mentioned information and diatom records from these three sediment cores, it can be concluded that there are most likely only a few possible sources of freshwater taxa in Florida Bay: 1) the Everglades marshes via natural creeks and Taylor Slough, which freshwater is transported to northeastern Florida Bay from the northwest, and overflow from the C-111 canal (Fig. 3.1) provides freshwater to northeastern Florida Bay from the northeast (Zucker and Hittle 2002); 2) Shark River Slough, which waters that become brackish due to the mixing with the Gulf of Mexico waters, flow to Florida Bay around Cape Sable; 3) small lakes in the middle of the mangrove islands in Florida Bay that may 
freshen during unusually wet periods (that are common every few years due to El Niňo events (Cronin et al. 2001, 2002)), and spill out around the islands; and 4) erosion of older deposits which often contain freshwater taxa. The freshwater diatom valves that come from these sources can easily be redistributed throughout the bay by water currents, and sediments, which are eroding in the eastern portion of the bay and accreting in the western portion (Wanless and Tagett 1989).

Major changes in the $\beta$-diversity during the last approximately 150 years, observed in all four cores (Fig. 3.13), correspond to the major human-introduced changes that happened during that time in the South Florida region (Fig. 3.14). The first peak in $\beta$-diversity, which occurred during the first part of the $20^{\text {th }}$ century (1900-1920) at Trout Cove, Ninemile Bank, and Russell Bank coincide with the construction of the railroad between 1907-1912, canals in central and east-central Florida and Tamiami Canal (between 1915-1928; Sklar et al. 2001; Fig. 3.14). The railway construction resulted in restriction of the exchange of water between Florida Bay and the Atlantic Ocean, while construction levees in the central and central-east part of the Everglades and Tamiami Canal and levee, separated southern Everglades from northern and caused limitation of water supply, especially to the western part of Shark River Slough, and lowering of the water levels throughout the Everglades from 1 foot below ground surface in 1915 to 5 feet below ground by 1939 (Light and Dineen 1994; Sklar et al. 2001). Diatom-based reconstructions show that during that time salinity, nutrients and WTOC first decreased (1911-1915) and then increased (1915-1919) at the Trout Cove location. Similar changes were observed at Russell Bank and Ninemile Bank, except at the latter, salinity and nutrient levels changed just a bit. Similar trends were reported by Swart et al. (1996) 
from the study of $\delta^{18} \mathrm{O}$ and $\delta^{13} \mathrm{C}$ levels in fossil coral skeletons from Lignumvitae Basin. The authors concluded that low values of $\delta^{18} \mathrm{O}$ are related to substantial lowering of salinity during that time, while increased values of $\delta^{13} \mathrm{C}$ correspond to either the decreased influence of carbon derived from marine sources or increased photosynthesis and algal blooms. Water quality conditions at the coring locations during that period were additionally affected by natural events, since salinity in Florida Bay is strongly correlated with rainfall, and anthropogenic influences are often listed as a secondary factor (Nelsen et al. 2002; Wingard et al. 2007). For example, the unusually wet wet seasons that occurred in this region between 1890-1905 and 1915-1920 (Cronin et al. 2001) could have significantly lowered salinity in the bay.

At the Bob Allen Bank and the Russell Bank coring sites, even more significant increases in $\beta$-diversity occurred in the 1870 's and the 1880 's. These could be caused by natural events such as hurricanes, unusually wet seasons, droughts, or flooding on the mainland that could bring unprecedented amounts of water to the bay. These natural events can cause erosion, deposition and transport of sediment, and freshening or hypersalinity in the bay, resulting in changes of water quality that would affect diatom community composition. Additionally, changes could be farther reinforced by the constructions of the canals between Lake Okeechobee and Caloosahatchee River and canals connecting Kissimmee chain of lakes in central Florida in the early 1880's (Fig. 3.14). These developments resulted in lowering of water level in Lake Okeechobee (2-3 feet) and reduced overflows from the lake into the Everglades and subsequently into Florida Bay (Sklar et al. 2001). 
Based on the diatom reconstructions of salinity, nutrients and WTOC, there was a significant lowering of salinity and an increase in nutrient and organic carbon content in the water at the Russell Bank site during the early 1990's, while at the Bob Allen location water quality fluctuated. Chemical biomarkers of marine diatoms (C25 Highly Branched Isoprenoids) also occurred in low concentrations at the same levels in the Russell Bank core, further supporting the concept of low salinity conditions that existed at that time (Xu et al. 2006). Similar changes were observed by Brewster-Wingard et al. (2001) in the molluskan fauna in the Bob Allen Bank core deposits between 1890-1901, which is within the range of dating error.

The turnover rate ( $\beta$-diversity) was more or less at the same level during the 1930's and the 1940's, which corresponds to the time when all the major construction plans on the mainland were put on hold due to the Great Depression (Light and Dineen 1994). Also, no major hurricanes passed by this region at that time, except for Labor Day Hurricane of 1935 (Fig. 3.14). A huge change in $\beta$-diversity occurred again during the 1950's and 1960's in Trout Cove, Russell Bank and Bob Allen Bank cores, and after the 1980 's in the Ninemile Bank core. The increased species turnover rates during these periods correspond with major constructions of the canals, levees, pump stations, water conservation areas and highways in South Florida (Light and Dineen 1994; Sklar et al. 2001; Fig. 3.14). These constructions resulted in reduction of seepage to the Biscayne Aquifer, almost complete elimination of the natural overland flow to Shark River Slough and to the southern portion of the Everglades, and significant lowering of the amount of water flowing into Florida Bay (Sklar et al. 2001; Fig. 3.15). Additionally, there were several major hurricanes that passed over South Florida during that time (e.g., Hurricane 
Donna in 1960, Hurricane Andrew in 1992; Fig. 3.14) and a few periods of drought (e.g., 1955-57, 1961-63, 1971-74, 1980-82, 1985, 1988-89, 1990; http://www.noaa.gov/). In fact, at Trout Cove salinity decreased significantly in 1992 (the year of Hurricane Andrew) and many freshwater valves were found in the Bob Allen Bank core at the 1948 level (the year of Hurricane of 1948). Distinct fluctuations in salinity conditions that can be seen in all studied cores are most likely due to the wetter and drier periods caused by the El Niňo and La Niňa events (Cronin et al. 2001), although the precision of the ${ }^{210} \mathrm{~Pb}$ determined ages cannot be used to test this. The short-term fluctuations in salinity (4-6 year periodicity), as measured by $\delta^{18} \mathrm{O}$ levels, were also observed in the fluorescent banding of corals from Lignumvitae Basin (Smith et al. 1989; Swart et al. 1999) and ostracode records at several sites in central and eastern Florida Bay (Dwyer and Cronin 2001; Cronin et al. 2001, 2002). A significant decrease of salinity at Ninemile Bank since the mid-1980's is contemporaneous with the approval of the South Florida Water Management District (SFWMD) "Rainfall Plan" and closing of the Buttonwood Canal (Figs 3.14). According to this plan, the amount of water flow to Shark River Slough (SRS) was adjusted based on the amount of rainfall and evaporation that occurs in the South Florida region and the water level in Water Conservation Area 3a (WCA 3a; Light \& Dineen 1994). Changes in salinity caused by this plan were also recorded in the ostracode records in Oyster Bay, which populations changed drastically after the mid1980's (Alvarez Zarikian et al. 2001). Increases in nutrient and TOC levels were observed in the Russell Bank, the Bob Allen Bank and the Trout Cove cores in the late 1980's. A similar trend was described by Orem et al. (1999) in sediment nutrient levels in cores extracted from the same locations. These episodes correspond to the time of 
major seagrass die-offs, which decomposition most likely resulted in release of nutrients into the water column. During the same time seagrass biomarkers (Paq and $\mathrm{C}_{25} / \mathrm{C}_{27}$ ) significantly decreased, especially in the Russell Bank, Trout Cove and Ninemile Bank cores (Xu et al. 2007). An increase in nutrients is also distinct in the Ninemile Bank core around 1990 and the Trout Cove core around 1982, which can possibly be linked to the same events. Peaks in nutrient and WTOC levels also occurred in older parts of the Bob Allen Bank core in approximately the late 1600's and early 1700's. Orem et al. (1999), in his analysis of organic carbon, total nitrogen and total phosphorus in sediments in a Whipray Basin core, found that a large productivity event occurred at that location in the mid-1700s. Small discrepancies in the onset timing of these events in the diatom-based and Orem et al. (1999) studies, might be due to the fact that diatom-based reconstructions are of water rather than sediment nutrients, that the cores were not takes from exactly the same locations and that ages have an associated errors. Diatom-based reconstructions also suggest that there was an episode of increased nutrient concentrations at the beginning of the $20^{\text {th }}$ century, which was also observed during the study of $\delta^{13} \mathrm{C}$ in coral skeletons in Lignumvitae Basin (Swart et al. 1996, 1999), possibly related to the construction of the railway from Miami to Key West that is blamed for changes in circulation and increased eutrophication in the bay. Xu et al. $(2006,2007)$ reported that concentration of microbial-derived biomarkers $\left(\mathrm{C}_{20}, \mathrm{C}_{25}\right.$, dinosterol) increased in all cores after 1950, probably due to the nutrient enrichment, and that the bay-wide disturbance occurred after the beginning of the $20^{\text {th }}$ century.

Reconstruction of the abundance of diatom assemblages typical of specific ecosystem types provided valuable information about sources of diatoms in the cores. 
Reconstructions show that assemblages typical for mangrove ecosystems dominated the entire Trout Cove core, except for the early 1970's and late 1980's when freshwater diatom assemblages became more important, and in 1992 when open-bay assemblages prevailed. The 1992 event can be linked to Hurricane Andrew that most likely caused sediment erosion in the bay and transport towards the coasts.. At the same time, the release of freshwater from canals and increased rainfall resulted in decreased salinity, which was captured in the salinity reconstruction (Figs 3.6,3.15). Similar trends were observed by Xu et al. (2007), who also reported that Teraxarol (mangrove biomarker) concentration was high throughout the Trout Cove core. In the Russell Bank core assemblages typical for nearshore habitats were dominant most of the time, except for few episodes when assemblages typical for mangrove ecosystems also occurred. Xu et al. (2007) also reported that some biomarkers typical for seagrass, especially $\mathrm{C} 23+\mathrm{C} 25 n$ alkanes, and mangroves (Teraxarol) had the highest concentration in this core. In the Bob Allen Bank core, dominance of assemblages typical of freshwater marshes corresponded with increased abundance of freshwater taxa. In the Ninemile Bank core, the increased dominance of assemblages typical of mangrove, open-bay and nearshore ecosystems was also reflected in increased concentrations of mangrove and seagrass biomarkers (Xu et al. 2007).

Reconstructions of the abundance of planktonic, epipelic and epiphytic diatom assemblage types in the cores were less successful. They indicated that diatoms occupying sediments dominated most of the time in all cores, which is very doubtful knowing that most of the locations were vegetated in the last few decades (Wingard et al. 2007). Studies of seagrass biomarkers at the coring locations indicated that seagrass 
density increased in the last two decades at the Russell Bank site, around 1940 at the Bob Allen Bank site, after 1966 at Ninemile Bank and after 1919 at the Trout Cove site (Xu et al. 2007). Failure in the prediction of different diatom assemblage types is most likely due to the fact that Florida Bay is a highly dynamic system where turbidity is often high and sediment transport is common (Fourqurean et al. 2001). Additionally, studies of modern diatoms in Florida Bay (Chapter 2) showed that taxa which were often described in other studies as epiphytic or epipelic were often found in the water column, while planktonic and epiphytic types were often found in great numbers in sediment samples. Due to the multiple physical factors that act on diatom communities in estuaries, including Florida Bay, it is extremely rare that taxa are found exclusively in a single habitat (Juggins 1992), so there is usually a big overlap between taxa living in and on sediment, epiphyton and plankton (O'Quinn and Sullivan 1983). The only way to improve this type of reconstruction, which could provide valuable information about algal blooms and vegetation density, would be to improve our knowledge of each taxon's habitat preferences through experimental studies rather than field studies in order to reduce the effect that physical processes have on the diatom valve vertical distribution. In general, diatom reconstructions provided a very good estimation of past salinity, WTN, WTP and WTOC conditions at the coring sites and valuable information about physical processes influencing water quality in the bay. Some of the reconstructions, though, have large errors and they should be interpreted with caution. Additionally, reconstructions confirmed that human-introduced changes are superimposed on long-term natural changes in climate, and that it is difficult to 
distinguish these two from each other. Furthermore, this study implies that short-term climatic events such as hurricanes may also play an important role.

\subsection{Conclusions}

The data from all studied sediment cores suggest that there have been major changes in diatom communities at all coring locations, especially at the end of the $19^{\text {th }}$ century as shown in the Bob Allen Bank and Russell Bank cores, at the beginning of the $20^{\text {th }}$ century in the Trout Cove and Ninemile Bank cores, and after the 1950's in all cores except for the Ninemile Bank core, where changes occurred again after the 1980's. The $20^{\text {th }}$ century changes in the quality and quantity of water flowing to Florida Bay and related changes in diatom assemblages at four coring locations described in this study, were caused by natural processes that were further reinforced by constructions of canals, levees, water conservation areas, pump stations and highways on the mainland.

Lowering of salinity at the Ninemile Bank location since the 1980's was most likely caused by South Florida Water Menagement District practices on the mainland that affected Shark River Slough water levels and quality. A general trend towards lower salinity conditions can be observed at Bob Allen Bank and Russell Bank, while a trend towards higher salinity levels is obvious at Trout Cove. These changes were most likely caused by re-direction of water from Taylor Slough headwaters back to the southern portion of the slough, which caused a larger amount of water flow into the bay. The biggest fluctuations in salinity conditions were observed in the bottom parts of all cores, except for the Trout Cove core which contain sediments no older than 100 years. The 
bottom sections of the above-mentioned cores, especially the Bob Allen Bank and the Ninemile Bank cores, contain sediments over 4000 years old. Diatom-based reconstructions of salinity in these sections show that salinity fluctuations at that time were caused by long-term natural events such as sea-level rise that resulted in the formation of Florida Bay, coupled with short-term climatic events such as hurricanes and wetter and drier episodes. Less variability in salinity, WTN, WTP and WTOC in the younger sections of the cores are most likely caused by short-term climatic events superimposed on long-term climatic changes. Reconstructions of the abundance of taxa typical for different types of ecosystems provided important information about physical processes acting on diatom communities in the bay. Reconstructions of the abundance of diatoms living on different substrata and in the water column need further investigation in order to determine their true habitat preferences, so interpretation of the results should be treated with great caution.

\section{Acknowledgments}

This research was partially supported by a grant to Collins and others from the National Science Foundation through the Division of Earth Science, Geology and Paleontology Program (EAR-071298814), and Florida Coastal Everglades Long Term Ecological Research (FCE-LTER; DEB-9910514). Many thanks are due to colleagues from the Periphyton Lab for their assistance with sample collection, Marci Marot of the USGS for providing sampling logistics, Lynn Wingard and Frank Marshall for many 
valuable comments on the results of this study, and Charles Holmes for providing ${ }^{210} \mathrm{~Pb}$ models and dating of the peat deposits. 
Table 3.1 Radiocarbon dates determined from shells for Trout Cove, Russell Bank, Bob Allen Bank and Ninemile Bank cores. Ages obtained by L. Collins from Beta Analytic Laboratory, Miami, FL.

\begin{tabular}{lcccc}
\hline Core Location & $\begin{array}{c}\text { Core } \\
\text { depth } \\
(\mathrm{cm})\end{array}$ & $\begin{array}{c}\text { Conventional } \\
\text { radiocarbon } \\
\text { age (B.P.) }\end{array}$ & $\begin{array}{c}\text { Two sigma age range } \\
\text { (Cal. Years A.D.) or } \\
\text { *(B.C.) }\end{array}$ & $\begin{array}{c}\text { Two sigma age } \\
\text { range (Cal. Years } \\
\text { B.P.) }\end{array}$ \\
\hline Trout Cove & $60-62$ & $720 \pm 40$ & $1500-1670$ & $450-280$ \\
& $88-90$ & $1690 \pm 40$ & $640-770$ & $1310-1180$ \\
Russell Bank & & & & $240-40$ \\
& $144-146$ & $480 \pm 40$ & $1710-1910$ & $500-320$ \\
& $165-166$ & $780 \pm 40$ & $1450-1620$ & $360-240$ \\
Bob Allen Bank & & & & $480-300$ \\
& $58-60$ & $630 \pm 40$ & $1590-1710$ & $680-560$ \\
& $82-84$ & $760 \pm 40$ & $1470-1650$ & $4080-3850$ \\
& $130-132$ & $1060 \pm 40$ & $1270-1390$ & $4840-4580$ \\
& $188-190$ & $3640 \pm 40$ & $2130-1900^{*}$ & $280-80$ \\
& $201-202$ & $4190 \pm 40$ & $2630-2890^{*}$ & $1690-1510$ \\
& & & & $3480-3330$ \\
& $92-94$ & $550 \pm 40$ & $1670-1870$ & $3040-2770$
\end{tabular}


Table 3.2 Mean salinity, water total nitrogen (WTN), water total phosphorus (WTP) and water total organic carbon (WTOC) in different time periods as determined from diatom assemblages. Zones were determined using stratigraphically constrained cluster analysis using CONISS.

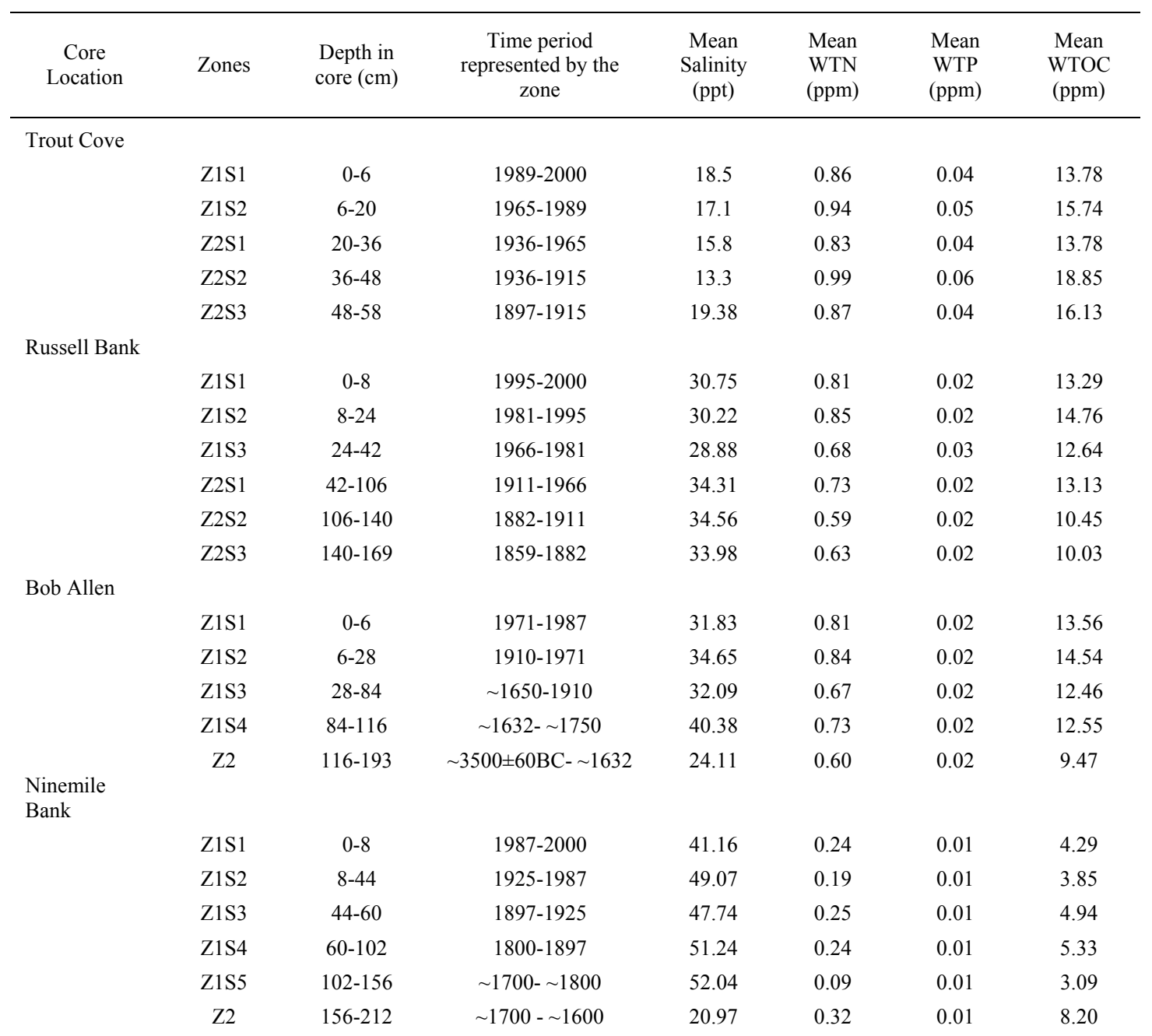




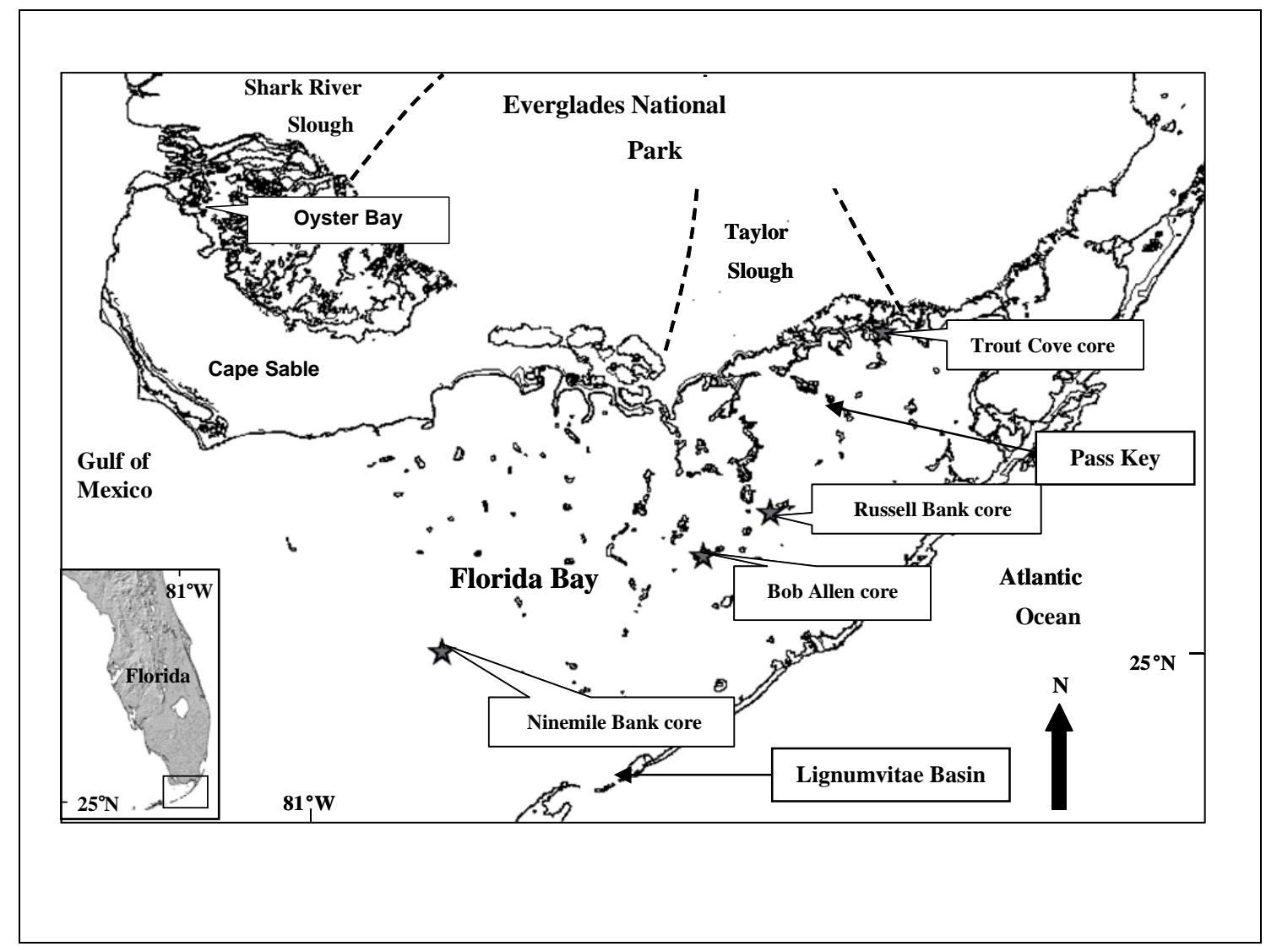

Fig. 3.1 Map of Florida Bay, Florida, showing sediment core locations. 
a)

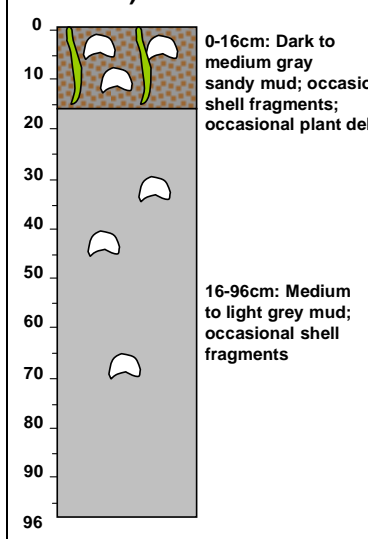

Legend

$\curvearrowright$ Shell and shell fragments

Plant remains b)
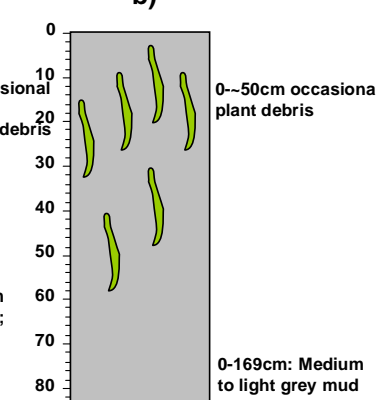

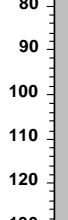

130

150 144-169cm: abundan

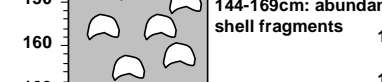

$169=$ c)

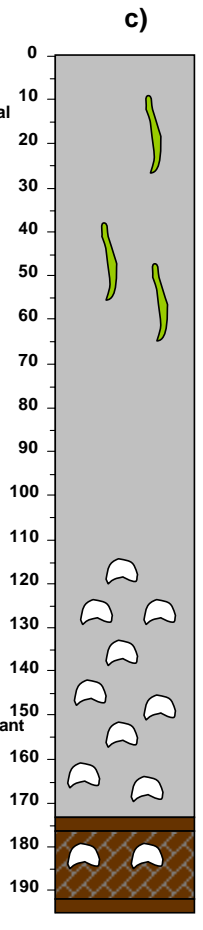

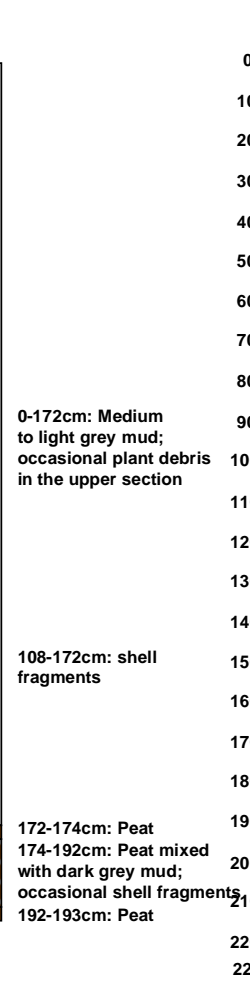

d)

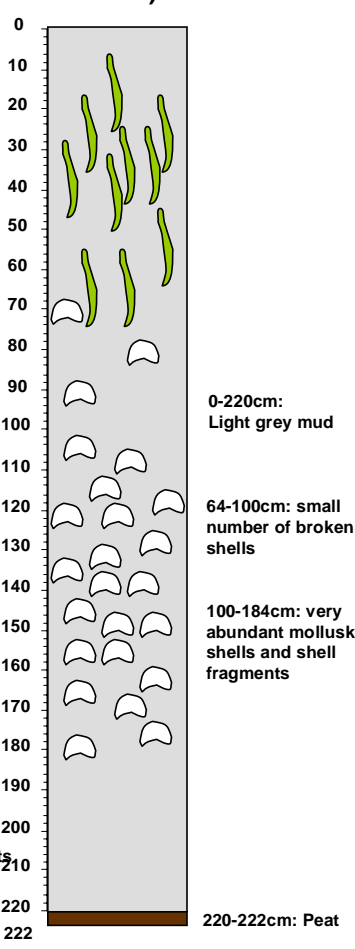

Fig. 3.2 Description of the Trout Cove (a), Russell Bank (b), Bob Allen (c), and Ninemile Bank (d) cores. Depths are in centimeters. 


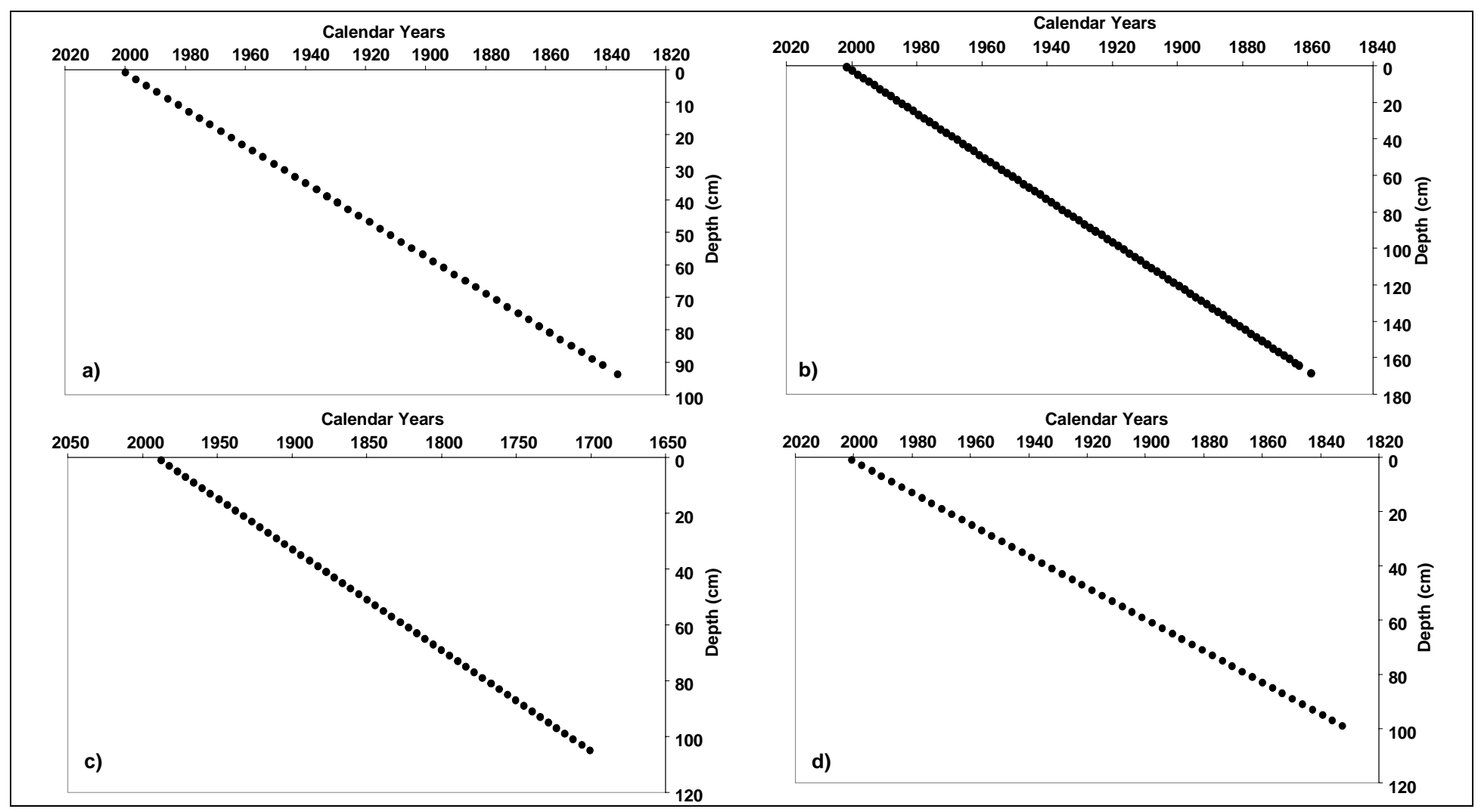

Fig. $3.3{ }^{210} \mathrm{~Pb}$ models for the Trout Cove (a), Russell Bank (b), Bob Allen (c), and Ninemile Bank (d) cores (Charles Holmes, USGS). 


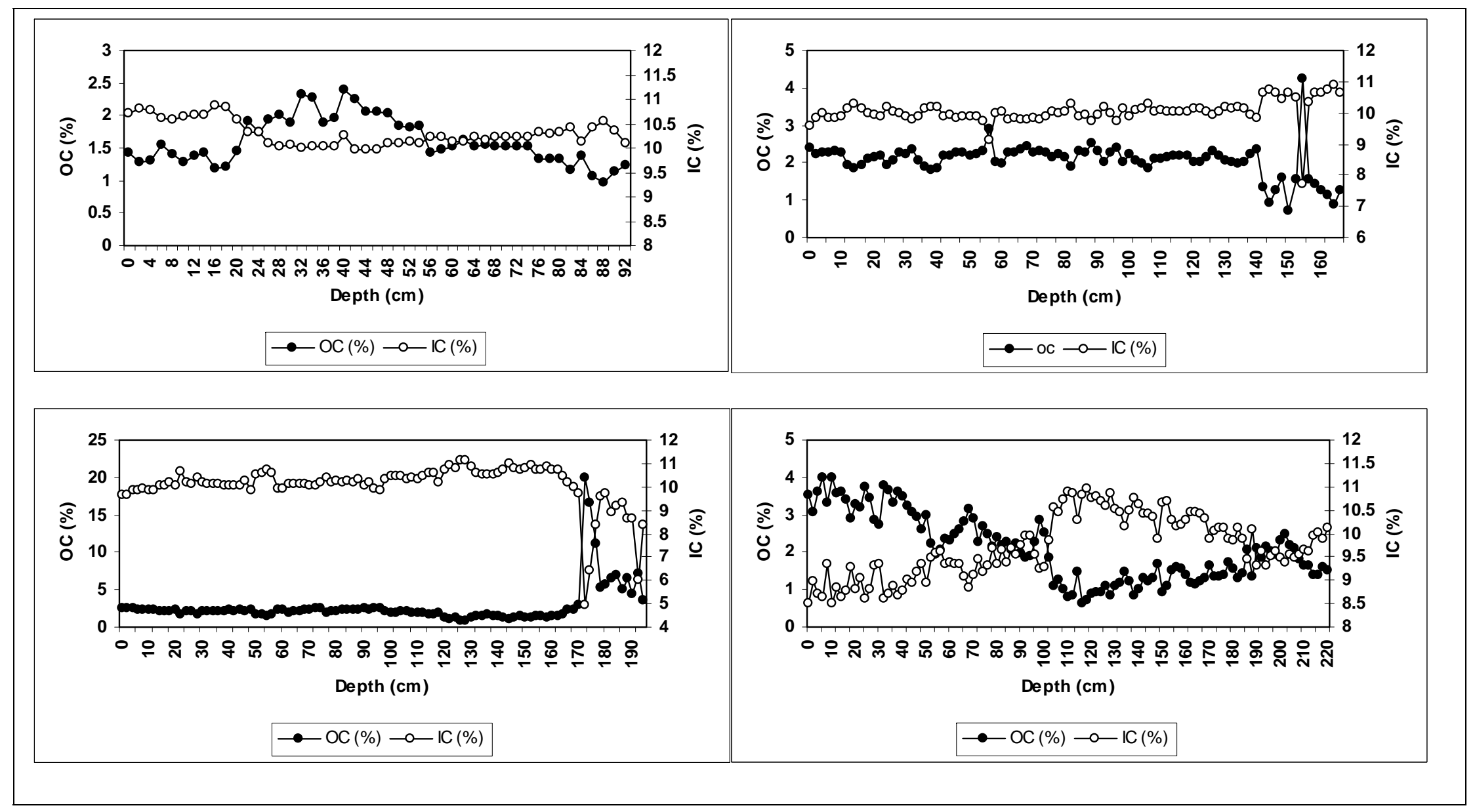

Fig. 3.4 Organic carbon (OC) and inorganic carbon (IC) content in the Trout Cove (a), Russell Bank (b), Bob Allen (c), and Ninemile Bank (d) cores. 


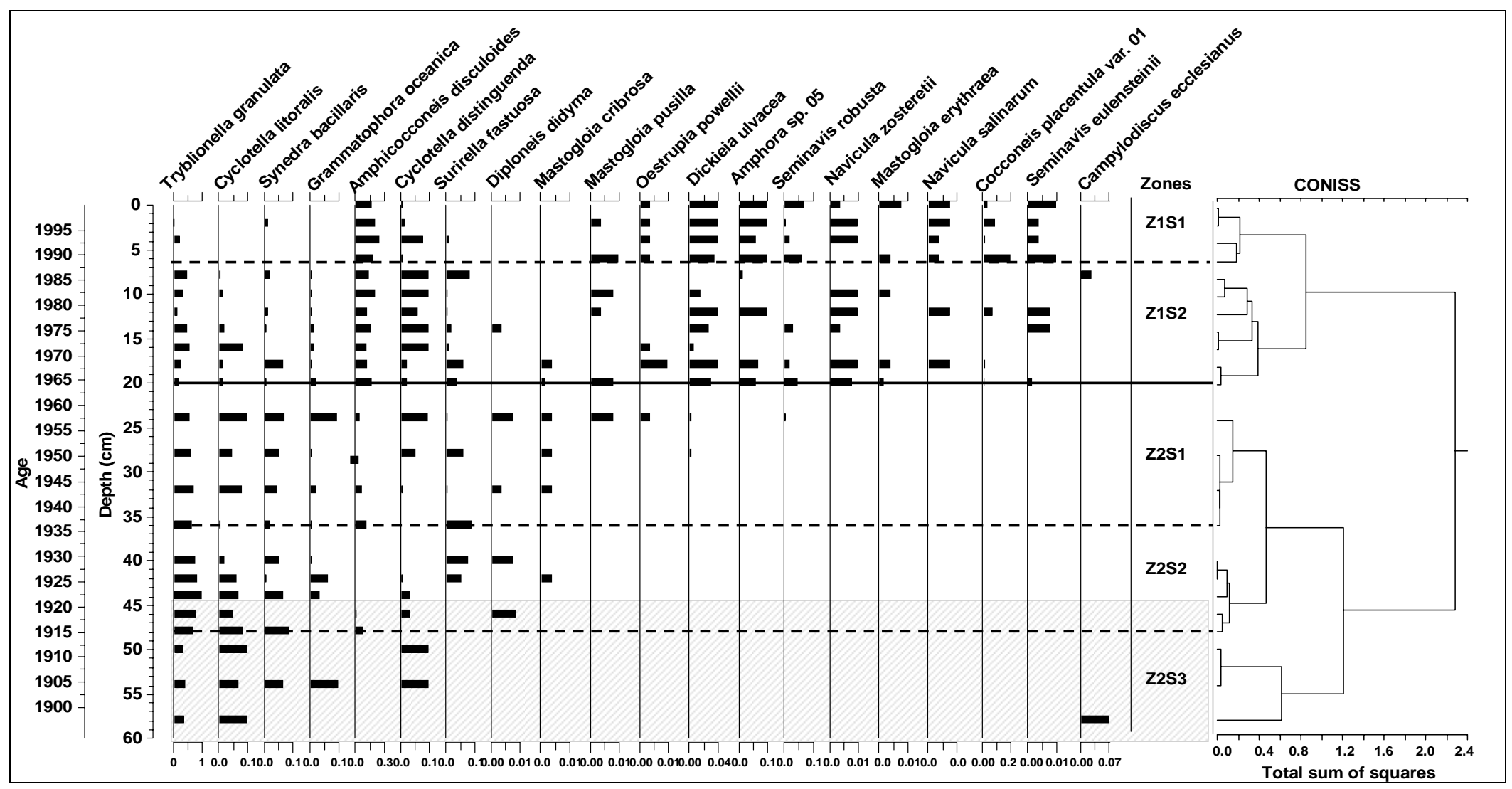

Fig. 3.5 Stratigraphy of the most common diatom taxa in the Trout Cove sediment core. Zones are based on constrained cluster analysis by the method of incremental sum of squares (CONISS). Solid line represents boundary between major clusters and dashed lines represent the boundary between major sub-zones. Gray shading represents levels in the sediment core with very low diatom count. 


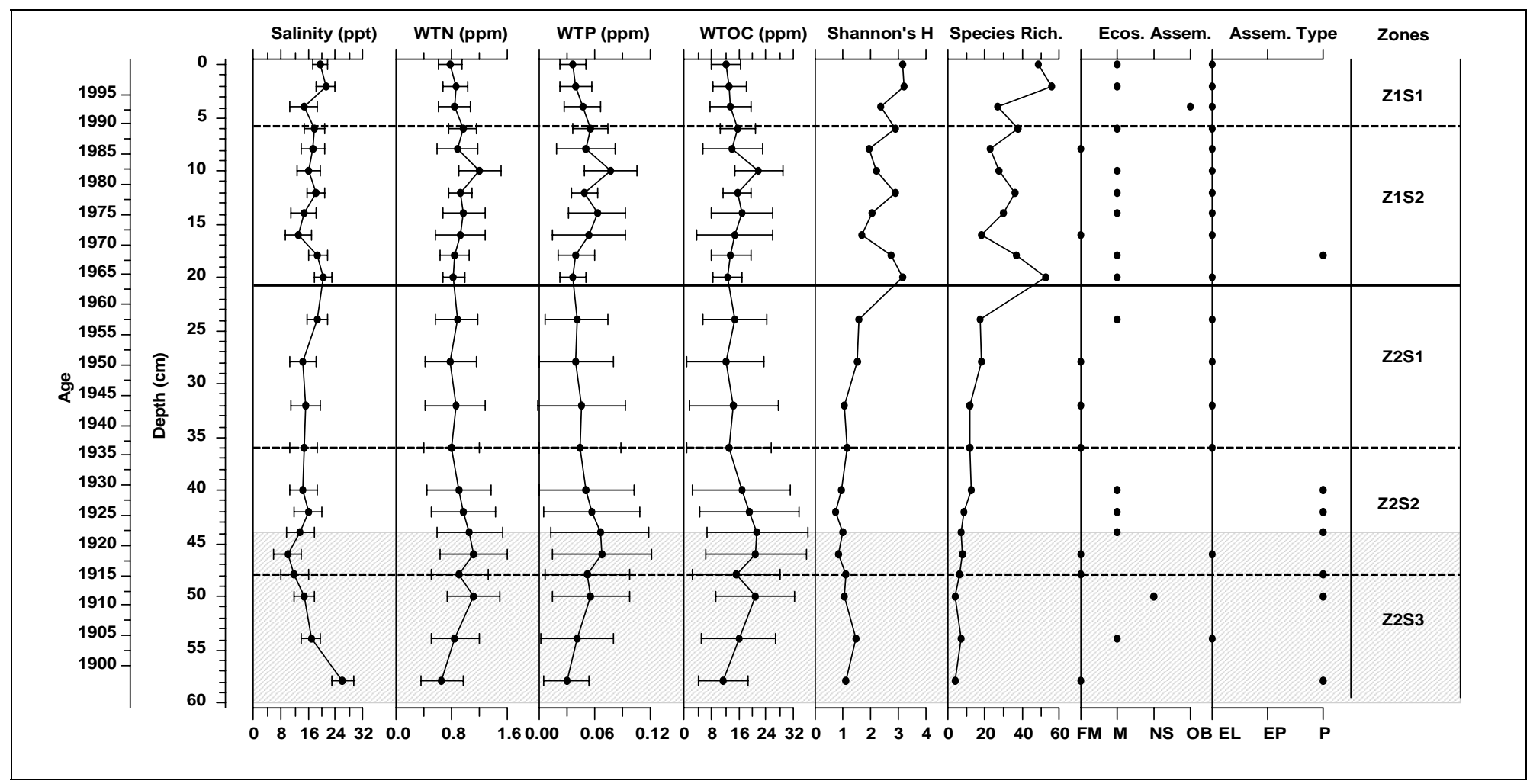

Fig. 3.6 Diatom-inferred salinity, water total nitrogen (WTN), water total phosphorus (WTP), water total organic carbon (WTOC), species richness, species diversity determined by the Shannon-Wiener diversity index, abundance of diatom groups typical for different type of habitats and dominant life habits in the Trout Cove core. Abbreviations:

$\mathrm{FM}=$ freshwater marshes, $\mathrm{M}=$ mangroves, $\mathrm{NS}=$ nearshore, $\mathrm{OB}=$ open-bay, $\mathrm{EL}=$ sediment, $\mathrm{EP}=$ epiphyton, $\mathrm{P}=$ plankton. 


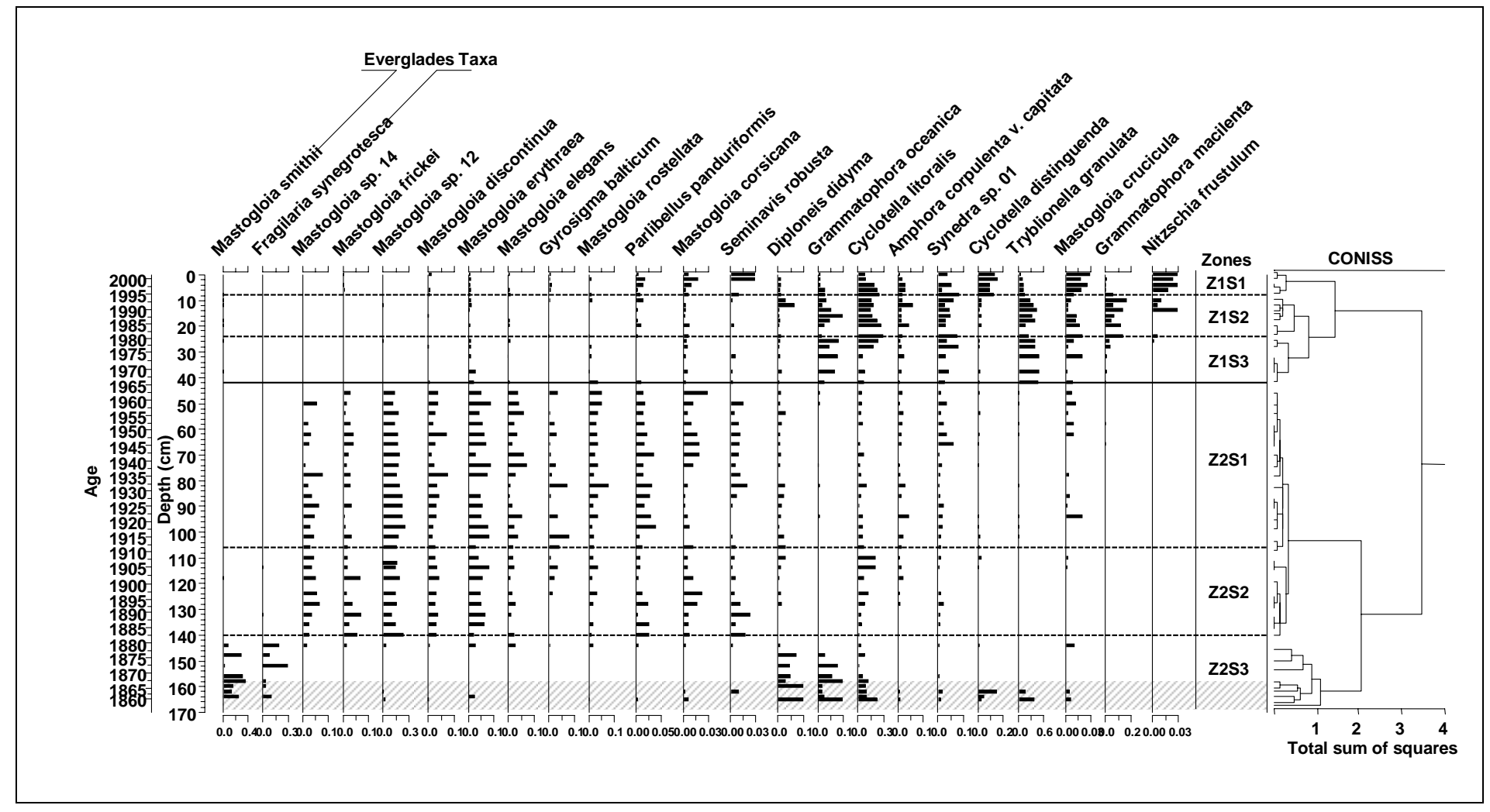

Fig. 3.7 Stratigraphy of the most common diatom taxa in the Russell Bank sediment core. Zones, lines and shadings as in Fig. 3.5. 


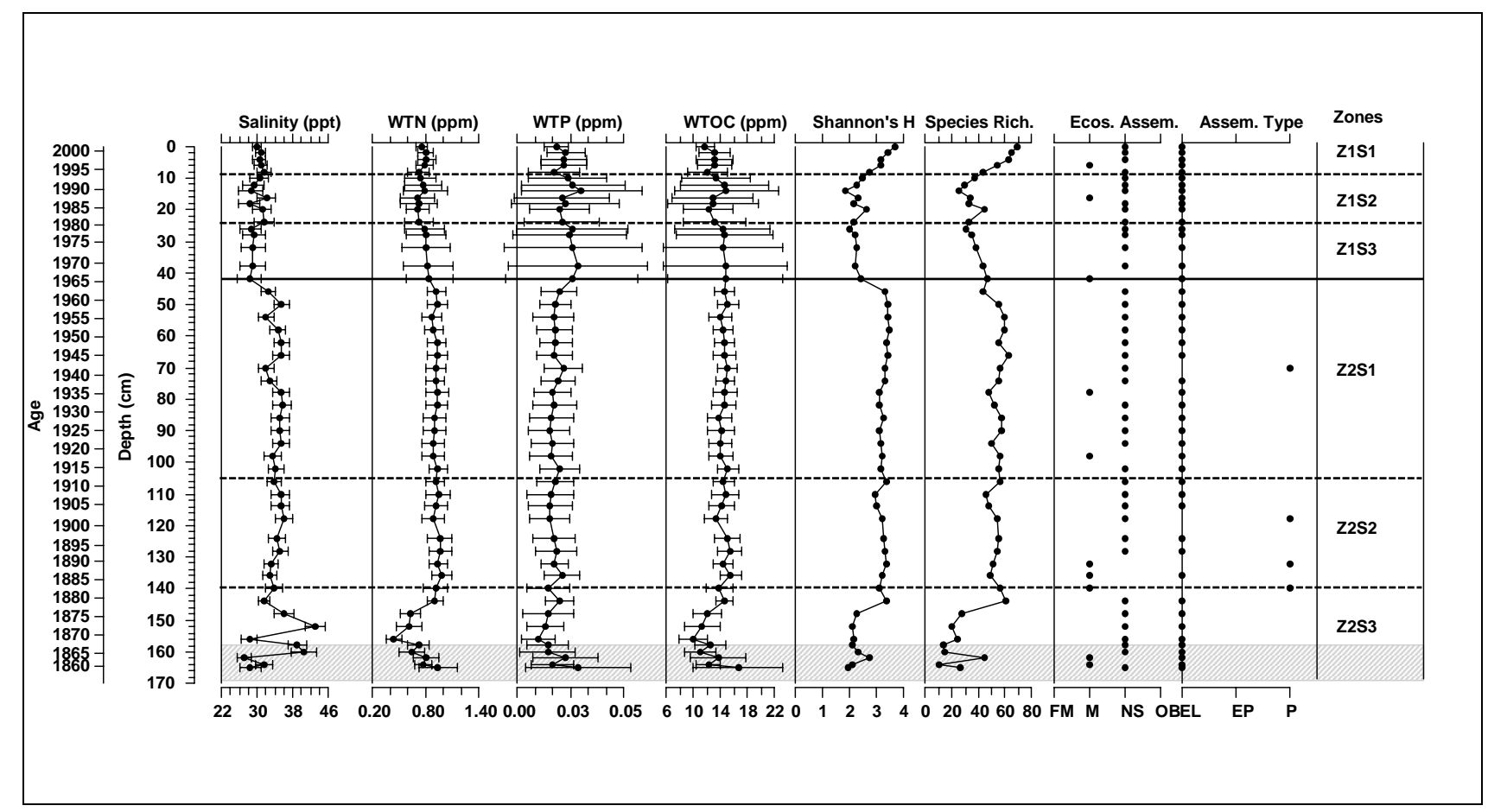

Fig. 3.8 Diatom-inferred salinity, water total nitrogen (WTN), water total phosphorus (WTP), water total organic carbon (WTOC), species richness, species diversity determined by the Shannon-Wiener diversity index, abundance of diatom groups typical for different type of ecosystems and dominant assemblage types in the Russell Bank core. Abbreviations as in Fig. 3.6. 


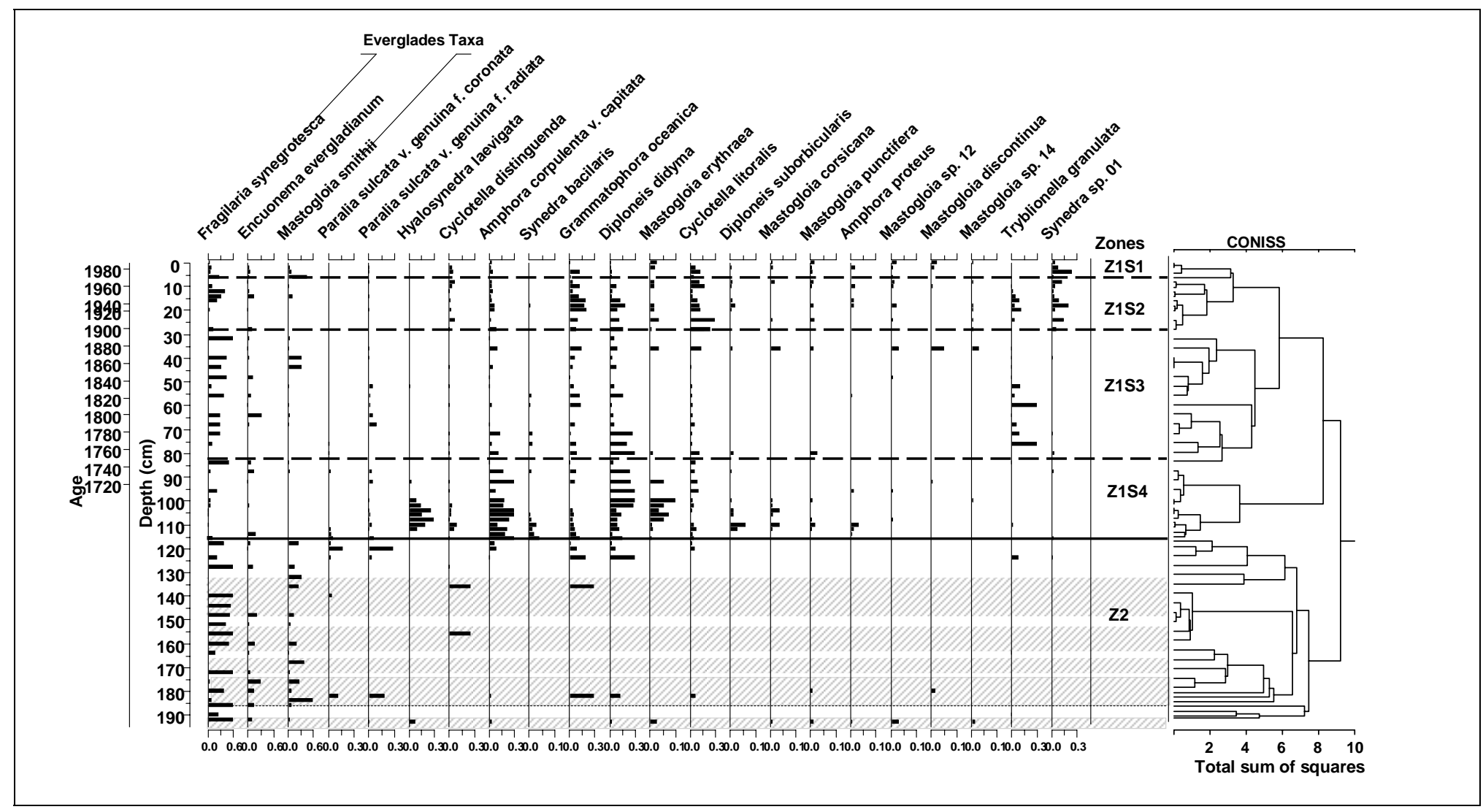

Fig. 3.9 Stratigraphy of the most common diatom taxa in the Bob Allen sediment core. Zones, lines and shadings as in

Fig. 3.5. 


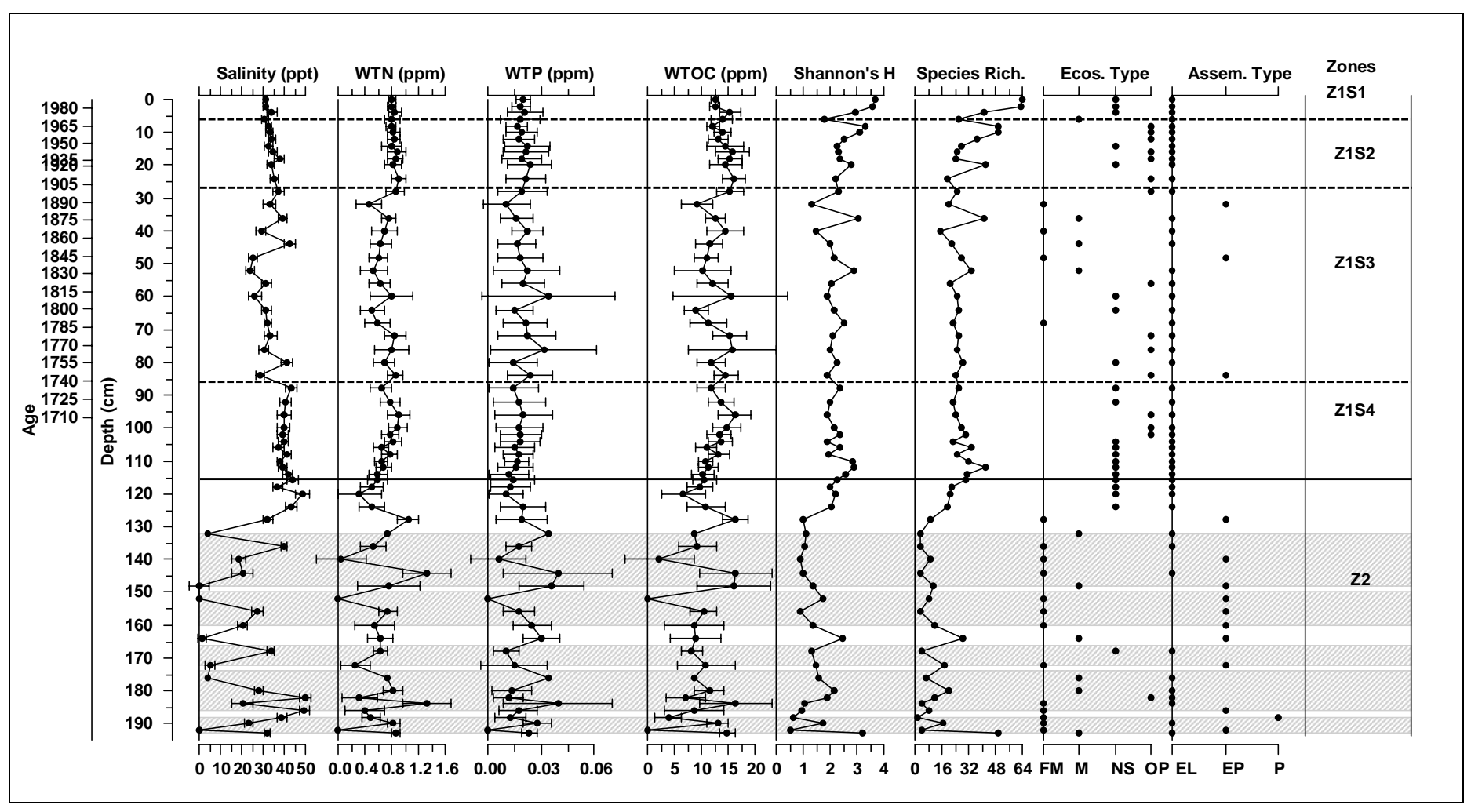

Fig. 3.10 Diatom inferred salinity, water total nitrogen (WTN), water total phosphorus (WTP), water total organic carbon (WTOC), species richness, species diversity determined by the Shannon-Wiener diversity index, abundance of diatom groups typical for different type of ecosystems and dominant assemblage types in the Bob Allen core. Abbreviations as in Fig. 3.6. 


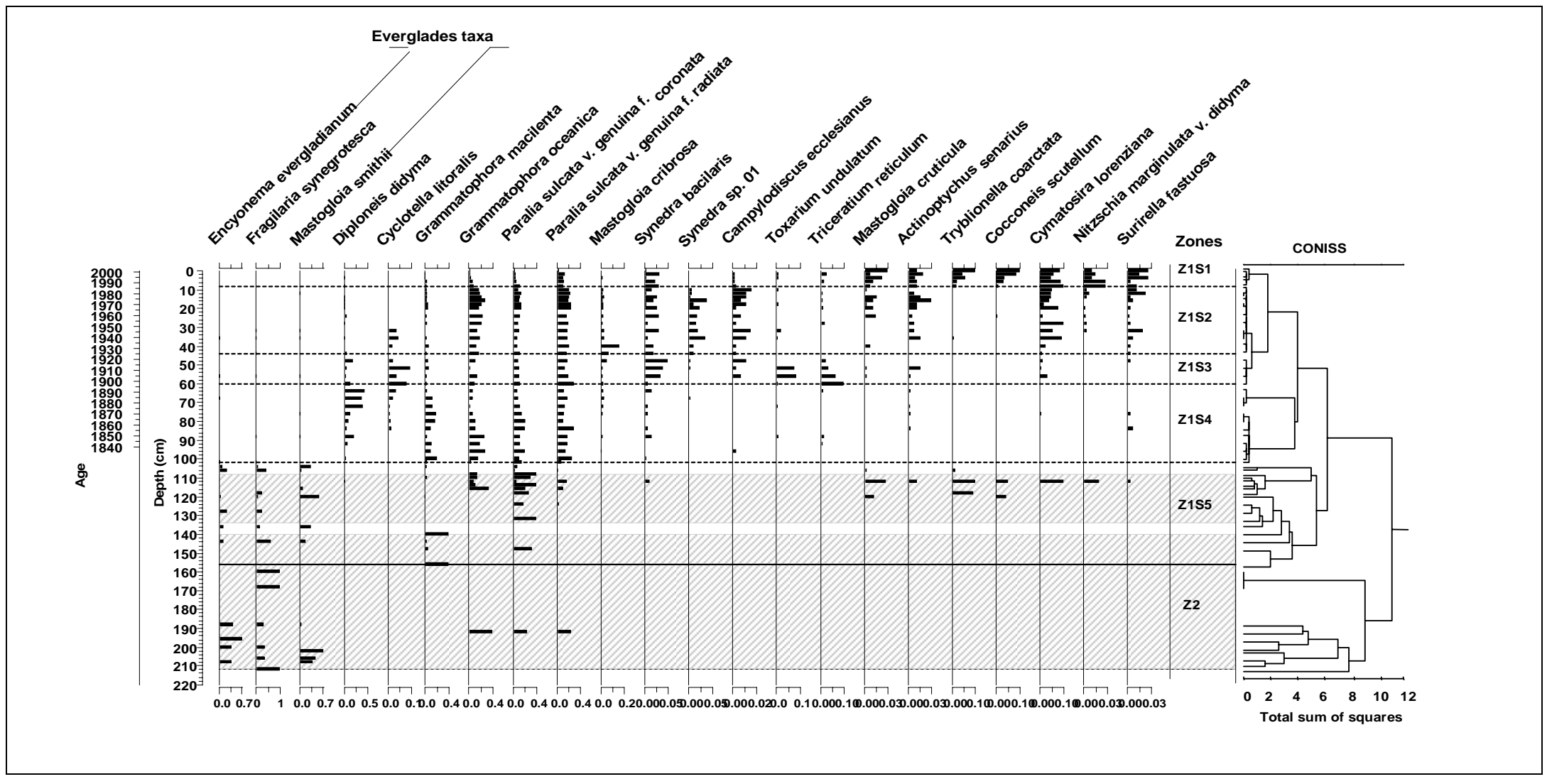

Fig. 3.11 Stratigraphy of the most common diatom taxa in the Ninemile Bank sediment core. Zones, lines and shadings as in Fig. 3.5. 


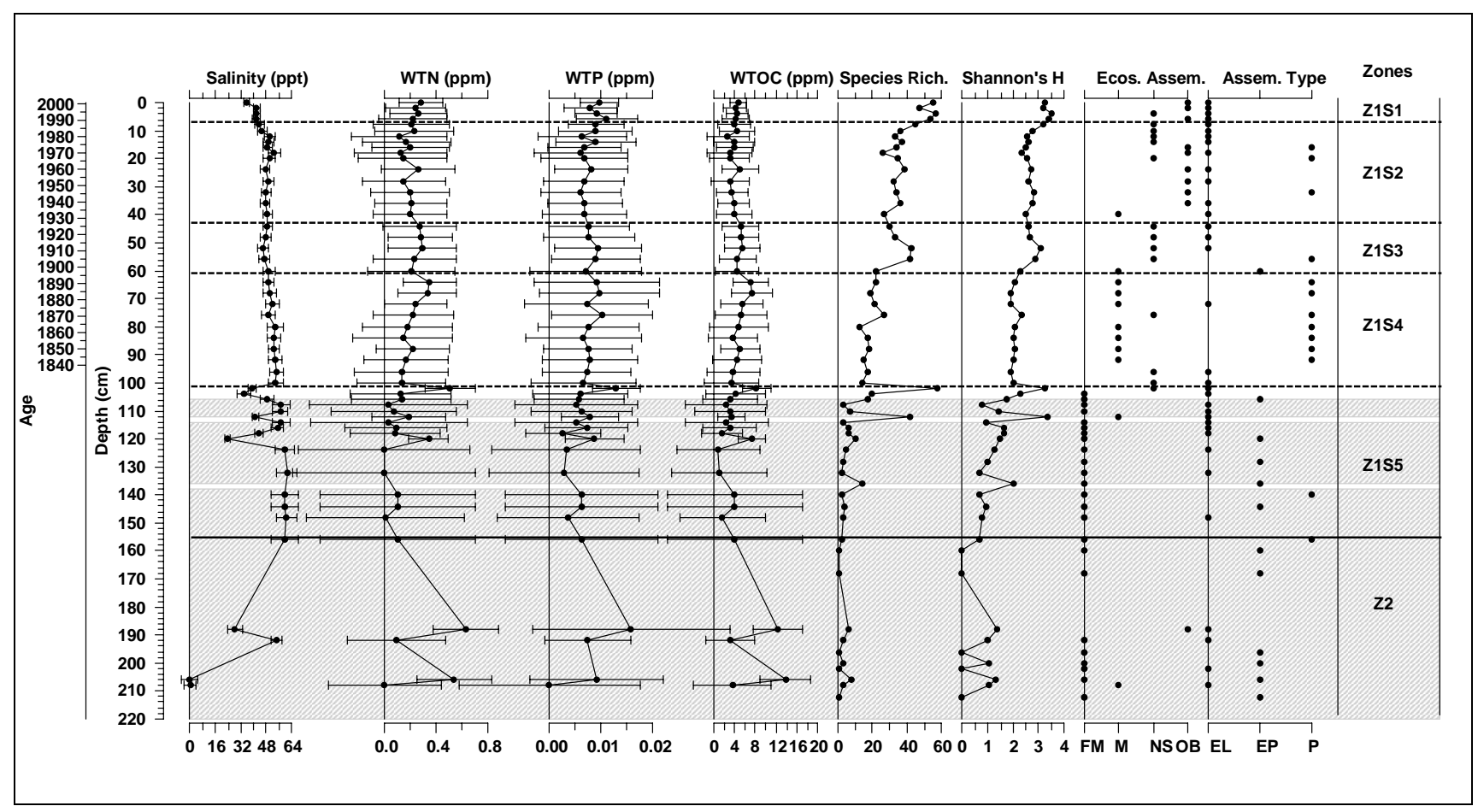

Fig. 3.12 Diatom inferred salinity, water total nitrogen (WTN), water total phosphorus (WTP), water total organic carbon (WTOC), species richness, species diversity determined by the Shannon-Wiener diversity index, abundance of diatom groups typical for different type of ecosystems and dominant assemblage types in the Ninemile Bank core. abbreviations as in Fig. 3.6. 

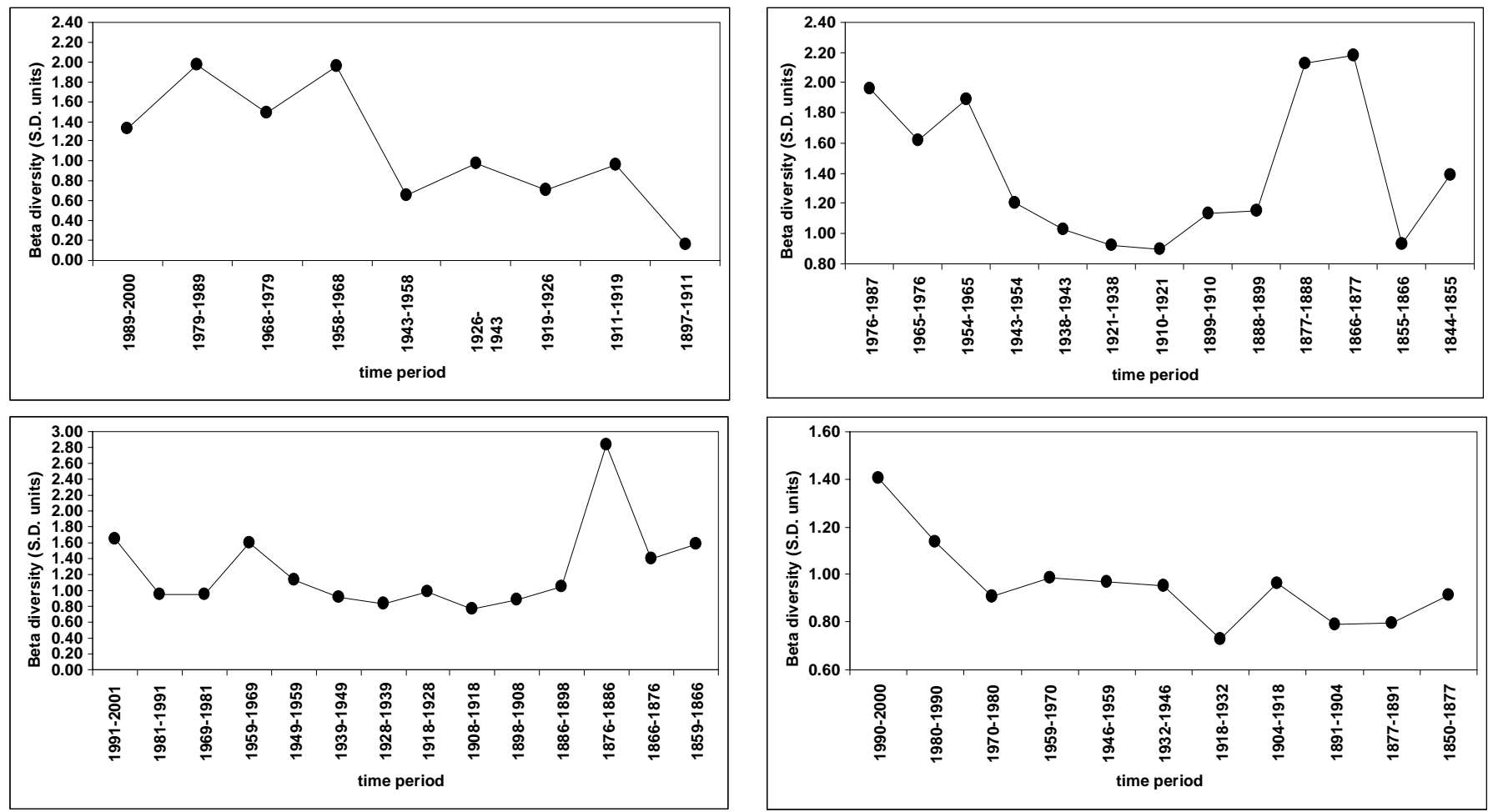

Fig. 3.13 Changes in $\beta$-diversity (species turnover rate) over time in Trout Cove (a), Russell Bank (b), Bob Allen (c), and Ninemile Bank (d) cores. 


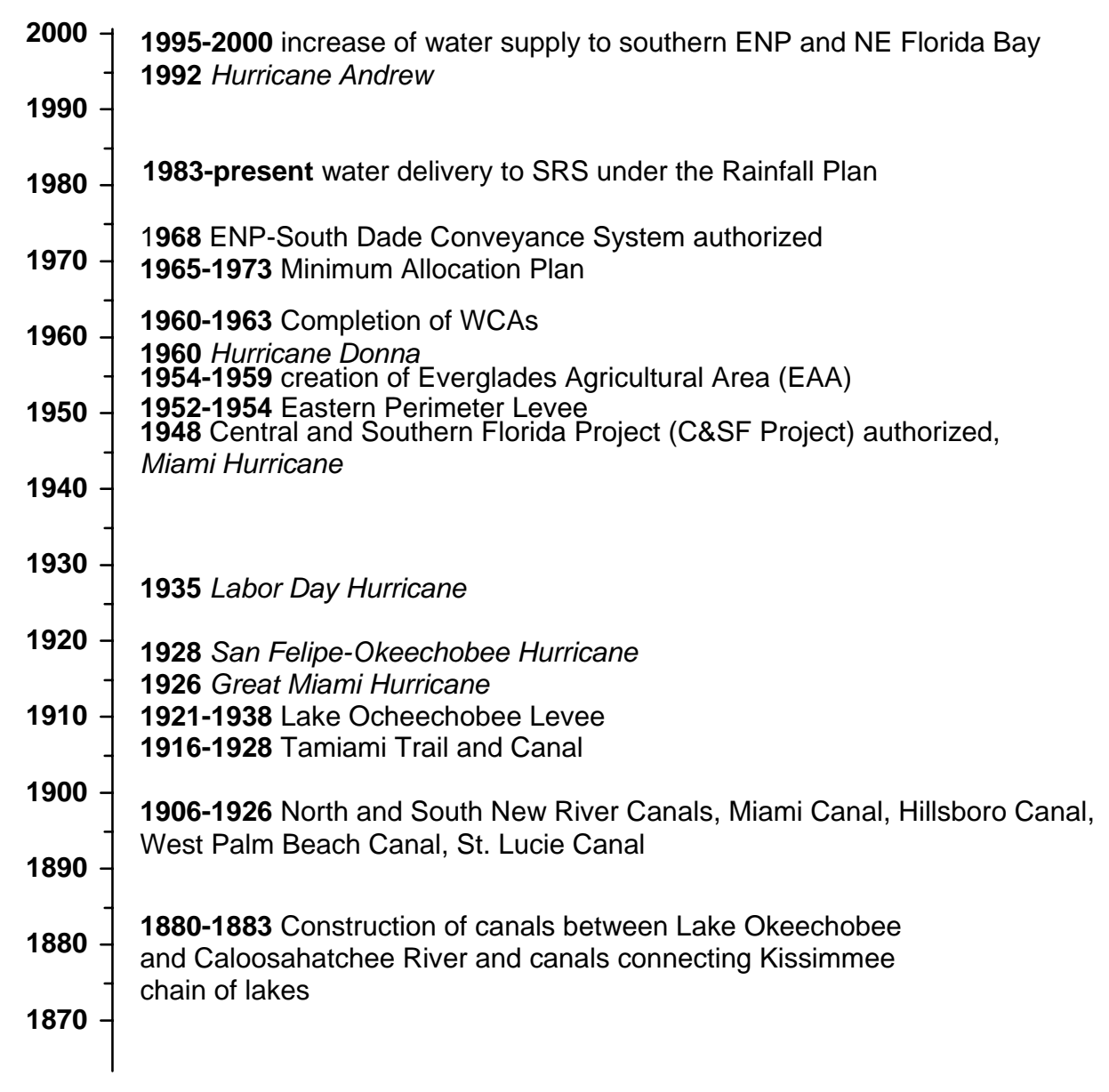

Fig. 3.14 Major constructions plans and hurricane events that affected Everglades and adjacent estuaries landscape and hydrology. 


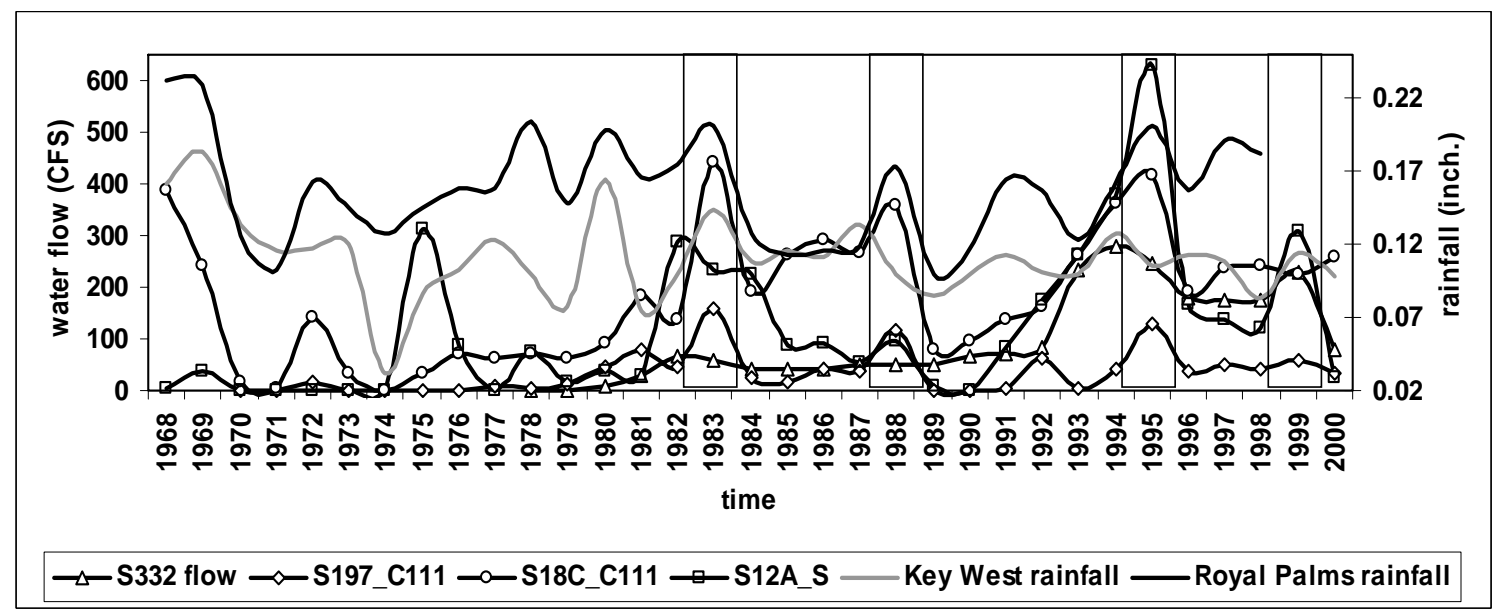

Fig. 3.15 Changes of water flow from major South Florida Water Management District structures into the Everglades and fluctuations of rainfall at two stations in South Florida (http://www.sfwmd.gov/). Highlighted areas indicate co-occurance of increased rainfall and water flow from the canals. 


\section{REFERENCES}

Alongi, D.M. 1998. Coastal ecosystem processes. CRC Press New York, pp. 419

Alvarez Zarikian, C.A., P.K. Swart, T. Hood, P.L. Blackwelder, T.A. Nelsen, and C. Featherstone. 2001. A Century of Variability in Oyster Bay using Ostracode Ecological and Isotopic Data as Paleoenvironmental Tools. Bulletins of American Paleontology 361:133-143.

Battarbee, R.W. 1986. Diatom analysis. In: B.E. Berglund (Editor), Handbook of Holocene Palaeoecology and Palaeohydrology. The Blackburn Press, Caldwell, New Jersey, USA, pp. 527-570.

Bennet P.C. 1991. Quartz dissolution in organic-rich aqueous systems. Geochim. Cosmochim. Acta 55:1781-1797

Bianchi, T. 2003. Biochemistry of estuaries. New York: Oxford University Press, pp. 706.

Bosence, D. 1989. Biogenic carbonate production in Florida Bay. Bulletin of Marine Science 44(1):419-433.

Björck, S., and B. Wohlfarth. 2001. ${ }^{14} \mathrm{C}$ chronostratigraphic techniques in paleolimnology. In: Last, W. M. \& J. P. Smol (eds.), Tracking Environmental Change Using Lake Sediments. Volume 1: Basin Analysis, Coring, and Chronological Techniques, Kluwer Academic Publishers, Dordrecht, The Netherlands, pp. 205-245.

Brandenberger, J.M., E.A. Crecelius, P. Louchouarn, S.R. Cooper, K. McDougall, E. Leopold, and G. Liu. 2008b. Reconstructing trends in hypoxia using multiple paleoecological indicators recorded in sediment cores from Puget Sound, WA. National Oceanic and Atmospheric Administration, Pacific Northwest National Laboratory Report No. PNWD-4013.

Brewster-Wingard, G.L., and S.E. Ishman. 1999. Historical trends in salinity and substrate in central and northern Florida Bay: a paleoecological reconstruction using modern analogue data: Estuaries 22:369-383.

Brewster-Wingard, G.L., J.R. Stone, and C.W. Holmes. 2001. Molluscan faunal distribution in Florida Bay, past and present: an integration of down-core and modern data. Bulletins of American Paleontology 361:199-231.

Clarke, K.R., and R.M. Warwick. 2001. Change in marine communities: an approach to statistical analysis and interpretation. Primer-E Ltd. Plymouth. 
Clarke K R., and R.N. Gorley. 2001. Primer v5: user manual/tutorial. - Primer-E Ltd. Plymouth.

Conley, D.J., and C.L. Schelske. 1989. Processes controlling the benthic regeneration and sedimentary accumulation of biogenic silica in Lake Michigan. Arch. Hydrobiologia 116:23-43.

Cooper, S.R., and G.S. Brush. 1993. A 2500 year history of anoxia and eutrophication in Chesapeake Bay. Estuaries 16:617-626.

Cooper, S.R. (1995). Chesapeake Bay watershed historical land use: impact on water quality and diatom communities. Ecological Applications 5:703-723.

Cronin, T.M., C.W. Holmes, G.L. Brewster-Wingard, S.E. Ishman, H.J. Dowsett, D. Keyser, and N. Waibel. 2001. Historical trends in epiphytal ostracodes from Florida Bay: Implication for seagrss and macro-benthic algal variability, In: B.R. Wardlaw (Editor), Paleoecological Studies of South Florida: Bulletins of American Paleontology 361:159198.

Cronin, T.M., G.S. Dwyer, S.B. Schwede, C.D. Vann, and H. Dowsett. 2002, Climate variability from the Florida Bay sedimentary record: possible teleconnections to ENSO, PNA, and CNP. Climate Research 19:233-245.

Davies, T.D. 1980. Peat formation in Florida Bay and its significance in interpreting the recent vegetation and geological history of the bay area. Ph. D. Dissertation, The Pennsylvania State University, University Park, Pennsylvania. pp. 338.

Davies, T.D., and A.D. Cohen. 1989. Composition and significance of the peat deposits ofFlorida Bay, Bulletin of Marine Science 44:387-398.

Douglas, M. 1998. The Everglades: river of grass. Pineapple Pr Inc Sarasota, Florida, U.S.A. pp. 447.

Dwyer, G.S., and T.M. Cronin. 2001. Ostracode Shell Chemistry as a Paleosalinity Proxy in Florida Bay. Bulletins of American Paleontology 361:249-276.

Enos, P., and R.D. Perkins. 1979. Evolution of Florida Bay from island stratigraphy: Geological Society of America Bulletin, Part I, v. 90, p. 59-83.

Flower, R.J. 1993. Diatom preservation: experiments and observations on dissolution and breakage in modern and fossil material. Hydrobiologia 269/270:473-484.

Flower, R.J., C. Stickley, N.L. Rose, S.M. Peglar, A.A. Faathi, and P.G. Appleby. 2006. Environmental Changes at the Desert Margin: An Assessment of Recent 
Paleolimnological Records in Lake Qarun, Middle Egypt. Journal of Paleolimnology $35: 1-24$.

Fourqurean, J.W., and M. Robblee. 1999. Florida Bay: A history of recent ecological changes. Estuaries 22:345-357.

Fourqurean, J.W., M.J. Duraco, M.O. Hall, and L.N. Hefty. 2001. Seagrass distribution in South Florida: a multi-agency coordinated monitoring program. In The Everglages, Florida Bay, and Coral Reefs of the Florida Keys. An Ecosystem Sourcebook, pp. 497522.

Gaiser, E.E., J.H. Richards, J.C. Trexler, R.D. Jones, and D.L. Childers. 2006. Periphyton responses to eutrophication in the Florida Everglades: Cross-system patterns of structural and compositional change. Limnology and Oceanography 51:617-630.

Gottlieb, A.D., J.H. Richards, and E.E. Gaiser. 2006. Comparative study of periphyton community structure in long and short hydroperiod Everglades marshes. Hydrobiologia 569:195-207.

Grimm, E. 1987. CONISS: A Fortran 77 program for stratigraphically constrained cluster analysis by the method of incremental sum of squares. Comput. Geosci. 13:13-35.

Harwell, M.A. 1998. Science and environmental decision making in South Florida. Ecological Applications 8:580-590.

Hobbie J.E. 2000. Estuarine Science, a synthetic approach to research and practice. Island Press, Washington, D.C. pp. 539.

Holmes, C.W., D.A. Willard, G.L. Brewster-Wingard, M.E. Marot. 1999. Buttonwood Embankment: the historical perspective on its role in northeastern Florida Bay sedimentary dynamics and hydrology. In Programs and Abstracts-1999 Florida Bay and Adjacent Marine Systems Science Conference. pp. 166-168

Horton, B.P., Y. Zong, C. Hillier, and S. Engelhart. 2007. Diatoms from Indonesian mangroves and their suitability as sea-level indicators for tropical environments. Marine Micropaleontology 63:155-168.

Howarth, R. W., D. Walker, and A. Sharpley. 2002. Sources of nitrogen pollution to coastal waters of the United States. Estuaries 25:656-676.

Huvane, J.K., and S.R. Cooper. 2001. Diatoms as indicators of environmental change in sediment cores from Northeastern Florida Bay. Bulletins of American Paleontology 361:145-158. 
Juggins, S. 1992. Diatoms in the Thames Estuary, England: ecology, paleoecology, and salinity transfer function. J. Cramer, Berlin-Stuttgard, pp. 216.

Juggins, S. 2005. The C2 Software for Ecological and Palaeoecological Data Analysis and Visualisation. University of Newcastle, Newcastle-upon-Tyne, United Kingdom.

Kuylenstierna, M. 1990. Benthic algal vegetation in the Nordre lv Estuary (Swedish west coast) 2 volumes. PhD. Dissertation, University of G tesburg, G tesburg, Sweden.

Light, S.S., and J.W. Dineen. 1994. Water control in the Everglades: A historical perspective. In (Davis, S.M., and J.C. Ogden, (eds.). Everglades, the Ecosystem and its Restoration, St. Lucie Press, pp. 47-84.

Lodge T.E. 2005. The Everglades handbook - understanding the ecosystem. Boca Raton, FL: CRC Press, pp. 336.

Lotze, H.K., H.S. Lenihan, B.J. Bourque, R.H. Bradbury, R.G. Cooke, M.C. Kay, S.M. Kidwell, M.X. Kirby, C.H. Peterson, and J.B.C. Jackson. 2006. Depletion, Degradation, and Recovery Potential of Estuaries and Coastal Seas. Science Magazine 312:1806-1809.

McCune, B., and J.B. Grace. 2002. Analysis of Ecological Communities. MJM Software Design, Gleneden Beach, Oregon.

McQuoid, M.R. and L.A. Hobson. 1998. Assessment of palaeoenvironmental conditions on southern Vancouver Island, British Columbia, Canada, using the marine tychoplankter "Paralia sulcata". Diatom Research 13:311-321.

McQuoid, M.R., and K. Nordberg. 2003. The diatom Paralia sulcata as an environmental indicator species in coastal sediments. Estuarine, Coastal and Shelf Science 2:339-354.

Nelsen, T.A., G. Garte, and C. Featherstone. 2002. Linkages between the South Florida peninsula and coastal zone: a sediment-based history of natural and anthropogenic influences. In Porter, J.W., and Porter, K.G., (eds.), Everglades, Florida Bay and Coral Reefs of the Florida Keys: An Ecosystem Sourcebook, CRC Press, Boca Raton Florida, pp. 415-449.

Olsson, I.U. 1986. Radiometric dating, in BE Berglund (ed.), Handbook of Holocene Palaeoecology and Palaeohydrology, Chichester and New York: John Wiley, pp. 273312.

O'Quinn, S.R., and M.J. Sullivan. 1983. Community structure dynamics of epilithic and epiphytic diatoms in a Mississippi stream. Journal of Phycology 19:123-128.

Orem, W.H., C.W. Holmes, C. Kendall, H.E. Lerch, A.L. Bates, S.R. Silva, A. Boylan, M. Corum, and C. Hedgman. 1999. Geochemistry of Florida Bay sediments: nutrient 
history at five sites in eastern and central Florida Bay. Journal Coastal Research 15:10551071.

Quinn, G.P., and M.J. Keough. 2002. Experimental design and data analysis for biologists. Cambridge, UK Cambridge University Press, Relyea, RA.

Pyle, L., S.R. Cooper, and J.K. Huvane. 1998. Diatom paleoecology Pass Key core 37, Everglades National Park, Florida Bay. Open-File Report 98-522, pp 38.

Ricklefs, R.E.2000. The Economy of Nature. 5th ed. W.H. Freeman and Company: New York.

Ryves, D.B., S. Juggins, S.C. Fritz, and R.W. Battarbee. 2001. Experimental diatom dissolution and the quantification of microfossil preservation in sediments.

Palaeogeography, Palaeoclimatology, Palaeoecology 172:99-113.

Saunders, K.M., A. Mcminn, D. Roberts, D.A. Hodgson, and H. Heijnis. 2007. Recent human-induced salinity changes in Ramsar-listed Orielton Lagoon, south-east Tasmania, Australia: a new approach for coastal lagoon conservation and management. Aquatic Conservation: Marine and Freshwater Ecosystems 17:51-70.

Sklar, F., C. McVoy, R. VanZee, D.E. Gawlik, K. Tarboton, D. Rudnick, and S. Miao. In The Everglages, Florida Bay, and Coral Reefs of the Florida Keys. An Ecosystem Sourcebook, pp. 39-82.

Smith, T.J., III., H. Hudson, M.B. Robblee, G.V.N. Powel, and P.J. Isdale. 1989. Freshwater flow from the Everglades to Florida Bay: a historical reconstruction based on fluorescent banding in the coral Soleastrea bournoni. Bulletin of Marine Science 44:274282.

Swart, P.K., G. Healy, R.E. Dodge, P. Kramer, J.H. Hudson, R.B. Halley, and M.B. Robblee. 1996. The stable oxygen and carbon isotopic record from a coral growing in Florida Bay: A 160 year record of climatic and anthropogenic influence.

Palaeogeography, Palaeoclimatology, Palaeoecology, 123:219-237.

Swart, P.K., G. Healy, L. Greer, M. Lutz, A. Saied, D. Anderegg, R.E. Dodge, and D. Rudnick. 1999. The use of proxy chemical records in coral skeletons to ascertain past environmental conditions in Florida Bay. Estuaries 22:384-397.

Ter Braak, C.J.E. 1986. Canonical correspondence analysis: a new eigenwector technique for multivariate direct gradient analysis. Ecology 67:1167-1179.

Ter Braak, C.J.F., and P. Šmilauer, 2002. CANOCO Reference manual and CanoDraw for Windows user's guide: Software for Canonical Community Ordination (version 4.5), Microcomputer Power, Ithaca, NY, USA. 
Wanless, H., R. Parkinson, and L. Tedesco. 1994. Sea level control on stability of Everglades wetlands: Everglades, the Ecosystem and its Restoration: St. Luci Press, Delray Beach, Florida.

Weckström, K., and S. Juggins. 2005. Coastal diatom-environment relationships from the Gulf of Finland, Baltic Sea. Journal of Phycology 42:21-35.

Wingard, G.L., J.W. Hudley, C.W. Holmes, D.A. Willard, and M. Marot. 2007. Synthesis of age data and chronology for Florida Bay and Biscayne Bay cores collected for ecosystem history of South Florida's estuaries project. Open File Report 2007-1203.

Willard, A., L. Brewster-Wingard, C. Fellman, and S.E. Ishman. 1997. Paleonthological data from Mud Creek Core 1, South Florida. USGS Open-File Report 97-736, Reston, VA, U.S.A.

Witak M., A. Wachnicka, A. Kuijpers, S. Troelstra, M.A. Prins, and A. Witkowski. 2005. Holocene North Atlantic surface circulation and climate variability: Evidence from diatom records, The Holocene 15(1):85-96.

Zong, Y., J.M. Lloyd, M.J. Leng, W.W.-S. Yim, and G. Huang. 2006. Reconstruction of Holocene monsoon history from the Pearl River Estuary, southern China, using diatoms and carbon isotope ratios: The Holocene 16:251-263.

Xu, Y., R. Jaffe, A. Wachnicka, and E. Gaiser. 2006. Occurrence of C25 highly branched isoprenoids (HBIs) in Florida Bay: Paleoenvironmental indicators of diatom-derived organic matter inputs. Organic Geochemistry 37:847-859.

Xu, Y. C.W. Holmes, and R. Jaffe. 2007. Paleoenvironmental assessment of recent environmental changes in Florida Bay, USA: A biomarker based study. Estuarine, Coastal, and Shelf Science 73:201-210. 


\section{CHAPTER 4. DEVELOPMENT OF DIATOM-BASED PREDICTION MODELS FOR}

\section{ASSESSMENT OF PAST WATER QUALITY IN BISCAYNE BAY, U.S.A.}

Abstract

The spatial and temporal distribution of planktonic, benthic and epiphytic diatoms among 58 sites during two seasons in Biscayne Bay, Florida was examined in order to develop assessment models for salinity and water quality for this region. Cluster analysis distinguished nearshore from off-shore assemblages that were more distinct during the wet season than the dry season. Among a suite of measured physico-chemical variables, salinity, water depth, and sediment total phosphorus (STP) most greatly influenced diatom distribution in the dry season, while salinity, $\mathrm{pH}$, STP and water total phosphorus (WTP) were the most important driving variables in the wet season. Because water concentrations of salts, total phosphorus (WTP), total nitrogen (WTN) and total organic carbon (WTOC) are partly controlled by water management in this region, I produced diatom-based models to assess these variables in modern and retrospective assessments. Weighted averaging partial least squares (WA-PLS) regression produced reliable estimates of salinity, WTP, WTN and WTOC from diatoms $\left(\mathrm{r}^{2}=0.91,0.78,0.76\right.$ and 0.83 , respectively). A discriminant function (DF) analysis demonstrated that diatoms can also be used to infer changes in the distribution of ecological zones and habitat availability in the bay. 


\subsection{Introduction}

Coastal and estuarine environments are among the most productive and valuable aquatic ecosystems on Earth. They serve as feeding and nursery areas for many aquatic organisms, and are home to many species of aquatic plants (Costanza et al. 1997). Due to the growing human population in nearshore areas, these dynamic and variable environments have increasingly been threatened by anthropogenic impacts (Carnahan et al. 2008).

In the historical past, Biscayne Bay, Southeast Florida was bordered by expansive coastal mangroves and herbaceous freshwater marshes, and was fed by freshwater coming from the Everglades via the transverse glades. The bay also received fresh groundwater through artesian upwelling, which formed freshwater "boils" in the bay (Graves et al. 2005; Browder et al. 2005). Environmental conditions in Biscayne Bay changed in response to the rapid population growth along the southeast Florida coast (especially in the $20^{\text {th }}$ century) with the construction of canals and levees which provide drainage and flood protection (Graves et al. 2005). This situation led to almost complete elimination of the natural sheet and ground freshwater discharges into Biscayne Bay and lowering of regional and coastal water tables by approximately 1 to $3 \mathrm{~m}$ (Parker 1955; Langevin 2003). In addition, the destruction of coastal wetlands led to elimination of the natural filtering capacity of nutrients and pollutants. These alterations changed the bay to a system with highly pulsed point-source freshwater discharges, with larger peak discharges in the wet season, resulting in significant fluctuation in salinity and nutrient levels (Larsen et al. 1995). Algal blooms and seagrass die-offs, which affected stability 
of the bay sediments, caused offshore migration of some benthic communities, and increased pollution by sewage, solid wastes, fuel and oil (Meeder and Boyer 2001; Browder et al. 2005; Caccia and Boyer 2005). The quality of water in the bay has improved in the last thirty years as a result of the elimination of the direct discharge of sewage and other pollutants into the bay, as per water quality regulations set by the Biscayne National Park (Alleman et al. 1995). Additionally, the central and southern parts of Biscayne Bay have been classified as an Outstanding Florida Water (OFW) based upon the designation of Biscayne National Park.

Due to the planned water management changes related to the Comprehensive Everglades Restoration Plan (CERP), which aims to decrease freshwater flow to the bay from canals and restore flow through natural creeks (Browder et al. 2005), it is important to be able to monitor the performance and rehabilitation of this estuary. Because water monitoring programs in Biscayne Bay do not predate the 1980's, the lack of historic records on freshwater delivery and nutrient loading complicates the selection of appropriate restoration targets. In lieu of continuous water quality data, biological remains such as diatoms, pollen, foraminifera, mollusks, ostracodes, and biochemical biomarkers that are preserved in sedimentary records may provide proxies of past environmental conditions in the bay. Diatoms are well known as excellent bio-indicators (Battarbbee 1986), and have successfully been used in assessing changes in salinity and water quality in modern and retrospective studies in coastal and estuarine environments around the world (e.g., Weckstrőm and Juggins 2005; Sounders et al. 2007; Sylvestre et al. 2007; Taffs et al. 2008). 
Although diatoms have been shown to be important proxies of salinity and water quality in coastal areas, accurate environmental inferences from diatom assemblages depend on the availability of taxonomic and autecological data for diatoms from the region in question. Few studies have examined the composition or distribution of diatoms in Biscayne Bay, although they have been identified as a major component of the phytoplankton, whose spatial and temporal distribution is governed by nutrients and salinity (Brand 1988). A study by Reyes-Vasquez (1970) of epiphytic diatoms living on the seagrass Thalassia testudinum within Biscayne Bay showed little impact of salinity and temperature on the majority of taxa. In contrast the work of (Chapter 2) of similar epiphytic assemblages in nearby Florida Bay showed a strong effect of salinity and seasonality on species distributions. Some taxonomic and ecological data are available for taxa from Florida Bay (Wachnicka and Gaiser 2007; Frankovich et al. 2006; Huvane 2002) and from adjacent coastal mangrove wetlands (Ross et al. 2001; Gaiser et al. 2005), but no study has comprehensively examined the composition or distribution of epiphytic, planktonic and benthic diatoms in Biscayne Bay.

In this chapter I describe the diatom flora of Biscayne Bay and examine the spatial distribution of taxa relative to water quality gradients over two seasons. My specific objectives are to (1) determine the current spatial and seasonal distribution of diatoms across Biscayne Bay, (2) develop prediction models for important variables of interest, including salinity, water total nitrogen (WTN), water total phosphorus (WTP), and water total organic carbon (WTOC), and (3) to test the possibility of predicting dominance by epiphytic, epipelic or planktonic communities or the presence of particular diatom assemblages typically found in nearshore or open-bay habitats. 


\subsection{Study Area}

Biscayne Bay is a large $\left(\sim 700 \mathrm{~km}^{2}\right)$, shallow (4m average depth) subtropical lagoonal estuary adjacent to the Miami metropolitan area of southeast Florida (Fig. 4.1; Roessler et al. 1975). The exchange of waters between the Atlantic Ocean and the bay occurs through the central main opening to the bay (Safety Valve) and the tidal creeks between the islands (Cantillo et al. 2000; Wang et al. 2003). The mainland western boundary is part of the Miami Limestone ridge in the northwest and the agriculture areas in the southwest (Cantillo et al. 2000). Surface water flow into the bay is controlled by the system of canals, levees, and control structures maintained by the South Florida Water Management District (SFWMD). Additional sources of freshwater come from precipitation, small tidal creeks and groundwater seepage (Langevin 2003; Stalker 2008). Based on the geographical location, hydrologic input, and hydrodynamic characteristics, Biscayne Bay can be divided into three major parts: North Bay, Central Bay, and South Bay (SFWMD 1995; Browder et al. 2005). The environmental conditions of the Central Bay (Fig. 4.1), located between Port of Miami and Featherbed Bank, were greatly affected by construction of the canals and levees in the 1940's and 1960's. The hydrological changes on the mainland significantly reduced groundwater discharge into this part of the bay, eliminated offshore freshwater springs, and increased nutrient loads from the canals (Parker 1974; Ross et al. 2001; Caccia and Boyer 2007). The South Bay, located between Featherbed Bank and Card Sound, is the area least affected by human activities. The coastal areas directly adjacent to this part of the bay experienced the largest rate of salty groundwater encroachment registered in the South Florida region (up 
to $3 \mathrm{~km}$ inland) in the last few decades due to the construction of canals, levees and highways on the mainland, which reduced freshwater supply, and to global sea level rise (Meeder and Boyer 2001). The North Bay, located north of the Port of Miami, was not included in this study.

\subsection{Materials and Methods}

\subsubsection{Sampling and Laboratory Methods}

Diatoms were collected from 58 sites across south and central Biscayne Bay in April and October, 2005 (Fig. 4.1). Samples collected in April represent the dry season (period between November and April) while October samples represent the wet season (period between May and October). A total of 32 sites were located in close proximity to the coast in order to assess the influence of the canals on nearshore water quality, while the remaining 28 off-shore sites are part of the Water Quality Monitoring (WQM) program of the Southeast Environmental Research Center (http://serc.fiu.edu/wqmnetwork/) aimed at assessing conditions within the bay itself.

Three types of samples were collected from each sampling location: sediments, plants and plankton. Sediment samples consisted of a composite of three ca. 1.5-cm-indiameter, 1-cm-deep cores collected using a calibrated syringe (with the tip removed); where $1 \mathrm{~cm}$ approximately equals 1 year of sedimentation (Wingard et al. 2007). Most of the cores were collected in areas densely vegetated by seagrasses and red, green and brown algae, while others were retrieved from sandy sites that were sparsely vegetated by 
sponges and corals. At least 10 blades of the most dominant seagrasses and green algae (Thalassia testudinum at the open-bay sites and Halodule wrightii, Syringodium filiforme, Thalassia testudinum or Batophora sp. at the nearshore sites) were cut off from the bottom and combined into one sample. Plankton was collected on a $20-\mu \mathrm{m}$ mesh net from water pumped through a 25 -cm-in-diameter plastic pipe submerged mid-depth in the water column. Diatom samples were placed in plastic bags and frozen until analysis. Salinity, dissolved oxygen, $\mathrm{pH}$, turbidity, and temperature were measured at the middepth level with a multiparameter sonde YSI 6600 EDS and turbidity meter, and a $120 \mathrm{ml}$ water sample was collected near the surface for WTN, WTP and WTOC analysis (Appendix 4.1). Water depth was measured using a hand-held sonar depth sounder. In the laboratory, sediment samples were homogenized to break down large particles, epiphytes were scraped with the razor blade from the plant blades, and plankton collected on the mesh was removed by spraying with deionized water. Additionally, 10 $\mathrm{ml}$ of slurry was obtained from each of the sample types for diatom analysis. The remaining sediment samples were dried at $80^{\circ} \mathrm{C}$, ground to a powder and analyzed for sediment total phosphorus (STP), sediment total nitrogen (STN) and sediment total carbon (STC). WTP and STP were analyzed with a UV-2101PC Scanning Spectrophotometer according to the method described by Solorzano and Sharp (1980), WTN was measured with an ANTEK 7000N Nitrogen Analyzer following the procedure of Frankovich and Jones (1998), STN and STC were analyzed in a Perkin Elmer Series II CHNS/O (2400) Analyzer according to the method described by Nelson and Sommers (1996), and WTOC was measured with a Shimadzu TOC-5000 following U.S. Environmental Protection Agency guidelines (1983) (Appendix 4.1). The diatom 
samples were thawed and oxidized following oxidation procedures recommended by Battarbee (1986), and approximately $1 \mathrm{ml}$ of slurry was placed on No.1 coverslips, air dried and mounted onto glass slides using Naphrax ${ }^{\circledR}$. At least 500 diatom valves were counted on each slide on random transects using a Nikon E400 light microscope at 788x magnification (N.A. $=1.4)$ and identified according to the local and standard diatom taxonomic literature.

\subsubsection{Statistical Methods}

Only taxa with a frequency of occurrence in more than $5 \%$ of the samples and having a mean relative abundance of over $2 \%$ were included in the analyses, and the data for each species was expressed as relative abundance. Diatom data were arcsine squareroot transformed (Emerson 1991) to down-weight the importance of very abundant species and to ensure that rarer species will also contribute to the results (McCune and Grace 2002). Environmental data were square root transformed, checked for outliers and relativized by adjustment to standard deviates in order to more closely approximate a normal distribution for the statistical procedures and to make units of variables comparable since they were measured on different scales (McCune and Grace 2002). Analysis of variance (ANOVA) was used to determine the differences in water parameters of interest between the locality clusters. Spearman rank correlation analysis and the Kruskal-Wallis test were used to test for independence among environmental variables (Quinn and Keough 2002). A Mantel test with Pearson's correlation coefficient was used to evaluate the correlation between taxa and environmental distance matrices 
(Mantel 1967). When significant relationships were found, the BIO-ENV procedure with Spearman correlation $\left(\rho_{\mathrm{w}}\right)$ was used to determine which elements were likely to be important in describing the correlation between these distance matrices (Clarke and Ainsworth 1993; Clarke and Warwick 1994).

Nonmetric multidimensional scaling (NMDS; Kruskal and Wish 1978), a technique that searches for the best position of objects in $k$-dimensions (axes) that minimizes stress (goodness of fit between dissimilarity and distance) of the $k$ dimensional configuration (McCune and Grace 2002) with the Sørensen similarity index (Bray \& Curtis 1957), was used to explore spatial and temporal patterns in the distribution of modern diatom species between nearshore and open-bay regions and among the different substrate types to identify the environmental variables that influence taxa the most, and to determine how robustly the environmental variables of interest can be reconstructed on statistical grounds (Battarbee et al. 2001). The dimensionality of NMDS solutions was determined using the Monte Carlo randomization test and joint plots were constructed to illustrate the relationship between environmental variables and diatom community patterns. The angle and length of the "vectors" on the joint plots indicate the strength and direction of this relationship. Hierarchical clustering with the Sørensen distance measure and flexible beta $(\beta=-0.25)$ linkage method was used to define groups of sites with a distinct diatom community structure, which were later superimposed on the ordination diagrams (McCune and Grace 2002). Analysis of similarity (ANOSIM), a nonparametric permutation procedure that tests the null hypothesis that there is no difference in community composition between sites, was used to test the statistical significance between diatom assemblages grouped by cluster 
analysis, habitat, life habit and season (Clarke \& Gorley 2001). The Species

Contributions to Similarity (SIMPER) method was used to determine which individual species contribute the most to the separation of the groups defined in NMDS and cluster analysis (Clark and Warwick 2001). Indicator species analysis (ISA) was used to identify indicator taxa based on the concentration of species abundance in a particular group and on the reliability of occurrence in that group (Dufrêne and Legendre 1997).

Weighted averaging (WA) regression (Ter Braak and Barendregt 1986), which assumes that at a site with a specific environmental variable value, taxa with optima close to that value will be the most abundant (Birks 1995), was used to calculate optima and tolerances for indicator species for salinity, WTN, WTP, and WTOC. Environmental gradient lengths, calibrated in standard deviation units (SD), were measured by detrended canonical correspondence analysis (DCCA), a multivariate direct gradient analysis technique that relates community composition to known variation in the environment (Ter Braak 1986), to determine which method (linear if gradient length is $\leq 2 \mathrm{SD}$ or unimodal if gradient length is $>2 \mathrm{SD}$ ) should be used to develop diatom-based prediction models for the aforementioned variables (Birks 1993). Transfer functions were derived using both the WA method mentioned above and the WA-PLS procedure (Ter Braak et al. 1993). The WA-PLS method combines features of WA and partial least squares (PLS) regressions and uses the residual correlation structure in the data to improve the fit between biological data and environmental data in the training set (Birks 1995). Both methods were used with the leave-one-out cross validation procedure to develop statistical prediction models that can be used in future reconstructions of past environmental conditions in Biscayne Bay. The randomization t-test was used to 
investigate wheather the chosen model was not overfit by discriminating "hidden" overfitting from real model improvements (Juggins, personal communication). The predictive powers of transfer functions were tested by plotting observed versus inferred values of salinity, WTN, WTP and WTOC data in the training-set, and evaluation of the root mean square error of prediction (RMSEP) and maximum and average values of bias in the models that contained the smallest useful PLS components (in the case of WA-PLS models; Birks et al. 1990; Dixon 1993). Additionally, I looked for any significant correlations between the observed values of all other measured variables and residual values for salinity, WTN, WTP, and WTOC in order to determine if any were responsible for the bias in the prediction models. The coefficient of determination $\left(\mathrm{r}^{2}\right)$ was used to compare models for different environmental variables (Birks 1998). The intra-set crossvalidation method was used to assess the performance of diatom-based transfer functions in an independent way. To do this, the 58-site Biscayne Bay training-set and an independent 37-site Florida Bay test-set (Chapter 2) were used to test the prediction precision of the developed transfer functions.

Discriminant function (DF) analysis, which generates a linear combination of variables that maximizes the probability of correctly assigning observations to their predetermined groups or classifies new observations into one of the groups (Quinn and Keough 2002), was used to predict diatom community types in open-bay vs. nearshore habitats or by life habit (epiphytic, planktonic, benthic). In order to test the precision of the diatom-based predictions, I used the Biscayne Bay dry season calibration set to predict life habits and habitats from diatom assemblages in the wet season test-set and vice versa. 
All of the above mentioned analyses were performed using PC-ORD version 5.0 (McCune \& Mefford, 1999), Primer version 5.2.9 (Clark \& Warwick, 2001), SPSS version 13.0 (Levesque, 2007), and C2 version 1.4.2 (Juggins, 2005). The locations of the sampling sites were mapped using ArcView GIS 3.2a.

\subsection{Results}

\subsubsection{Diatom Species Composition}

A total of 547 diatom taxa were identified from the dry season sampling event and 430 from the wet season sampling event (Appendix 4.2). Most taxa (almost 2/3 of the total) were rare (found in less than $5 \%$ of all samples) or had low relative abundance (less than $2 \%$ ). In order to reduce noise in the dataset, they were not included in further analyses, leaving 206 taxa representing 52 genera. The most common genera having the highest number of species were Mastogloia (39 taxa), Amphora (28 taxa) and Nitzschia (22 taxa). The dominant taxa were Hyalosynedra laevigata, Cocconeis placentula var. euglypta, Amphora tenerrima, Psammodictyon panduriforme, Tabularia waernii, Cyclotella distinguenda and Brachysira aponina.

\subsubsection{Spatial and Temporal Patterns}

Cluster analysis distinguished two major clusters in both seasons (Fig. 4.2). In the dry season, Cluster 1 included all nearshore sites and three open-bay sites located in close 
proximity to the coast $(101,102,103)$, while Cluster 2 contained the rest of the open-bay sites (Fig. 4.2a). In the wet season, Cluster 1 comprised nearshore sites located north of Mowry Canal, while Cluster 2 included nearshore sites south of Mowry Canal and all open-bay sites (Fig. 4.2b). Differences between these major clusters were greater in the wet season than the dry season ( $R=0.90$ vs. $R=0.75$, respectively, $p=0.001$; Figs. 4.1 and 4.3). A cluster analysis also revealed that there are two distinct groups of nearshore sites having significantly different diatom assemblages in both seasons (Figs. 4.2 and 4.3). Sites located north of Mowry Canal contained significantly different diatom assemblages than sites located south of this canal. The differences between these two groups of sites were more pronounced in the wet season $(\mathrm{R}=0.991, \mathrm{p}=0.001)$ than the dry season $(\mathrm{R}=0.770, \mathrm{p}=0.001)$. The differences between sites located south of Mowry Canal and the open-bay sites were smaller in the wet season compared to the dry season $(\mathrm{R}=0.625$, $\mathrm{p}=0.001$ and $\mathrm{R}=0.668, \mathrm{p}=0.001$, respectively). Similarly, the differences between diatom assemblages at the nearshore sites north of Mowry Canal and the open-bay sites increased in the wet season as well (from $\mathrm{R}=0.958, \mathrm{p}=0.001$ to $\mathrm{R}=0.991$, $\mathrm{p}=0.001$ ).

Seasonal differences in diatom assemblages were significant $(\mathrm{R}=0.61, \mathrm{p}=0.001)$ and were captured in 2-dimensional NMDS with low stress values (Fig. 4.3a,b). In the dry season (Fig. $4.3 \mathrm{a}$ ) the two axes represented $72.4 \%$ and $11.2 \%$, respectively (cumulative $83.7 \%$ ) of variance in the ordination space. Communities also differed according to life habits (plankton, sediment, epiphyton) $(\mathrm{R}=0.68, \mathrm{p}=0.001$; Fig. $4.4 \mathrm{a})$, and these differences were more pronounced in Cluster 1 compared to Cluster $2(\mathrm{R}=0.85$, $\mathrm{p}=0.001$ and $\mathrm{R}=0.79, \mathrm{p}=0.001$, respectively; Fig. $4.4 \mathrm{a}$ ). In the wet season (Fig. $4.3 \mathrm{~b}$ ) the two axes in the NMDS ordination represented $69.7 \%$ and $12.6 \%$, respectively 
(cumulative $82.3 \%$ ) of variance in the ordination space. Differences between diatom assemblages living in the water column, on sediment and on macrophytes were also distinct $(\mathrm{R}=0.32, \mathrm{p}=0.001)$, and that was more pronounced in Cluster $1(\mathrm{R}=0.52$, $\mathrm{p}=0.001)$ compared to Cluster $2(\mathrm{R}=0.48, \mathrm{p}=0.001)$ (Fig. $4.4 \mathrm{~b})$. Diatom assemblages occupying the water column, and growing on sediments and macrophytes, experienced larger mixing in the wet season (especially sediment taxa and plankton), while they were more associated with their original habitats in the dry season (Fig. 4.4a,b). A Mantel test revealed statistically significant relationships between diatom species composition at the sites and environmental conditions in both seasons $(r=0.39, p=0.001$ in the dry season, and $\mathrm{r}=0.64, \mathrm{p}=0.001$ in the wet season). The BIO-ENV procedure found that salinity, depth and STP explained most of the variation in diatom species composition in the dry season $\left(\rho_{\mathrm{w}}=0.677\right)$, while in the wet season salinity, $\mathrm{pH}$, total phosphorus of sediment (STP) and WTP were the most important $\left(\rho_{\mathrm{w}}=0.706\right)$.

According to SIMPER, the average contribution of the diatom taxa to the total average dissimilarity between Clusters 1 and 2 in the dry season was 55.33. Most of the dissimilarity was due to the presence of Cyclotella distinguenda, Parlibellus panduriforme, Dimmeregramma dubium and Cocconeis placentula var. euglypta $(9.66 \%$ of total contribution). Other important species included: Licmophora remulus, Nitzschia libetruthii, Cymatosira lorenziana, Amphora tenerrima, Synedra formosa, Toxarium hennedianum, Microtabella interrupta, Licmophora debilis and Mastogloia corsicana. In the wet season, the average contribution of the species to the total average dissimilarity between Clusters 1 and 2 was 60.35 . Taxa that were the best discriminators between these clusters were Tabularia waernii, C. placentula var. euglypta, C. distinguenda, 
Brachysira aponina and Reimerothrix floridensis (16.03\% of total contribution). Other important taxa included Licmophora normanniana, Cyclotella choctawhatcheana, A. tenerrima, M. corsicana, Hyalosynedra laevigata and Amphora sp. 06. Most of the best discriminators from Clusters 1 and 2 in the dry and wet seasons were also identified by ISA as good indicators of these clusters (Table 4.1). Cluster 1 contained a higher number of indicator taxa than Cluster 2 in the wet season, but the situation was reversed in the dry season. The highest number of indicator species in both seasons was always associated with sediment samples (16 species in the wet season and 7 in the dry season) and the lowest usually with epiphyton ( 7 species in the dry season and 2 in the wet season; Table $4.3)$.

\subsubsection{Water Quality Conditions}

Water quality parameters varied spatially and temporally among sampled sites. A one-way ANOVA revealed that there were significant seasonal differences among sites in salinity, turbidity, temperature, $\mathrm{pH}, \mathrm{STP}, \mathrm{STC}$ and WTN $(\alpha<0.05)$. In the dry season, significant differences between Cluster 1 and Cluster 2 were observed in oxygen, salinity, depth, temperature, STP, STN and WTOC levels. In the wet season the differences between Cluster 1 and Cluster 2 were significant for WTN, WTP, WTOC, STN, STP, STC, salinity, depth and pH. WTN, WTP, WTOC and salinity were highly correlated with each other and many other water parameters in both seasons (Table 4.2). Also, most of the water parameters exhibited significant correlations with clusters and zones (nearshore and open-bay) but not with life habit (Table 4.2). 


\subsubsection{Environmental Preferences}

Salinity optima, as estimated by the WA regression, ranged from $26.8 \mathrm{ppt}$ for Mastogloia braunii to $35.6 \mathrm{ppt}$ for Climacosphenia moniligera. Taxa displayed a wide range of estimated tolerances between $1.25 \mathrm{ppt}$ for Paralia sulcata to $4.35 \mathrm{ppt}$ for Stephanodiscus medius. WTP optima varied between 0.004 ppm for Licmophora cf. proboscidea to $0.02 \mathrm{ppm}$ for Nitzschia debilis. The tolerances ranged from $0.0003 \mathrm{ppm}$ for Nitzschia reversa to $0.01 \mathrm{ppm}$ for Nitzschia sp. 11. The lowest optimum for WTN was $0.17 \mathrm{ppm}$ for Climacosphenia moniligera and the highest was $0.44 \mathrm{ppm}$ for $M$. braunii. The tolerances varied between $0.04 \mathrm{ppm}$ for Nitzschia sp. 01 and $0.16 \mathrm{ppm}$ for Pinnunavis yarriensis. WTOC optima ranged from $1.74 \mathrm{ppm}$ for $C$. moniligera to 11.03 ppm for $N$. debilis. The tolerances ranged from 0.35 ppm for Licmophora sp. 01 to 4.21 ppm for Tryblionella granulata. The optima and tolerance values for indicator taxa are listed in Table 4.1.

\subsubsection{Transfer Functions and Prediction of Community Types}

The initial analysis of the diatom dataset by DCCA revealed that the compositional gradient length was greater than 2 SD units only for WTOC (2.247 SD units) but not for salinity, WTN and WTP (1.643, 1.190 and 1.902, respectively). Although the gradient length for some variables was shorter than this rule-of-thumb value, suggesting a linear rather than unimodal relationship between diatoms and these variables, I used WA and WA-PLS regression methods to develop transfer functions 
because they outperformed the PLS (Partial Least Squares) regression method that I used for testing the data. WA-PLS with leave-one-out cross validation was used to develop models for salinity and WTN using an averaged dry and wet season calibration sets, and for WTOC using the wet season calibration set only (this dataset produced a stronger inference model). WA with tolerance downweighting, inverse deshrinking regression and a boot-strap cross validation method was used to derive a WTP inference model from the wet season calibration set. The two-component WA-PLS model produced over 10\% reduction in prediction error compared to the one-component WA-PLS, but this result was not statistically significant.

Diatoms estimated all of the environmental variables of interest in this study very well, with relatively high correlations between observed and predicted values of these variables and a small RMSEP (Fig. 4.5a-d). All WA-PLS prediction models were developed with two PLS components. Although the relationship between observed and diatom-predicted salinity values was very strong $\left(r^{2}=0.91\right)$ the residuals revealed a small underestimation at high values and overestimation at low values. A bias in residuals was also obvious for the WTP and WTOC models, where the values were clearly overestimated at the low ends and underestimated at the high ends of the gradients. The bias was less severe for the WTN model. In general, the second component was not able to correct for the bias in the salinity, WTN and WTOC models, but it did provide a significant reduction in prediction errors ( $11 \%$ for salinity, $12.8 \%$ for WTN and $13.1 \%$ for WTOC). In the case of WTP, the $10.1 \%$ reduction in prediction error by the second component was not statistically significant. The residual values for the developed salinity prediction model was significantly correlated with turbidity $(r=-0.265)$, whereas 
the residual values for the WTP model were correlated with STP $(r=-0.273)$ and WTOC $(\mathrm{r}=-0.316)$. The residual values for the WTN and WTOC prediction models were not correlated with any other water quality variables.

The intra-set cross-validation showed that the salinity, WTN, WTP and WTOC transfer functions gave good approximations of measured values in the independent 37 site Florida Bay test set for sites with values of these variables not exceeding those covered by the models (Fig. 4.6a-d). The errors associated with the diatom-based predictions for sites with the variable values covered by the models were within the range of intra-annual variability of the measured values (monthly data available from http://serc.fiu.edu/wqmnetwork/SFWMD-CD/Pages/FB.htm).

Discriminant function analysis determined that from community types specific to either Cluster1 or Cluster 2, 49.1\% could be correctly identified by the cross-validation (CV) method when using the combined dry- and wet-season dataset, $45.7 \%$ by the intraset cross-validation (ICV) method when predicting wet-season community types from dry-season data, and $71.8 \%$ when predicting dry season community types from wet season data. The nearshore community types displayed higher predictability when predicted from wet-season data, whereas open-bay community types could be predicted with the same results regardless of the season (Fig. 4.7a-c). Additionally, when predicting from the dry-season data, $73.7 \%$ (ICV) of the sites that had been assigned to Cluster 1 hosted diatom assemblages typical of Cluster 2 , and similarly $35 \%$ (ICV) of the sites classified in Cluster 2 contained assemblages typical of Cluster 1 . When predicted from the dry-season data, $21.9 \%$ (ICV) of the sites classified as Cluster 1 hosted diatom communities typical of Cluster 2 and 34.6\% (ICV) of sites assigned to Cluster 2 
contained assemblages typical of Cluster 1 . As assessed by $\mathrm{CV}, 79.5 \%$ of assemblages within Cluster 1 could be correctly identified as either sediment, epiphyton or plankton. Similarly, 28.6\% (dry-season communities predicted from the wet-season data) and $53.5 \%$ (the wet-season communities predicted from dry-season data) of assemblages could be correctly identified by the ICV method (Fig. 4.7d-f). Within Cluster 2, 37.7\% of the assemblages could be identified either as sediment, epiphyton or plankton by $\mathrm{CV}$, whereas $36.2 \%$ (dry-season communities predicted from the wet-season data) and $36 \%$ (wet-season communities predicted from the dry-season data) could be correctly identified by the ICV method (Fig. 4.7g-i).

\subsection{Discussion}

The diatom species composition in Biscayne Bay is similar to that of Florida Bay (DeFelice and Lynts 1978; Montgomery 1978; Huvane 2002; Frankovich et al. 2006; (Chapter 2) and adjacent coastal regions (Ross et al. 2001; Gaiser et al. 2005). The floristic composition also resembles that of many other subtropical and tropical coasts (e.g., Giffen 1984; Foged 1984; Hein et al., 2008) as well as temperate estuaries and coastal regions (e.g., Hartley 1986; Simonsen 1987; Witkowski 1994) around the world. As in the earlier studies in this area, Biscayne Bay communities were dominated by species belonging to the genera Mastogloia and Amphora, but unlike the latest results from Florida Bay (Chapter 2), the number of species belonging to Mastogloia exceeds those belonging to Amphora. In the dry season, C. placentula var. euglypta, H. laevigata, C. distinguenda and $M$. interrupta were the dominant taxa at the nearshore sites, while $R$. 
floridensis, H. laevigata, D. dubium and L. remulus dominated at the open-bay sites. All of these species flourished under high salinity (> 35ppt) and low phosphorus conditions. In the wet season, when salinity decreased (from $>35$ to $<20$ ) due to increased precipitation and a higher discharge of nutrient-rich freshwater from the canals and groundwater (Caccia and Boyer 2005, 2007; Stalker 2008), the nearshore sites were dominated by $T$. waernii, C. placentula var. euglypta, B. aponina and H. laevigata, which flourished under salinities that lower than in the dry season $(<20$ compared to $>35)$ and higher nutrient conditions. In contrast, in the wet season at the open-bay sites, where salinity was also lower than in the dry season $(<30$ compared to $>35)$ and the phosphorus concentration was even lower (especially in the southern and northern parts of the bay), H. laevigata, C. placentula v. euglipta, C. choctawhatcheana, and $R$. floridensis were the most abundant taxa. Many of the above-mentioned taxa were reported in earlier studies in South Florida estuaries from phosphorus-limited, often seagrass-dominated sites (Reyes-Vasquez 1970; Prasad et al. 2001; Huvane 2002; Frankovich et al. 2006; (Chapter 2) as well as from brackish sites in adjacent coastal mangroves (Ross et al. 2001; Gaiser et al. 2005).

Spatial and temporal differences in water quality conditions were responsible for great differences in diatom species composition among the study sites. The assemblages at the nearshore sites were greatly influenced by freshwater flowing from the canals, natural creeks and ground water, and experienced greater intra-annual fluctuations in salinity and nutrient conditions than the open-bay sites, which were influenced mostly by precipitation and inflow from the Atlantic Ocean. The nearshore sites located south of Mowry Canal were more impacted by freshwater coming from the canals than the sites 
located north of this canal. This situation was most likely caused by the fact that most of the major canals are located in the South Bay. Additionally, because water currents carry water from these canals towards the south (Wang et al. 2003) diatom assemblages at the sites south of Mowry Canal are more similar to those present at the open-bay sites rather than the sites north of this canal. In earlier studies Graves et al. (2005) also observed that macroinvertebrate community composition and distributions were directly linked to the elevated nutrient concentration in the water coming from Mowry Canal and Snapper Creek. This situation was reflected in the correlation between measured water quality parameters. For example, in the wet season salinity was strongly negatively correlated with WTOC and sediment and water nutrients, which indicates that when salinity in the bay drops due to the increased freshwater supply the sediment and water nutrient levels rise due to the increased supply of nutrients from the canals and groundwater, and there is more organic material flushed from the mainland. The situation was less severe in the dry season when salinity was still significantly negatively correlated with WTP and WTOC (but not with WTN) and STP and STN (but not with STC), and the correlations were weaker than for the wet season. These results indicate that when the canal gates are closed in the dry season to keep groundwater levels from dropping, the freshwater discharges from canals and submarine groundwater discharges significantly decrease, so the nutrient and dissolved organic material supply decreases as well.

There were several water parameters (salinity, depth and STP in the dry season and salinity, $\mathrm{pH}, \mathrm{STP}$ and WTP in the wet season) responsible for structuring diatom communities in the bay. These parameters have been frequently reported in other studies in estuaries and coastal regions. For example, Admiral and Peletier (1979a), who studied 
the diatom response to different levels of sulfide, ammonia, salinity, oxygen and light in the Ems-Dollard Estuary of the Netherlands, concluded that no single variable, but rather a combination of them, could best explain the species distribution. Salinity was mentioned in numerous studies conducted in shallow estuaries and lagoons in the past as one of the most important water chemistry variable determining diatom species composition (Snoeijs 1999; Frankovich et al. 2006; Tibby et al. 2007). Water depth and the associated light limitation have been mentioned frequently as well (Weckstrőm and Juggins 2005). Additionally, nutrients, especially phosphorus, have been found to control marine algal composition in South Florida (Armitage et al. 2006; Frankovich et al. 2006) and have influenced diatom composition in clusters and seasons in this study (STP in the dry season and STP and WTP in the wet season). In general, nitrogen is considered to be the main limiting nutrient to primary production in estuaries (Howarth and Marino 2006), but in Biscayne Bay, as in many other carbonate-dominated estuaries in the tropics, nitrogen is abundant while phosphorus is removed from the water column by the calcium carbonate sediments, thus becoming the principal limiting nutrient for macrophytes and algal primary production (McGlathery et al. 1994; Caccia and Boyer 2005).

Blooms of planktonic species such as M. interrupta in April and Chaetoceros spp. and C. choctawhatcheana in September are most likely related to dry-season nutrient buildup (especially phosphorus) in the sediments, canals and groundwater, and their subsequent flushing into the nearshore region of the bay after the first spring rains (Brand 1988), and the increased wet-season nutrient inflow from canals and groundwater (Byrne 1999; Caccia \& Boyer 2005; Stalker 2008). Taxa belonging to the genus Chaetoceros 
are among the most frequent diatoms found in marine plankton (Suto 2006), and major contributors to primary production in nutrient rich coastal areas and upwelling regions (Rines and Hargraves 1988; Rines and Theriot 2003). Similarly, C. choctawhatcheana and $M$. interrupta were reported earlier from nutrient-rich, turbid lakes located in the southwestern Everglades and nearshore Florida Bay sites (Chapter 2) as well as from highly disturbed sites of the Chesapeake Bay (Cooper 1995b), Lagoa de Araruama of Brazil (Sylvestre et al. 2001), and the Baltic Sea (Andrén et al. 2000; Weckstrőm and Juggins 2005).

Compared to the Florida Bay study (Chapter 2), the relatively great number of indicator taxa identified by ISA for Biscayne Bay nearshore and open-bay sites, and for sediment, epiphyton and plankton, is most likely due to the presence of diverse habitats and the less turbid conditions of the estuary. In Florida Bay sediments and microorganisms attached to the macrophytes are resuspended in the water column due to the shallow nature of the system, resulting in a smaller number of indicator species for the same life habits and similar habitats as this study. Howaver, even though Biscayne Bay is relatively deep and the water turbidity is low, some taxa (e.g., Nitzschia sigma, Licmophora pfannkucheae) originally described as epiphytic or epipelic (Witkowski et al. 2000) were identified by ISA as good indicators of planktonic communities, indicating a moderate degree of mixing.

Intra-annual variability of water quality conditions in the nearshore zone affects diatom community structure in this area. For example, in the wet season, when salinity drops to less than 20 and the bay is freshened by an increased discharge from the canals and groundwater, storm water runoff and increased precipitation, diatom communities 
contain taxa commonly reported in the adjacent brackish water mangrove zone (e.g., $T$. waernii, Achnanthes sp. 07; Gaiser et al. 2005), while in the dry season, when increased precipitation often results in hypersaline conditions and salinity can reach $40 \mathrm{ppt}$, the abundance of these taxa significantly decreases and species which can tolerate higher salinity (e.g., C. placentula var. euglypta, R. floridensis, H. laevigata) dominate. Additionally, I sporadically encountered some taxa (e.g., Encyonema evergladianum, Mastogloia smithii, Brachysira neoexilis) which were commonly reported in periphyton mats in the freshwater Everglades marshes (Gaiser et al. 2006; Gottlieb et al. 2006), in samples collected at the nearshore sites close to the canals, which indicates transport of the material from that region through canals.

Salinity optima and tolerances of diatoms living in Biscayne Bay differ from those reported earlier from Florida Bay by Frankovich et al. (2006), which were on average $3.4 \mathrm{ppt}$ higher than in this study. In contrast, in a study by Huvane (2002), they were on average $6.9 \mathrm{ppt}$ lower than in this study, and in the study by Gaiser et al. (2005) on coastal mangroves adjacent to Biscayne Bay, they were on average 13.5 ppt lower. The optima and tolerances reported by (Chapter 2) from Florida Bay differ less, on average $1.6 \mathrm{ppt}$ lower, because the gradients explored were more similar in length. Diatom communities occupying the nearshore sites contained many taxa with broad salinity and nutrient tolerances, also observed by Admiral (1984) for most of the epipelic species in the Ems-Dollard Estuary, by Tibby et al. (2007) for coastal wetlands in southeast Australia, by Snoeijs (1999) for the Baltic Sea, and by (Chapter 2) for Florida Bay and the adjacent Everglades marshes. All of these authors reported that the highly 
variable salinity and nutrient conditions in these estuaries, seas and coastal regions select for taxa with broad tolerances.

The salinity, WTN, WTP and WTOC prediction models obtained from the WA and WA-PLS regressions were strong, but not without problems. All models, except for WTN model, were affected by the "edge effect" (Birks 1998). Despite the imperfections, the inference model for salinity of Biscayne Bay (Fig. 4.5) can predict this variable from diatom communities with a very small prediction error $(\mathrm{RMSEP}= \pm 1.09)$ which represents about $3.4 \%$ of the average salinity recorded at the sampling sites in both seasons. The error was slightly larger for the other variables of interest in this study. For example, the prediction error for the WTN model (RMSEP $= \pm 0.05 \mathrm{ppm})$ represents $19 \%$, WTP $(\mathrm{RMSEP}= \pm 0.003 \mathrm{ppm})$ represents $22.3 \%$, and WTOC $(\mathrm{RMSEP}= \pm 0.85 \mathrm{ppm})$ represents $6.5 \%$ of the combined seasonal average values of these variables (Fig. 4.5). The predictive powers of these models are as strong or stronger than those obtained in other studies in this region (Gaiser et al. 2005; Chapter 2). The minor differences are most likely due to the differences in gradient lengths, number of samples collected to develop the transfer function, and method used to analyze the data (the WA-PLS regression method usually gives better results than the WA regression). The estimation errors in these inference models, although reduced by the addition of extra components (except for the WTP model), are most likely caused by the diatom community response to other water parameters. For example, the improvements in the prediction error in the salinity model were possible because the second WA-PLS component exploited the structure in the residuals related to turbidity, and used it to improve the salinity predictions. The Component 2 scores in the WTN and WTOC models were not 
significantly correlated with any of the other measured water parameters, suggesting that the moderate improvements in these models were possibly due to improved fitting of some samples. The prediction error in the WTP model was probably due to significant correlations with STP and WTOC.

The intra-set cross-validation procedure demonstrated that the salinity, WTN, WTP and WTOC transfer functions based on the 58-site Biscayne Bay training-set estimated the actual values of these variables in an independent 37-site Florida Bay testset (Chapter 2) with very small differences except for the brackish values and high values of WTN, WTP and WTOC (Fig. 4.6). They were especially close at the sites with salinity, WTN, WTP and WTOC conditions close to those that fell within the range covered by the models. All values of the measured variables at these particular sites fell within the range of intra-annual variability. In general, the models were unable to predict the above-mentioned variables accurately at sites with significantly higher or lower values of these variables. For example, in the case of the salinity model, predictions were far from perfect for sites located in the freshwater Everglades and many of the coastal mangrove sites. These sites experience annual values of salinity between $0 \mathrm{ppt}$ and 15 ppt, and this range was not covered by the salinity inference model, which resulted in overestimation of this variable at these sites. In the future, in order to eliminate these differences, the collection of samples should be conducted from a greater number of sites, especially in the middle and lower spectrum of the salinity gradient and the higher spectrum of nutrient gradients.

The comparison of diatom-inferred and measured salinity, WTN, WTP and WTOC in the test-set demonstrated the power of the numerical transfer functions, and 
showed how they can be applied over longer time scales. This should be done only after the addition of sites in low- and medium-salinity and high-nutrient ranges, which can be accomplished by combining the Biscayne Bay dataset with earlier studies from Florida Bay, the adjacent coastal mangroves and freshwater marshes. Additionally, as was demonstrated by the DF analysis, the diatoms can also be used to provide extremely valuable information about the historical availability and quality of common substrata (e.g., an epiphyte-dominated habitat can indicate the presence of dense, underwater vegetation cover). They also provide information about the status of the water quality conditions at the study sites (e.g., a plankton-dominated habitat can indicate increased nutrient availability). The imperfections in the predictions are most likely due to the fact that I used dry-season data to predict life habits and habitats from wet-season data. The errors in predictions will most likely decrease with conducting more detailed autecological investigations in this region. Because, many variables can influence diatom community structures and obscure quantitative reconstructions, I suggest that they be used with a combination of other proxy data in order to provide the best estimation of past water quality conditions in the bay.

\subsection{Conclusions}

This research showed that diatom assemblages are strongly influenced by spatial and seasonal water quality changes, implying that one season of sampling is insufficient to develop reliable and precise prediction models for the study of past environmental conditions in the bay. I demonstrated that predictions of past salinity, WTN, WTP and 
WTOC from fossil diatom assemblages in Biscayne Bay should be accurate and reliable for values that do not exceed the ranges found in this study. Moreover, I showed that diatoms can also be successfully used to study changes in habitats (nearshore habitats vs. open-bay habitat) and community types (plankton, sediment, epiphyton) in the bay. These models aid in the study of the onset and magnitude of the ecological changes in the bay caused by fluctuating climate and anthropogenic alterations on the mainland.

\section{Acknowledgments}

This study was financially supported by Everglades National Park (National Park Service \#5284-AP00-371) and was coordinated to compliment the Florida Coastal Everglades Long Term Ecological Research program (National Science Foundation DEB-9910514). Many thanks are due to Rafael Travieso and Christine Taylor for field assistance and Peter Harlem for providing authors with documents that improved their understanding of conditions present in the bay in the past few decades. 
Table 4.1 Indicator species of clusters identified by ISA and optima (Opt.) and tolerances

(Tol.) for salinity (Sal.) and water total nitrogen (WTN), water total phosphorus (WTP), and water total organic carbon (WTOC) as calculated by weighted averaging regression. All indicator values are significant at $\alpha<0.05$.

\begin{tabular}{|c|c|c|c|c|c|c|c|c|c|}
\hline Taxon name & $\begin{array}{c}\text { Observed } \\
\text { Indicator } \\
\text { Value }\end{array}$ & $\begin{array}{l}\text { Sal. } \\
\text { (ppt) } \\
\text { Opt. }\end{array}$ & $\begin{array}{c}\text { Sal. } \\
\text { (ppt) } \\
\text { Tol. }\end{array}$ & $\begin{array}{c}\text { WTN } \\
\text { (ppm) } \\
\text { Opt. }\end{array}$ & $\begin{array}{c}\text { WTN } \\
\text { (ppm) } \\
\text { Tol. }\end{array}$ & $\begin{array}{c}\text { WTP } \\
\text { (ppm) } \\
\text { Opt. }\end{array}$ & $\begin{array}{c}\text { WTP } \\
\text { (ppm) } \\
\text { Tol. }\end{array}$ & $\begin{array}{c}\text { WTOC } \\
\text { (ppm) } \\
\text { Opt. }\end{array}$ & $\begin{array}{c}\text { WTOC } \\
\text { (ppm) } \\
\text { Tol. }\end{array}$ \\
\hline \multicolumn{10}{|l|}{ CLUSTER 1} \\
\hline \multicolumn{10}{|l|}{ dry season } \\
\hline Amphora sp. 05B & 53.9 & 32.0 & 4.4 & 0.4 & 0.3 & 0.01 & 0.02 & 6.7 & 4.9 \\
\hline Amphora sp. 05F & 65.7 & 31.3 & 5.2 & 0.4 & 0.3 & 0.02 & 0.02 & 6.6 & 5.7 \\
\hline Amphora aponina & 74.0 & 30.9 & 3.6 & 0.3 & 0.1 & 0.02 & 0.02 & 4.9 & 2.2 \\
\hline Amphora coffeaeformis & 58.2 & 31.0 & 5.9 & 0.4 & 0.3 & 0.01 & 0.02 & 6.2 & 4.4 \\
\hline Amphora tenerima & 68.8 & 31.4 & 3.5 & 0.3 & 0.1 & 0.02 & 0.02 & 4.8 & 2.1 \\
\hline Caloneis excentrica & 57.6 & 29.6 & 4.5 & 0.4 & 0.2 & 0.02 & 0.03 & 6.7 & 4.7 \\
\hline $\begin{array}{l}\text { Cocconeis placentula } \\
\text { Cocconeis placentula var. }\end{array}$ & 67.0 & 30.0 & 6.1 & 0.4 & 0.2 & 0.01 & 0.02 & 6.7 & 4.2 \\
\hline euglypta & 72.5 & 29.3 & 6.7 & 0.5 & 0.3 & 0.02 & 0.02 & 8.2 & 4.0 \\
\hline Cocconeis woodii & 69.6 & 29.4 & 3.1 & 0.3 & 0.1 & 0.02 & 0.02 & 5.3 & 2.5 \\
\hline Cyclotella distinguenda & 96.1 & 28.2 & 4.9 & 0.5 & 0.3 & 0.02 & 0.03 & 7.8 & 4.6 \\
\hline Cyclotella litoralis & 50.8 & 27.8 & 7.7 & 0.7 & 0.2 & 0.02 & 0.02 & 11.0 & 4.1 \\
\hline Entomoneis pseudoduplex & 62.5 & 32.1 & 3.5 & 0.3 & 0.1 & 0.01 & 0.02 & 4.2 & 2.1 \\
\hline $\begin{array}{l}\text { Tabularia waernii } \\
\text { Hyalosynedra laevigata }\end{array}$ & 54.8 & 26.4 & 7.2 & 0.4 & 0.2 & 0.02 & 0.03 & 6.8 & 3.8 \\
\hline var. angustata & 71.6 & 30.7 & 4.6 & 0.5 & 0.3 & 0.02 & 0.02 & 7.3 & 4.5 \\
\hline Licmophora normaniana & 65.2 & 28.2 & 5.9 & 0.4 & 0.3 & 0.02 & 0.02 & 7.2 & 4.3 \\
\hline Mastogloia sp. 10 & 51.0 & 31.6 & 4.7 & 0.4 & 0.3 & 0.01 & 0.02 & 6.6 & 3.7 \\
\hline Mastogloia angusta & 46.8 & 31.1 & 4.3 & 0.3 & 0.1 & 0.02 & 0.03 & 4.9 & 2.6 \\
\hline Mastogloia crucicula & 56.2 & 31.7 & 4.8 & 0.4 & 0.3 & 0.01 & 0.02 & 6.2 & 4.5 \\
\hline Mastogloia elegans & 74.0 & 29.3 & 3.3 & 0.3 & 0.1 & 0.02 & 0.03 & 5.8 & 2.2 \\
\hline Mastogloia halophila & 56.4 & 28.6 & 5.7 & 0.5 & 0.3 & 0.02 & 0.02 & 8.4 & 6.0 \\
\hline Mastogloia ovata & 61.6 & 31.7 & 3.5 & 0.3 & 0.1 & 0.01 & 0.02 & 4.5 & 2.0 \\
\hline Mastogloia pisciculus & 59.3 & 30.6 & 5.3 & 0.5 & 0.3 & 0.02 & 0.02 & 7.5 & 4.1 \\
\hline Mastogloia pusilla & 65.8 & 31.0 & 3.8 & 0.3 & 0.1 & 0.02 & 0.02 & 4.8 & 2.3 \\
\hline $\begin{array}{l}\text { Navicula durrenbergiana } \\
\text { Navicula }\end{array}$ & 69.0 & 29.9 & 6.2 & 0.4 & 0.3 & 0.02 & 0.02 & 7.0 & 5.4 \\
\hline pseudocrassirostris & 42.9 & 29.6 & 3.4 & 0.3 & 0.1 & 0.02 & 0.02 & 5.3 & 2.0 \\
\hline Nitzschia frustulum & 48.6 & 30.9 & 5.0 & 0.5 & 0.4 & 0.02 & 0.03 & 7.7 & 5.6 \\
\hline $\begin{array}{l}\text { Nitzschia liebetruthii } \\
\text { Nitzschia longissima } \mathrm{f} .\end{array}$ & 84.3 & 31.2 & 4.4 & 0.4 & 0.3 & 0.02 & 0.02 & 6.5 & 4.2 \\
\hline $\begin{array}{l}\text { parva } \\
\text { Pleurosigma } \mathrm{cf} .\end{array}$ & 48.9 & 30.6 & 4.1 & 0.3 & 0.1 & 0.01 & 0.02 & 4.6 & 2.7 \\
\hline compactum & 65.2 & 30.0 & 4.6 & 0.3 & 0.2 & 0.02 & 0.02 & 5.2 & 2.9 \\
\hline Reimerotrix floridensis & 50.8 & 32.0 & 5.0 & 0.4 & 0.2 & 0.01 & 0.02 & 5.4 & 3.4 \\
\hline Rhopalodia constricta & 71.8 & 30.3 & 4.0 & 0.3 & 0.1 & 0.01 & 0.02 & 5.1 & 2.5 \\
\hline Thalassionema sp. 01 & 50.7 & 30.2 & 3.7 & 0.3 & 0.1 & 0.01 & 0.01 & 4.8 & 2.2 \\
\hline Tryblionella granulata & 40.0 & 30.8 & 3.4 & 0.3 & 0.1 & 0.02 & 0.02 & 5.6 & 2.0 \\
\hline \multicolumn{10}{|l|}{ wet season } \\
\hline Amphora sp. 02 & 57.7 & 33.0 & 3.6 & 0.3 & 0.2 & 0.01 & 0.01 & 5.2 & 3.1 \\
\hline Amphora sp. 06 & 88.2 & 32.0 & 4.4 & 0.4 & 0.3 & 0.01 & 0.02 & 6.7 & 4.9 \\
\hline
\end{tabular}




\begin{tabular}{|c|c|c|c|c|c|c|c|c|c|}
\hline Amphora sp. 05 & 68.2 & 31.3 & 5.2 & 0.4 & 0.3 & 0.02 & 0.02 & 6.6 & 5.7 \\
\hline $\begin{array}{l}\text { Amphora abludens } \\
\text { Amphora corpulenta var. }\end{array}$ & 70.9 & 34.2 & 2.2 & 0.2 & 0.1 & 0.01 & 0.01 & 3.2 & 1.2 \\
\hline capitata & 68.6 & 32.8 & 4.4 & 0.4 & 0.3 & 0.01 & 0.01 & 6.4 & 4.2 \\
\hline $\begin{array}{l}\text { Amphora coffeaeformis } \\
\text { Amphora graeffeana var. }\end{array}$ & 48.2 & 31.0 & 5.9 & 0.4 & 0.3 & 0.01 & 0.02 & 6.2 & 4.4 \\
\hline 02 & 51.0 & 34.2 & 2.1 & 0.2 & 0.1 & 0.01 & 0.00 & 3.2 & 1.8 \\
\hline Amphora gramenosum & 53.6 & 33.5 & 3.5 & 0.3 & 0.2 & 0.01 & 0.01 & 4.1 & 2.6 \\
\hline Amphora hamata & 68.3 & 31.3 & 4.5 & 0.5 & 0.3 & 0.01 & 0.02 & 6.8 & 4.1 \\
\hline Amphora securicula & 49.0 & 31.8 & 3.9 & 0.3 & 0.1 & 0.01 & 0.01 & 4.5 & 2.4 \\
\hline Amphora semperparolum & 48.5 & 33.0 & 3.0 & 0.3 & 0.1 & 0.02 & 0.03 & 3.8 & 1.4 \\
\hline Cocconeis sp. 01 & 74.4 & 33.1 & 2.8 & 0.2 & 0.1 & 0.01 & 0.02 & 3.9 & 1.7 \\
\hline Cymatosira lorenziana & 57.9 & 34.7 & 1.9 & 0.2 & 0.1 & 0.01 & 0.01 & 2.8 & 1.3 \\
\hline Diploneis vacilans & 73.8 & 32.7 & 3.2 & 0.3 & 0.1 & 0.01 & 0.02 & 4.0 & 2.0 \\
\hline Dimeregramma dubium & 73.7 & 34.6 & 1.8 & 0.2 & 0.1 & 0.01 & 0.01 & 2.8 & 1.1 \\
\hline Entomoneis pseudoduplex & 71.1 & 32.1 & 3.5 & 0.3 & 0.1 & 0.01 & 0.02 & 4.2 & 2.1 \\
\hline Haslea ostrearia & 48.7 & 31.9 & 4.0 & 0.3 & 0.1 & 0.02 & 0.03 & 4.2 & 2.2 \\
\hline $\begin{array}{l}\text { Hyalosynedra laevigata } \\
\text { Licmophora }\end{array}$ & 56.0 & 32.2 & 3.4 & 0.3 & 0.1 & 0.01 & 0.02 & 4.2 & 2.0 \\
\hline pfannkucheae & 54.1 & 32.7 & 4.7 & 0.3 & 0.2 & 0.01 & 0.01 & 4.1 & 2.4 \\
\hline Licmophora remulus & 47.4 & 34.0 & 2.6 & 0.2 & 0.1 & 0.01 & 0.01 & 3.1 & 1.4 \\
\hline Mastogloia sp. 10 & 46.0 & 31.6 & 4.7 & 0.4 & 0.3 & 0.01 & 0.02 & 6.6 & 3.7 \\
\hline Mastogloia sp. 12 & 46.2 & 33.9 & 2.4 & 0.2 & 0.1 & 0.01 & 0.01 & 3.4 & 1.5 \\
\hline Mastogloia bahamensis & 57.0 & 33.8 & 2.5 & 0.3 & 0.2 & 0.01 & 0.01 & 4.4 & 2.6 \\
\hline Mastogloia barbadensis & 73.2 & 33.1 & 4.3 & 0.4 & 0.3 & 0.01 & 0.01 & 6.4 & 4.0 \\
\hline Mastogloia binotata & 78.9 & 33.9 & 2.7 & 0.3 & 0.2 & 0.01 & 0.02 & 4.1 & 2.6 \\
\hline Mastogloia biocellata & 63.5 & 31.9 & 4.7 & 0.4 & 0.3 & 0.01 & 0.02 & 6.3 & 5.0 \\
\hline Mastogloia corsicana & 83.9 & 33.3 & 3.3 & 0.4 & 0.2 & 0.01 & 0.02 & 5.3 & 3.5 \\
\hline Mastogloia cribrosa & 61.6 & 33.2 & 3.9 & 0.3 & 0.2 & 0.01 & 0.01 & 5.4 & 3.4 \\
\hline Mastogloia crucicula & 65.2 & 31.7 & 4.8 & 0.4 & 0.3 & 0.01 & 0.02 & 6.2 & 4.5 \\
\hline Mastogloia cyclops & 62.1 & 32.2 & 3.3 & 0.3 & 0.1 & 0.01 & 0.02 & 4.3 & 1.9 \\
\hline Mastogloia discontinua & 73.7 & 33.1 & 4.2 & 0.4 & 0.3 & 0.01 & 0.01 & 6.3 & 4.1 \\
\hline Mastogloia laminaris & 53.2 & 31.8 & 5.2 & 0.5 & 0.3 & 0.01 & 0.02 & 7.3 & 6.1 \\
\hline $\begin{array}{l}\text { Mastogloia lineata } \\
\text { Mastogloia }\end{array}$ & 60.5 & 33.4 & 2.6 & 0.3 & 0.2 & 0.01 & 0.01 & 4.6 & 2.9 \\
\hline pseudolatecostata & 68.8 & 34.0 & 2.9 & 0.4 & 0.3 & 0.01 & 0.01 & 6.0 & 4.1 \\
\hline Mastogloia punctifera & 72.6 & 32.7 & 4.1 & 0.4 & 0.2 & 0.01 & 0.02 & 5.9 & 3.5 \\
\hline Mastogloia rostellata & 59.1 & 34.0 & 2.0 & 0.2 & 0.1 & 0.01 & 0.00 & 3.3 & 1.4 \\
\hline Mastogloia strigilis & 57.3 & 32.8 & 3.2 & 0.3 & 0.1 & 0.01 & 0.01 & 3.9 & 1.8 \\
\hline Microtabella sp. 01 & 71.1 & 32.5 & 3.2 & 0.2 & 0.1 & 0.01 & 0.02 & 4.3 & 2.1 \\
\hline Microtabella interrupta & 88.5 & 32.2 & 4.3 & 0.3 & 0.2 & 0.01 & 0.02 & 4.8 & 2.8 \\
\hline Navicula sp. 21 & 68.4 & 33.0 & 3.8 & 0.8 & 0.2 & 0.01 & 0.01 & 11.3 & 2.6 \\
\hline Navicula directa & 62.1 & 31.7 & 4.7 & 0.4 & 0.3 & 0.01 & 0.02 & 6.5 & 4.4 \\
\hline Nitzschia angularis & 82.8 & 31.4 & 7.0 & 0.5 & 0.4 & 0.01 & 0.01 & 7.5 & 7.1 \\
\hline Nitzschia closterium & 49.4 & 33.6 & 3.1 & 0.2 & 0.1 & 0.01 & 0.01 & 3.4 & 2.0 \\
\hline $\begin{array}{l}\text { Nitzschia dissipata } \text { var. } \\
\text { media }\end{array}$ & 50.7 & 33.3 & 2.4 & 0.2 & 0.1 & 0.01 & 0.01 & 4.2 & 1.9 \\
\hline Nitzschia grossestriata & 56.5 & 30.0 & 7.3 & 0.5 & 0.3 & 0.01 & 0.01 & 7.9 & 6.0 \\
\hline Nitzschia improvisa & 57.9 & 33.4 & 2.6 & 0.2 & 0.1 & 0.01 & 0.02 & 3.6 & 1.8 \\
\hline Nitzschia liebetruthii & 66.8 & 31.2 & 4.4 & 0.4 & 0.3 & 0.02 & 0.02 & 6.5 & 4.2 \\
\hline Pleurosigma elongatum & 51.4 & 30.9 & 7.2 & 0.4 & 0.3 & 0.01 & 0.02 & 6.9 & 4.1 \\
\hline Reimerotrix floridensis & 96.3 & 32.0 & 5.0 & 0.4 & 0.2 & 0.01 & 0.02 & 5.4 & 3.4 \\
\hline Rhopaodia pacifica & 59.8 & 32.5 & 3.1 & 0.2 & 0.1 & 0.01 & 0.01 & 4.0 & 1.7 \\
\hline Seminavis delicatula & 54.0 & 31.9 & 5.1 & 0.5 & 0.3 & 0.01 & 0.01 & 7.0 & 4.3 \\
\hline Seminavis gracilenta & 40.1 & 28.8 & 8.1 & 0.4 & 0.2 & 0.01 & 0.02 & 7.0 & 3.8 \\
\hline Seminavis strigosa & 72.1 & 30.5 & 7.1 & 0.5 & 0.3 & 0.01 & 0.02 & 7.3 & 5.8 \\
\hline Synedra bacillaris & 69.8 & 33.0 & 3.2 & 0.3 & 0.1 & 0.01 & 0.01 & 3.7 & 1.8 \\
\hline
\end{tabular}




\begin{tabular}{|c|c|c|c|c|c|c|c|c|c|}
\hline Synedra fulgens & 55.8 & 33.9 & 2.9 & 0.3 & 0.2 & 0.01 & 0.01 & 3.8 & 2.2 \\
\hline Toxarium undulatum & 59.1 & 34.4 & 2.8 & 0.3 & 0.2 & 0.01 & 0.01 & 4.0 & 3.0 \\
\hline Tryblionella coarctata & 84.5 & 33.2 & 4.2 & 0.4 & 0.3 & 0.01 & 0.01 & 5.8 & 3.5 \\
\hline \multicolumn{10}{|l|}{ CLUSTER 2} \\
\hline \multicolumn{10}{|l|}{ dry season } \\
\hline $\begin{array}{l}\text { Amphora caribaea } \\
\text { Amphora corpulenta var. }\end{array}$ & 67.1 & 33.6 & 3.7 & 0.4 & 0.3 & 0.01 & 0.01 & 5.6 & 4.2 \\
\hline capitata & 45.4 & 32.8 & 4.4 & 0.4 & 0.3 & 0.01 & 0.01 & 6.4 & 4.2 \\
\hline Amphora gramenorum & 56.9 & 33.5 & 3.5 & 0.3 & 0.2 & 0.01 & 0.01 & 4.1 & 2.6 \\
\hline Amphora laevigata & 42.5 & 33.1 & 4.0 & 0.4 & 0.3 & 0.01 & 0.01 & 6.2 & 4.5 \\
\hline Ardissonia formosa & 81.8 & 33.6 & 2.8 & 0.2 & 0.1 & 0.01 & 0.01 & 3.5 & 1.8 \\
\hline Actinocyclus ehrenbergii & 40.2 & 33.7 & 2.1 & 0.2 & 0.1 & 0.01 & 0.00 & 3.1 & 1.2 \\
\hline Climaconeis koenigii & 43.4 & 34.5 & 1.9 & 0.2 & 0.1 & 0.01 & 0.02 & 2.9 & 1.3 \\
\hline Cocconeis britanica & 52.2 & 33.9 & 2.3 & 0.2 & 0.1 & 0.01 & 0.02 & 3.4 & 1.7 \\
\hline Cymatosira lorenziana & 78.1 & 34.7 & 1.9 & 0.2 & 0.1 & 0.01 & 0.01 & 2.8 & 1.3 \\
\hline Diploneis crabro & 46.3 & 33.3 & 2.7 & 0.2 & 0.1 & 0.02 & 0.02 & 3.7 & 1.7 \\
\hline Diploneis suborbicularis & 59.2 & 31.1 & 5.7 & 0.5 & 0.3 & 0.01 & 0.02 & 6.9 & 4.6 \\
\hline $\begin{array}{l}\text { Dimeregramma dubium } \\
\text { Ggrammatophora }\end{array}$ & 90.0 & 34.6 & 1.8 & 0.2 & 0.1 & 0.01 & 0.01 & 2.8 & 1.1 \\
\hline angulosa & 74.2 & 34.7 & 1.7 & 0.2 & 0.1 & 0.01 & 0.01 & 2.9 & 1.3 \\
\hline Grammatophora oceanica & 52.1 & 31.6 & 3.5 & 0.3 & 0.1 & 0.01 & 0.02 & 4.4 & 2.0 \\
\hline Licmophora debilis & 72.2 & 34.6 & 1.4 & 0.2 & 0.1 & 0.01 & 0.01 & 3.1 & 1.0 \\
\hline Licmophora proboscidea & 54.4 & 34.6 & 1.9 & 0.2 & 0.1 & 0.00 & 0.00 & 2.5 & 1.0 \\
\hline Licmophora remulus & 83.1 & 34.0 & 2.6 & 0.2 & 0.1 & 0.01 & 0.01 & 3.1 & 1.4 \\
\hline Mastogloia sp. 12 & 41.6 & 33.9 & 2.4 & 0.2 & 0.1 & 0.01 & 0.01 & 3.4 & 1.5 \\
\hline Mastogloia bahamensis & 45.7 & 33.8 & 2.5 & 0.3 & 0.2 & 0.01 & 0.01 & 4.4 & 2.6 \\
\hline Mastogloia beufortiana & 41.1 & 32.5 & 3.4 & 0.3 & 0.2 & 0.01 & 0.02 & 4.6 & 3.4 \\
\hline Mastogloia binotata & 76.5 & 33.9 & 2.7 & 0.3 & 0.2 & 0.01 & 0.02 & 4.1 & 2.6 \\
\hline Mastogloia corsicana & 64.6 & 33.3 & 3.3 & 0.4 & 0.2 & 0.01 & 0.02 & 5.3 & 3.5 \\
\hline Mastogloia cribrosa & 52.8 & 33.2 & 3.9 & 0.3 & 0.2 & 0.01 & 0.01 & 5.4 & 3.4 \\
\hline Mastogloia delicatula & 44.0 & 34.1 & 2.4 & 0.4 & 0.2 & 0.01 & 0.00 & 5.0 & 2.9 \\
\hline Mastogloia discontinua & 43.2 & 33.1 & 4.2 & 0.4 & 0.3 & 0.01 & 0.01 & 6.3 & 4.1 \\
\hline Mastogloia fimbriata & 59.1 & 33.8 & 2.7 & 0.2 & 0.1 & 0.01 & 0.02 & 3.5 & 1.9 \\
\hline Mastogloia goessii & 53.8 & 33.7 & 3.4 & 0.3 & 0.2 & 0.01 & 0.01 & 4.5 & 3.3 \\
\hline Mastogloia lacrimata & 52.1 & 34.0 & 2.5 & 0.4 & 0.2 & 0.01 & 0.01 & 5.3 & 3.5 \\
\hline Mastogloia ovata & 63.6 & 33.7 & 2.3 & 0.2 & 0.1 & 0.01 & 0.01 & 3.5 & 1.4 \\
\hline Mastogloia rostellata & 58.8 & 34.0 & 2.0 & 0.2 & 0.1 & 0.01 & 0.00 & 3.3 & 1.4 \\
\hline Navicula sp. 18 & 41.9 & 34.0 & 2.2 & 0.2 & 0.1 & 0.01 & 0.01 & 3.2 & 1.3 \\
\hline Navicula sp. 21 & 63.7 & 33.0 & 3.8 & 0.8 & 0.2 & 0.01 & 0.01 & 11.3 & 2.6 \\
\hline Nitzschia angularis & 54.0 & 31.4 & 7.0 & 0.5 & 0.4 & 0.01 & 0.01 & 7.5 & 7.1 \\
\hline Nitzschia closterium & 71.8 & 33.6 & 3.1 & 0.2 & 0.1 & 0.01 & 0.01 & 3.4 & 2.0 \\
\hline Nitzschia grossestriata & 52.6 & 30.0 & 7.3 & 0.5 & 0.3 & 0.01 & 0.02 & 7.9 & 6.0 \\
\hline Nitzschia macilenta & 59.1 & 35.0 & 1.8 & 0.2 & 0.1 & 0.00 & 0.00 & 2.5 & 1.1 \\
\hline Neosynedra tortosa & 82.4 & 33.5 & 3.5 & 0.3 & 0.2 & 0.01 & 0.01 & 3.7 & 2.4 \\
\hline $\begin{array}{l}\text { Paralia sulcata } \\
\text { Psammodictyon }\end{array}$ & 47.8 & 35.4 & 1.2 & 0.2 & 0.1 & 0.00 & 0.00 & 2.5 & 1.4 \\
\hline panduriforme & 63.9 & 32.8 & 3.0 & 0.3 & 0.1 & 0.01 & 0.02 & 3.8 & 1.9 \\
\hline Seminavis cyrtorapha & 68.8 & 33.8 & 2.4 & 0.2 & 0.1 & 0.01 & 0.02 & 3.5 & 1.6 \\
\hline Surirella fluminensis & 52.2 & 34.7 & 1.5 & 0.2 & 0.1 & 0.01 & 0.00 & 2.8 & 1.0 \\
\hline Triceratium reticulum & 69.1 & 34.0 & 2.2 & 0.3 & 0.1 & 0.01 & 0.01 & 4.1 & 2.3 \\
\hline Toxarium hennedianum & 67.7 & 33.0 & 3.1 & 0.2 & 0.1 & 0.01 & 0.01 & 3.6 & 2.0 \\
\hline $\begin{array}{l}\text { Toxarium undulatum } \\
\text { Thalassiophysa hyaline }\end{array}$ & 65.2 & 34.4 & 2.8 & 0.3 & 0.2 & 0.01 & 0.01 & 4.0 & 3.0 \\
\hline var. insecta & 61.6 & 30.8 & 6.0 & 0.5 & 0.3 & 0.01 & 0.03 & 7.0 & 4.0 \\
\hline \multicolumn{10}{|l|}{ wet season } \\
\hline $\begin{array}{l}\text { Amphora coffeaeformis } \\
\text { var. aponina }\end{array}$ & 62.9 & 30.9 & 3.6 & 0.3 & 0.1 & 0.02 & 0.02 & 4.9 & 2.2 \\
\hline
\end{tabular}




$\begin{array}{lccccccccc}\text { Amphora cymbifera var. } & & & & & & & & & \\ \text { heritierarum } & 47.0 & 31.2 & 3.8 & 0.3 & 0.1 & 0.01 & 0.01 & 4.8 & 2.5 \\ \text { Caloneis excentrica } & 52.7 & 29.6 & 4.5 & 0.4 & 0.2 & 0.02 & 0.03 & 6.7 & 4.7 \\ \text { Climaconeis colemaniae } & 52.4 & 31.1 & 3.4 & 0.3 & 0.1 & 0.02 & 0.02 & 4.6 & 2.1 \\ \text { Cyclotella distinguenda } & 87.1 & 28.2 & 4.9 & 0.5 & 0.3 & 0.02 & 0.03 & 7.8 & 4.6 \\ \text { Cyclotella meneghiniana } & 56.7 & 19.9 & 8.3 & 0.6 & 0.3 & 0.02 & 0.04 & 11.1 & 5.7 \\ \text { Tabularia waernii } & 86.1 & 26.4 & 7.2 & 0.4 & 0.2 & 0.02 & 0.03 & 6.8 & 3.8 \\ \text { Fragilaria cf. nanana } & 81.5 & 27.1 & 8.7 & 0.7 & 0.3 & 0.02 & 0.04 & 10.7 & 4.6 \\ \text { Licmophora normaniana } & 78.6 & 28.2 & 5.9 & 0.4 & 0.3 & 0.02 & 0.02 & 7.2 & 4.3 \\ \text { Mastogloia elegans } & 74.7 & 29.3 & 3.3 & 0.3 & 0.1 & 0.02 & 0.03 & 5.8 & 2.2 \\ \text { Mastogloia halophila } & 80.6 & 28.6 & 5.7 & 0.5 & 0.3 & 0.02 & 0.02 & 8.4 & 6.0 \\ \text { Navicula palestinae } & 45.6 & 27.7 & 6.2 & 0.6 & 0.3 & 0.02 & 0.03 & 9.6 & 5.3 \\ \text { Navicula } & & & & & & & & & \\ \text { pseudocrassirostris } & 76.0 & 29.6 & 3.4 & 0.3 & 0.1 & 0.02 & 0.02 & 5.3 & 2.0 \\ \text { Navicula salinicola } & 45.0 & 20.1 & 9.6 & 0.5 & 0.2 & 0.01 & 0.00 & 9.6 & 4.8 \\ \text { Rhopalodia gibberula } & 53.7 & 30.5 & 5.4 & 0.4 & 0.3 & 0.01 & 0.01 & 6.1 & 5.1 \\ \text { Seminavis eulensteinii } & 82.3 & 29.7 & 4.0 & 0.3 & 0.1 & 0.02 & 0.03 & 5.1 & 2.3\end{array}$


Table 4.2 Spearman rank correlation coefficients for quantitative variables and Kruskall-Wallis values for categorical variables for environmental variables of interest measured in dry and wet seasons. Asterisk next to values indicate significant correlation at $\alpha<0.05$. Asymp. Sig. $=$ Asymptotic significance, Chi-Square $=$ Chi-square statistical test. Symbols indicate: Sal. $=$ salinity, Turb=turbidity, $\mathrm{O} 2=$ oxygen, Temp. $=$ temperature, $\mathrm{STP}=$ sediment total phosphorus, $\mathrm{STN}=$ sediment total nitrogen, $\mathrm{STC}=$ sediment total carbon, $\mathrm{WTN}=$ water total nitrogen, $\mathrm{WTP}=$ water total phosphorus, $\mathrm{WTOC}=$ water total organic carbon.

\begin{tabular}{|c|c|c|c|c|c|c|c|c|c|c|c|c|c|c|}
\hline Env. Variable & $\begin{array}{c}\mathrm{O} 2 \\
(\mathrm{mg} / \mathrm{L}) \\
\end{array}$ & $\begin{array}{c}\text { Turb. } \\
\text { (NTU) }\end{array}$ & $\begin{array}{c}\text { Depth } \\
\text { (m) }\end{array}$ & $\begin{array}{l}\text { Sal. } \\
\text { (ppt) }\end{array}$ & $\begin{array}{c}\text { Temp. } \\
\left({ }^{\circ} \mathrm{C}\right)\end{array}$ & $\mathrm{pH}$ & $\begin{array}{c}\text { STP } \\
(\mathrm{ppm})\end{array}$ & $\begin{array}{r}\text { STN } \\
\text { (ppm) }\end{array}$ & $\begin{array}{c}\mathrm{STC} \\
(\mathrm{ppm})\end{array}$ & $\begin{array}{l}\text { WTN } \\
(\mathrm{ppm}) \\
\end{array}$ & $\begin{array}{c}\text { WTP } \\
(\mathrm{ppm}) \\
\end{array}$ & $\begin{array}{c}\text { WTOC } \\
(\mathrm{ppm})\end{array}$ & Axis1 & Axis2 \\
\hline \multicolumn{15}{|l|}{ dry season } \\
\hline Sal. (ppt) & $0.287^{*}$ & -0.051 & $0.301^{*}$ & 1 & 0.052 & $-0.462 *$ & $-0.554^{*}$ & $\overline{0.478 *}$ & -0.22 & -0.206 & $-0.374 *$ & $-0.286^{*}$ & -0.041 & $0.647 *$ \\
\hline WTN(ppm) & $-0.397^{*}$ & 0.025 & -0.092 & -0.206 & 0.12 & -0.117 & 0.166 & 0.162 & 0.007 & 1 & 0.131 & $0.296^{*}$ & $-0.38^{*}$ & $0.281 *$ \\
\hline WTP(ppm) & $-0.453^{*}$ & -0.091 & $-0.788^{*}$ & $-0.374 *$ & -0.251 & 0.061 & $0.568^{*}$ & $0.539^{*}$ & 0.167 & 0.131 & 1 & $0.702 *$ & $\begin{array}{l}-0.113 \\
-\end{array}$ & $\begin{array}{l}0.683^{*} \\
-\end{array}$ \\
\hline WTOC(ppm) & $-0.44^{*}$ & -0.052 & $-0.725^{*}$ & $-0.286^{*}$ & -0.208 & 0.034 & $0.552 *$ & $0.551 *$ & 0.078 & $0.296^{*}$ & $0.702 *$ & 1 & $0.341^{*}$ & $0.699 *$ \\
\hline axis1 & $0.288^{*}$ & 0.126 & 0.213 & -0.041 & -0.085 & 0.116 & -0.033 & $\begin{array}{l}-0.082 \\
-\end{array}$ & $\begin{array}{l}-0.011 \\
-\end{array}$ & $\begin{array}{l}-0.38^{*} \\
-\end{array}$ & -0.113 & $-0.341^{*}$ & 1 & 0.237 \\
\hline axis2 & $0.613^{*}$ & 0.034 & $0.775^{*}$ & $0.647^{*}$ & 0.08 & -0.182 & $-0.749 *$ & $0.686^{*}$ & $0.344^{*}$ & $0.281^{*}$ & $-0.683 *$ & $-0.699 *$ & 0.237 & 1 \\
\hline \multicolumn{15}{|l|}{ wet season } \\
\hline Sal. (ppt) & 0.157 & $\begin{array}{l}- \\
0.370^{*}\end{array}$ & $0.623 *$ & 1.000 & -0.139 & $0.759 *$ & $-0.448^{*}$ & $-\overline{0.545^{*}}$ & $\begin{array}{l}-472 * \\
0.4\end{array}$ & $-0.56^{*}$ & $-0.775^{*}$ & $-0.745^{*}$ & $0.761 *$ & $\begin{array}{l}- \\
0.707 *\end{array}$ \\
\hline WTN(ppm) & $-0.318^{*}$ & 0.183 & -0.230 & $-0.560^{*}$ & -0.134 & $-0.326^{*}$ & 0.212 & $0.278^{*}$ & 0.139 & 1 & $0.408 *$ & $0.445^{*}$ & $\begin{array}{l}0.434 * \\
-\end{array}$ & $0.476^{*}$ \\
\hline WTP(ppm) & -0.137 & $0.365^{*}$ & $-0.741^{*}$ & $-0.775^{*}$ & 0.175 & $-0.654^{*}$ & $0.672 *$ & $0.708^{*}$ & $0.693^{*}$ & $0.408^{*}$ & 1 & $0.821^{*}$ & $0.774 *$ & $0.682 *$ \\
\hline WTOC(ppm) & $-0.336^{*}$ & $\begin{array}{l}0.200 \\
-\end{array}$ & $-0.647 *$ & $-0.745^{*}$ & $\begin{array}{l}-0.076 \\
-\end{array}$ & $-0.603 *$ & $0.574 *$ & $\begin{array}{l}0.634 * \\
-\end{array}$ & $\begin{array}{l}0.558^{*} \\
-\end{array}$ & $\begin{array}{l}0.445^{*} \\
-\end{array}$ & $0.821 *$ & 1 & $-0.62 *$ & $\begin{array}{l}0.686^{*} \\
-\end{array}$ \\
\hline axis1 & 0.097 & $0.499 *$ & $0.718^{*}$ & $0.761^{*}$ & $0.400^{*}$ & $0.719 *$ & $-0.464 *$ & $0.631^{*}$ & $0.535^{*}$ & $0.434 *$ & $-0.774 *$ & $-0.62 *$ & $\begin{array}{l}1 \\
-\end{array}$ & $0.542 *$ \\
\hline axis2 & -0.248 & $0.426^{*}$ & $-0.392 *$ & $-0.707^{*}$ & -0.097 & $-0.546^{*}$ & $0.586^{*}$ & $0.489^{*}$ & $0.596^{*}$ & $0.476^{*}$ & $0.682 *$ & $0.686^{*}$ & $0.542 *$ & 1 \\
\hline
\end{tabular}




\begin{tabular}{|c|c|c|c|c|c|c|c|c|c|c|c|c|c|}
\hline \multicolumn{14}{|c|}{ Categorical Variables } \\
\hline \multicolumn{14}{|l|}{ dry season } \\
\hline \multirow[t]{2}{*}{ life habits } & 0.000 & 0.000 & 0.000 & 0.000 & 0.000 & 0.000 & 0.000 & 0.000 & 0.000 & 0.000 & 0.000 & 0.000 & Chi-Square \\
\hline & 1.000 & 1.000 & 1.000 & 1.000 & 1.000 & 1.000 & 1.000 & 1.000 & 1.000 & 1.000 & 1.000 & 1.000 & Asymp. Sig. \\
\hline \multirow[t]{2}{*}{ clusters } & 34.000 & 3.500 & 121.300 & 34.600 & 15.400 & 15.200 & 80.800 & 66.500 & 4.000 & 4.400 & 95.500 & 107.700 & Chi-Square \\
\hline & $0.000 *$ & 0.062 & $0.000^{*}$ & $0.000^{*}$ & $0.000 *$ & $0.000^{*}$ & $0.000^{*}$ & $0.000 *$ & $0.045^{*}$ & $0.036^{*}$ & $0.000 *$ & $0.000^{*}$ & Asymp. Sig. \\
\hline \multirow[t]{2}{*}{ Locatons } & 25.500 & 7.500 & 128.500 & 44.500 & 19.800 & 6.200 & 103.200 & 82.300 & 7.600 & 0.500 & 112.300 & 95.200 & Chi-Square \\
\hline & $0.000 *$ & 0.006 & $0.000 *$ & $0.000^{*}$ & $0.000 *$ & $0.013^{*}$ & $0.000 *$ & $0.000 *$ & $0.006^{*}$ & 0.479 & $0.000 *$ & $0.000 *$ & Asymp. Sig. \\
\hline \multicolumn{14}{|l|}{ wet season } \\
\hline \multirow[t]{2}{*}{ life habits } & 0.000 & 0.000 & 0.000 & 0.000 & 0.000 & 0.000 & 0.000 & 0.000 & 0.000 & 0.000 & 0.000 & 0.000 & Chi-Square \\
\hline & 1.000 & 1.000 & 1.000 & 1.000 & 1.000 & 1.000 & 1.000 & 1.000 & 1.000 & 1.000 & 1.000 & 1.000 & Asymp. Sig. \\
\hline \multirow[t]{2}{*}{ clusters } & 4.064 & 8.438 & 127.568 & 81.289 & 6.488 & 73.430 & 78.854 & 98.121 & 67.003 & 18.056 & 128.459 & 95.624 & Chi-Square \\
\hline & $0.044 *$ & $0.004 *$ & $0.000^{*}$ & $0.000^{*}$ & $0.011^{*}$ & $0.000^{*}$ & $0.000 *$ & $0.000 *$ & $0.000^{*}$ & $0.000 *$ & $0.000 *$ & $0.000^{*}$ & Asymp. Sig. \\
\hline \multirow[t]{2}{*}{ Locations } & 10.190 & 60.476 & 60.061 & 104.101 & 2.780 & 103.580 & 60.095 & 61.703 & 68.314 & 26.317 & 96.722 & 75.559 & Chi-Square \\
\hline & $0.001 *$ & $0.000^{*}$ & $0.000 *$ & $0.000^{*}$ & 0.095 & $0.000^{*}$ & $0.000^{*}$ & $0.000^{*}$ & $0.000^{*}$ & $0.000^{*}$ & $0.000^{*}$ & $0.000^{*}$ & Asymp. Sig. \\
\hline
\end{tabular}


Table 4.3 Indicator species of planktonic, epiphytic and epipelic habitats identified by

Indicator Species Analysis (ISA). All indicator values are significant at $\alpha<0.05$.

\begin{tabular}{|c|c|c|c|c|}
\hline \multirow[b]{2}{*}{ Taxon Name } & \multicolumn{3}{|c|}{$\begin{array}{c}\% \text { of samples in given group where } \\
\text { taxon is present }\end{array}$} & \multirow{2}{*}{$\begin{array}{c}\text { Observec } \\
\text { Indicator } \\
\text { Value }\end{array}$} \\
\hline & Sediment & Epiphyton & Plankton & \\
\hline \multicolumn{5}{|l|}{ Plankton } \\
\hline \multicolumn{5}{|l|}{$\underline{\text { Dry season }}$} \\
\hline Entomoneis peludosa & 2 & 3 & 62 & 59.3 \\
\hline Entomoneis pseudoduplex & 0 & 31 & 64 & 49.5 \\
\hline Licmophora pfannkuheae & 5 & 48 & 74 & 52.6 \\
\hline Microtabella interrupta & 34 & 93 & 95 & 53.5 \\
\hline Microtabella sp. 01 & 0 & 47 & 84 & 68.1 \\
\hline Nitzschia longissima f. parva & 0 & 0 & 48 & 48.3 \\
\hline Nitzschia sigma & 2 & 9 & 57 & 52.8 \\
\hline Psammodictyon panduriforme & 17 & 76 & 98 & 69.6 \\
\hline Thalassionema sp. 01 & 0 & 7 & 64 & 60.4 \\
\hline \multicolumn{5}{|l|}{$\underline{\text { Wet season }}$} \\
\hline Chaetoceros sp. 02 & 0 & 0 & 57 & 56.9 \\
\hline Cyclotella choctawhatcheana & 76 & 79 & 90 & 50.1 \\
\hline Microtabella interrupta & 17 & 43 & 69 & 43.2 \\
\hline Synedra sp. 03 & 0 & 0 & 57 & 56.9 \\
\hline \multicolumn{5}{|l|}{ Epiphytes } \\
\hline \multicolumn{5}{|l|}{ Dry season } \\
\hline Amphora sp. 05 & 28 & 67 & 43 & 43.5 \\
\hline Amphora sp. 06 & 24 & 66 & 3 & 54.1 \\
\hline Brachysira aponina & 72 & 84 & 93 & 41.1 \\
\hline Cocconeis placentula var. euglypta & 78 & 100 & 81 & 61.6 \\
\hline $\begin{array}{l}\text { Cocconeis placentula } \\
\text { Hyalosynedra laevigata var. }\end{array}$ & 90 & 90 & 90 & 53.5 \\
\hline angustata & 9 & 59 & 2 & 49.7 \\
\hline Mastogloia pusilla & 60 & 76 & 19 & 41.1 \\
\hline Nitzschia dissipata var. media & 0 & 50 & 0 & 50 \\
\hline Nitzschia liebetruthii & 38 & 78 & 38 & 45.9 \\
\hline \multicolumn{5}{|l|}{$\underline{\text { Wet season }}$} \\
\hline \multicolumn{5}{|l|}{ Sediment } \\
\hline \multicolumn{5}{|l|}{$\underline{\text { Dry season }}$} \\
\hline Amphora corpulenta var. capitata & 55 & 14 & 10 & 45.3 \\
\hline Amphora floridae & 60 & 10 & 16 & 45.4 \\
\hline Amphora proteus & 50 & 3 & 7 & 41.6 \\
\hline Caloneis excentrica & 55 & 5 & 16 & 41.8 \\
\hline Cyclotella distinguenda & 67 & 43 & 38 & 40.1 \\
\hline Dimeregramma dubium & 52 & 24 & 3 & 43 \\
\hline Diploneis suborbicularis & 59 & 5 & 9 & 48.4 \\
\hline Frustulia sp. 01 & 53 & 0 & 9 & 47.4 \\
\hline Grammatophora oceanica & 72 & 26 & 17 & 53.3 \\
\hline
\end{tabular}




$\begin{array}{lcccc}\text { Mastogloia erythraea } & 81 & 48 & 41 & 43.3 \\ \text { Mastogloia nabulosa } & 69 & 9 & 34 & 50 \\ \text { Mastogloia pisciculus } & 57 & 17 & 14 & 42.2 \\ \text { Oestrupia grandis } & 67 & 7 & 12 & 56.1 \\ \text { Rhopalodia constricta } & 69 & 3 & 41 & 48.4 \\ \text { Rhopalodia gibberula } & 88 & 67 & 17 & 46.7 \\ \text { Seminavis latior } & 76 & 26 & 47 & 40.9 \\ \text { Wet season } & & & & \\ \text { Rhopalodia pacifica } & 84 & 24 & 38 & 57.9 \\ \text { Mastogloia strigilis } & 84 & 29 & 52 & 51.3 \\ \text { Fragilaria geocollegarum } & 59 & 12 & 5 & 49 \\ \text { Amphicocconeis disculoides } & 57 & 2 & 21 & 46 \\ \text { Mastogloia bahamensis } & 55 & 9 & 9 & 45.1 \\ \text { Mastogloia crucicula } & 95 & 74 & 72 & 43.2 \\ \text { Hyalosynedra laevigata } & 100 & 93 & 100 & 40.5\end{array}$


Fig 4.1 Map of Biscayne Bay showing locations of the sampled sites.

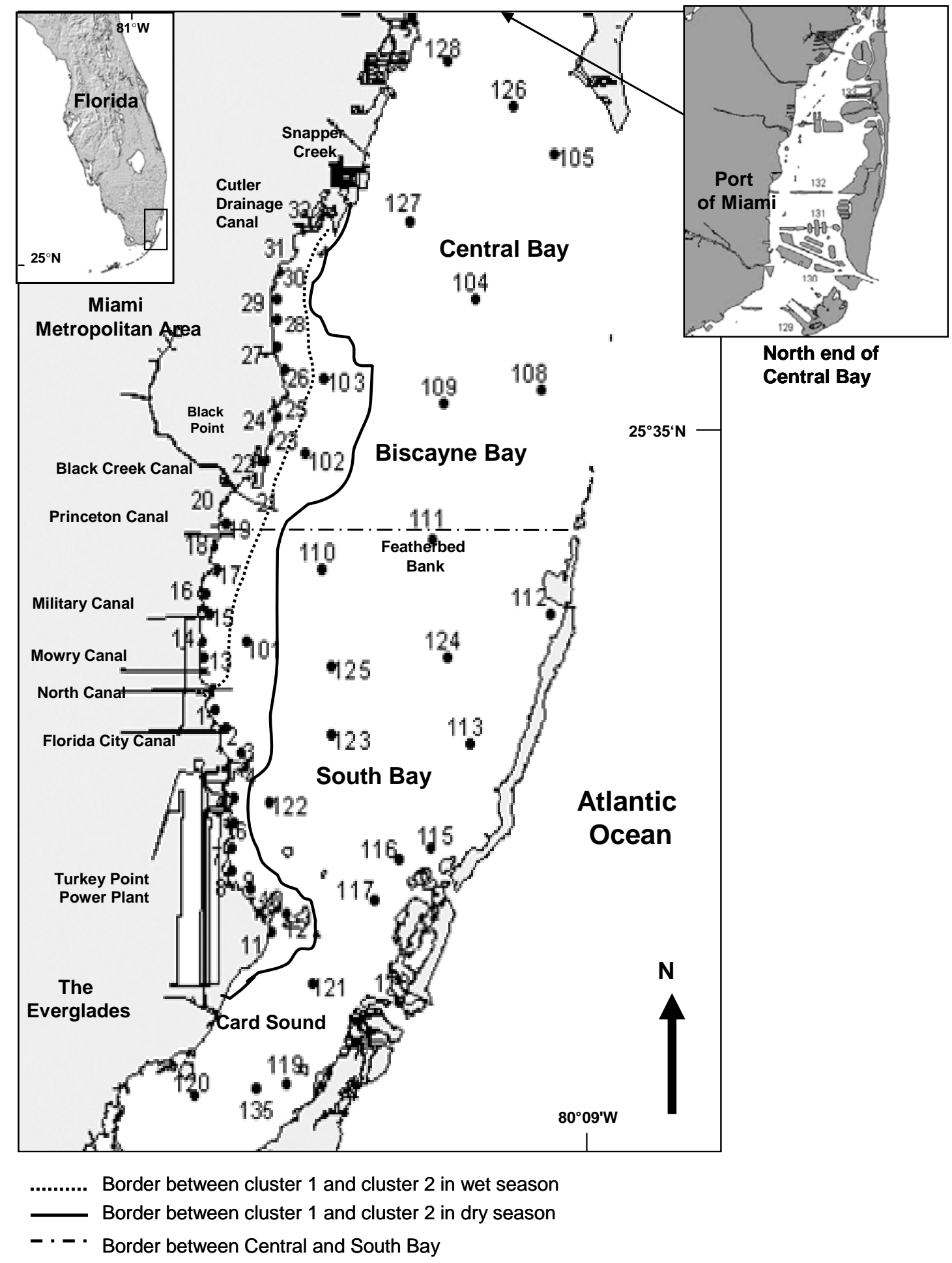


Fig. 4.2 Dendrograms showing groups of sites clustered based on diatom assemblage similarities in the dry season (a) and in the wet season (b). Open circles represent open-bay sites and black diamonds represent nearshore sites.

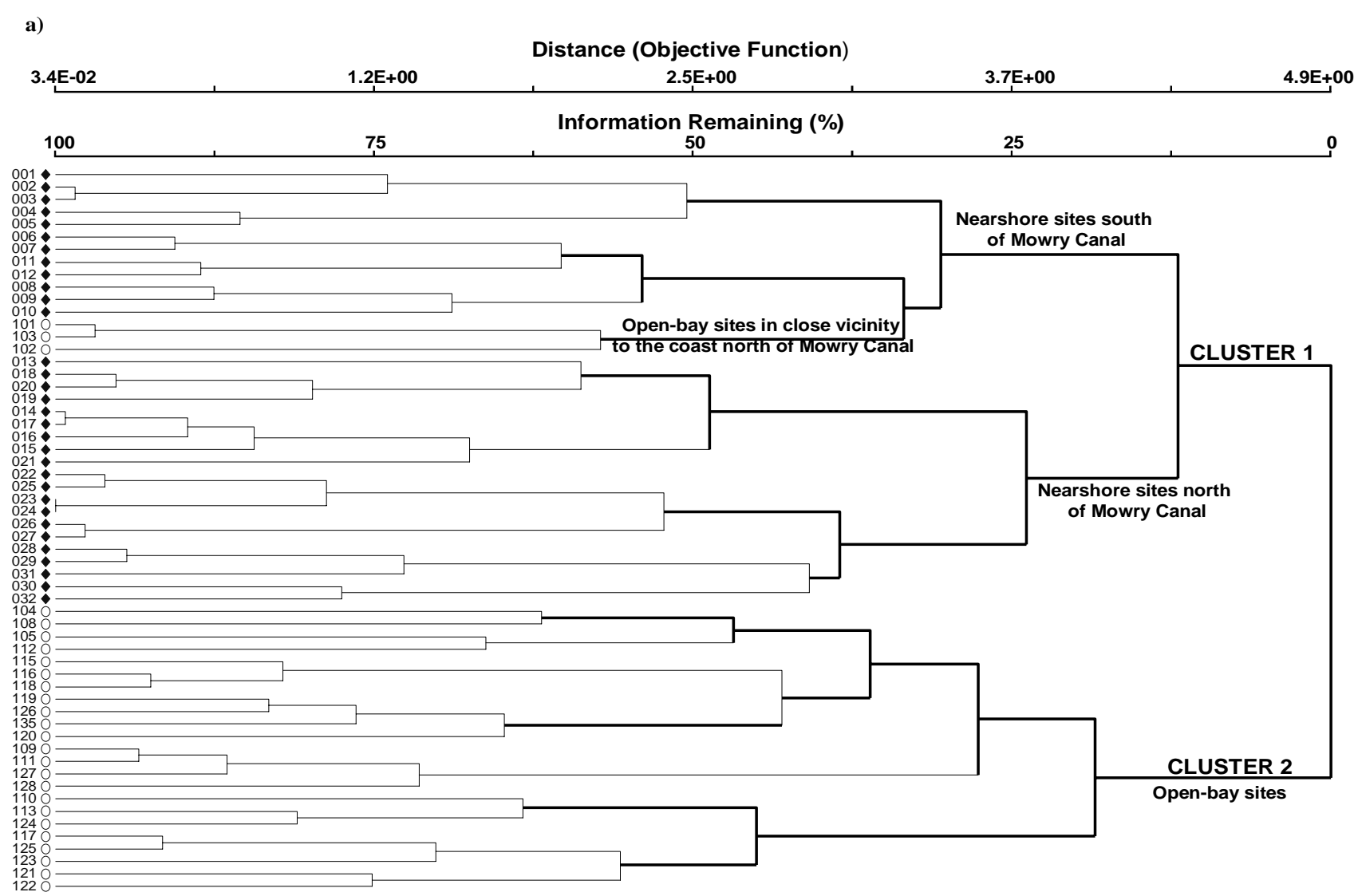


b)

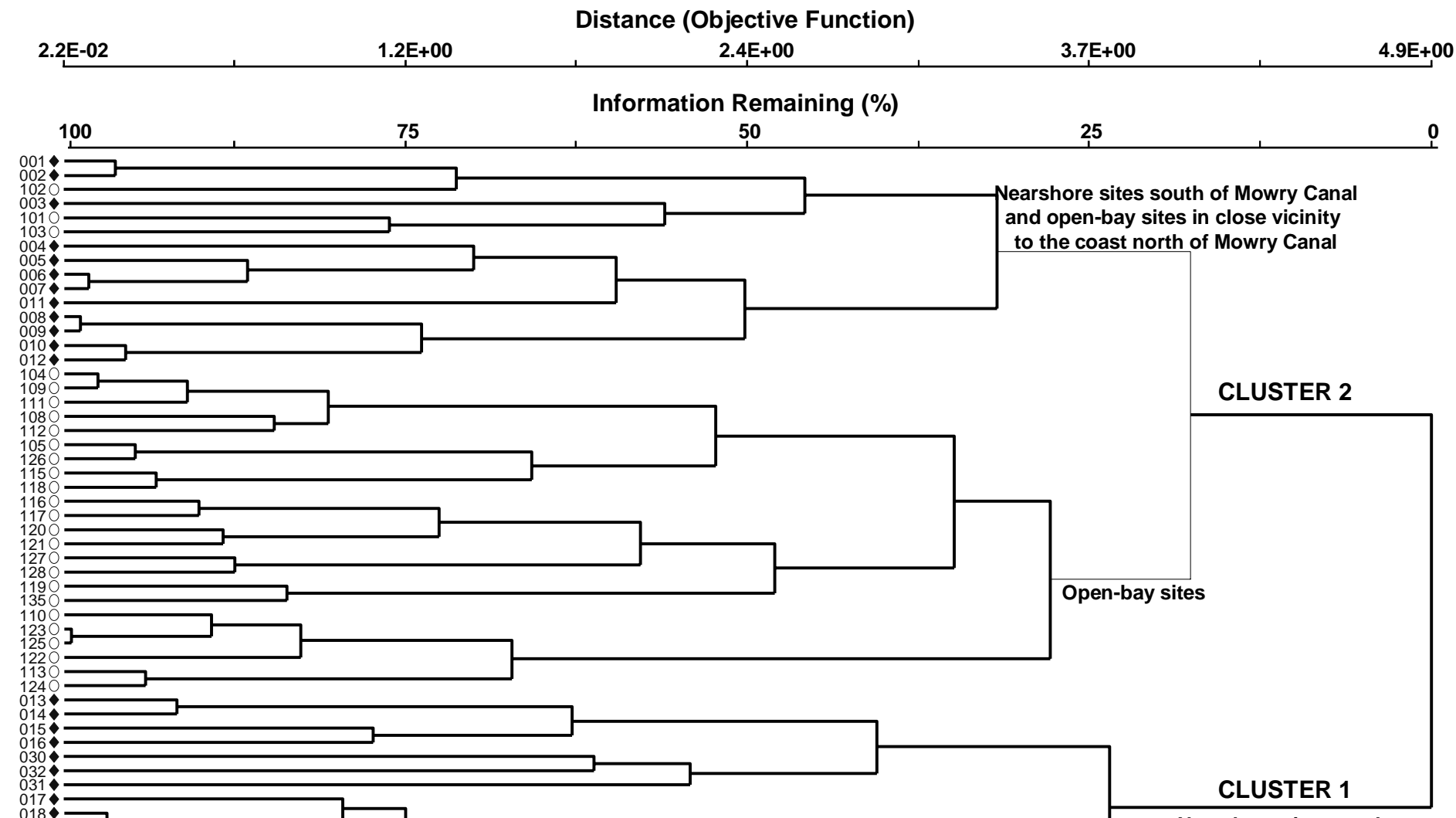

Nearshore sites south of Mowry Canal 


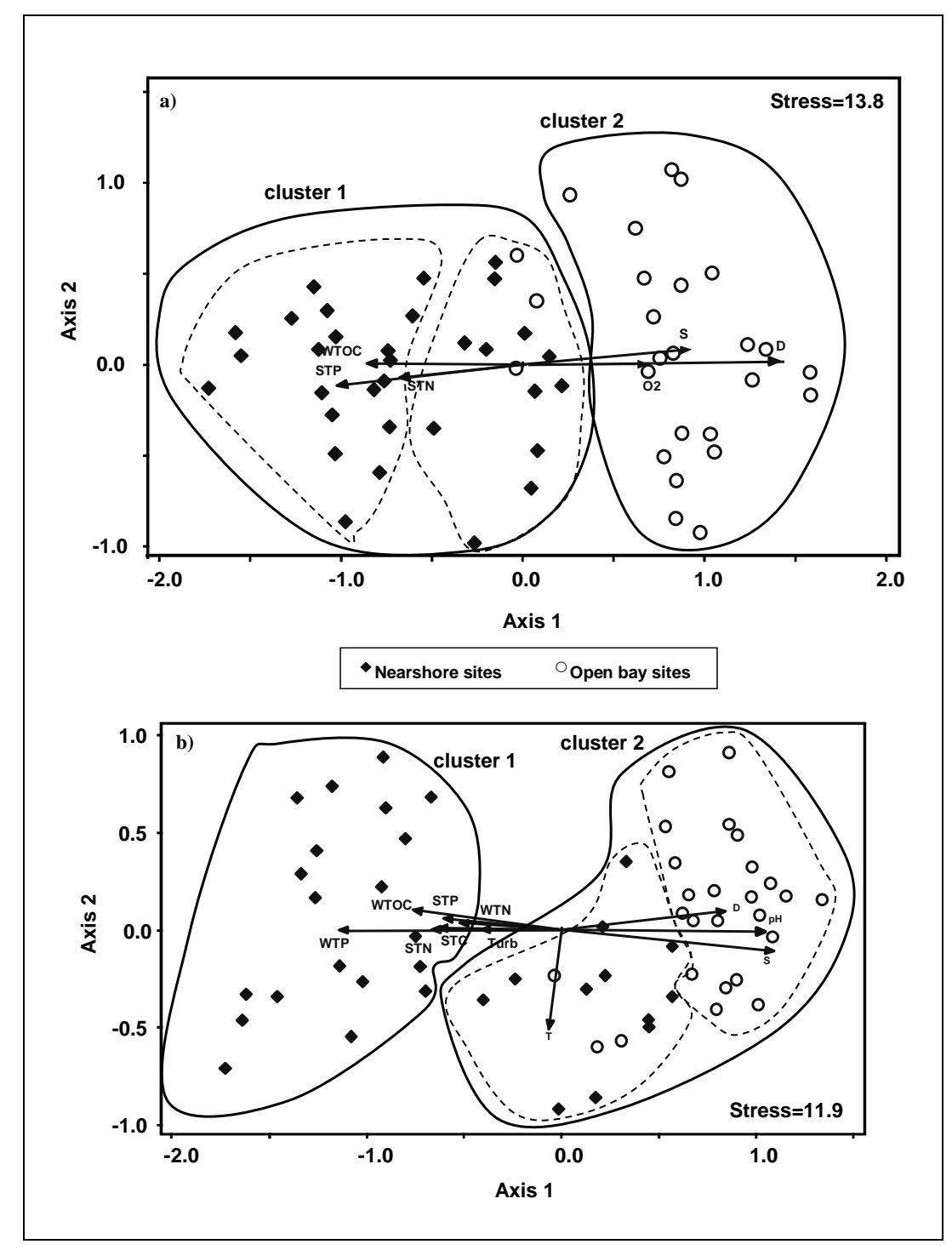

Fig. 4.3 NMDS ordination site scores for dry (a) and wet (b) seasons coded by geographical location and separated into clusters (solid lines) and sub-clusters (broken line) based on the cluster analysis of Fig. 4.2. Vectors correspond to the direction of maximum correlation of environmental variables having significant correlation with NMDS site scores. Symbols of the variables represented by the vectors have been defined in the text. 


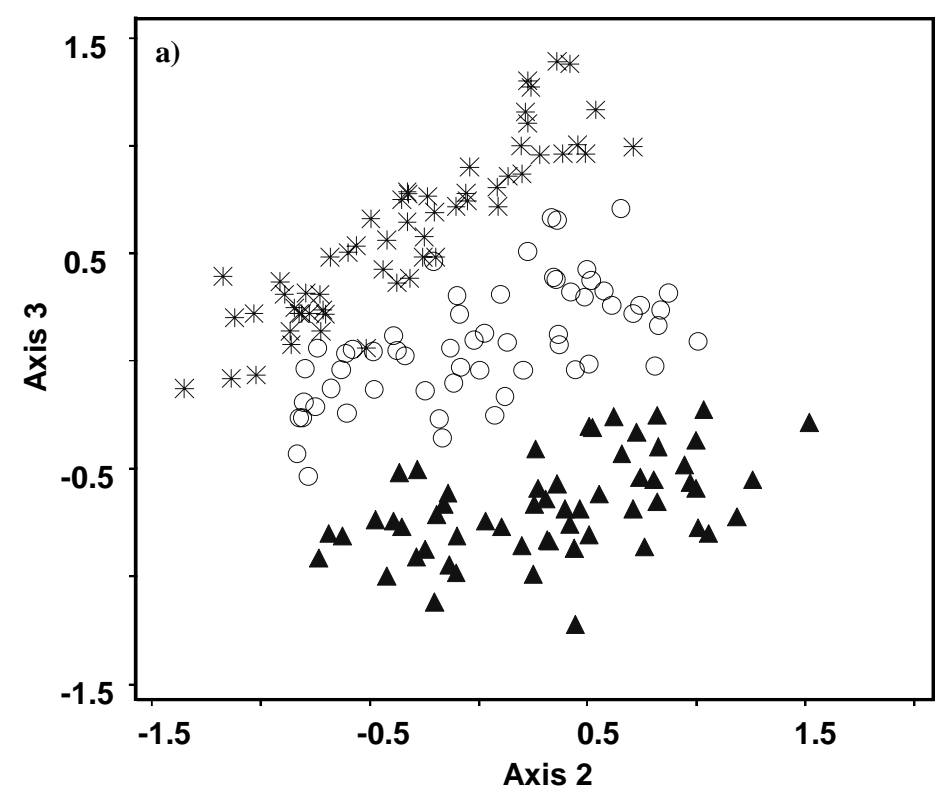

\ plankton $\bigcirc$ epiphyton $*$ epipelon

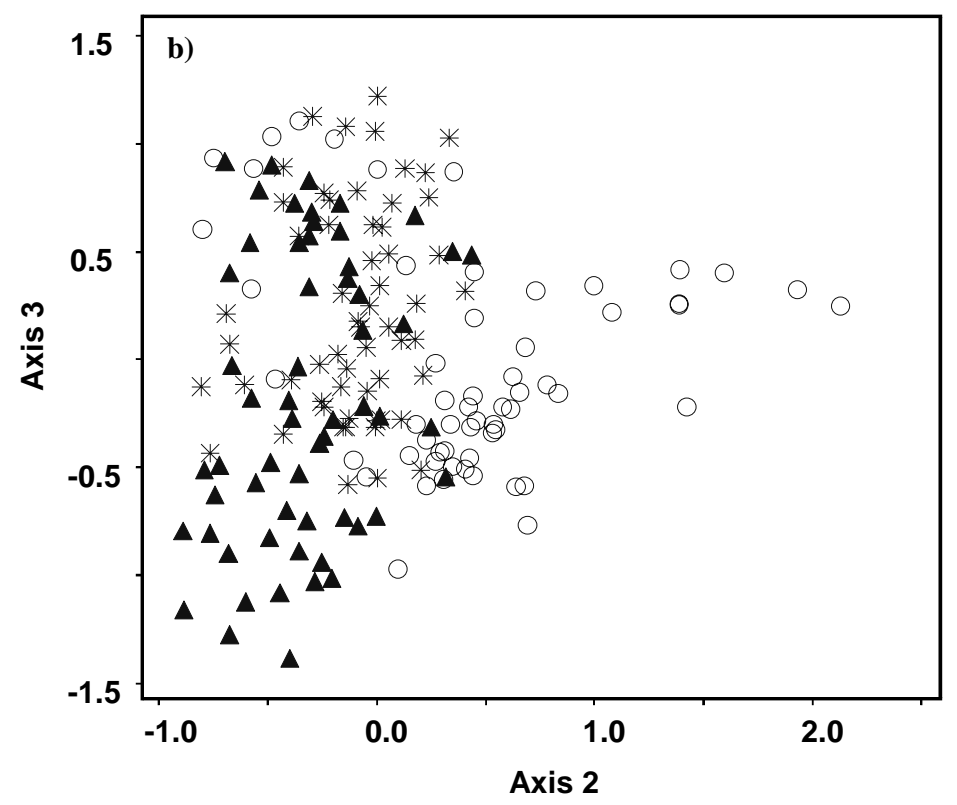

Fig. 4.4 NMDS ordination site scores for dry (a) and wet (b) seasons coded by life habit types in two dimensional space. 
a)
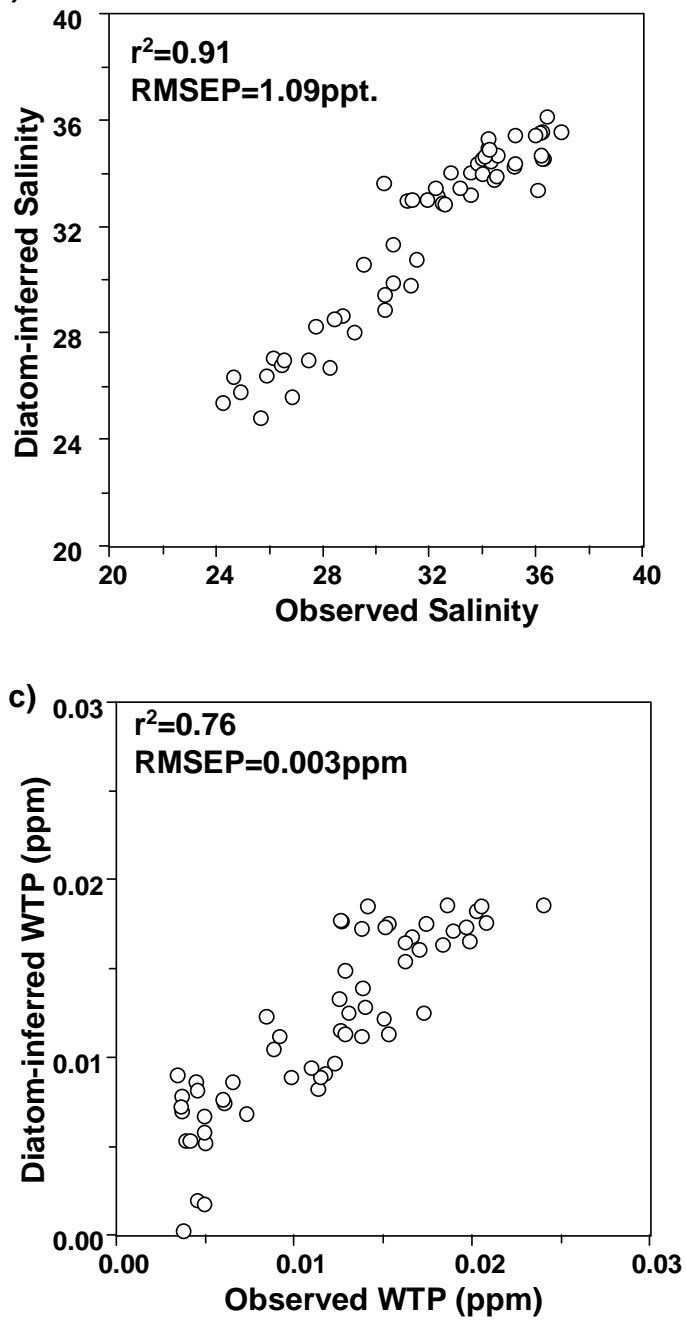

b)
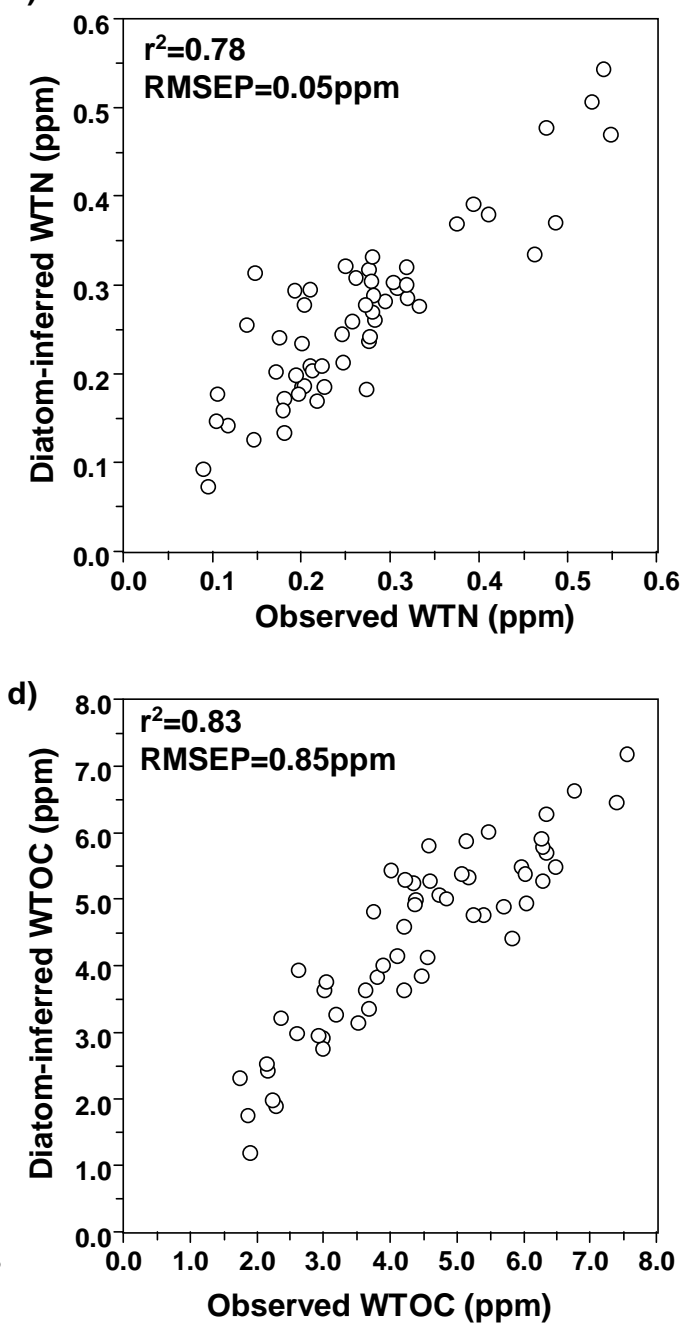

Fig. 4.5 Relationships between observed vs. diatom-inferred salinity (a), WTN (b), WTP (c) and WTOC (d) WA-PLS and WA regression and calibration models. 


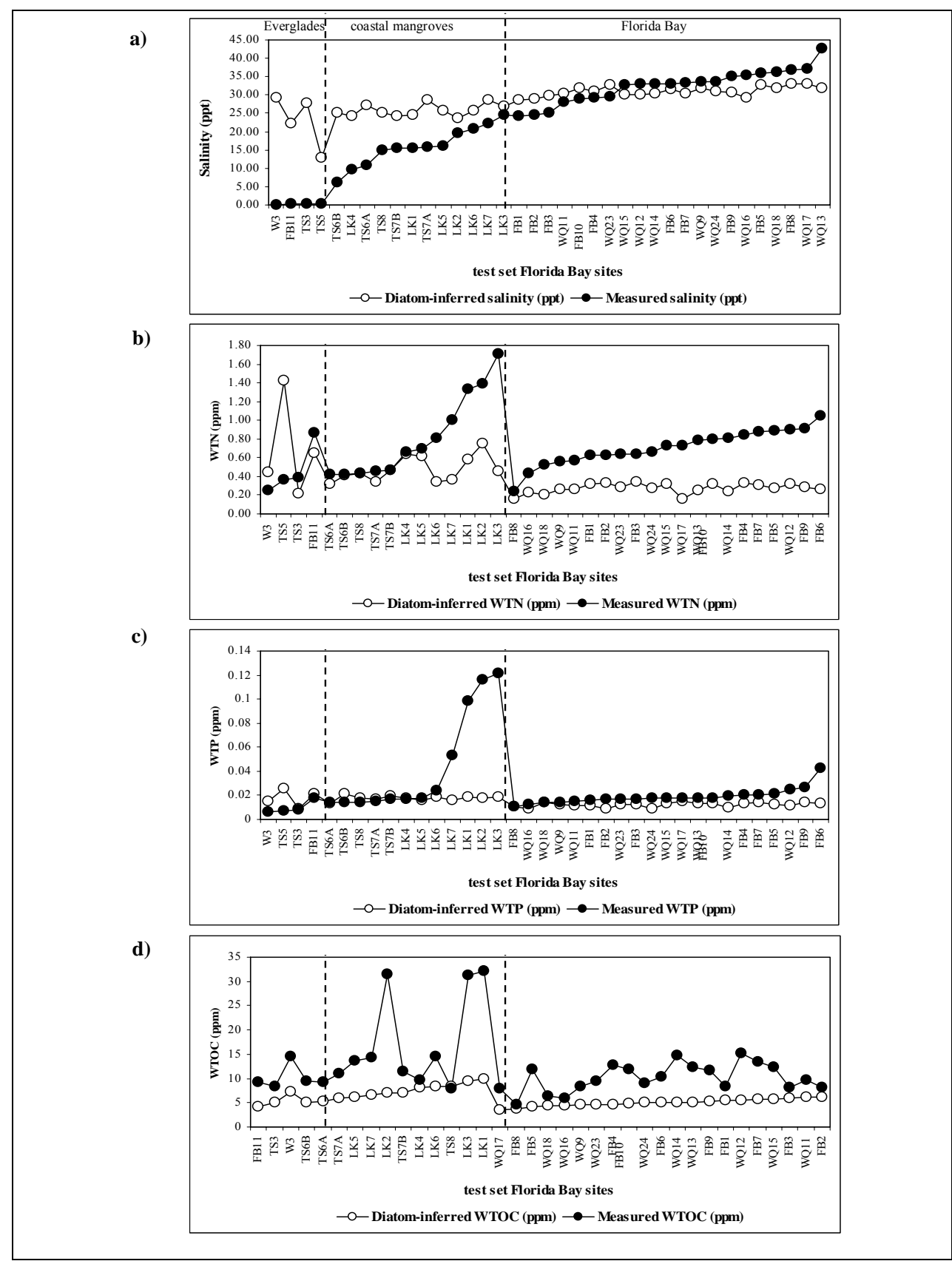

Fig. 4.6 Diatom-based WAPLS predictions of salinity (a), WTN (b), WTP (c), and WTOC (d) based on 96-site training set for 37-site Florida Bay independent test-set (Chapter 2) with site specific root mean square error of prediction indicated by error bars compared to the measured values of these variables. 


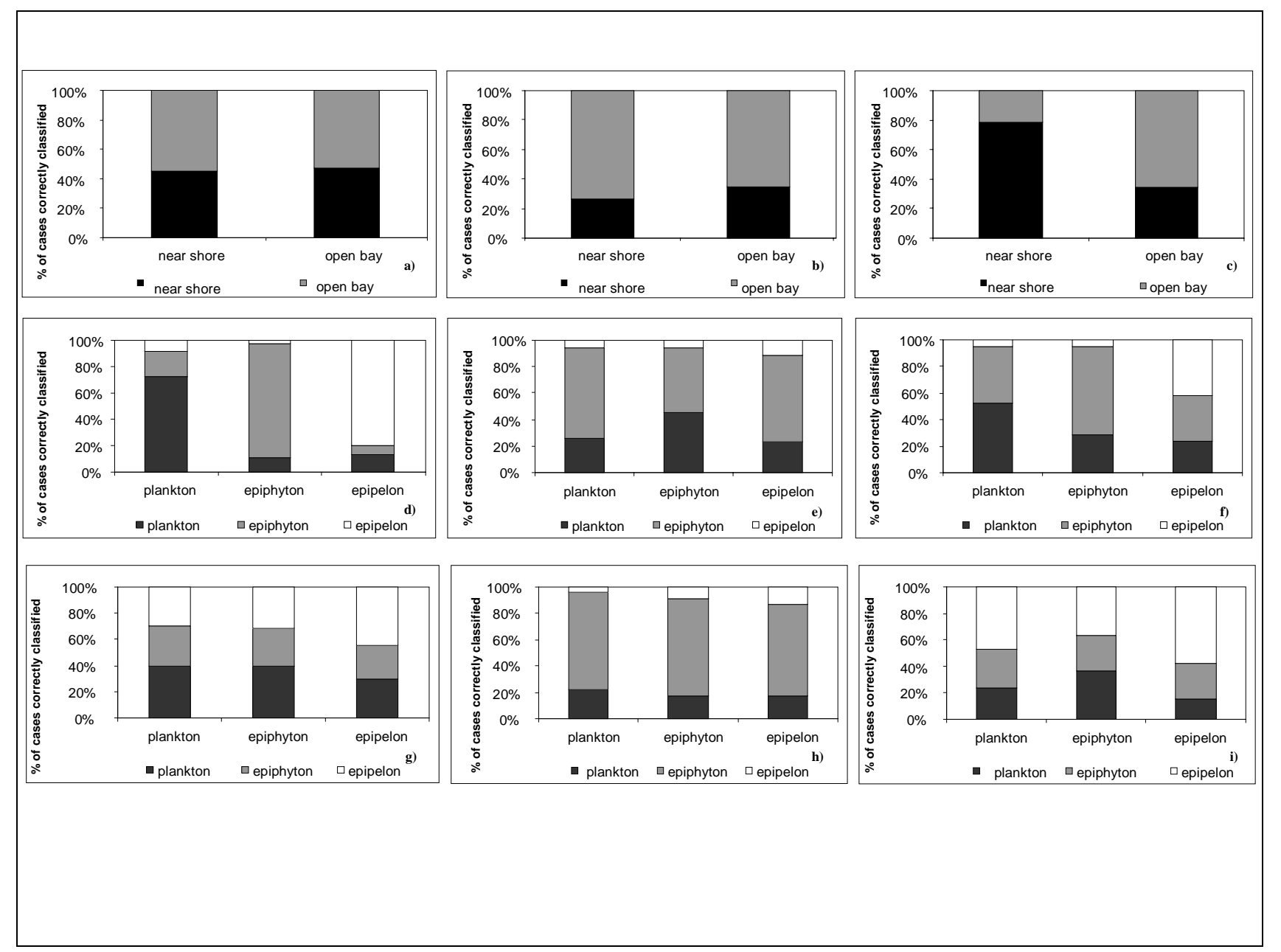

Fig. 4.7 Diatom-based predictions of habitat $(\mathrm{a}-\mathrm{c})$ and life-habit type in Cluster $1(\mathrm{~d}-\mathrm{f})$ and Cluster $2(\mathrm{~g}-\mathrm{i})$ based on discriminant function analysis using dry- and wet-season data sets. 


\section{REFERENCES}

Admiraal,W. 1984. The ecology of estuarine sediment-inhabiting diatoms. Progress in Phycological Research 3:269-322.

Admiral, W., and H. Peletier. 1979. Influence of organic compounds and light limitation on the growth rate of estuarine benthic diatoms. British Phycological Journal 14:197-206.

Andrén E., Andren T., and H. Kunzendorf. 2000. Holocene history of the Baltic Sea as a background for assessing records of human impact in the sediments of the Gotland Basin. Holocene 10:687-702.

Armitage, A.R., Frankovich, T.A., and J.W. Fourqurean. 2006. Variable responses within epiphytic and benthic microalgal communitiestonutrient enrichment. Hydrobiologia 569:423-435.

Battarbee, R.W. 1986. Diatom analysis. In: B.E. Berglund (Editor), Handbook of Holocene Palaeoecology and Palaeohydrology. The Blackburn Press, Caldwell, New Jersey, USA, pp. 527-570.

Battarbee, R.W., Jones, V.J., Flower, R.J., Cameron, N.G., and G. Benoit. 2001. Diatoms. In: J.P. Smol, H.J.B. Birks, and W.M. Last (Editors), Tracking environmental change using lake sediments. Volume 3: Terrestrial, algal, and siliceous indicators. Kluwer Academic Publishers, Dordrecht, Netherlands, pp. 155-202.

Birks, H.J.B., Line, J.M., Juggins, S., Stevenson, A.C., and C.J.F. Ter Braak. 1990. Diatoms and pH reconstruction. Phil. Trans. R. Soc. Lond. B. 327:263-278.

Birks, H.J.B. 1993: Quaternary palaeoecology and vegetation science - current contributions and possible future developments. Review of Palaeobotany and Palynology 79:153-177.

Birks, H.J.B. 1998. Numerical tools in paleolimnology - progress, potentialities, and problems. Journal of Paleolimnology 20:307-332.

Brand, L. 1988. Assessment of plankton resources and their environmental interaction in Biscayne Bay, Florida. Dade Environmental Resource Management Technical Report 88$1.79 \mathrm{p}$ and appendices.

Bray, J.R., and J.T. Curtis. 1957. An ordination for the upland forest of Southern Wisconsin. Ecol. Monogr. 27:325-349.

Browder, J.A., R. Alleman, S. Markley, P. Ortner, and P.A. Pitts. 2005. Biscayne Bay Conceptual Ecological Model. Wetlands 25:854-869. 
Byrne, M.J. 1999. Groundwater nutrient loading in Biscayne Bay, Biscayne National Park, Florida: Miami, Florida International University, M.S. thesis, 88 p.

Caccia, V.G. and J.N. Boyer. 2005. Spatial patterning of water quality in Biscayne Bay, Florida as a function of land use and water management. Marine Pollution Bulletin 50:1416-1429.

Caccia, V.G. and J.N. Boyer. 2007. A nutrient loading budget for Biscayne Bay, Florida. Marine Pollution Bulletin 54: 994-1008.

Cantillo, A.Y., K. Hale, E. Collins, L. Pikula, and R. Caballero. 2000. Biscayne Bay: Environmental history and annotated bibliography: U.S. Department of Commerce, NOAA Technical Memorandum NOS NCCOS CCMA 145, Silver Spring, MD, 116 pp.

Carnahan, E. A., A. M. Hoare, P. Hallock, B. H. Lidz, and C.D. Reich. 2008. Distribution of Heavy Metals and Foraminiferal Assemblages in Sediments of Biscayne Bay, Florida, USA. Journal of Coastal Research, 24:159-169.

Clarke K.R., and M. Ainsworth. 1993. A method of linking multivariate community structure to environmental variables. Marine Ecological Progress Series 92:205-219.

Clark, K.R., and R.M. Warwick. 1994. Similarity-based testing for community pattern: the 2-way layout with no replication. Marine Biology 118:167-176.

Clarke, K.R. and R.M. Warwick. 2001. Change in marine communities: an approach to statistical analysis and interpretation. Primer-E Ltd. Plymouth.

Clarke K R., and R.N. Gorley. 2001. Primer v5: user manual/tutorial. - Primer-E Ltd. Plymouth.

Costanza, R., R. d'Arge, R. de Groot, S. Farber, M. Grasso, B. Hannon, K. Limburg, S. Naeem, R. V. O’Neill, J. Paruelo, R. G. Raskin, P. Sutton and M. van de Belt. 1997. The Value of the World's Ecosystem Services and Natural Capital. Nature 387:253-260.

Cooper, S.R. 1995b. An abundant, small brackish water Cyclotella species in Chesapeake Bay, U.S.A., In: J.P. Kociolek, M.J., Sullivan (Editors), A Century of Diatom Research in North America: A Tribute to the Distinguished Careers of Charles W. Reimer \& Ruth Patrick. Belog Scientific Books.

DeFelice, D. R., and G.W. Lynts. 1978. Benthic marine diatom associations: upper Florida Bay (Florida) and associated sounds. Journal of Phycology 14:25-33.

Dixon, P.M. 1993. The bootstrap and the jackknife: describing precision in ecological studies. In: S.M. Scheiner, J. Gurevitch (Editors), Design and analysis of ecological experiments. New York Chapman and Hall, pp. 445. 
Dufrêne, M., and P. Legendre. 1997. Species assemblages and indicator species: the need for a flexible asymmetrical approach. Ecological Monographs 67:345-366.

Emerson, J.D. 1991. Introduction to transformation. In DC Hoaglin, F. Mosteller, \& JW Tukey (Eds.), Fundamentals of exploratory analysis of variance. New York, Willey.

Foged, N. 1984. Freshwater and littoral diatoms from Cuba. Bibliotheca Diatomologica $5: 1-243$.

Frankovich, T.A., and R.D. Jones. 1998. A rapid, precise, and sensitive method for the determination of total nitrogen in natural waters. Marine Chemistry 60:227-234.

Frankovich, T.A., Gaiser, E., Wachnicka, A., and J.C. Zieman. 2006. Spatial and temporal distributions of epiphytic diatoms: relationships to salinity and nutrients in a subtropical ecosystem. Hydrobiologia 569:259-271.

Gaiser, E.E., Wachnicka, A., Ruiz, P., Tobias, F.A., and M.S. Ross. 2005. Diatom indicators of ecosystem change in coastal wetlands. In: S. Bortone (Editor), Estuarine Indicators. CRC Press, Boca Raton, FL, pp. 127-144.

Gaiser, E.E., Richards, J. H., Trexler, J.C., Jones, R.D., and D.L. Childers. 2006. Periphyton responses to eutrophication in the Florida Everglades: Cross-system patterns of structural and compositional change. Limnology and Oceanography 51:617-630.

Giffen, M.H. 1984. A checklist of marine litoral diatoms from Namaqualand, South Africa. Bacillaria 7:179-200.

Gottlieb, A.D., Richards, J.H., and E.E. Gaiser. 2006. Comparative study of periphyton community structure in long and short hydroperiod Everglades marshes. Hydrobiologia 569:195-207.

Graves, G., M. Thompson, G. Schmitt, D. Fike, C. Kelly, and J. Tyrrell. 2005. Using macroinvertebrates to document the effects of a storm water-induced nutrient gradient on a subtropical estuary. In Estuarine indicators, ed. S.A. Bortone, 333-349. Boca Raton, Florida: CRC Press.

Hartley, B. 1986. A check-list of the freshwater, brackish and marine diatoms of the British Isles and adjoining coastal waters. Journal of Marine Biological Association, U.K. 66:531-610.

Hein, M.K., Winsborough, B.M., and M.J. Sullivan. 2008. Bacillariophyta (Diatoms) of the Bahamas. Iconographia Diatomologica 19:1-300. 
Howarth, R.W., and R. Marino. 2006. Nitrogen as the limiting nutrient for eutrophication in coastal marine ecosystems: Evolving views over three decades. Limnology and Oceanography 51:364-376.

Huvane, J.K. 2002. Modern diatom distributions in Florida Bay: A preliminary analysis. In: J.W. Porter, K.G. Porter (Editors), The Everglades, Florida Bay, and Coral Reefs of the Florida Keys: An Ecosystem Sourcebook. CRC Press, Boca Raton, FL, pp. 479-493.

Juggins, S. 2005. The C2 Software for Ecological and Palaeoecological Data Analysis and Visualisation. University of Newcastle, Newcastle-upon-Tyne, United Kingdom.

Kruskal, J. B., and M. Wish. 1978. Multidimensional scaling. In J.L. Sullivan, R.G. Niemi (Editors), Quantitative Applications in Social Sciences Series 11, Beverly Hills, CA: Sage University Series, $92 \mathrm{pp}$.

Langevin, C.D. 2003. Simulation of submarine ground water discharge to a marine estuary: Biscayne Bay, Florida. Ground Water 41:758-771.

Larsen, P.L. 1995. Everglades water budget presentation. Technical advisory committee report, governor's commission foe a sustainable South Florida. Miami, FL. pp. 78.

Levesque, R., 2007. SPSS Programming and Data Management: A Guide for SPSS and SAS Users, Fourth Edition, SPSS Inc., Chicago Ill.

Mantel, N. 1967. The detection of disease clustering and a generalized regression approach. Cancer Research 27:209-220.

McCune, B., and J.B. Grace. 2002. Analysis of Ecological Communities. MJM Software Design, Gleneden Beach, Oregon.

McCune, B., and M.J. Mefford. 1999. PC-ORD. Multivariate Analysis of Ecological Data, Version 4. MJM Software Design, Gleneden Beach, Oregon, USA.

McGrathery, K.J, R. Marino, and R.W. Howarth. 1994. Variable rates of phosphate uptakeby shallow marine carbonate sediments: mechanism and ecological significance. Biogeochemistry 25:127-146.

Meeder, J. and J. N. Boyer. 2001. Total ammonia concentrations in soil, sediments, surface water, and groundwater along the western shoreline of Biscayne Bay with the focus on Black Point and a reference mangrove site. Final Report to the National Park Service under NPS/FIU Cooperative Agreement No. CA5280-8-9038.

Montgomery, R.T. 1978. Environmental and ecological studies of the diatom communities associated with the coral reefs of the Florida Keys. Ph.D. Dissertation, Florida State University, Tallahassee, FL, USA. 
Nelson, D.W., and L.E. Sommers. 1996. Total carbon, organic carbon, and organic matter. In: A.L. Page (Editor), Methods of Soil Analysis, Part 2, Agronomy. 9. Am. Soc. of Agron., Inc. Madison, Wisconsin, USA, pp. 961-1010.

Parker, G.G., G.E. Ferguson, and S.K. Love. 1955. Water resources of southeastern Florida, with special reference to the geology and ground water of the Miami area: U.S. Geological Survey Water-Supply Paper 1255, 965 p.

Parker, G.G. 1974. Hydrology of the pre-drainage system of the Everglades in southern Florida, in P.J. Gleason, ed., Environments of south Florida--Present and past: Miami, Fla., Miami Geological Society, Memoir 2, p. 18-27.

Prasad, A. K. S. K., J. A. Nienow and K. A. Riddle. 2001. Fine structure, taxonomy and systematics of Reimerothrix (Fragilariaceae: Bacillariophyta), a new genus of synedroid diatomd from Florida Bay, USA. Phycologia 40:35-46.

Quinn, G.P., and M.J. Keough. 2002. Experimental design and data analysis for biologists. Cambridge, UK Cambridge University Press, Relyea, RA.

Reyes-Vasquez, G. 1970. Studies on the diatom flora living on Thalassia testudinum König in Biscayne Bay, Florida. Bulletin of Marine Science 20:105-134.

Rines J.E.B., and P.E. Hargraves. 1988. The Chaetoceros Ehrenberg (Bacillariophyceae) flora of Narragansett Bay, Rhode Island, U.S.A. Bibliotheca Phycologica 79:1-196.

Rines J.E.B., and E.C. Theriot. 2003. Systematics of Chaetocerotaceae (Bacillariophyceae). I. A phylogenetic analysis of the family. Phycological Research 51:83-98.

Roessler, M.A., Beardsley, G.L., Rehrer, R., Garcia, J., 1975. Effects of thermal effluents on the fishes and benthic invertebrates of Biscayne Bay-Card Sound, Florida. Technical Report UM-RSMAS-75027.

Ross, M.S., Gaiser, E.E, Meeder, J. F., and M.T. Lewin. 2001. Multi-taxon analysis of the "white zone", a common ecotonal feature of South Florida coastal wetlands. In: J. Porter, K. Porter (Editors), The Everglades, Florida Bay, and Coral Reefs of the Florida Keys. CRC Press, Boca Raton, FL, USA. pp. 205-238.

Solorzano, L., and J.H. Sharp. 1980. Determination of total dissolved nitrogen in natural waters. Limnology and Oceanography 25:751-754.

SFWMD. 1995. District Water Management Plan, Planning Department, South Florida Water Management District, West Palm Beach, FL. 
Saunders, K.M., A. Mcminn, D. Roberts, D.A. Hodgson, and H. Heijnis. 2007. Recent human-induced salinity changes in Ramsar-listed Orielton Lagoon, south-east Tasmania, Australia: a new approach for coastal lagoon conservation and management. Aquatic Conservation: Marine and Freshwater Ecosystems 17:51-70.

Simonsen, R. 1987. Atlas and Catalogue of the Diatom Types of Friedrich Hustedt, Volumes 1-3, Catalog. J. Cramer, Berlin.

Snoeijs P. 1999. Diatoms and environmental change in brackish waters. In The Diatoms: Applications to the Environmental and Earth Sciences, eds. E.F. Stoermer and J.P. Smol. Cambridge University Press.

Stalker, J., 2008. Hydrological dynamics between a coastal aquifer and the adjacent estuarine system, biscayne bay, south florida. Unpublished PhD Dissertation, Florida International University.

Sylvestre, F., B. Beck-Eichler, W. Duleba, and J. Debenay. 2001. Modern benthic diatom distribution in a hypersaline coastal lagoon: the Lagoa de Araruama (R.J.), Brasil. Hydrobiologia 443:213-231.

Sylvestre, F., D. Guiral, and J.P. Debenay. 2007. Modern diatom distribution in mangrove swamps from the aw Estuary (French Guiana). Marine Geology 208:281-293.

Taffs, K.H., L.J. Farago, H. Heijnis, and G. Jacobsen. 2008. A diatom-based Holocene record of human impact from a coastal environment: Tuckean Swamp, eastern Australia. Journal of Paleolimnology 39:71-82.

Ter Braak, C. J. E, Juggins, S., Birks, H. J. B., Van der Voet, H., 1993. Weighted averaging partial least squares regression (WA-PLS): definition and comparison with other methods for speciesenvironment calibration. In: G.R Patil, C.R. Rao (Editors), Multivariate Environmental Statistics. North-Holland, Amsterdam, Nederlands, pp. 525560.

Tibby, J., Gell, P.A., Fluin, J., and I.R.K. Sluiter. 2007. Diatom-salinity relationships in wetlands: assessing the influence of salinity variability on the development of inference models. Hydrobiologa 591:207-218.

U.S. EPA 1983. EPA Method 150.1, pH, in Methods for Chemical Analysis of Water and Wastes, EPA/600/4-79/020.

Wachnicka, A., and E.E. Gaiser. 2007. Morphological characterization of Amphora and Seminavis (Bacillariophyceae) from South Florida, U.S.A. Diatom Research 22:387-455.

Weckström, K., and S. Juggins. 2005. Coastal diatom-environment relationships from the Gulf of Finland, Baltic Sea. Journal of Phycology 42:21-35. 
Wingard, G.L., Hudley, J.W., Holmes, C.W., Willard, D.A., and M.M. Marot. 2007. Synthesis of age data and chronology for Florida Bay and Biscayne Bay cores collected for ecosystem history of South Florida's estuaries project. Open File Report 2007-1203.

Witkowski, A. 1994. Recent and fossil diatom flora of the Gulf of Gdańsk, Southern Baltic Sea. Biblitheca Diatomologica 28, J. Cramer, Berlin, Stuttgart.

Witkowski, A., H. Lange-Bertalot, and D. Metzeltin. 2000. Diatom flora of marine coasts I. Iconographia Diatomologica 7, A.R.G. Gantner Verlag K.G. 


\section{CHAPTER 5. DIATOM-BASED EVIDENCE OF 660 YEARS OF WATER QUALITY FLUCTUATIONS IN BISCAYNE BAY, FLORIDA}

Abstract

A major goal of this study was to determine if urbanization of the South Florida region that occurred during the $20^{\text {th }}$ century had significant impact on water quality and natural habitat conditions of Biscayne Bay. In order to achieve this goal the combined datasets containing information on the spatial and temporal distribution of diatom communities in Biscayne Bay, Florida Bay, and adjacent coastal regions were used to develop inference models for salinity, water total nitrogen (WTN), water total phosphorus (WTP) and water total organic carbon (WTOC). These models were later applied to diatoms preserved in three sediment cores extracted from No Name Bank, Featherbed Bank and Card Sound Bank in central and southern Biscayne Bay. Diatom assemblages in each core were grouped into distinct clusters constrained by depth. Species turnover ( $\beta$-diversity) increased at No Name Bank and Featherbed Bank after the 1950's and 1940's, respectively, while at Card Sound Bank it increased after the late 1920's. The inference models suggest that the magnitude of salinity oscillations increased after the early 1960's at all studied sites. Additionally, water nutrients and WTOC increased during the late 1980's and early 1990's at No Name Bank and Featherbed Bank. Salinity appears to have been stable from the early 1900's until the early 1960 's at No Name Bank and in the late $19^{\text {th }}$ century until the beginning of the $20^{\text {th }}$ century at Featherbed Bank. Salinity fluctuations at Card Sound Bank were insignificant 
at the decadal scale prior to the 1960's. The presence of taxa which are often associated with seagrass-vegetated areas was low in the bottom part of the No Name Bank core but increased slightly after the 1990's, implying the presence of sparse vegetation at this site throughout the time of deposition, except in the last ten years when vegetation cover most likely increased. Similarly, an increase in the abundance of this type of assemblage was also observed in the Featherbed Bank core after the early 1980's, implying increased vegetation cover after that time. The high abundance of seagrass-associated taxa throughout the Card Sound Bank core suggests the presence of dense vegetation in the past. Almost geologically simultaneous changes in water quality conditions at the studied sites in the last century suggests that these changes were widespread in Biscayne Bay, and possibly also in the adjacent estuaries.

\subsection{Introduction}

Estuaries represent dynamic ecosystems with some of the highest biodiversity and productivity in the world (Alongi 1998). Many estuaries around the world, especially those adjacent to heavily populated coastal regions, experience significant changes in their overall biochemical cycling (Bianchi 2007). Nutrient enrichment, especially nitrogen, represents one of the most widespread problems in estuaries that often cause harmful algal blooms (Howarth 2002). Additionally, alterations in the watershed hydrology and water diversions result in changes in the magnitude and temporal patterns of freshwater flow and sediment discharge to estuaries (Hobbie 2000). 
Biscayne Bay (Fig. 5.1) has also been affected by the aforementioned factors due to the accelerating development of South Florida caused by population growth. The biggest $20^{\text {th }}$ century changes on the mainland include construction of the extensive systems of canals, levees and pump stations in the 1940's and 1960's, and conversion of large parts of the landscape to urban and agricultural areas (Lodge 2005). These changes are blamed for the significant reduction of groundwater discharge, elimination of offshore freshwater springs, and increased nutrient loads from the canals into the central part of the bay (Parker 1974; Ross et al. 2001; Caccia and Boyer 2007). Additionally, the significant reduction of the freshwater supply, especially into the southern part of the bay, caused extensive salty groundwater encroachment (up to $3 \mathrm{~km}$ ) into adjacent coastal regions in the last few decades (Meeder and Boyer 2001).

In order to understand the mechanisms that cause ecosystem changes and determine the magnitude of these changes in Biscayne Bay, it is imperative to obtain information about environmental conditions that were present there before and during the 1900's urban development in South Florida. Because continuous water monitoring programs do not pre-date the 1980's in Biscayne Bay, proxy data from sources such as mollusks, pollen, ostracodes, foraminifera, and geochemistry, have proved to be reliable tools in determining past sequences of environmental changes in the bay. Multi-proxy studies have shown that salinity in the central and southern parts of Biscayne Bay became increasingly marine during the $20^{\text {th }}$ century (Ishman et al. 1998; Wingard et al. 2003; Wingard et al. 2004). Additionally, while salinity conditions stabilized in the central part of the bay at off-shore sites, they became more variable at the nearshore sites and in the southern part of the bay (Stone et al. 2000; Wingard et al. 2003; Wingard et al. 2004). 
The same studies also revealed that No Name Bank (Fig. 5.1) experienced a minor freshwater influence throughout the time of deposition, and Featherbed Bank was influenced by mesohaline waters. Furthermore, there is evidence that sub-aquatic vegetation declined in the central Bay during the last century (Wingard et al. 2003). All the water quality and vegetation changes have been linked to the combined effects of human-introduced changes and rising sea-level (Wingard et al. 2004). Diatom-based paleoecological studies have never been conducted in Biscayne Bay, mostly due to the paucity of taxonomic work and scarcity of autecological data available in this region.

The main objectives of this study were: 1) to reconstruct past salinity, water total phosphorus (WTP), water total nitrogen (WTN) and water total organic carbon (WTOC) from the fossil diatom records preserved in three sediment cores collected from the central and southern parts of Biscayne Bay, by applying quantitative prediction models developed with modern diatom records of Biscayne Bay, Florida Bay and adjacent coastal regions (Chapters 2 and 4). No Name Bank and Featherbed Bank are located in the central part of the bay east and northeast of the major canals that discharge freshwater into Biscayne Bay. I hypothesize that these locations experienced the biggest changes in salinity and nutrient conditions and increased primary productivity after the construction of the canals in the 1940's and 1960's. Furthermore, I hypothesize that Card Sound Bank, located in Card Sound, had relatively stable salinity, water nutrients and WTOC conditions during the time of deposition due to its geographical isolation; 2) to reconstruct the abundance of diatom habitat (nearshore and open-bay). I hypothesize that the nearshore assemblages were most abundant at No Name Bank due to its close proximity to the coast, Featherbed Bank was dominated by the open-bay diatoms due to 
its closeness to the Safety Valve inlet that allows inflow of Atlantic waters into the Bay, and that Card Sound Bank contained nearshore assemblages in the lower portions of the core that pre-date canal construction but open-bay assemblages dominated the upper portions due to the increasing rate of sea level rise observed since ca. 1930.

\subsection{Study Area}

Biscayne Bay is a relatively large $\left(\sim 700 \mathrm{~km}^{2}\right)$, shallow (4m average depth), subtropical lagoonal estuary adjacent to the Miami metropolitan area of southeast Florida (Fig. 5.1; Roessler et al. 1975). Holocene sea level rise resulted in flooding of the deepest areas of the bay about 6000 years ago (Wanless 1976). The sediments of Biscayne Bay consist mostly of calcareous and siliceous skeletal benthic organisms and calcareous algal remains of taxa that still live in the bay (Wanless 1976). Additionally, the northern part of the bay receives detrital sediment and a quartz-carbonate sand influx from the southern Appalachian Mountains and pure quartz Pleistocene Pamlico Sand of the mainland Atlantic Coastal Ridge (Wanless 1976). Thin $(<30 \mathrm{~cm})$ layers of peat from red mangroves underlie the calcareous, sandy deposits near the barrier islands in the eastern part of the bay (Wanless 1976).

Sediment cores analyzed in this study were collected from No Name Bank $\left(25^{\circ} 34.484^{\prime} \mathrm{N}, 80^{\circ} 16.320^{\prime} \mathrm{W}\right)$ in central Biscayne Bay, on the southwestern side of the Featherbed Bank $\left(25^{\circ} 31.850^{\prime} \mathrm{N}, 80^{\circ} 15.575^{\prime} \mathrm{W}\right)$ in the south bay, and on the northwestern

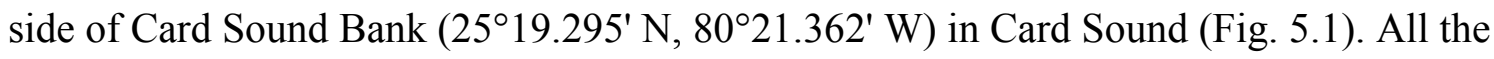
cores were collected by the U. S. Geological Survey (USGS) in April 2002. 
The surface of No Name Bank, located west of Safety Valve, is composed of calcareous sand deposits covered by very dense seagrass beds of Thalassia testudinum mixed with Syringodium filiforme (Wingard et al. 2004). The core was extracted from this bank at the water depth of $0.5 \mathrm{~m}$ (Wingard et al. 2003). Featherbed Bank (Fig. 5.1) is positioned southwest of Safety Valve and contains a series of carbonate sand "stringer shoals" (Wanless 1976). The water depth at the coring location on this bank was ca. 0.6 $\mathrm{m}$ and the site was densely vegetated by Thalassia testudinum and Syringodium filiforme mixed with Halodule sp. and the green macroalgae Laurencia sp. (Wingard et al. 2004). Card Sound Bank (Fig. 5.1), is characterized by a restricted water circulation due to its geographic isolation, which increases the residence time of its waters to up to 2.3 months (Ishman 1997). The surface sediments at the coring site were composed of carbonate sand that was vegetated by patchy Thalassia testudinum (Wingard et al. 2004). The core was retrieved from $0.76 \mathrm{~m}$ water deepth (Wingard et al. 2003).

5.3 Methods

\subsubsection{Core Collection}

Sediment cores were collected following USGS procedures described in detail by Stone et al. (2000). All cores were examined visually for the type of deposits, and Xrayed to determine the presence of lamination and to evaluate the degree of sediment disruption (e.g., bioturbation). They were sectioned into 2-cm intervals and stored at USGS laboratories for further analysis. 


\subsubsection{Chronology}

The age models for each coring site were established using ${ }^{210} \mathrm{~Pb},{ }^{14} \mathrm{C}$ and the first occurrence of Casuarina (Australian Pine) pollen (Wingard et al. 2003; 2007). ${ }^{210} \mathrm{~Pb}$ has been used to date samples up to approximately 150 years old (Holmes et al. 2001), whereas ${ }^{14} \mathrm{C}$ analyses for the lower portion of the cores using accelerator mass spectrometry (AMS). Radiocarbon $2 \sigma$ age ranges were calibrated to calendar years and a standard marine correction of 400 years was applied to correct for the reservoir effect (Wingard et al. 2007). The ${ }^{14} \mathrm{C}$ dating was performed at the Beta Analytic Radiocarbon Dating Laboratory in Miami and the USGS Radiocarbon Lab, Reston, Virginia. The ${ }^{210} \mathrm{~Pb}$ ages were done at the USGS Center for Coastal and Watershed Studies in St. Petersburg, Florida. The oldest age of sediments was $\sim 660$ years B.P. Detailed descriptions of the dating methods can be found in Wingard et al. $(2003 ; 2007)$.

\subsubsection{Laboratory Methods}

The method of preparing permanent diatom slides was described in detail in Chapter 3 of this manuscript.

\subsubsection{Data Analyses}

The abundance of each taxon was expressed as relative to the total in each sample. They were arcsine squareroot transformed in order to more closely approximate 
a normal distribution by down-weighting the importance of highly abundant species, and to ensure that the rarer species will also contribute to the results (McCune and Grace 2002).

Stratigraphically constrained cluster analysis with the method of incremental sum of squares was performed on the diatom data. The statistical significance of the chronological differences in diatom community structure among clusters was tested using the analysis of similarities (ANOSIM; Clarke and Gorley 2001).

The two-component weighted averaging partial least squares (WA-PLS) prediction models for salinity, water total phosphorus (WTP) and water total organic carbon (WTOC), and the weighted averaging (WA) prediction model with tolerance downweighting and inverse deshrinking (Birks 1998) for water total nitrogen (WTN), were applied to all three sediment cores in order to track the general trends in inferred salinity, WTN, WTP and WTOC levels. These models were developed based on combined contemporary diatom assemblages and environmental data collected from 58 sites in Biscayne Bay and Card Sound and 38 sites in Florida Bay and the adjacent coastal regions (Chapters 2 and 4). The strongest model, which had the highest predictive ability, was obtained for salinity $\left(\mathrm{r}^{2}=0.96, \mathrm{RMSEP}=2.82 \mathrm{ppt}\right)$, whereas the WTN, WTP and WTOC models were weaker $\left(r^{2}=0.75\right.$, RMSEP $=0.20 p p m ; r^{2}=0.59$, $\left.\mathrm{RMSEP}=0.01 \mathrm{ppm} ; \mathrm{r}^{2}=0.82, \mathrm{RMSEP}=2.31 \mathrm{ppm}\right)$. The updated optima and tolerance values for taxa involved in the models development were presented in Table 5.1.

The discriminant function (DF) analysis was used to determine which diatom habitat (e.g., typical for nearshore or open-bay habitats) was dominant at each coring sites in specific time periods. This method was successfully used in Chapter 4 to predict 
habitat types present at 38 sites in Biscayne Bay and Card Sound in the dry season with wet season data.

Detrended Canonical Correspondence Analysis (DCCA) was used to estimate the amount of compositional turnover of diatom species, or beta $(\beta)$-diversity, expressed in standard deviation (SD) units, among the cores and within each core during the last

approximately 150 years as assessed by ${ }^{210} \mathrm{~Pb}$ and ${ }^{14} \mathrm{C}$ methods (approximately every 10 years). All the datasets were analyzed with arcsine squareroot transformed diatom data, no down-weighting of rare taxa, detrending by segments, and nonlinear rescaling. The Shannon-Wiener index was used to measure the alpha $(\alpha)$ diversity of diatom assemblages within each sample of the cores (Ricklefs 2000).

Detailed descriptions of these methods were given in Chapter 3. The aforementioned analyses were done in C2 version 1.4.2. (Juggins 2005), CONISS version 2.70 (Grimm 1987), and CANOCO version 4.53 (TerBraak and Šmilauer 2002).

\subsection{Results}

\subsubsection{Lithostratigraphy and Chronology}

The initial length of the cores collected from No Name Bank, Featherbed Bank and Card Sound Bank were $150 \mathrm{~cm}, 195.5 \mathrm{~cm}$, and $157.5 \mathrm{~cm}$, respectively, but due to compaction during transport and sampling the lengths decreased to $144 \mathrm{~cm}, 188 \mathrm{~cm}$ and $149 \mathrm{~cm}$, respectively (Wingard et al. 2003). X-radiographs and visual inspection of the cores revealed that sediments in the upper portion of the cores were mostly composed of 
soupy, soft mud deposits mixed with plant material and abundant shells of mollusks, whereas the middle and bottom portions of the cores were composed of more cohesive mud deposits mixed with more scattered shells and plant material (Wingard et al. 2003). The total carbon (TC), organic carbon (OC), total nitrogen (TN) and total phosphorus (TP) concentrations were highest in the Card Sound Bank core, while the inorganic carbon (IC) content was the lowest there (Wingard et al. 2004). Detailed descriptions of these cores including X-radiographs were provided by Wingard et al. $(2003 ; 2004 ; 2007)$.

The chronology of the core sediments revealed that the average $20^{\text {th }}$ century sedimentation rate was highest at Featherbed Bank $(\sim 0.7 \mathrm{~cm} /$ year $)$ followed by No Name Bank ( 0.6 cm/year) and lowest on Card Sound Bank $(\sim 0.3-0.5 \mathrm{~cm} /$ year; Wingard et al. 2007). The pre- $20^{\text {th }}$-century sedimentation rate was higher than during the 1900 's at Featherbed Bank ( $1.4 \mathrm{~cm} /$ year), while at No Name Bank and Card Sound Bank it was lower or about the same $(\sim 0.3 \mathrm{~cm} /$ year; Wingard et al. 2007). The deepest sediments in the longest Featherbed Bank core are only ca. 200 years old ( 1800 A.D.), whereas the basal age of the No Name Bank core and Card Sound Bank core are ca. 453 YBP and ca. 600 YBP, respectively (Wingard et al. 2007).

\subsubsection{Diatom Stratigraphy, Beta Diversity and Water Quality Conditions}

\section{No Name Bank}

A total of 186 diatom taxa were identified in the No Name Bank core (Appendix 5.1) but only $36.4 \%$ (75) were present in the modern training set, which included 206 taxa after exclusion of rare taxa. The preservation of diatom valves was excellent 
throughout the core (Appendix 5.1). Species richness was highest at $\sim 1850$ (66 taxa) and lowest at $\sim 1639$ (29 taxa) with six distinct peaks around 1690, 1850, 1920, 1949, 1980, and 1996 (Fig. 5.4). Alfa diversity fluctuated between $3.6(\sim 1850)$ and $1.5(\sim 1977)$ and distinct peaks were present around the same time that species richness peaks (Fig. 5.4). The most frequently occurring taxa in the core that were included in reconstructions were Grammatophora oceanica, Mastogloia bahamensis, Mastogloia corsicana, Mastogloia cribrosa, Campylodiscus ecclesianus, Dimeregramma dubium and Synedra fulgens (Fig. 5.3). The most abundant taxa in the core were Bidulphia pulchella, Tryblionella granulata, D. dubium and Paralia sulcata var. genuina f. radiata (Fig. 5.3). The major changes in diatom assemblages occurred around 1961 and this date marks the boundary between Z1 and Z2 (Table 5.2). These two zones contain distinct diatom assemblages $(\mathrm{R}=0.535, \mathrm{p}=0.001)$. The change was also captured in increased $\beta$-diversity values (from around 1.2 before the 1960 's to over 1.8 after ca. 1961, except for the period between 1980-1989 when the value dropped to 1.3; Fig. 5.2a). The post-1961 assemblages contained the few taxa that did not occur or occurred in very low abundance in older sediments (e.g., B. pulchella and P. sulcata spp.) and were mixed with species that were common throughout the core (e.g., D. dubium, C. ecclesianus and M. cribrosa; Fig. 5.3). The Z2 biozone was divided into four distinct sub-zones (Z2S1, Z2S2, Z2S3, Z2S4) that differed from each other in species abundance and composition (Fig. 5.3, Table 5.2). The biggest differences in diatom assemblages were observed between Z2S2 and Z2S3 $(\mathrm{R}=0.777, \mathrm{p}=0.001)$ and smaller differences between $\mathrm{Z} 2 \mathrm{~S} 1-\mathrm{Z} 2 \mathrm{~S} 2$ and Z2S3-Z2S4 $(\mathrm{R}=0.434, \mathrm{p}=0.001$; and $\mathrm{R}=0.469, \mathrm{p}=0.001$, respectively $)$. 
Reconstructions of the abundance of diatom assemblages typical for different habitats (e.g., nearshore and open-bay) revealed that No Name Bank contained mostly diatom assemblages typically recorded in the nearshore habitats of Biscayne Bay (Fig. 5.4). All taxa which were identified in Chapter 2 as indicators of the freshwater Everglades marshes were considered allochthonous and were excluded from reconstructions because their inclusion would compromise the reconstruction results, which instead of reflecting the real changes in water quality conditions would most likely reflect the physical processes acting in the studied areas.

Salinity at No Name Bank increased after the early 1840's and reached maximum levels between the late 1960's and early 1970's (a maximum of 45.1 ca. 1974;Fig. 5.4). Salinity fluctuations were small before the $20^{\text {th }}$ century, then become insignificant from the early 1900's until the early 1960's, and increased again afterwards (Fig. 5.4). WTN, WTP and WTOC were high in the period before the $19^{\text {th }}$ century (highest in $18^{\text {th }}$ century and early $19^{\text {th }}$ century), then decreased during the $19^{\text {th }}$ century and early $20^{\text {th }}$ century, and increased again after the 1960's, reaching a maximum in the early 1980's (Fig. 5.4; Table 5.2). All of these values fluctuated throughout the core, with the highest observed in the pre-1 $9^{\text {th }}$ century period (Fig. 5.4).

\section{Featherbed Bank}

A total of 222 diatom taxa were identified in the Featherbed Bank core (Appendix 5.2) but only $35.4 \%$ (73) were present in the modern training set containing 206 taxa. The preservation of diatom valves was poor throughout the core, except the uppermost 20 $\mathrm{cm}$ and the section between 40-102 $\mathrm{cm}$ (Appendix 5.2). Species richness was highest in 
the late 1980's and throughout the 1990's (a maximum of 68 ca. 1996), lowest in the early 1800's and the early 1960's (a minimum of 2 ca. 1817), and fluctuated throughout the core (Fig. 5.6). Alfa diversity followed a similar trend and fluctuated between 0.6 ( 1817) and 3.7 ( 1996; Fig. 5.6). The most frequently occurring taxa in the core that were included in reconstructions were Paralia sulcata var. genuina f. coronata, G. oceanica, $P$. sulcata var. genuina f. radiata and C. ecclesianus, and the same taxa were the most abundant (Fig. 5.5). The major changes in diatom assemblages occurred ca. 1947 and this date marks the boundary between zones Z1 and Z2 (Table 5.2) that contain significantly different diatom assemblages $(\mathrm{R}=0.448, \mathrm{p}=0.001)$. This zone was divided into three distinct sub-zones $(\mathrm{Z} 1 \mathrm{~S} 1, \mathrm{Z} 1 \mathrm{~S} 2, \mathrm{Z} 1 \mathrm{~S} 3)$ that also differed among each other in species composition (Fig. 5.5, Table 5.2). Assemblage differences were significant between Z1S2 and Z1S3 $(\mathrm{R}=0.403, \mathrm{p}=0.013)$ and Z1S1 and Z1S2 $(\mathrm{R}=0.245, \mathrm{p}=0.028)$.

The largest increase in $\beta$-diversity also occurred after the early 1940's (up to more than 3 between the 1940's and 1960's from an average of 1.2 before the 1940's), and the values decreased afterwards (to an average of 2.3) after the early 1970's (Fig. 5.2b). The post-1947 assemblages contained a few taxa that did not occur or occurred in very low abundance in older sediments (e.g., B. pulchella, Mastogloia corsicana and Mastogloia cruticula) and freshwater taxa commonly recorded in the Everglades (e.g., Mastogloia smithii, Encyonema evergladianum and Fragilaria synegrotesca, especially in the period between ca. 1952-1982; Fig. 5.5). These taxa were mixed with taxa that were abundant in older parts of the core (e.g., G. oceanica, C. ecclesianus and M. cribrosa) but later became less abundant in Z1 (Fig. 5.5). The Z2 zone was divided into four distinct subzones (Z2S1, Z2S2, Z2S3, Z2S4) that contained different diatom assemblages (Fig. 5.3; 
Table 5.2). The biggest differences in diatom assemblages were observed between Z2S2 and Z2S3 ( $\mathrm{R}=0.773, \mathrm{p}=0.001)$, while smaller differences were observed between Z2S1Z2S2 and Z2S3-Z2S4 $(\mathrm{R}=0.332, \mathrm{p}=0.001$; and $\mathrm{R}=0.372, \mathrm{p}=0.002$, respectively).

Reconstructions of the abundance of diatom assemblages typical for nearshore and open-bay habitats revealed that Featherbed Bank contained mostly diatom assemblages typically recorded in open-bay habitats of Biscayne Bay, except for the periods between the 1974-1979 and the 1985-1993, when nearshore assemblages became dominant (Fig. 5.6). All taxa which were identified in Chapter 2 as indicators of the freshwater Everglades marshes were considered allochthonous and were excluded from reconstructions.

Salinity at Featherbed Bank fluctuated throughout the core, except for the periods between the 1833-1843 and the 1872-1900 when salinity was more or less stable (Fig. 5.6). Salinity was highest ca. 1817 (55.2 ppt) and more recently in 1963 (50.9 ppt), and lowest (35.7 ppt) in 1982 (Fig. 5.6; Table 5.2). Similarly, WTN, WTP and WTOC fluctuated throughout the core and reached their highest values around 1957 (0.6 ppm, 0.014 ppm and 8.6 ppm, respectively), 1850 (0.7 ppm, $0.02 \mathrm{ppm}$ and $8.7 \mathrm{ppm}$, respectively) and $1826(0.8 \mathrm{ppm}, 0.012 \mathrm{ppm}$ and $9.3 \mathrm{pptm}$, respectively), while the lowest values were recorded in 1822 (0.1 ppm, 0.001 ppm and 0.8 ppm, respectively; Fig. 5.6).

\section{$\underline{\text { Card Sound Bank }}$}

A total of 191 diatom taxa were identified in the Card Sound Bank core (Appendix 5.3) but only 35.9\% (74) were present in the modern training set, which

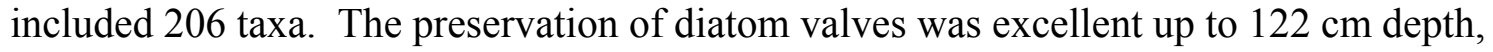


below which the valve count was low (Appendix 5.3). Species richness was high throughout the core (a maximum of 63 in 2000), except for the $14^{\text {th }}$ and $15^{\text {th }}$ centuries, when it was low (an average of 2; Fig. 5.8). There were also two significant drops in species richness around 1926 and 1946 (15 and 19, respectively; Fig. 5.8). Diversity followed a similar trend, and fluctuated between 0 (during two periods in the $15^{\text {th }}$ century) and 3.5 ( 1991;Fig. 5.8). The most frequently occurring taxa in the core that were included in reconstructions were G. oceanica, Amphora corpulenta var. capitata, Cyclotella distinguenda and Synedra bacilaris, whereas G, oceanica, Rhopalodia acuminate, $P$. sulcata var. genuina $\mathrm{f}$. coronata and $C$. distinguenda were the most abundant (Fig. 5.7). The major changes in diatom assemblages occurred ca. 1538 $(\mathrm{R}=0.519, \mathrm{p}=0.004)$ and this date marks the boundary between $\mathrm{Z} 1$ and $\mathrm{Z} 2$ (Table 5.2). Z1 was divided into five distinct sub-zones (Z1S1, Z1S2, Z1S3, Z1S4, Z1S5) that also differed in species composition (Fig. 5.7, Table 5.2). The biggest differences were observed between Z1S1 and Z1S2 (R=0.997, $\mathrm{p}=0.002)$, followed by Z1S2 and Z1S3 $(\mathrm{R}=0.788, \mathrm{p}=0.001), \mathrm{Z} 1 \mathrm{~S} 3$ and Z1S4 $(\mathrm{R}=0.653, \mathrm{p}=001)$, and Z1S4 and Z1S5 $(\mathrm{R}=0.593$, $\mathrm{p}=0.001$; Table 5.2). Species turnover rates increased after the early 1900's (largest between 1981-1991; Fig. 5.2c). The post-1966 diatom assemblages contained several taxa that also occurred in Z1S3 and Z1S4, but were often absent from Z1S2, Z1S5 and Z2 (Fig. 5.7). Additionally, several taxa (e.g., Dimeregramma dubium, C. distinguenda and D. didyma) that were common between Z1S3-Z1S5 were absent in post-1966 assemblages (Fig. 5.7). The Z2 zone was dominated by G. oceanica, which appeared in the upper parts of the core (Fig. 5.7). 
Reconstructions of the abundance of diatom assemblages typical for nearshore and open-bay habitats revealed that this site was dominated by nearshore assemblages for most of the $13^{\text {th }}$ and $14^{\text {th }}$ centuries and the period between 1899-1976 (Fig. 5.8). The open-bay assemblages dominated at this location from the middle of the $16^{\text {th }}$ century until the beginning of the $20^{\text {th }}$ century, and then again after the early 1980's (Fig. 5.8).

Past salinities at Card Sound Bank were relatively stable from the late $15^{\text {th }}$ century until the early 1960's (an average of 36 ppt) after which it experienced small fluctuations (between $32-38$ ppt; Fig. 5.8, Table 5.2). The largest drop in salinity in the last 100 years occurred around 1981 (a minimum of 32 ppt). The largest fluctuations in salinity occurred in the $14^{\text {th }}$ and early $15^{\text {th }}$ centuries (Fig. 5.8, Table 5.2). Water nutrients and WTOC levels fluctuated throughout the core, especially in the bottom $20 \mathrm{~cm}$ (Fig. 5.8, Table 5.2).

\subsection{Discussion}

All studied cores contained diatom assemblages that displayed a large variety of taxa, suggesting the presence of variable ecological conditions in the past. Similar to taxa in Florida Bay cores (Chapter 3), taxa recorded in the Biscayne Bay cores were present in the original modern dataset but the modern analogs were not always available in the training set used in transfer function development. Additionally, a lower number of taxa in the cores compared to the modern dataset was most likely due to the dissolution of weakly silicified and small valves (Conley et al. 1989). For example, small taxa such as Cyclotella choctawhatcheana, Cyclotella tuberculata and Chaetoceros spp., which were 
very abundant in contemporary diatom assemblages throughout Biscayne Bay, were completely absent from all three cores, even from the uppermost layers. Cooper (1993, 1995) also observed the absence of Chaetoceros spp. from sediment cores collected in Chesapeake Bay. Furthermore, Flower et al. (2006) and Ryves et al. (2001) in their experimental work on diatom dissolution characterized C. choctawhatcheana as prone to dissolution.

The fluctuating abundance of different diatom assemblages (allochthonous and autochthonous) in Biscayne Bay cores represents the end result of multiple processes that acted in Biscayne Bay in the past. These processes were ecological (e.g., the variability of spatial and temporal habitat types) and physical (e.g., erosion, transport and deposition). The presence of freshwater Everglades taxa, such as Encyonema evergladianum, $M$. smithii and $F$. synedrotesca, among marine taxa in all the cores is most likely due to the fact that several major canals (e.g., Mowry Canal, Black Creek, Snapper Creek) carry freshwater diatom valves from the mainland into nearshore areas of the bay. These valves are subsequently redistributed throughout the bay with water currents. This situation is common in estuaries, which represent highly dynamic and complicated ecosystems that often contain mixed living and dead diatom assemblages. This situation was observed by Juggins (1992) in the study of fossil diatoms in Thames Estuary, England.

Significant increases in species turnover rates at No Name Bank, Featherbed Bank and Card Sound Bank between 1961-1970, 1941-1952, and 1926-1946, respectively, coincide with the construction of major canals, levees, water conservation areas and highways in South Florida (Fig. 3.14 in Chapter 3). Construction of the Southeast 
Florida drainage system in the 1940 's, 1950's and 1960's led to almost complete elimination of the natural sheet and ground freshwater discharges into Biscayne Bay and lowering of regional and coastal water table by approximately 1-3 m (Parker 1955; Meeder and Boyer 2001; Langevin 2003). For example, the Eastern Perimeter Levee located east of Biscayne Bay runs parallel to the coastal ridge and stretches from Palm Beach County to southern Miami Dade County (Light and Dineen 1994). Construction of this system caused significant changes in the landscape and hydrology of Southeast Florida by reducing the seepage of water into Biscayne Aquifer and subsequently Biscayne Bay, which affected environmental conditions in the adjacent Biscayne Bay (Light and Dineen 1994; Sklar et al. 2001).

Diatom-based reconstructions show that salinity at No Name Bank started increasing from the early 1900's and became increasingly stable afterwards. Water nutrients and WTOC followed similar trends. In earlier studies based on pollen, ostracodes, mollusks and foraminifera, Wingard et al. (2003) also reported that salinity conditions increased and became more stable at this site after 1915. The increasing trends in salinity and nutrient levels in the bay correspond to the time of the early construction of canals and levees in the central part of Florida (Sklar et al. 2001; Fig. 3.14 in Chapter 3). This construction reduced the amount of water flowing into the Everglades and subsequently into the transverse glades that freshened the nearshore areas of Biscayne Bay, which most likely resulted in increased salinity in the bay. Additionally, construction of Government Cut and Haulover Cut in the early 1900's have altered circulation patterns in the northern part of the bay, resulting in increased salinity (Meeder and Boyer 2001). This situation changed in the 1960's, when salinity first 
increased and then decreased after the early 1990's. Increased salinity, water nutrients and WTOC fluctuations have also been observed at Card Sound Bank after the late 1950's. Water nutrients and WTOC conditions also appeared to be more stable from the early 1900's until the early 1960 's, but started fluctuating after that time. The increase in salinity in the 1960's was most likely caused by the construction of the L31E canal and levee, which completely eliminated the sheet flow of water to the bay, and completion of the water conservation areas in the northeastern part of the Everglades, which significantly reduced the amount of water delivered to the coastal areas along Biscayne Bay (Meeder and Boyer 2001; Sklar et al. 2001; Fig. 5.9). Additionally, increased oscillations might be related to the construction of numerous canals in this region that control the amount of freshwater release depending on the amount of rain, especially during wet seasons (Fig. 5.9).

A simultaneous increase in water nutrients has been recorded at all coring sites, especially at No Name Bank and Featherbed Bank, after the early 1990's. Additionally, a distinct peak in water nutrients and WTOC occurred between 1981-1983, while at the same time salinity dropped. Decreasing salinity after the mid 1990's was most likely caused by an increasing amout of rainfall and related to that, the release of an increased amount of freshwater from the canals (Fig. 5.9). The significant peak in salinity in the mid-1970's was most likely due to the drought that occurred at that time in this region, according to the Palmer Drought Severity Index (PDSI) (http://www.cdc.noaa.gov/data/timeseries/). Although Wingard et al. $(2003,2004)$ reported that Card Sound Bank has experienced large swings in salinity, this study indicates that salinity fluctuations at this site were rather moderate (Fig. 5.8). However, 
reconstructions of the abundance of diatom assemblages typical of either nearshore or open-bay habitats do indicate the dominance of nearshore assemblages in certain parts of the core. The nearshore assemblages include taxa that can tolerate broad salinity fluctuations. These results suggest that most likely there were some oscillations in salinity conditions at this site in the past but they were rather short-termed. For example, unusually wet seasons could result in an increased release of freshwater into Card Sound and lower salinity in some years but at the decadal scale the salinity appears to be stable. The differences between this study and that of Wingard et al. $(2003,2004)$ could be related to studies of different time periods in the core (e.g., study of every $2 \mathrm{~cm}$ in the core vs. every $4 \mathrm{~cm}$ in the core). This analysis also indicates the dominance of marine taxa since the early 1980 's, which might be a response to redirection of waters back to Taylor Slough instead of the C111 canal and Barnes Sound (Light and Dineen 1994; Sklar et al. 2001).

Taxa often associated with seagrass beds (e.g., Mastogloia spp., Hyalosynedra laevigat and Cocconeis placentula; Frankovich et al. 2006) seem to have increased in abundance since the early 1980's at Featherbed Bank, implying the presence of dense vegetation at this site. At Card Sound Bank, these taxa are present throughout the core except for the period prior to ca. 1538 and between 1925-1970, when they occurred in lower abundance. This finding suggests that Card Sound Bank did not experience significant declines in vegetation except for the aforementioned periods, which supports earlier findings of Wingard et al. (2003). The epiphytic taxa are also present at No Name Bank but in very low numbers, except for the period after the early 1990's when they 
increase in abundance, which suggests the presence of historically sparse vegetation at this site that most likely has become denser in the last decade.

Synchronized changes in past water quality conditions at the studied sites in Biscayne Bay indicate that the changes are definitely not limited only to these sites. They are most likely not even limited to Biscayne Bay because significant environmental changes have also been reported in the earlier study of fossil diatom records at four sites in Florida Bay (Chapter 3), which also occurred after the mid-1900's. The $20^{\text {th }}$ century water quality alterations in these estuaries have apparently been significantly influenced by the alterations of hydrology on the mainland, but the anthropogenically caused changes are superimposed on the changes caused by rising sea level and changing climate.

\subsection{Conclusions}

The diatom-based reconstructions of all of the studied sites in Biscayne Bay suggest that major changes in water quality conditions and habitat types occurred during the $20^{\text {th }}$ century. The changes were most pronounced at No Name Bank, which is located closest to the coast and is greatly influenced by freshwater discharges from the canals. Featherbed Bank, located farther offshore, experienced larger fluctuations of water quality compared to the other sites, which was most likely caused by inter- and intraannual changes in the amount of precipitation. Similar patterns of water quality after the mid-1900's suggests that Featherbed Bank was also influenced by the construction of the canals. Card Sound Bank had the most stable water quality conditions, being an area 
isolatef from canals and natural creeks, but distinct water quality changes also occurred at this site after the mid-1900's, implying that this site also responded to the $20^{\text {th }}$ century hydrological changes of South Florida.

\section{Acknowledgments}

This research was supported by the USGS (\#03ERAG0049). Many thanks are due to Lynn Wingard of the USGS for providing me with sediment core samples, associated data and many valuable comments on the study results. 
Table 5.1 Updated salinity (Sal.), water total nitrogen (WTN), water total phosphorus

\section{(WTP) and water total organic carbon (WTOC) optima (Opt.) and tolerance (Tol.) of taxa}

used in the development of the inference models.

\begin{tabular}{|c|c|c|c|c|c|c|c|c|}
\hline Taxon Name & $\begin{array}{l}\text { Sal. } \\
\text { (ppt) } \\
\text { Opt. }\end{array}$ & $\begin{array}{l}\text { Sal. } \\
\text { (ppt) } \\
\text { Tol. }\end{array}$ & $\begin{array}{l}\text { WTN } \\
\text { (ppm) } \\
\text { Opt. }\end{array}$ & $\begin{array}{c}\text { WTN } \\
\text { (ppm) } \\
\text { Tol. }\end{array}$ & $\begin{array}{c}\text { WTP } \\
\text { (ppm) } \\
\text { Opt. }\end{array}$ & $\begin{array}{c}\text { WTP } \\
\text { (ppm) } \\
\text { Tol. }\end{array}$ & $\begin{array}{l}\text { WTOC } \\
\text { (ppm) } \\
\text { Opt. }\end{array}$ & $\begin{array}{c}\text { WTOC } \\
\text { (ppm) } \\
\text { Tol. }\end{array}$ \\
\hline Achanthes danica & 30.8 & 3.7 & 0.28 & 0.10 & 0.0112 & 0.0057 & 5.0 & 2.5 \\
\hline Achnanthes amoena & 13.9 & 4.9 & 0.58 & 0.40 & 0.0301 & 0.0404 & 13.0 & 9.6 \\
\hline Achnanthes sp. 06 & 29.4 & 3.3 & 0.29 & 0.09 & 0.0167 & 0.0125 & 5.9 & 2.5 \\
\hline Actinocyclus ehrenbergii & 33.7 & 2.1 & 0.23 & 0.09 & 0.0053 & 0.0024 & 3.1 & 1.2 \\
\hline Actinoptychus senarius & 36.5 & 2.7 & 0.55 & 0.25 & 0.0181 & 0.0066 & 7.7 & 3.5 \\
\hline Amphora acuminata & 30.9 & 5.4 & 0.38 & 0.30 & 0.0156 & 0.0229 & 6.0 & 6.6 \\
\hline Amphora caribea & 33.6 & 3.7 & 0.39 & 0.28 & 0.0103 & 0.0092 & 5.6 & 4.2 \\
\hline Amphora cf. leavis & 33.1 & 4.0 & 0.41 & 0.30 & 0.0140 & 0.0146 & 6.2 & 4.5 \\
\hline Amphora coffeaeformis & 31.0 & 5.9 & 0.37 & 0.25 & 0.0169 & 0.0218 & 6.2 & 4.4 \\
\hline Amphora corpulenta var. capitata & 32.8 & 4.4 & 0.42 & 0.28 & 0.0135 & 0.0126 & 6.4 & 4.2 \\
\hline Amphora crenulata & 15.8 & 4.1 & 0.67 & 0.44 & 0.0307 & 0.0364 & 13.3 & 8.4 \\
\hline Amphora decussata & 30.5 & 3.6 & 0.64 & 0.26 & 0.0194 & 0.0108 & 9.2 & 3.6 \\
\hline Amphora floridae & 31.1 & 4.7 & 0.46 & 0.27 & 0.0154 & 0.0150 & 6.9 & 4.0 \\
\hline Amphora graeffeana & 26.4 & 8.9 & 0.86 & 0.48 & 0.0537 & 0.0566 & 16.0 & 12.9 \\
\hline Amphora graeffei var. 01 & 25.6 & 8.0 & 0.88 & 0.43 & 0.0449 & 0.0486 & 16.0 & 10.5 \\
\hline Amphora gramenosum & 33.5 & 3.5 & 0.28 & 0.19 & 0.0103 & 0.0135 & 4.1 & 2.6 \\
\hline Amphora hamata & 31.3 & 4.5 & 0.45 & 0.27 & 0.0158 & 0.0162 & 6.8 & 4.1 \\
\hline Amphora indentata & 34.2 & 1.9 & 0.22 & 0.07 & 0.0088 & 0.0114 & 3.5 & 1.3 \\
\hline Amphora ostrearia var. vitrea & 35.2 & 1.3 & 0.21 & 0.12 & 0.0077 & 0.0113 & 3.0 & 1.7 \\
\hline Amphora proteus & 31.7 & 4.7 & 0.43 & 0.31 & 0.0161 & 0.0186 & 6.9 & 5.5 \\
\hline Amphora pseudoproteus & 26.2 & 7.9 & 0.53 & 0.48 & 0.0312 & 0.0396 & 10.5 & 10.4 \\
\hline Amphora pseudotenuissima & 25.1 & 9.1 & 0.74 & 0.33 & 0.0286 & 0.0302 & 12.0 & 7.2 \\
\hline Amphora sp. 02 & 33.0 & 3.6 & 0.34 & 0.23 & 0.0129 & 0.0143 & 5.2 & 3.1 \\
\hline Amphora sp. 03 & 32.9 & 2.8 & 0.26 & 0.09 & 0.0134 & 0.0181 & 3.9 & 1.7 \\
\hline Amphora sp. 05 & 31.3 & 5.2 & 0.37 & 0.31 & 0.0202 & 0.0258 & 6.6 & 5.7 \\
\hline Amphora sp. 06 & 32.0 & 4.4 & 0.42 & 0.30 & 0.0168 & 0.0208 & 6.7 & 4.9 \\
\hline Amphora sp. 35 & 30.4 & 4.8 & 0.65 & 0.26 & 0.0211 & 0.0137 & 8.2 & 2.3 \\
\hline Amphora subtropica & 17.7 & 8.2 & 0.69 & 0.38 & 0.0308 & 0.0341 & 13.8 & 7.6 \\
\hline Amphora sulcata & 16.6 & 11.4 & 0.60 & 0.33 & 0.0259 & 0.0361 & 12.9 & 7.3 \\
\hline Amphora vadosinum & 33.5 & 2.0 & 0.24 & 0.08 & 0.0133 & 0.0168 & 3.9 & 1.4 \\
\hline Bacilaria paxilifer & 19.0 & 9.7 & 0.48 & 0.11 & 0.0169 & 0.0032 & 8.8 & 2.2 \\
\hline Brachysira aponina & 28.8 & 7.4 & 0.48 & 0.29 & 0.0197 & 0.0231 & 7.8 & 5.1 \\
\hline Brachysira neoexilis & 3.2 & 6.8 & 0.45 & 0.23 & 0.0139 & 0.0138 & 13.0 & 4.9 \\
\hline Caloneis excentrica & 29.6 & 4.5 & 0.38 & 0.24 & 0.0198 & 0.0257 & 6.7 & 4.7 \\
\hline Caloneis sp. 02 & 30.8 & 3.3 & 0.25 & 0.09 & 0.0110 & 0.0050 & 4.5 & 2.2 \\
\hline Campylodiscus ecclesianus & 34.5 & 4.1 & 0.59 & 0.24 & 0.0161 & 0.0049 & 8.1 & 3.8 \\
\hline Climaconeis koenigii & 34.5 & 1.9 & 0.21 & 0.10 & 0.0130 & 0.0229 & 2.9 & 1.3 \\
\hline Climacosphenia moniligera & 35.6 & 1.7 & 0.17 & 0.07 & 0.0055 & 0.0018 & 2.8 & 1.4 \\
\hline Cocconeis barleyi & 35.2 & 1.6 & 0.18 & 0.07 & 0.0045 & 0.0010 & 2.4 & 0.7 \\
\hline Cocconeis britanica & 33.9 & 2.3 & 0.22 & 0.09 & 0.0140 & 0.0229 & 3.4 & 1.7 \\
\hline $\begin{array}{l}\text { Cocconeis } \text { cf. placentula var. } \\
\text { lineata }\end{array}$ & 14.9 & 5.6 & 0.58 & 0.27 & 0.0207 & 0.0215 & 11.0 & 5.4 \\
\hline
\end{tabular}




\begin{tabular}{|c|c|c|c|c|c|c|c|c|}
\hline Cocconeis placentula & 30.0 & 6.1 & 0.41 & 0.25 & 0.0167 & 0.0190 & 6.7 & 4.2 \\
\hline Cocconeis placentula var. euglipta & 29.3 & 6.7 & 0.51 & 0.25 & 0.0185 & 0.0180 & 8.2 & 4.0 \\
\hline Cocconeis woodii & 29.4 & 3.1 & 0.30 & 0.12 & 0.0162 & 0.0206 & 5.3 & 2.5 \\
\hline Coscinodiscus centralis & 29.0 & 5.5 & 0.61 & 0.33 & 0.0235 & 0.0250 & 9.9 & 7.7 \\
\hline Coscinodiscus oculus iridis & 27.0 & 7.5 & 0.77 & 0.28 & 0.0299 & 0.0334 & 13.0 & 7.8 \\
\hline Cyclotella atomus & 20.5 & 11.2 & 0.74 & 0.39 & 0.0298 & 0.0316 & 13.9 & 7.0 \\
\hline Cyclotella choctawhatcheana & 28.2 & 7.8 & 0.59 & 0.38 & 0.0253 & 0.0322 & 9.9 & 7.9 \\
\hline Cyclotella distinguenda & 28.2 & 4.9 & 0.47 & 0.27 & 0.0207 & 0.0244 & 7.8 & 4.6 \\
\hline Cyclotella litoralis & 27.8 & 7.7 & 0.70 & 0.25 & 0.0219 & 0.0163 & 11.0 & 4.1 \\
\hline Cyclotella meneghiniana & 19.9 & 8.3 & 0.63 & 0.33 & 0.0277 & 0.0289 & 11.1 & 5.7 \\
\hline Cyclotella striata & 33.1 & 2.7 & 0.26 & 0.07 & 0.0069 & 0.0039 & 3.9 & 2.0 \\
\hline Cyclotella tuberculata & 19.2 & 12.0 & 0.65 & 0.51 & 0.0341 & 0.0450 & 13.4 & 10.9 \\
\hline Cymatosira belgica & 35.2 & 1.9 & 0.59 & 0.26 & 0.0194 & 0.0072 & 8.7 & 4.5 \\
\hline Dickieia resistans & 19.7 & 5.0 & 1.31 & 0.50 & 0.1022 & 0.0512 & 27.8 & 10.4 \\
\hline Dimeregramma dubium & 31.8 & 3.5 & 0.23 & 0.09 & 0.0163 & 0.0274 & 4.6 & 2.4 \\
\hline Dimeregramma minor & 34.5 & 3.0 & 0.19 & 0.11 & 0.0070 & 0.0108 & 2.7 & 1.3 \\
\hline Diploneis didyma & 32.6 & 4.0 & 0.43 & 0.29 & 0.0155 & 0.0142 & 7.0 & 4.1 \\
\hline Diploneis ovata & 11.4 & 6.7 & 0.43 & 0.13 & 0.0132 & 0.0040 & 10.7 & 2.5 \\
\hline Diploneis smithii & 22.9 & 10.2 & 0.60 & 0.23 & 0.0174 & 0.0098 & 9.2 & 3.3 \\
\hline Diploneis suborbicularis & 31.1 & 5.7 & 0.45 & 0.29 & 0.0168 & 0.0191 & 6.9 & 4.6 \\
\hline Encyonema evergladianum & 2.7 & 8.5 & 0.46 & 0.25 & 0.0120 & 0.0105 & 12.2 & 4.7 \\
\hline Encyonema sp. 03 & 0.2 & 0.1 & 0.44 & 0.22 & 0.0106 & 0.0044 & 12.5 & 4.6 \\
\hline Entomoneis alata & 32.2 & 4.5 & 0.48 & 0.30 & 0.0157 & 0.0109 & 7.8 & 4.9 \\
\hline Entomoneis peludosa & 31.1 & 3.9 & 0.29 & 0.12 & 0.0144 & 0.0232 & 4.6 & 2.2 \\
\hline Fallacia sp. 04 & 15.3 & 5.4 & 0.70 & 0.24 & 0.0254 & 0.0182 & 12.2 & 2.6 \\
\hline Fragilaria geocollegarum & 32.5 & 2.7 & 0.32 & 0.20 & 0.0135 & 0.0130 & 5.2 & 3.1 \\
\hline Fragilaria nana & 27.1 & 8.7 & 0.68 & 0.28 & 0.0237 & 0.0251 & 10.7 & 4.6 \\
\hline Frustulia sp. 01 & 31.5 & 3.7 & 0.29 & 0.12 & 0.0142 & 0.0226 & 4.6 & 2.6 \\
\hline Frustulia sp. 02 & 24.8 & 7.8 & 0.61 & 0.18 & 0.0178 & 0.0046 & 10.1 & 2.2 \\
\hline Grammatophora angulosa & 34.7 & 1.7 & 0.21 & 0.11 & 0.0063 & 0.0091 & 2.9 & 1.3 \\
\hline Grammatophora macilenta & 35.9 & 3.8 & 0.58 & 0.20 & 0.0181 & 0.0040 & 9.0 & 4.4 \\
\hline Grammatophora sp. 01 & 34.4 & 6.8 & 0.64 & 0.18 & 0.0188 & 0.0060 & 8.8 & 3.2 \\
\hline Haslea cf. wavricae & 29.8 & 4.0 & 0.34 & 0.14 & 0.0220 & 0.0338 & 5.6 & 2.3 \\
\hline Haslea ostrearia & 31.9 & 4.0 & 0.27 & 0.13 & 0.0151 & 0.0286 & 4.2 & 2.2 \\
\hline $\begin{array}{l}\text { Hyalosynedra laevigata var. } \\
\text { angusta }\end{array}$ & 30.7 & 4.6 & 0.45 & 0.29 & 0.0193 & 0.0202 & 7.3 & 4.5 \\
\hline Licmophora cf. proboscidea & 34.6 & 1.9 & 0.22 & 0.11 & 0.0043 & 0.0018 & 2.5 & 1.0 \\
\hline Licmophora gracilis & 34.9 & 1.6 & 0.19 & 0.09 & 0.0046 & 0.0017 & 2.6 & 1.1 \\
\hline Licmophora normaniana & 28.2 & 5.9 & 0.44 & 0.25 & 0.0179 & 0.0196 & 7.2 & 4.3 \\
\hline Licmophora pfannkucheae & 32.7 & 4.7 & 0.27 & 0.16 & 0.0108 & 0.0129 & 4.1 & 2.4 \\
\hline Licmophora sp.01 & 32.6 & 2.7 & 0.27 & 0.10 & 0.0065 & 0.0038 & 3.2 & 1.2 \\
\hline Mastogloia angusta & 31.1 & 4.3 & 0.31 & 0.15 & 0.0178 & 0.0279 & 4.9 & 2.6 \\
\hline Mastogloia bahamensis & 33.8 & 2.5 & 0.29 & 0.18 & 0.0106 & 0.0111 & 4.4 & 2.6 \\
\hline Mastogloia beufortiana & 32.5 & 3.4 & 0.33 & 0.19 & 0.0111 & 0.0180 & 4.6 & 3.4 \\
\hline Mastogloia binotata & 33.9 & 2.7 & 0.29 & 0.18 & 0.0115 & 0.0177 & 4.1 & 2.6 \\
\hline Mastogloia biocellata & 31.9 & 4.7 & 0.41 & 0.29 & 0.0156 & 0.0190 & 6.3 & 5.0 \\
\hline Mastogloia braunii f. elongatum & 25.9 & 11.3 & 0.58 & 0.18 & 0.0166 & 0.0020 & 9.6 & 2.7 \\
\hline Mastogloia cf. barbadensis & 33.1 & 4.3 & 0.43 & 0.27 & 0.0135 & 0.0121 & 6.4 & 4.0 \\
\hline Mastogloia corsicana & 33.3 & 3.3 & 0.35 & 0.25 & 0.0133 & 0.0160 & 5.3 & 3.5 \\
\hline Mastogloia cribrosa & 33.2 & 3.9 & 0.35 & 0.24 & 0.0130 & 0.0124 & 5.4 & 3.4 \\
\hline Mastogloia crucicula & 31.7 & 4.8 & 0.39 & 0.27 & 0.0164 & 0.0199 & 6.2 & 4.5 \\
\hline Mastogloia delicatissima & 34.1 & 2.4 & 0.35 & 0.19 & 0.0099 & 0.0055 & 5.0 & 2.9 \\
\hline
\end{tabular}




\begin{tabular}{|c|c|c|c|c|c|c|c|c|}
\hline Mastogloia discontinua & 33.1 & 4.2 & 0.44 & 0.29 & 0.0129 & 0.0123 & 6.3 & 4.1 \\
\hline Mastogloia emarginata & 34.8 & 1.7 & 0.59 & 0.29 & 0.0149 & 0.0068 & 8.3 & 4.2 \\
\hline Mastogloia erythreae & 30.8 & 5.4 & 0.45 & 0.30 & 0.0177 & 0.0212 & 7.2 & 5.3 \\
\hline Mastogloia erythreae var. grunowii & 29.4 & 6.6 & 0.56 & 0.30 & 0.0189 & 0.0194 & 8.4 & 5.1 \\
\hline Mastogloia foliolum & 33.5 & 4.1 & 0.62 & 0.26 & 0.0198 & 0.0112 & 9.0 & 4.1 \\
\hline Mastogloia gibbosa & 27.9 & 7.7 & 0.65 & 0.23 & 0.0192 & 0.0101 & 9.4 & 3.1 \\
\hline Mastogloia goessii & 33.7 & 3.4 & 0.31 & 0.21 & 0.0103 & 0.0130 & 4.5 & 3.3 \\
\hline Mastogloia halophila & 28.6 & 5.7 & 0.52 & 0.33 & 0.0224 & 0.0271 & 8.4 & 6.0 \\
\hline Mastogloia jalinecki & 33.3 & 2.3 & 0.26 & 0.09 & 0.0095 & 0.0120 & 3.6 & 1.8 \\
\hline Mastogloia lacrimata & 34.0 & 2.5 & 0.36 & 0.24 & 0.0127 & 0.0133 & 5.3 & 3.5 \\
\hline Mastogloia laminaris & 31.8 & 5.2 & 0.49 & 0.30 & 0.0163 & 0.0223 & 7.3 & 6.1 \\
\hline Mastogloia lancetula & 18.0 & 7.1 & 0.97 & 0.54 & 0.0511 & 0.0482 & 17.9 & 10.8 \\
\hline Mastogloia lineata & 33.4 & 2.6 & 0.34 & 0.21 & 0.0090 & 0.0084 & 4.6 & 2.9 \\
\hline Mastogloia nabulosa & 29.6 & 6.1 & 0.42 & 0.27 & 0.0177 & 0.0230 & 6.8 & 4.9 \\
\hline Mastogloia ovata & 33.7 & 2.3 & 0.23 & 0.08 & 0.0096 & 0.0124 & 3.5 & 1.4 \\
\hline Mastogloia pisciculus & 30.6 & 5.3 & 0.48 & 0.28 & 0.0186 & 0.0202 & 7.5 & 4.1 \\
\hline Mastogloia pseudolatecostata & 34.0 & 2.9 & 0.40 & 0.29 & 0.0122 & 0.0102 & 6.0 & 4.1 \\
\hline Mastogloia punctifera & 32.7 & 4.1 & 0.39 & 0.25 & 0.0146 & 0.0165 & 5.9 & 3.5 \\
\hline Mastogloia rimosa & 33.4 & 6.9 & 0.68 & 0.25 & 0.0170 & 0.0076 & 10.1 & 3.5 \\
\hline Mastogloia sirbonensis & 34.6 & 2.7 & 0.64 & 0.31 & 0.0197 & 0.0109 & 8.5 & 3.5 \\
\hline Mastogloia smithii & 2.9 & 7.7 & 0.48 & 0.26 & 0.0132 & 0.0165 & 11.8 & 5.0 \\
\hline Mastogloia sp. 02 & 34.9 & 5.8 & 0.67 & 0.24 & 0.0159 & 0.0049 & 9.5 & 3.7 \\
\hline Mastogloia sp. 10 & 31.6 & 4.7 & 0.42 & 0.26 & 0.0158 & 0.0169 & 6.6 & 3.7 \\
\hline Mastogloia sp. 13 & 33.4 & 2.6 & 0.21 & 0.07 & 0.0113 & 0.0140 & 3.7 & 1.4 \\
\hline Mastogloia sp. 14 & 34.1 & 2.5 & 0.40 & 0.26 & 0.0088 & 0.0074 & 5.1 & 3.9 \\
\hline Mastogloia varians & 30.6 & 6.5 & 0.67 & 0.39 & 0.0271 & 0.0295 & 10.9 & 8.8 \\
\hline Melosira sp. 01 & 25.6 & 9.0 & 0.79 & 0.34 & 0.0295 & 0.0316 & 13.0 & 7.7 \\
\hline Microtabella interrupta & 32.2 & 4.3 & 0.31 & 0.18 & 0.0133 & 0.0187 & 4.8 & 2.8 \\
\hline Microtabella sp. 01 & 32.5 & 3.2 & 0.24 & 0.10 & 0.0128 & 0.0170 & 4.3 & 2.1 \\
\hline Navicula cf. stancovichii & 13.0 & 5.3 & 0.56 & 0.32 & 0.0207 & 0.0252 & 11.4 & 5.5 \\
\hline Navicula cryptocephala & 9.5 & 4.8 & 0.43 & 0.02 & 0.0153 & 0.0016 & 9.5 & 1.1 \\
\hline Navicula directa & 31.7 & 4.7 & 0.42 & 0.28 & 0.0152 & 0.0181 & 6.5 & 4.4 \\
\hline Navicula durrenbergiana & 29.9 & 6.2 & 0.42 & 0.30 & 0.0198 & 0.0263 & 7.0 & 5.4 \\
\hline Navicula durrenbergiana var. 01 & 24.1 & 6.9 & 0.89 & 0.48 & 0.0453 & 0.0497 & 16.0 & 11.8 \\
\hline Navicula longa var. irregularis & 32.8 & 4.4 & 0.60 & 0.25 & 0.0171 & 0.0127 & 8.9 & 3.6 \\
\hline Navicula palestinae & 27.7 & 6.2 & 0.58 & 0.29 & 0.0234 & 0.0284 & 9.6 & 5.3 \\
\hline Navicula perminuta & 18.6 & 4.8 & 1.05 & 0.55 & 0.0734 & 0.0551 & 22.5 & 11.6 \\
\hline Navicula phylepta & 13.8 & 12.7 & 0.49 & 0.17 & 0.0156 & 0.0031 & 9.9 & 1.7 \\
\hline Navicula radiosa var. parva & 7.9 & 8.9 & 0.41 & 0.17 & 0.0125 & 0.0050 & 10.4 & 3.0 \\
\hline Navicula salinarum & 20.1 & 9.6 & 0.54 & 0.24 & 0.0190 & 0.0176 & 9.6 & 4.8 \\
\hline Navicula sp. 01 & 21.5 & 5.9 & 1.34 & 0.44 & 0.0913 & 0.0436 & 26.0 & 10.1 \\
\hline Navicula sp. 03 & 15.7 & 4.8 & 0.47 & 0.07 & 0.0150 & 0.0016 & 9.8 & 1.6 \\
\hline Navicula sp. 04 & 33.4 & 2.7 & 0.24 & 0.09 & 0.0125 & 0.0164 & 4.2 & 1.9 \\
\hline Navicula sp. 10 & 31.6 & 4.6 & 0.72 & 0.23 & 0.0210 & 0.0145 & 10.9 & 3.1 \\
\hline Navicula sp. 11 & 32.5 & 3.6 & 0.27 & 0.34 & 0.0146 & 0.0241 & 4.7 & 6.3 \\
\hline Navicula sp. 21 & 33.0 & 3.8 & 0.77 & 0.18 & 0.0189 & 0.0066 & 11.3 & 2.6 \\
\hline Navicula sp. 21 & 28.7 & 6.2 & 0.76 & 0.14 & 0.0212 & 0.0074 & 10.5 & 2.3 \\
\hline Navicula sp. 26 & 34.3 & 2.3 & 0.28 & 0.12 & 0.0053 & 0.0035 & 3.0 & 1.4 \\
\hline Navicula tubulosa & 26.4 & 11.3 & 0.69 & 0.10 & 0.0187 & 0.0042 & 11.1 & 3.2 \\
\hline Neosynedra tortosa & 33.5 & 3.5 & 0.28 & 0.17 & 0.0091 & 0.0115 & 3.7 & 2.4 \\
\hline Nitzschia angularis & 31.4 & 7.0 & 0.46 & 0.36 & 0.0178 & 0.0253 & 7.5 & 7.1 \\
\hline Nitzschia capitata & 28.0 & 7.1 & 0.72 & 0.37 & 0.0297 & 0.0325 & 12.0 & 8.0 \\
\hline
\end{tabular}




\begin{tabular}{|c|c|c|c|c|c|c|c|c|}
\hline Nitzschia cf. fusiformis & 27.9 & 3.5 & 0.38 & 0.15 & 0.0133 & 0.0036 & 6.6 & 2.9 \\
\hline Nitzschia closterium & 33.6 & 3.1 & 0.22 & 0.11 & 0.0082 & 0.0112 & 3.4 & 2.0 \\
\hline Nitzschia dissipata & 31.6 & 4.6 & 0.35 & 0.32 & 0.0187 & 0.0264 & 6.0 & 5.9 \\
\hline Nitzschia fontifuga & 28.5 & 6.0 & 0.85 & 0.28 & 0.0348 & 0.0391 & 13.0 & 8.3 \\
\hline Nitzschia frustulum & 30.9 & 5.0 & 0.47 & 0.35 & 0.0248 & 0.0273 & 7.7 & 5.6 \\
\hline Nitzschia graeffii & 35.7 & 2.9 & 0.58 & 0.25 & 0.0157 & 0.0051 & 8.7 & 4.0 \\
\hline Nitzschia grossestriata & 30.0 & 7.3 & 0.52 & 0.32 & 0.0167 & 0.0195 & 7.9 & 6.0 \\
\hline Nitzschia libentruthii & 31.2 & 4.4 & 0.43 & 0.28 & 0.0189 & 0.0228 & 6.5 & 4.2 \\
\hline Nitzschia macilenta & 35.0 & 1.8 & 0.18 & 0.09 & 0.0051 & 0.0022 & 2.6 & 1.3 \\
\hline Nitzschia marginulata var. didyma & 32.9 & 3.5 & 0.38 & 0.31 & 0.0142 & 0.0188 & 6.2 & 5.4 \\
\hline Nitzschia maxima & 31.3 & 4.5 & 0.41 & 0.26 & 0.0193 & 0.0218 & 6.7 & 3.3 \\
\hline Nitzschia microcephala & 24.5 & 9.7 & 0.45 & 0.38 & 0.0225 & 0.0312 & 8.6 & 6.9 \\
\hline Nitzschia persuadens & 28.9 & 3.9 & 0.32 & 0.13 & 0.0177 & 0.0176 & 5.5 & 2.0 \\
\hline Nitzschia reversa & 30.9 & 3.1 & 0.24 & 0.08 & 0.0155 & 0.0199 & 4.9 & 2.4 \\
\hline Nitzschia serpentiraphe & 1.6 & 7.7 & 0.45 & 0.26 & 0.0102 & 0.0049 & 12.3 & 3.9 \\
\hline Nitzschia sigma & 29.8 & 6.2 & 0.46 & 0.34 & 0.0196 & 0.0261 & 7.7 & 6.6 \\
\hline Nitzschia sp. 01 & 32.9 & 1.8 & 0.24 & 0.04 & 0.0172 & 0.0220 & 4.0 & 1.0 \\
\hline Nitzschia sp. 05 & 22.8 & 10.4 & 0.69 & 0.39 & 0.0312 & 0.0360 & 13.9 & 10.1 \\
\hline Nitzschia sublinearis & 30.5 & 3.7 & 0.29 & 0.11 & 0.0120 & 0.0058 & 5.4 & 2.7 \\
\hline Nitzschia thermaloides & 22.9 & 11.6 & 0.63 & 0.26 & 0.0196 & 0.0086 & 10.6 & 1.5 \\
\hline Nitzshia cf. rosenstockii & 29.8 & 6.3 & 0.30 & 0.13 & 0.0148 & 0.0185 & 5.0 & 2.5 \\
\hline Nitzshia dissipata var. media & 33.3 & 2.4 & 0.23 & 0.07 & 0.0123 & 0.0145 & 4.2 & 1.9 \\
\hline Oestrupia grandis & 30.6 & 4.3 & 0.28 & 0.12 & 0.0153 & 0.0203 & 5.1 & 2.6 \\
\hline Opephora pacifica & 33.9 & 3.7 & 0.21 & 0.11 & 0.0080 & 0.0056 & 3.5 & 2.2 \\
\hline Paralia sulcata & 35.4 & 1.2 & 0.19 & 0.12 & 0.0052 & 0.0032 & 2.5 & 1.4 \\
\hline $\begin{array}{l}\text { Paralia sulcata var. genuina } \\
\text { f.coronata }\end{array}$ & 35.8 & 2.7 & 0.41 & 0.27 & 0.0126 & 0.0069 & 6.2 & 4.3 \\
\hline $\begin{array}{l}\text { Paralia sulcata var. genuina } \\
\text { f.radiata }\end{array}$ & 33.1 & 4.5 & 0.43 & 0.24 & 0.0178 & 0.0200 & 6.7 & 3.4 \\
\hline Pinnunavis yarrensis & 19.6 & 7.2 & 1.03 & 0.47 & 0.0638 & 0.0486 & 21.0 & 11.3 \\
\hline Plagiotropis lepidoptera & 26.3 & 6.4 & 0.73 & 0.31 & 0.0321 & 0.0339 & 11.9 & 7.4 \\
\hline Pleurosigma cf. compactum & 30.0 & 4.6 & 0.30 & 0.16 & 0.0159 & 0.0193 & 5.2 & 2.9 \\
\hline Pleurosigma salinarum & 30.9 & 7.2 & 0.43 & 0.25 & 0.0162 & 0.0151 & 6.9 & 4.1 \\
\hline Pravifusus hyalinus & 23.6 & 9.4 & 0.93 & 0.38 & 0.0479 & 0.0417 & 18.3 & 11.4 \\
\hline Proschkinia bulnheimii & 28.6 & 7.4 & 0.71 & 0.25 & 0.0214 & 0.0172 & 11.2 & 5.3 \\
\hline Reimerothrix floridensis & 32.0 & 5.0 & 0.37 & 0.23 & 0.0145 & 0.0193 & 5.4 & 3.4 \\
\hline Rhabdonema adriaticum & 32.1 & 4.7 & 0.33 & 0.17 & 0.0107 & 0.0134 & 4.7 & 2.7 \\
\hline Rhopalodia acuminata & 25.9 & 8.5 & 0.62 & 0.34 & 0.0234 & 0.0238 & 10.4 & 6.1 \\
\hline Rhopalodia brebissonii & 19.7 & 5.2 & 1.02 & 0.47 & 0.0515 & 0.0550 & 19.1 & 10.2 \\
\hline Rhopalodia constricta & 30.3 & 4.0 & 0.29 & 0.13 & 0.0147 & 0.0181 & 5.1 & 2.5 \\
\hline Rhopalodia gibberula & 30.5 & 5.4 & 0.37 & 0.29 & 0.0150 & 0.0195 & 6.1 & 5.1 \\
\hline Seminavis basilica & 32.7 & 1.8 & 0.26 & 0.05 & 0.0138 & 0.0192 & 4.0 & 1.1 \\
\hline Seminavis delicatula & 31.9 & 5.1 & 0.49 & 0.29 & 0.0146 & 0.0122 & 7.0 & 4.3 \\
\hline Seminavis gracilenta & 28.8 & 8.1 & 0.44 & 0.24 & 0.0159 & 0.0143 & 7.0 & 3.8 \\
\hline Seminavis latior & 30.3 & 5.7 & 0.45 & 0.32 & 0.0186 & 0.0237 & 7.4 & 6.0 \\
\hline Seminavis robusta & 29.3 & 6.7 & 0.50 & 0.37 & 0.0221 & 0.0288 & 8.3 & 7.3 \\
\hline Seminavis sp. 02 & 4.3 & 22.8 & 0.33 & 0.07 & 0.0180 & 0.0387 & 16.9 & 9.9 \\
\hline Seminavis strigosa & 30.5 & 7.1 & 0.46 & 0.34 & 0.0176 & 0.0216 & 7.3 & 5.8 \\
\hline Striatella unipunctata & 34.4 & 8.6 & 0.47 & 0.23 & 0.0144 & 0.0087 & 6.1 & 2.5 \\
\hline Surirella fluminensis & 34.7 & 1.5 & 0.21 & 0.07 & 0.0050 & 0.0017 & 2.8 & 1.0 \\
\hline Surirella scalaris & 31.7 & 3.8 & 0.27 & 0.11 & 0.0124 & 0.0174 & 4.3 & 2.1 \\
\hline Synedra brockmanni & 34.0 & 2.8 & 0.23 & 0.10 & 0.0066 & 0.0031 & 3.3 & 1.4 \\
\hline Synedra fasciculata & 27.6 & 9.2 & 0.56 & 0.36 & 0.0262 & 0.0319 & 10.4 & 8.3 \\
\hline
\end{tabular}




\begin{tabular}{|l|c|c|c|c|c|c|c|c|}
\hline Synedra fulgens & 33.9 & 2.9 & 0.29 & 0.19 & 0.0088 & 0.0085 & 3.8 & 2.2 \\
\hline Synedra sp. 01 & 31.5 & 6.5 & 0.69 & 0.23 & 0.0192 & 0.0098 & 10.7 & 3.4 \\
\hline Synedra sp. 03 & 32.0 & 2.8 & 0.27 & 0.09 & 0.0124 & 0.0178 & 4.2 & 1.9 \\
\hline Synedra tabulata var. acuminata & 31.5 & 3.6 & 0.28 & 0.13 & 0.0112 & 0.0145 & 4.1 & 2.1 \\
\hline tabularia waernii & 26.4 & 7.2 & 0.37 & 0.21 & 0.0205 & 0.0277 & 6.8 & 3.8 \\
\hline Thalassiophysa hyalina var. insecta & 30.8 & 6.0 & 0.48 & 0.30 & 0.0178 & 0.0212 & 7.0 & 4.0 \\
\hline Thalassiosira cf. oestrupii & 24.8 & 9.0 & 1.13 & 0.53 & 0.0855 & 0.0605 & 24.0 & 13.4 \\
\hline Toxarium hennedyanum & 33.0 & 3.1 & 0.23 & 0.10 & 0.0094 & 0.0124 & 3.6 & 2.0 \\
\hline Toxarium undulatum & 34.4 & 2.8 & 0.29 & 0.20 & 0.0091 & 0.0113 & 4.0 & 3.0 \\
\hline Triceratium reticulum & 34.0 & 2.2 & 0.27 & 0.15 & 0.0110 & 0.0132 & 4.1 & 2.3 \\
\hline Tryblionella coarctata & 33.2 & 4.2 & 0.39 & 0.25 & 0.0119 & 0.0103 & 5.8 & 3.5 \\
\hline
\end{tabular}


Table 5.2 Mean values of salinity (Sal.), water total nitrogen (WTN), water total phosphorus (WTP) and water total organic carbon (WTOC) for different biozones present in the studied cores during specific time periods.

\begin{tabular}{|c|c|c|c|c|c|c|c|}
\hline $\begin{array}{c}\text { Core } \\
\text { Location }\end{array}$ & Zones & $\begin{array}{l}\text { Depth in core } \\
(\mathrm{cm})\end{array}$ & $\begin{array}{l}\text { Time period } \\
\text { represented by } \\
\text { the zone }\end{array}$ & $\begin{array}{c}\text { Mean } \\
\text { Salinity } \\
\text { (ppt) }\end{array}$ & $\begin{array}{l}\text { Mean } \\
\text { WTN } \\
(\mathrm{ppm}) \\
\end{array}$ & $\begin{array}{l}\text { Mean } \\
\text { WTP } \\
\text { (ppm) }\end{array}$ & $\begin{array}{c}\text { Mean } \\
\text { WTOC } \\
(\mathrm{ppm})\end{array}$ \\
\hline \multicolumn{8}{|l|}{$\begin{array}{l}\text { No Name } \\
\text { Bank }\end{array}$} \\
\hline & $\mathrm{Z1}$ & $0-24$ & 1961-1999 & 38.4 & 0.31 & 0.0079 & 4.4 \\
\hline & Z2S1 & $24-50$ & $1920-1961$ & 37.7 & 0.26 & 0.0056 & 4.7 \\
\hline & Z2S2 & $50-84$ & $1839-1920$ & 34.5 & 0.34 & 0.0101 & 6.4 \\
\hline & Z2S3 & $84-116$ & 1734-1839 & 29.8 & 0.45 & 0.0196 & 9.4 \\
\hline & Z2S4 & 116-142 & $1639-1734$ & 31.3 & 0.37 & 0.0150 & 7.9 \\
\hline \multicolumn{8}{|l|}{$\begin{array}{l}\text { Featherbed } \\
\text { Bank }\end{array}$} \\
\hline & Z1S1 & $0-10$ & 1985-1999 & 37.3 & 0.27 & 0.0074 & 4.1 \\
\hline & Z1S2 & $10-24$ & 1966-1985 & 40.7 & 0.33 & 0.0101 & 4.2 \\
\hline & Z1S3 & 24-38 & $1947-1966$ & 45.1 & 0.48 & 0.0103 & 5.9 \\
\hline & Z2S1 & $38-76$ & $1900-1947$ & 41.6 & 0.37 & 0.0086 & 5.3 \\
\hline & Z2S2 & $76-114$ & $1861-1900$ & 40.1 & 0.32 & 0.0060 & 4.3 \\
\hline & Z2S3 & 114-154 & 1826-1861 & 43.2 & 0.55 & 0.0135 & 7.2 \\
\hline & Z2S4 & 154-186 & $1801-1826$ & 45.2 & 0.51 & 0.0136 & 6.3 \\
\hline \multicolumn{8}{|l|}{$\begin{array}{l}\text { Card Sound } \\
\text { Bank }\end{array}$} \\
\hline & Z1S1 & $0-24$ & $1966-2001$ & 36.5 & 0.38 & 0.0108 & 5.9 \\
\hline & Z1S2 & $24-40$ & 1926-1966 & 35.5 & 0.37 & 0.0127 & 6.2 \\
\hline & Z1S3 & $40-62$ & $1865-1926$ & 36.4 & 0.33 & 0.0079 & 5.0 \\
\hline & Z1S4 & $62-92$ & $\sim 1655-1865$ & 36.9 & 0.32 & 0.0088 & 5.2 \\
\hline & Z1S5 & $92-112$ & $\sim 1538-\sim 1655$ & 37.3 & 0.29 & 0.0079 & 4.9 \\
\hline & $\mathrm{Z2}$ & $112-144$ & $\sim 1340-\sim 1538$ & 31.6 & 0.56 & 0.0170 & 9.7 \\
\hline
\end{tabular}




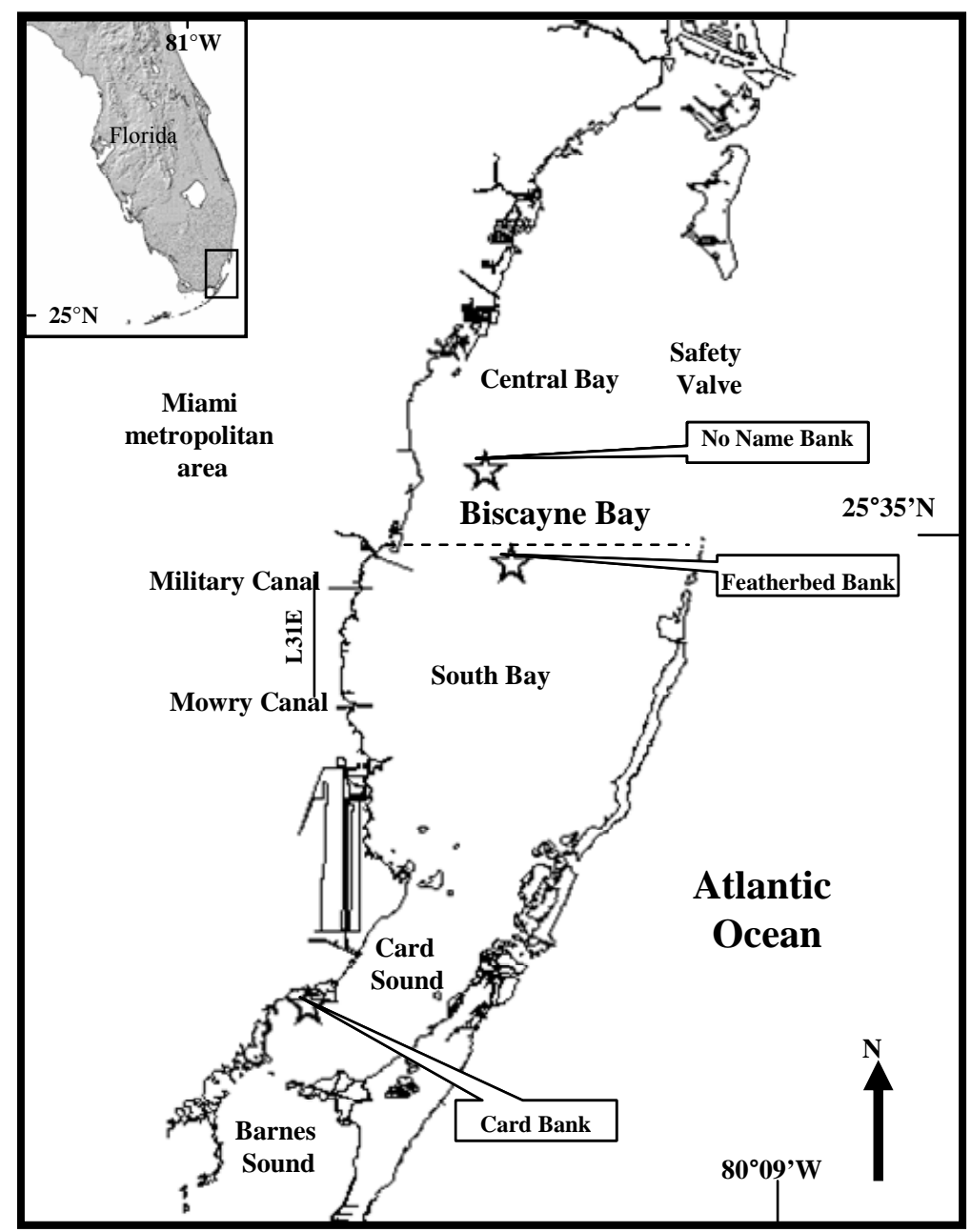

Fig. 5.1 Map of Biscayne Bay, Florida showing Sites where sediment cores were collected. 

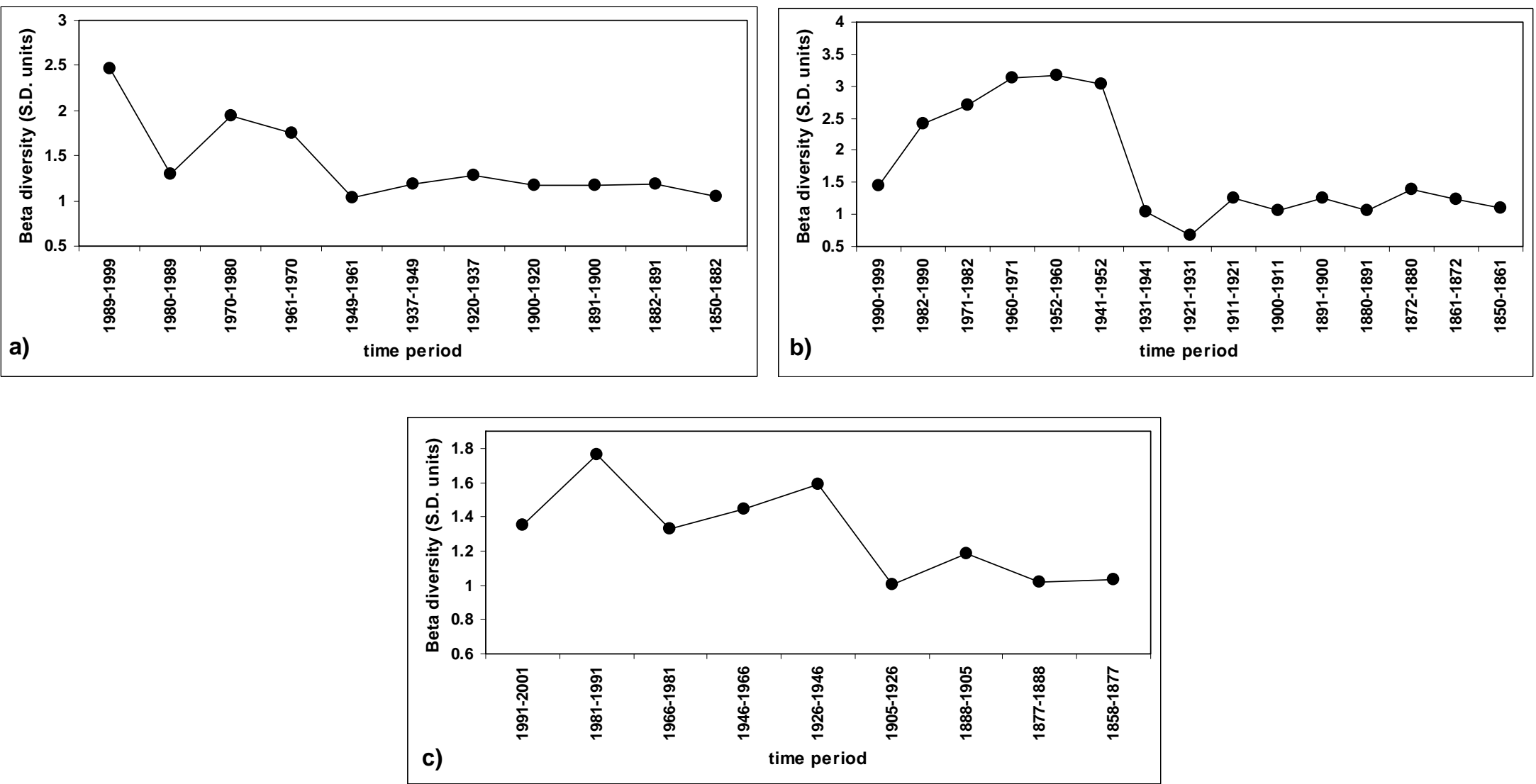

Fig. 5.2 Changes in $\beta$-diversity over time at No Name Bank (a), Featherbed Bank (b), and Card Sound Bank (c). 


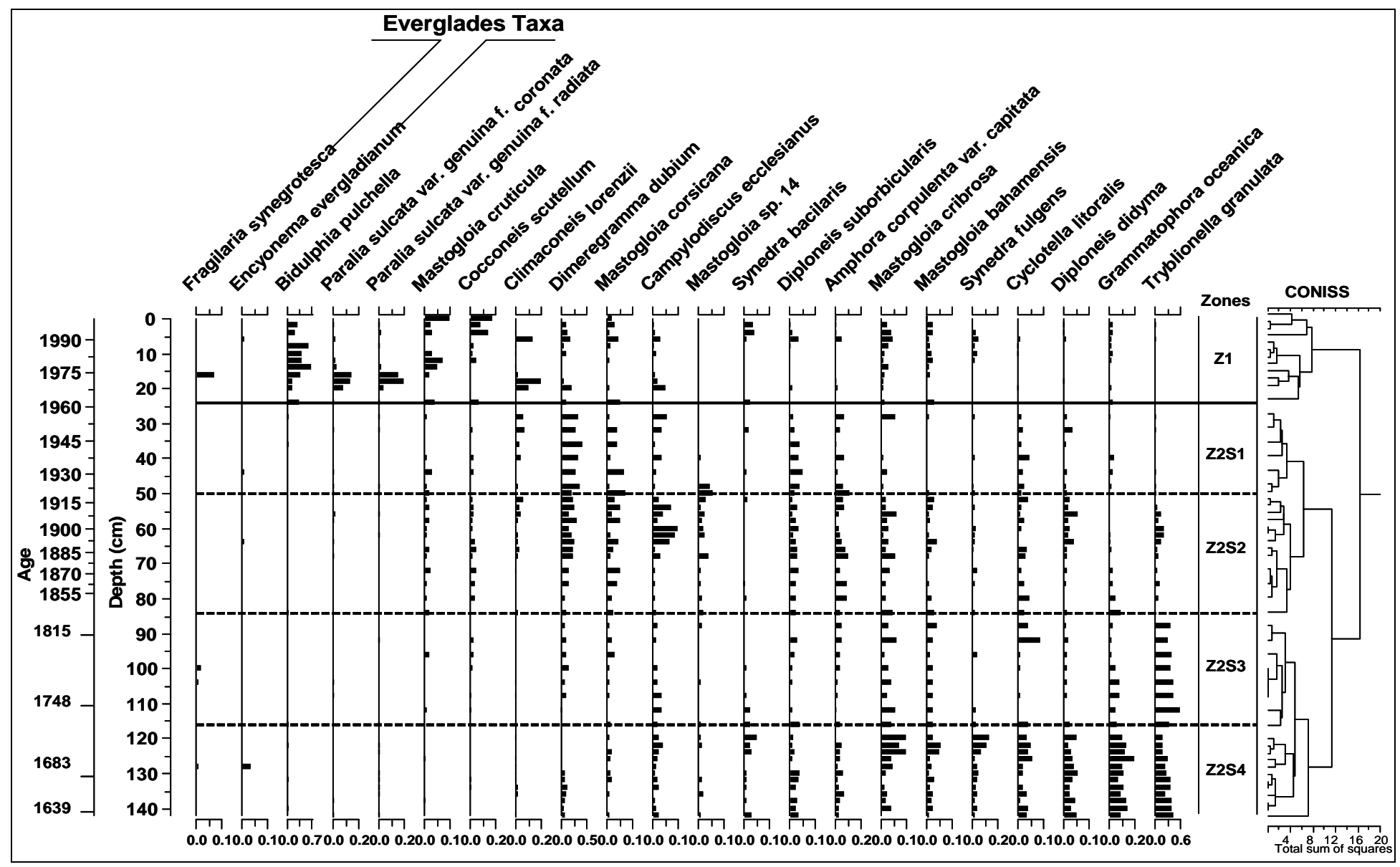

Fig. 5.3 Stratigraphy of the most common diatom taxa in the No Name Bank sediment core. Zones are based on constrained cluster analysis by the method of incremental sum of squares (CONISS). The solid line represents the boundary between major clusters and dashed lines represent the boundaries between major sub-zones. 


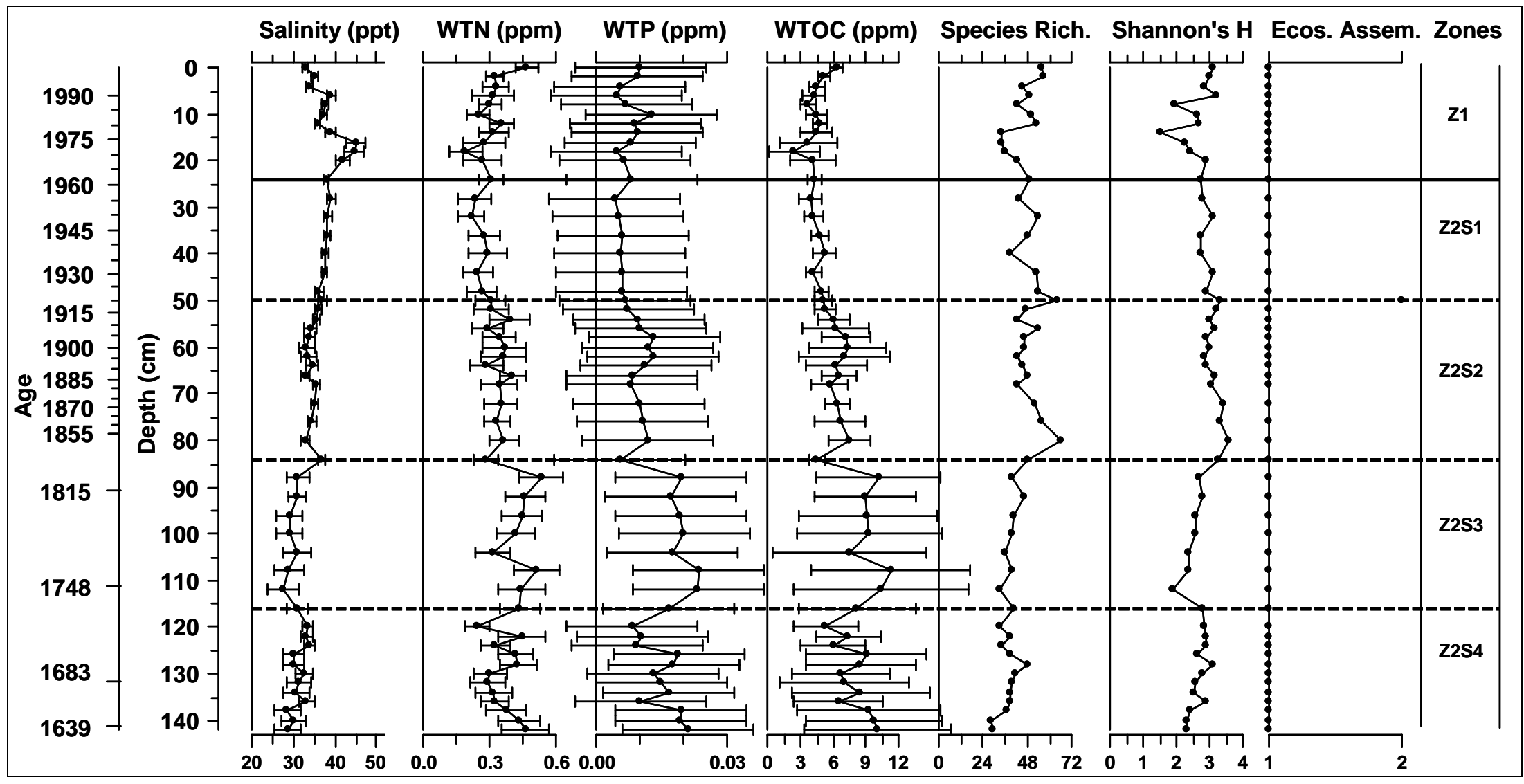

Fig. 5.4 Diatom-inferred salinity, water total nitrogen (WTN), water total phosphorus (WTP), water total organic carbon (WTOC), species richness, Shannon-Wiener (Shannon's H) diversity and abundance of assemblages typical for nearshore (1) and open-bay (2) diatom assemblages in the No Name Bank core. 


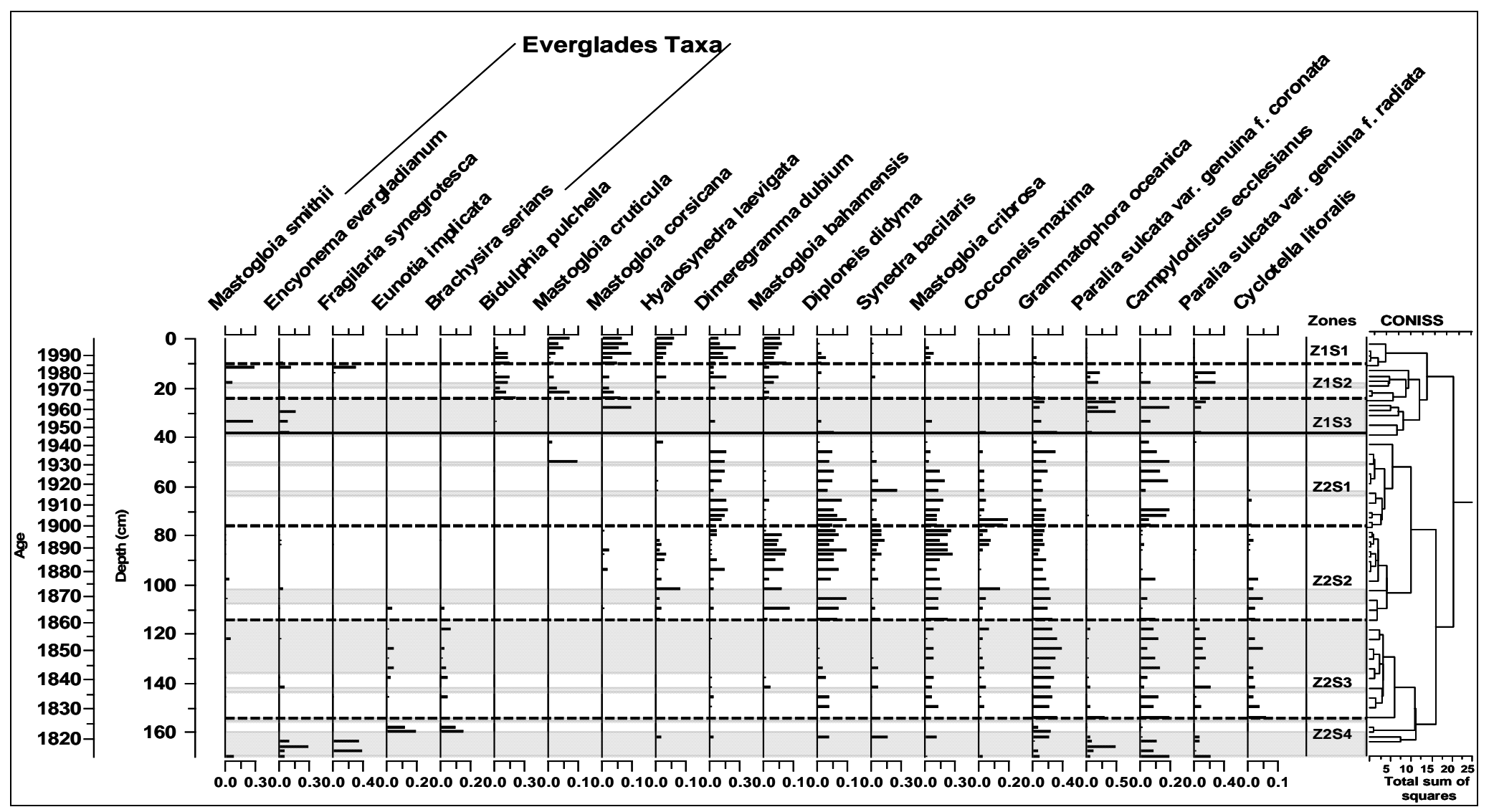

Fig. 5.5 Stratigraphy of the most common diatom taxa in the Featherbed Bank sediment core. Zones and lines as in Figure 5.3.

Gray shading represents levels with very low diatom abundance. 


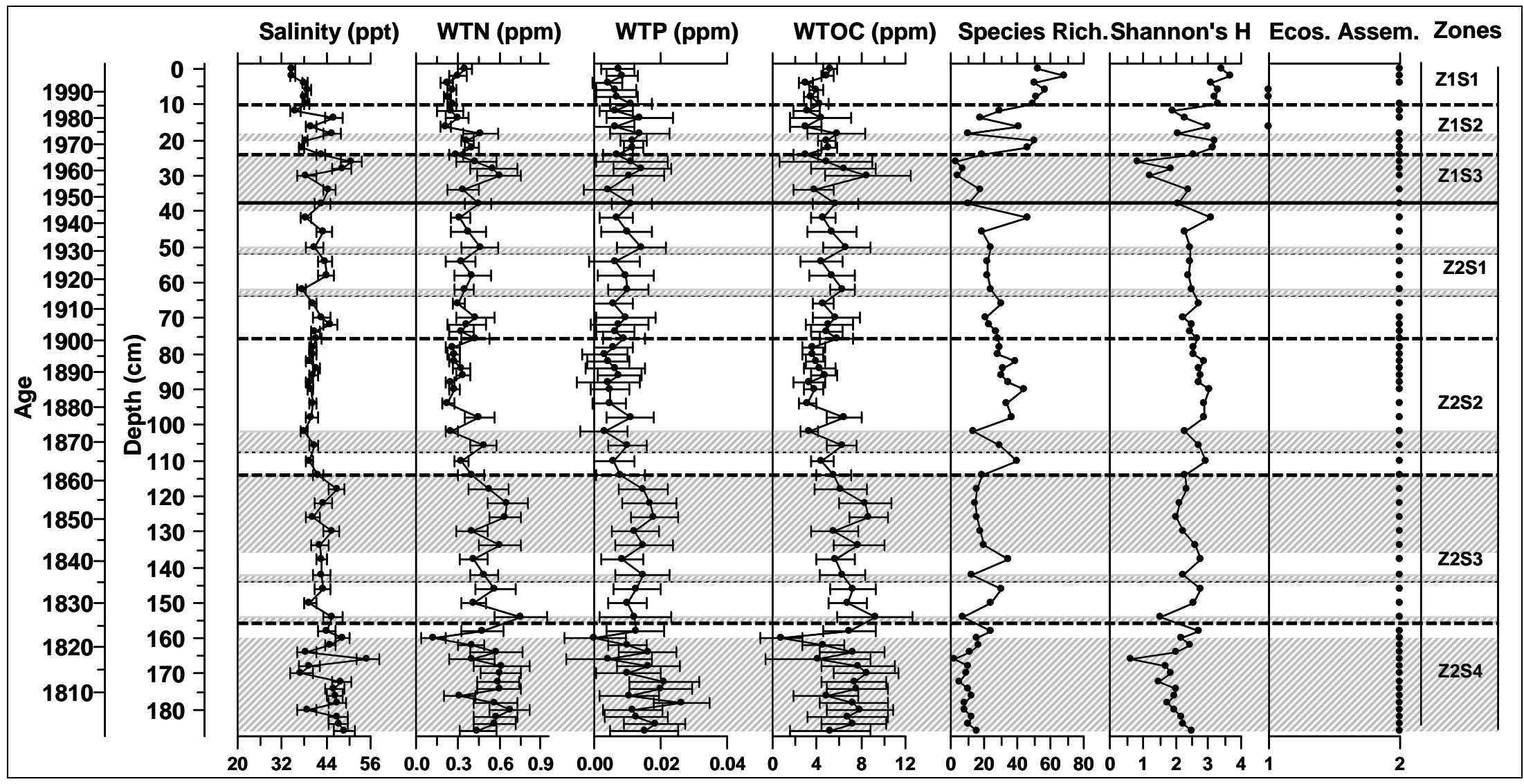

Fig. 5.6 Diatom-inferred salinity, water quality and diversity typical for nearshore (1) and open-bay (2) diatom assemblages in the Featherbed Bank core. Abbreviations and shading as in Figures 5.4. 


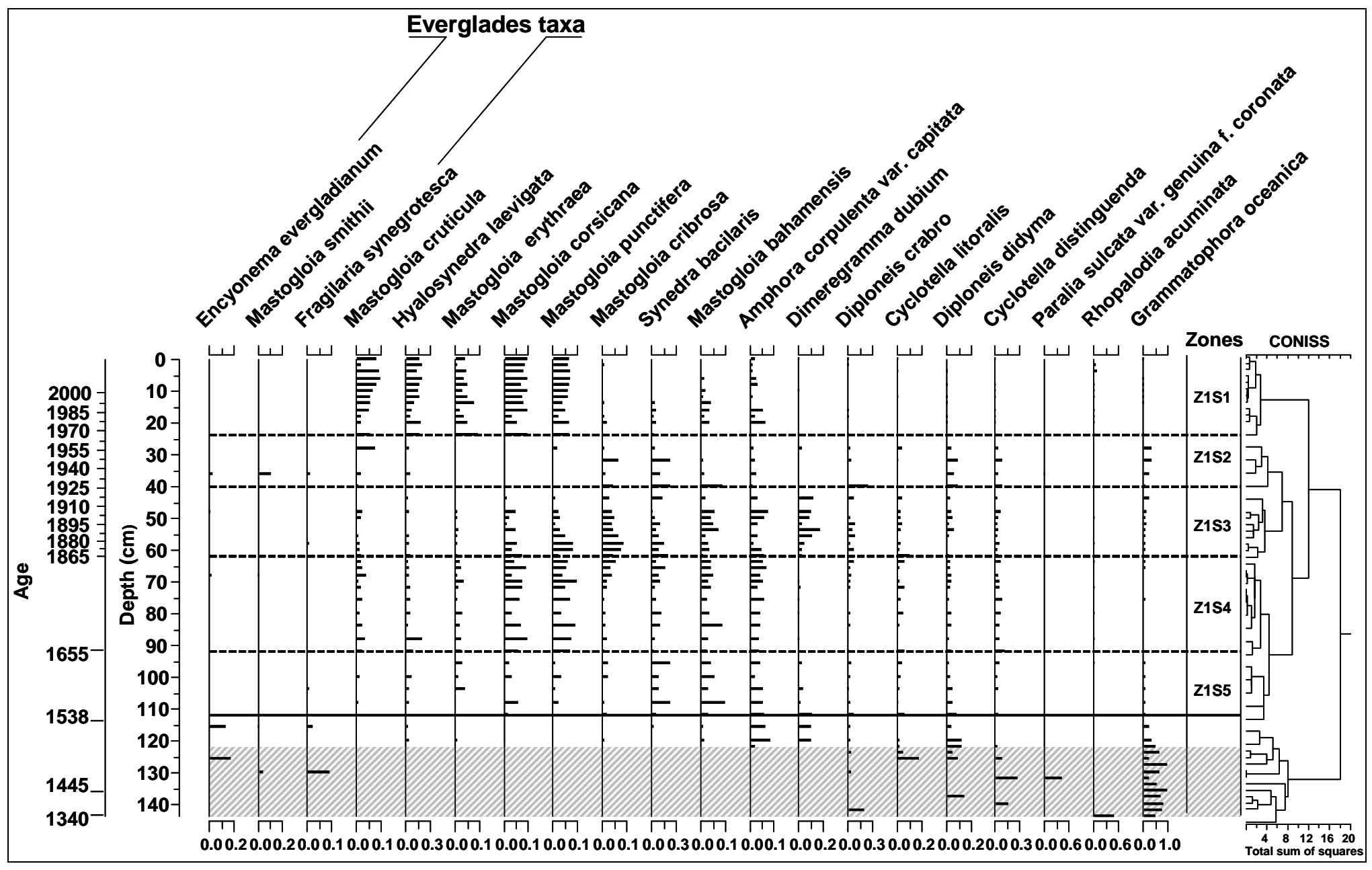

Fig. 5.7 Stratigraphy of the most common diatom taxa in the Card Sound Bank sediment core. Zones, lines and shading as in previous figures. 


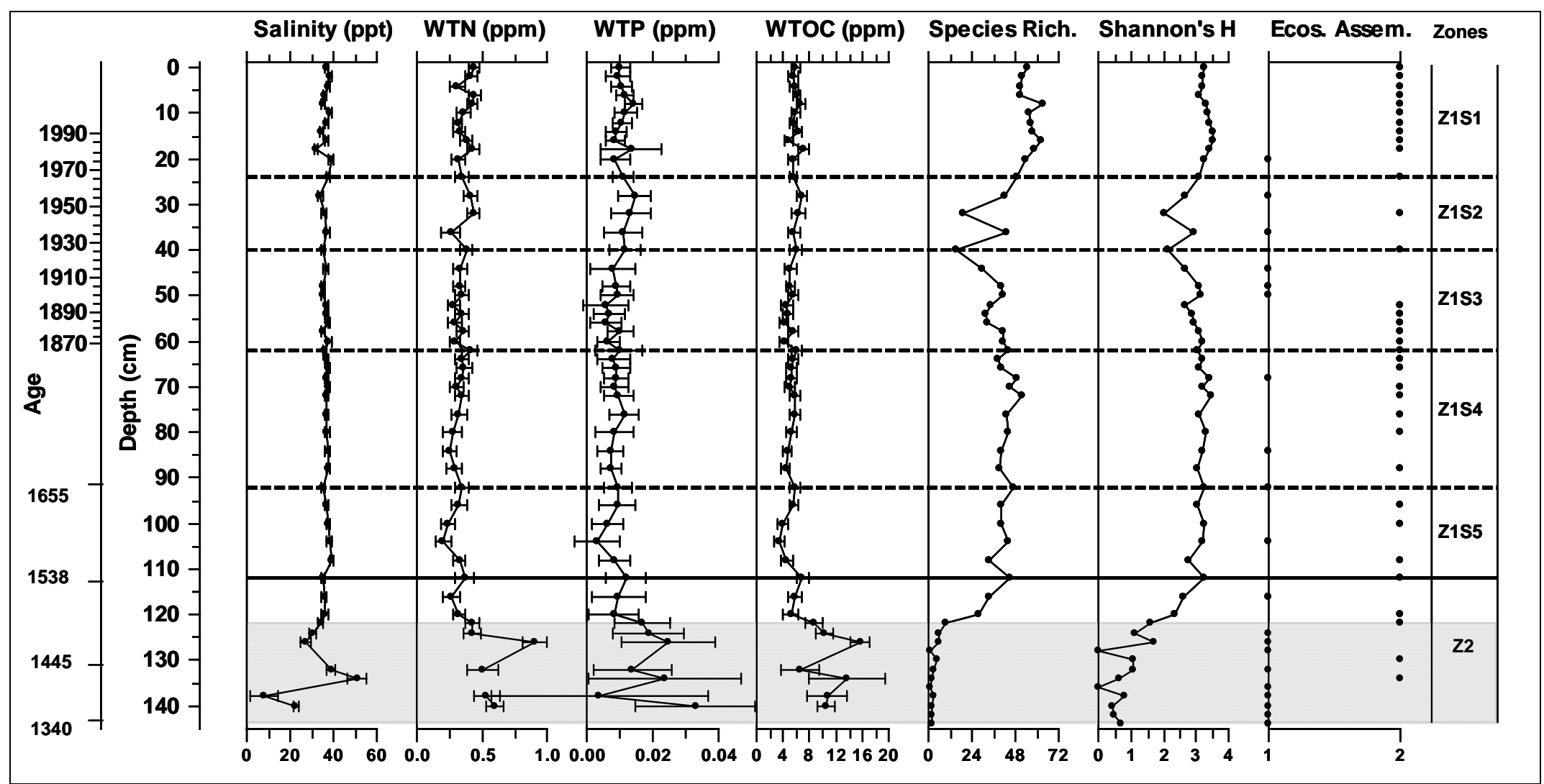

Fig. 5.8 Diatom-inferred salinity, water quality and diversity of assemblages typical for nearshore (1) and open-bay (2) diatom assemblages in the Card Sound Bank core. Abbreviations and shading as in previous figures. 


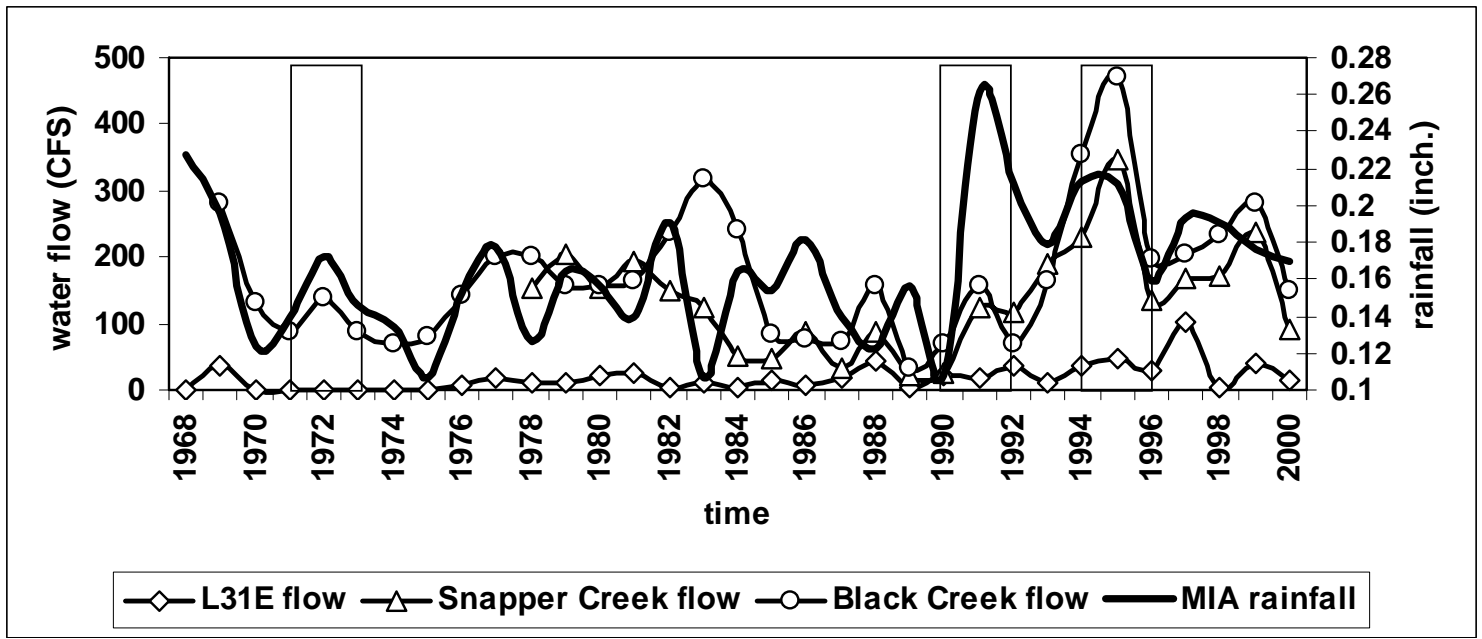

Fig. 5.9 Changes of water flow from major South Florida Water Management District structures into Biscayne Bay and fluctuations of rainfall at Miami International Airport (MIA) weather station (http://www.sfwmd.gov/). Highlighted areas indicate co-occurance of increased rainfall and water flow from the canals. 


\section{REFERENCES}

Alongi, D.M. 1998. Coastal ecosystem processes. CRC Press New York, pp. 419

Bianchi, T. 2003. Biochemistry of estuaries. New York: Oxford University Press, pp. 706.

Birks, H.J.B. 1998. Numerical tools in paleolimnology - progress, potentialities, and problems. Journal of Paleolimnology 20:307-332.

Caccia, V.G. and J.N. Boyer. 2007. A nutrient loading budget for Biscayne Bay, Florida. Marine Pollution Bulletin 54:994-1008.

Clarke K R., and R.N. Gorley. 2001. Primer v5: user manual/tutorial. - Primer-E Ltd. Plymouth.

Conley, D.J., and C.L. Schelske. 1989. Processes controlling the benthic regeneration and sedimentary accumulation of biogenic silica in Lake Michigan. Arch. Hydrobiologia 116:23-43.

Cooper, S.R., and G.S. Brush. 1993. A 2500 year history of anoxia and eutrophication in Chesapeake Bay. Estuaries 16:617-626.

Cooper, S.R. 1995. Chesapeake Bay watershed historical land use: impact on water quality and diatom communities. Ecological Applications 5:703-723.

Flower, R.J., C. Stickley, N.L. Rose, S.M. Peglar, A.A. Faathi, and P.G. Appleby. 2006. Environmental Changes at the Desert Margin: An Assessment of Recent Paleolimnological Records in Lake Qarun, Middle Egypt. Journal of Paleolimnology 35:1-24.

Grimm, E. 1987. CONISS: A Fortran 77 program for stratigraphically constrained cluster analysis by the method of incremental sum of squares. Comput. Geosci. 13:13-35.

Howarth, R. W., D. Walker, and A. Sharpley. 2002. Sources of nitrogen pollution to coastal waters of the United States. Estuaries 25:656-676.

Hobbie J.E. 2000. Estuarine Science, a synthetic approach to research and practice. Island Press, Washington, D.C. pp. 539.

Ishman, S.E., 1997. Ecosystem History of South Florida: Biscayne Bay Sediment Core Descriptions: U.S. Geologic Survey Open-File Report 97-437, 13pp. 
Ishman, S.E., T.M. Cronin, G.L. Brewster-Wingard, D.A.Willard, and D.J. Verardo. 1998. A record of ecosystem change, Manatee Bay, Bay, Barnes Sound, Florida. Journal of Coastal Research 26:125-138.

Juggins, S. 1992. Diatoms in the Thames Estuary, England: ecology, paleoecology, and salinity transfer function. J. Cramer, Berlin-Stuttgard, pp. 216.

Juggins, S. 2005. The C2 Software for Ecological and Palaeoecological Data Analysis and Visualisation. University of Newcastle, Newcastle-upon-Tyne, United Kingdom.

Light, S.S., and J.W. Dineen. 1994. Water control in the Everglades: A historical perspective. In (Davis, S.M., and J.C. Ogden, (eds.). Everglades, the Ecosystem and its Restoration, St. Lucie Press, pp. 47-84.

Langevin, C.D. 2003. Simulation of submarine ground water discharge to a marine estuary: Biscayne Bay, Florida. Ground Water 41:758-771.

Lodge T.E. 2005. The Everglades handbook - understanding the ecosystem. Boca Raton, FL: CRC Press, pp. 336.

McCune, B., and J.B. Grace. 2002. Analysis of Ecological Communities. MJM Software Design, Gleneden Beach, Oregon.

Meeder, J. and J.N. Boyer. 2001. Total ammonia concentrations in soil, sediments, surface water, and groundwater along the western shoreline of Biscayne Bay with the focus on Black Point and a reference mangrove site. Final Report to the National Park Service under NPS/FIU Cooperative Agreement No. CA5280-8-9038.

Parker, G.G. 1974. Hydrology of the pre-drainage system of the Everglades in southern Florida, in P.J. Gleason, ed., Environments of south Florida--Present and past: Miami, Fla., Miami Geological Society, Memoir 2, p. 18-27.

Ricklefs, R.E. and G.L. Miller. 2000. Ecology. 4th ed. Freeman

Roessler, M.A., Beardsley, G.L., Rehrer, R., and J. Garcia. 1975. Effects of thermal effluents on the fishes and benthic invertebrates of Biscayne Bay-Card Sound, Florida. Technical Report UM-RSMAS-75027.

Ross, M.S., Gaiser, E.E, Meeder, J. F., and M.T. Lewin. 2001. Multi-taxon analysis of the "white zone", a common ecotonal feature of South Florida coastal wetlands. In: J.

Porter, K. Porter (Editors), The Everglades, Florida Bay, and Coral Reefs of the Florida Keys. CRC Press, Boca Raton, FL, USA. pp. 205-238.

Ryves, D.B., S. Juggins, S.C. Fritz, and R.W. Battarbee. 2001. Experimental diatom dissolution and the quantification of microfossil preservation in sediments.

Palaeogeography, Palaeoclimatology, Palaeoecology 172:99-113. 
Stone, J.R., Cronin, T.M., Brewster-Wingard, G.L., Ishman, S.E., Wardlaw, B.R., and C.W. Holmes. 2000. A paleoecological reconstruction of the history of Featherbed Bank, Biscayne National Park, Biscayne Bay, Florida: USGS Open- File Report 00-191, 24 pp.

Ter Braak, C.J.F., and P. Šmilauer, 2002. CANOCO Reference manual and CanoDraw for Windows user's guide: Software for Canonical Community Ordination (version 4.5), Microcomputer Power, Ithaca, NY, USA.

Wanless, H.R. 1976. Geological setting and recent sediments of the Biscayne Bay region. In: Biscayne Bay: Past, Present and Future (Eds. Thorhaug, A. and Volker, A.) Special Report University of Miami Sea Grant, v. 5: p. 1-32.

Wanless, H., R. Parkinson, and L. Tedesco. 1994. Sea level control on stability of Everglades wetlands: Everglades, the Ecosystem and its Restoration: St. Luci Press, Delray Beach, Florida.

Wingard, G.L., T.M. Cronin, G.S. Dwyer, S.E. Ishman, D.A. Willard, C.W. Holmes, C.E. Bernhardt, C.P. Williams, M.E. Marot, J.B. Murray, R.G. Stamm, J.H. Murray, and C. Budet. 2003. Ecosystem History of Southern and Central Biscayne Bay: Summary Report on Sediment Core Analyses. U.S. Geological Survey Open File Report no. 03-375.

Wingard, G.L., T.M. Cronin, C.W. Holmes, D.A. Willard, G.S. Dwyer, S.E. Ishman, W. Orem, C.P.Williams, J. Albietz, C.E. Bernhardt, C. Budet, B. Landacre, T. Lerch, M.E. Marot, and R. Ortiz. 2004. Ecosystem History of Southern and Central Biscayne Bay: Summary Report on Sediment Core Analyses-Year Two. U.S. Geological Survey Open File Report no. 2004-1312.

Wingard, G.L., J.W. Hudley, C.W. Holmes, D.A. Willard, and M. Marot. 2007. Synthesis of age data and chronology for Florida Bay and Biscayne Bay cores collected for ecosystem history of South Florida's estuaries project. Open File Report 2007-1203. 


\section{CHAPTER 6. GENERAL CONCLUSIONS}

Studies of contemporary diatom assemblages in Florida Bay, Biscayne Bay and adjacent coastal regions have shown that single environmental variables and the impact of multiple environmental factors on inferences about past conditions can be quantified from diatom communities. My research also showed that modern diatom assemblages are strongly influenced by spatial and seasonal water quality changes, and as a result of these strong relationships at least two seasons of sampling are necessary to develop reliable salinity, water total nitrogen (WTN), water total phosphorus (WTP), and water total organic carbon (WTOC) transfer functions. One season of sampling would introduce a significant error of prediction, especially for sites that experience a large-intra annual variability of water quality conditions. Moreover, I demonstrated that diatom assemblages can also be successfully used to study changes in different types of habitats (nearshore, open-bay, mangrove, freshwater marsh).

Diatom-based inference models used in the Florida Bay and Biscayne Bay studies provided a functional estimate of past environmental conditions in those areas at a resolution sufficient to detect the onset and magnitude of ecological change caused by fluctuating sea level, precipitation and anthropogenic alterations on the mainland. An almost simultaneous occurrence of major changes in diatom communities in both bays at the end of the $19^{\text {th }}$ century, in the early 1900 's, after the mid-1960's and in the early- and mid-1990's suggests that these changes were widespread in South Florida estuaries. These alterations correspond to the major anthropogenic alterations of hydrology on the mainland and changing rainfall patterns. All of the coring sites in both bays have been 
affected by construction of water conservation areas and associated canals and levees, which significantly decreased the amount of water flowing into the coastal wetlands of South Florida (Light and Dineen 2001; Sklar et al. 2001). The amount of water released from the canals into the Everglades that subsequently affected adjacent estuaries depends strongly on the amount of precipitation in this area.

Although it is clear that both bays have been influenced by the modifications of South Florida hydrology, Biscayne Bay seem to be affected by different factors than Florida Bay. For example, lowering of the water table in the Biscayne Aquifer, construction of the Eastern Parameter Levee, L31E levee and canal, highways US1 and I95, and the cuts in northern Biscayne Bay; complete elimination of the previous natural sheet flow of water; and construction of the Turkey Point power plant and general development of the metropolitan Miami area acted as multiple barriers that freshwater could not pass. These factors directly affected the quantity and quality of water flowing into Biscayne Bay. Some of these changes, such as the rapid urban growth of the Miami metropolitan area, continue to restrict the amount of water flowing into Biscayne Bay to a much bigger extent than inflow to Florida Bay. Recently, the amount of freshwater being released into Biscayne Bay from canals has been completely controled by the South Florida Water Management District (Chapter 5, Fig. 5.9). In the last few decades, the amounts of water released into the bay from those stuctures increased due to increased rainfall (Chapter 5) but it is still much smaller than the amount of surface and ground water that was delievered to the bay by natural creeks and springs prior to canal constuction (Harlem 1979; Meeder and Boyer 2001). I hypothetize that water delivery to Biscayne Bay will most likely further decline in the future due to the expansion of Miami 
and its related increased water demand, and salinity in the bay will depend even more on rainfall and pulses of water released from canals.

Many of the South Florida Water Management decisions that have affected the quality and quantity of water flowing into Shark River Slough, Taylor River Slough and eventually into Florida Bay, have been modified by the agency in the last few decades (Sklar et al. 2001). For example, re-direction of water from the Taylor Slough headwaters back to the southern portion of the slough (since 1983) resulted in larger amounts of freshwater being released into Florida Bay and caused lowering of salinity in central and eastern Florida Bay (Light and Dineen 2001). Furthermore, introduction of the "Rainfall Plan" in 1985, which had the purpose of adjusting the amount of water flow to Shark River Slough (SRS) based on the amount of rainfall and evaporation that occurs in the South Florida region and the water level in Water Conservation Area 3a, aftected salinity in the western part of the bay (Light and Dineen 2001). These modifications combined with increased amounts of rainfall decreased salinity in Florida Bay in the last few decades (Chapter 3). Unlike Biscayne Bay, Florida Bay is not completely controlled by pulses of water from the canals. The bay still receives water from fresh groundwater and natural creeks and coastal lakes in the southwestern part of the Everglades. Furthermore, urban areas of Miami are not directly adjacent to Florida Bay and therefore efforts for the restoration of the Everglades, which has the goal of releasing larger amounts of water into the Everglades, combined with increased amounts of rainfall, will most likely further decrease the salinity of nearshore areas of Florida Bay. 


\section{REFERENCES}

Harlem, P.W. (1979). Arial photographic interpretation of the historical changes in northern Biscayne Bay, Florida: 1925 to 1976 . Unpublished Dissertation, University of Miami, Florida, Sea Grant Technical Bulletin 40.

Light, S.S., and J.W. Dineen. 1994. Water control in the Everglades: A historical perspective. In (Davis, S.M., and J.C. Ogden, (eds.). Everglades, the Ecosystem and its Restoration, St. Lucie Press, pp. 47-84.

Meeder, J. and J. N. Boyer. 2001. Total ammonia concentrations in soil, sediments, surface water, and groundwater along the western shoreline of Biscayne Bay with the focus on Black Point and a reference mangrove site. Final Report to the National Park Service under NPS/FIU Cooperative Agreement No. CA5280-8-9038.

Sklar, F., C. McVoy, R. VanZee, D.E. Gawlik, K. Tarboton, D. Rudnick, and S. Miao. In The Everglages, Florida Bay, and Coral Reefs of the Florida Keys. An Ecosystem Sourcebook, pp. 39-82. 


\section{APPENDICES}

(All appendices are available on a DVD placed at the back of the dissertation)

2.1 Diatom taxa counts recorded in epipelic (S), epiphytic (E) and planktonic (P) samples from 38 sites in Florida Bay in wet (W) and dry (D) seasons. Sampling sites IDs indicate Long Term Ecological Research sites in Taylor Slough (TS), Southeast Environmental Research Center water quality monitoring sites in Florida Bay (WQ), and additional sites chosen in Florida Bay (FB) and coastal lakes in southwestern Florida (LK).

2.2 Water quality data collected from 38 sites in Florida Bay in dry and wet seasons.

3.1 Total diatom valve counts in the Trout Cove core. Symbols indicate: FB=Florida Bay, $\mathrm{TC}=$ Trout Cove.

3.2 Total diatom valve counts in the Russell Bank core. Symbols indicate: $F B=F l o r i d a$ Bay, RB=Russell Bank.

3.3 Total diatom valve counts in the Bob Allen core. Symbols indicate: FB=Florida Bay, $\mathrm{BA}=$ Bob Allen.

3.4 Total diatom valve counts in the Ninemile Bank core. Symbols indicate: $F B=$ Florida Bay, NB=Ninemile Bank.

4.1 Water quality data collected from 58 sites in Biscayne Bay in dry and wet seasons.

4.2 Diatom taxa counts recorded in epipelic (S), epiphytic (E) and planktonic (P) samples from 58 sites in Biscayne Bay.

5.1 Total diatom valve counts in the No Name Bank core. Symbols indicate: $\mathrm{BB}=$ Biscayne Bay, NNA=No Name Bank.

5.2 Total diatom valve counts in the Featherbed Bank core. Symbols indicate: $\mathrm{BB}=$ Biscayne Bay, FBA=Featherbed Bank.

5.3 Total diatom valve counts in the Card Sound Bank core. Symbols indicate: $\mathrm{BB}=$ Biscayne Bay, $\mathrm{CBA}=\mathrm{Card}$ Sound Bank. 
VITA

\section{ANNA HONORATA WACHNICKA}

Education:

- (2009) Doctoral Candidate. Geosciences, Florida International University

- (1999) M.S.Marine Geography, University of Szczecin

Professional Experience:

- (2001-Present) Research Assistant, Southeastern Environmental Research Center, Florida International University, Miami, U.S.A.

- (1999-2001) Research Assistant, Institute of Marine Sciences, University of Szczecin Szczecin, Poland

Scholarships and Awards:

- 2007 Best Student Poster Award, LTER All Scientists Meeting, Miami, USA

- 2004 Jessup and McHenry Scholarship, the Academy of Natural Sciences, Philadelphia, USA

- 1999 Faroe Islands Scholarship, Biofar Laboratory, Kaldback, Faroe Islands

Presentations at Scientific Meetings:

- 2008 Wachnicka, A. \& E. Gaiser. Diatom-Based Inferences of Environmental Change in Florida Bay and Adjacent Coastal Wetlands of South Florida. Florida Bay and Adjacent Marine Systems Science Conference, Naples, Florida

- 2007 Wachnicka, A. \& E. Gaiser. The Combined Effects of Climatic and Anthropogenic Factors on the Past Environmental Conditions in Biscayne Bay, Florida. North American Diatom Symposium, Pellston, Michigan

- 2007 Wachnicka, A. \& E. Gaiser. Diatom-based water quality performance metrics for Biscayne Bay. Florida Coastal Everglades Long Term Ecological Research All Scientists Meeting, Miami, Florida, U.S.A.

- 2005 Wachnicka, A. \& E. Gaiser. New species of the Amphora and Seminavis species from the marine and coastal environments of South Florida, USA, North American Diatom Symposium, Mobil, Alabama, U.S.A. 
Published Publications:

- Wachnicka, A. \& Gaiser, E. (2007). Morphological characterization of Amphora and Seminavis (Bacillariacea) from South Florida, U.S.A. Diatom Research, 22(2), 387-455.

- Yunping Xu, Jaffé R., Wachnicka, A., \& Gaiser, E.E. (2006). Occurrence of $\mathrm{C}_{25}$ Highly Branched Isoprenoids in Florida Bay: implications for historical diatom change. Organic Geochemistry, 37(7), pp. 847-859.

- Frankovich, T.A., Gaiser, E., Zieman, J.C. \& A. Wachnicka (2006). Spatial and Temporal Distributions of Epiphytic diatoms growing on Thalassia testudinum Banks ex König: Relationships to Water Quality. Hydrobiologia, 569 (1), 259271.

- Witak, M., Wachnicka, A., Kuijpers, A., Troelstra, S., Prins, M, Witkowski, A. (2005). Holocene North Atlantic surface circulation and climate variability. Holocene Journal, 15 (1), pp. 85 - 96.

- Gaiser, E., Wachnicka, A., Ruiz, P., Tobias, F. and M. Ross (2005). Diatom indicators of ecosystem change in coastal wetlands. Evidence from diatom records. Estuarine Indicators, S. Bortone (Ed.) CRC Press. Boca Raton, FL.

Publications in Press and Preparation:

- Frankovich, T.A., Armitage, A., Wachnicka, A.H., Fourqurean, J., and E. Gaiser. (2009). Penrichment of seagrass meadows causes changes in epiphyte community structure at division level and within diatom communities. Journal of Phycology (In Press).

- Wachnicka, A.H., Gaiser, E.E., Collins, L.S., Frankovich, T.A., and J.N. Boyer. Developing diatom-based inferences of environmental change in Florida Bay and adjacent coastal wetlands of South Florida (In preparation for Estuaries and Coasts).

- Wachnicka, A.H., Gaiser, E.E., Collins, L.S. and J.N. Boyer. Development of diatom-based prediction models for assessment of past quality in Biscayne Bay, U.S.A. (In preparation for Ambio). 